\author{
UNIVERSIDADE DE SÃO PAULO \\ FACULDADE DE FILOSOFIA, LETRAS E CIÊNCIAS HUMANAS \\ DEPARTAMENTO DE LINGUÍSTICA \\ PROGRAMA DE PÓS-GRADUAÇÃO EM SEMIÓTICA E LINGUÍSTICA GERAL
}

VITOR AUGUSTO NÓBREGA

\title{
Abordagem Isomórfica: A Articulação entre o Léxico e a Sintaxe na Emergência da Linguagem
}

Tese apesentada ao Programa de Pós-Graduação em Semiótica e Linguística Geral do Departamento de Linguística da Faculdade de Filosofia, Letras e Ciências Humanas da Universidade de São Paulo, como requisito para obtenção do título de Doutor em Letras.

Área de Concentração: Semiótica e Linguística Geral

Orientadora: Prof. ${ }^{a}$ Dr. ${ }^{a}$ Ana Paula Scher 
AUTORIZO A REPRODUÇÃO E DIVULGAÇÃO TOTAL OU PARCIAL DESTE TRABALHO, POR QUALQUER MEIO CONVENCIONAL OU ELETRÔNICO, PARA FINS DE ESTUDO E PESQUISA, DESDE QUE CITADA A FONTE.

Catalogação da Publicação

Serviço de Documentação

Faculdade de Filosofia, Letras e Ciências Humanas da Universidade de São Paulo

Nóbrega, Vitor Augusto.

Abordagem Isomórfica: A Articulação entre o Léxico e a Sintaxe na Emergência da Linguagem/ Vitor Augusto Nóbrega; orientadora: Ana Paula Scher - São Paulo, 2018.

$268 \mathrm{f}$. : fig.

Tese (Doutorado - Programa de Pós-Graduação em Semiótica e Linguística Geral. Área de Concentração: Semiótica e Linguística Geral) - Faculdade de Filosofia, Letras e Ciências Humanas da Universidade de São Paulo.

1. Linguística Evolucionária. 2. Biolinguística. 3. Léxico. 4. Sintaxe. 5. Comunicação Animal. 6. Abordagem Isomórfica I. Scher, Ana Paula. II. Título. 


\title{
Folha de aprovação
}

\author{
VITOR AUGUSTO NÓBREGA
}

\section{ABORDAGEM ISOMÓRFICA: A ARTICULAÇÃo ENTRE O LÉXICO E A SINTAXE NA EMERGÊNCIA dA LINGUAGEM}

Tese apresentada ao Programa de Pós-Graduação em Semiótica e Linguística Geral do Departamento de Linguística da Faculdade de Filosofia, Letras e Ciências Humanas da Universidade de São Paulo, como requisito para obtenção do título de Doutor em Letras.

Área de Concentração: Semiótica e Linguística Geral

Aprovado em:

\section{BANCA EXAMINADORA}

Prof. ${ }^{a}$ Dr. ${ }^{\text {a Ana Paula Scher }}$

Orientadora

Departamento de Linguística

Universidade de São Paulo

Prof. Dr. Shigeru Miyagawa

Departamento de Linguística e Filosofia

Massachusetts Institute of Technology

Prof. ${ }^{a}$ Dr. ${ }^{a}$ Cilene Aparecida Nunes Rodrigues

Departamento de Letras

Pontifícia Universidade Católica do Rio de Janeiro

Prof. ${ }^{a}$ Dr. ${ }^{a}$ Esmeralda Vailati Negrão

Departamento de Linguística

Universidade de São Paulo 
Instituto de Estudos da Linguagem

Universidade Estadual de Campinas

Prof. ${ }^{\text {a Dr. }}{ }^{\text {a }}$ Patricia de Araújo Rodrigues

(Suplente 2)

Departamento de Literatura e Linguística

Universidade Federal do Paraná

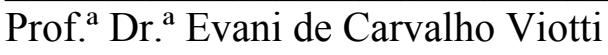

Departamento de Linguística

(Suplente 3)

Universidade de São Paulo 
Aos meus pais, Ana Flávia e Carlos, pelo amor incondicional. 


\section{Agradecimentos}

Quando assumimos o compromisso de investigar um dado fenômeno, não temos ideia de quais outras questões irão surgir em nosso percurso. Muitas vezes somos levados a trilhar caminhos que fogem imensamente ao escopo de nossas questões iniciais. Esse foi o meu caso. Os desafios não foram maiores do que o prazer em ampliar meus horizontes e de me dedicar a conhecer mais sobre áreas de conhecimento que não faziam parte de minha formação inicial. Fui levado a olhar para a competência linguística humana de outra forma, de outros vieses. Nesse trajeto, tive a imensa sorte de conhecer, de conversar, de aprender e de conviver com muitas pessoas, as quais tenho o prazer de mencionar e de agradecer neste breve espaço.

Agradeço, em primeiro lugar, aos meus pais. Pela paciência, pelo carinho e pelo apoio que me deram em todos esses anos. Sua preocupação em permitir que eu pudesse me dedicar àquilo que, para mim, é o sal da vida —o estudo e a pesquisa — merece minha gratidão eterna. Eles que, ainda sem compreender por que alguém deseja estudar linguística, não mediram esforços em permitir que eu continuasse minha formação. Muito obrigado pelo amparo nos momentos difíceis, pela atenção cotidiana e pelo estímulo que me fornecem para que eu siga sempre em frente. A vocês, meu amor e meu reconhecimento.

Agradeço ao CNPq pelo apoio financeiro concedido a mim (processo 160605/2014-8), sem o qual eu não poderia ter levado a cabo o projeto desta pesquisa. Agradeço também ao Departamento de Linguística da Universidade de São Paulo e ao Programa de Pós-Graduação em Semiótica e Linguística Geral por terem me acolhido nesses quatro anos, fornecendo-me suporte material e financeiro para o desenvolvimento e divulgação do trabalho. Quero fazer um agradecimento particular à Faculdade de Filosofia, Letras e Ciências Humanas, por ter me proporcionado experiências intelectuais e pessoais magníficas nesses últimos dez anos, as quais foram fundamentais para me moldar enquanto pesquisador e ser humano. Tenho um enorme orgulho de ter pertencido a essa casa.

Agradeço à minha orientadora, Ana Paula Scher. São oito anos de uma longa parceria, que deve ser destacada e celebrada. Agradeço à Ana Scher por estar sempre ao meu lado, por 
me ouvir e por me aconselhar, por trazer sensatez e razão nos momentos em que tenho dúvidas e incertezas, por ter me ensinado muito e por ainda vir me ensinando. Muito obrigado por acreditar em mim e por ter aceitado guiar minha pesquisa. Serei eternamente grato pela sua generosidade.

Agradeço à Professora Esmeralda Negrão pelos ensinamentos e por vir acompanhando minha formação há tantos anos. Agradeço-lhe, igualmente, por provocar em mim inúmeras questões, em especial, a curiosidade para explorar o surgimento da linguagem humana. Foi através de seu interesse sincero por essa problemática, que me senti desafiado a investigar esse tema.

Agradeço aos demais professores do Departamento de Linguística da USP por todo o conhecimento que me ofereceram nesses últimos dez anos, desde minha graduação. Um muito obrigado, em particular, aos professores Marcos Lopes, Evani Viotti, Marcello Modesto, Jairo Nunes, Paulo Chagas, Raquel Santana, Ana Muller, Marcelo Ferreira, Elaine Grolla, Luciana Storto, Cristina Salles, Olga Coelho e Ronald Mendes. Meu obrigado também à Erica Flávia, um auxílio imprescindível em todas as etapas decisivas deste trabalho. Agradeço-lhe pela colaboração e pela amizade.

Agradeço ao Professor Shigeru Miyagawa pela confiança e por todo o incentivo que tem me dado nos últimos quatro anos. Tenho uma grande honra de tê-lo como colaborador e como mentor. Agradeço imensamente seus conselhos, seu apoio intelectual e suas indagações, as quais me permitem progredir enquanto pesquisador. Agradeço-lhe também por ter tornado possível a minha visita ao Massachusetts Institute of Technology durante meu doutoramento. A visita que fiz ao Departamento de Linguística e Filosofia, no outono de 2016, foi essencial para o avanço da minha pesquisa.

Estendo os meus mais profundos agradecimentos ao Professor David Pesetsky, então chefe de departamento, que me recebeu e que me assistiu durante a estadia. Pude, através das nossas conversas, aprender a ser um pesquisador mais ponderado e a estar mais receptivo a apreciar as contribuições de modelos que divergem do meu ponto de vista inicial. Agradeço, de igual modo, aos demais professores do departamento, com quem tive o prazer de discutir diferentes versões deste e de outros trabalhos: Adam Albright, Norvin Richards, Danny Fox e Donca Steariade. 
Faço um agradecimento especial ao Professor Noam Chomsky, que gentilmente me recebeu em diferentes ocasiões durante minha visita e que, mesmo à distância, continuou me auxiliando e me enviando seus comentários. Agradeço, enormemente, sua solicitude. Ficará para sempre em minha memória seu entusiasmo em compartilhar conhecimento. Seu respeito pelas ideias alheias e sua simplicidade ampliaram grandemente minha reverência e admiração por sua pessoa. Faço um agradecimento particular à Bev Stohl, por tornar esses encontros possíveis e por me receber sempre com muito carinho.

Agradeço à Professora Maria José Foltran pela parceria, por me ensinar a admirar com entusiasmo dados ainda pouco explorados e por sua amizade verdadeira. Muito obrigado por ter me permitido trabalhar e aprender com você ao longo dos últimos quatro anos. Muito obrigado também por me apoiar, por compartilhar suas ideias, intuições e, obviamente, sua grande alegria de viver. Admiro muito o seu profissionalismo, que tomo como exemplo.

Agradeço à Professora Cilene Rodrigues por me empolgar e por me estimular a insistir em um trabalho linguístico que preza pela interdisciplinaridade. Obrigado por suas inúmeras sugestões, apontamentos e comentários em versões anteriores deste trabalho. Eles foram fundamentais para que a proposta chegasse ao seu formato atual. Seu interesse em desvendar a organização do mundo e da linguagem humana me serve de fonte de inspiração.

Agradeço à Professora Eloisa Pilati pelo interesse em meu trabalho, pela amizade e pelo incentivo que tem me dado há tantos anos. Sou muito grato por ter tido a oportunidade de discutir com você inquietações linguísticas, a vida, o futuro e as possíveis maneiras para se chegar a um mundo mais justo e igualitário. Estendo esse agradecimento ao Alexandre Pilati, que sempre me oferece uma dose de esperança.

Agradeço igualmente ao Professor Phoevos Panagitiodis, com quem tive o privilégio de trabalhar e de debater diversas questões envolvendo a morfologia e a sintaxe. Os nossos debates contribuíram decisivamente em meu trabalho. Sua paixão em explorar as filigranas da gramática me motivou enormemente. Agradeço também a sua paciência e a sua atenção nos últimos meses da redação da tese. 
Agradeço ao Grupo de Estudos em Morfologia Distribuída (GREMD) por contribuir substancialmente em minha formação intelectual. Através das discussões, pude aprender muito do que sei, não apenas teoricamente, mas profissionalmente. Obrigado a todos os membros que passaram pelo grupo, meus amigos de grande estima e respeito, em especial, Rafael Minussi, Indaiá Bassani, Júlio Barbosa, João Paulo Lazzarini-Cyrino, Paula Armelin, Aline Garcia Rodero-Takahira e Janayna Carvalho.

Agradeço aos professores e aos colegas que se dispuseram a discutir e a comentar meu trabalho ao longo desses quatro anos, contribuindo em vários aspectos durante sua elaboração, Sam Epstein, Hagit Borer, Alec Marantz, Patricia Rodrigues, Max Guimarães, Terje Lohndal, Eduardo Ottoni, Marcus Lunguinho, Eduardo Kenedy, Gabriel Othero, Fábio Mesquita, Erica Rodrigues, Letícia Sicuro, Márcio Leitão, Ana Paula Quadros Gomes, Luiz Carlos Schwindt, Luciana Sanchez, Ana Agostinho, Mitya Privoznov, Colin Davis, Ömer Demirok, Suzana Fong, Justin Colley, Ezer Rasin, Hanzhi Zhu, Elise Newman, Cora Lesure, Daniel Margulis, Abdul-Razak Sulemana, Isa Kerem Bayirli, Juliet Stanton, Roberta Pires de Oliveira, Karlos Arregi, Andrew Nevins, Michel Gaspar, Heloísa Salles, Helena Guerra, Rozana Naves, Paulo Medeiros, Alzira Neves, Núbia Rech, Teresa Wachowicz, Luana de Conto, Lívia Oushiro, Leslie Rose, Monica Frias, Bruna Moreira, Ana Paula Jakubów, a vocês meus mais sinceros agradecimentos. Agradeço, em separado, ao Professor Sérgio Menuzzi, que participou do meu exame de qualificação. O Professor Sérgio, juntamente com a Professora Esmeralda Negrão, fizeram apontamentos que foram essenciais para o avanço posterior deste trabalho.

Agradeço, profundamente, as oportunidades que me foram dadas para discutir os assuntos desta tese em outras universidades. Meu muitíssimo obrigado ao INCog (Grupo de Pesquisa Interdisciplinar em Neurociência e Cognição), da PUC-Rio; ao Lefog (Laboratório de Estudos Formais da Gramática), da UnB; ao GEG (Grupo de Estudos Gramaticais), da UFPR; ao NEG (Núcleo de Estudos Gramaticais), da UFSC, e ao InFoLinC (Investigações (in)Formais em Lingua(gem) e Cognição), da UNIFESP. Esses encontros me permitiram aprender muito mais sobre o assunto e me incentivaram a buscar mais conhecimento.

Agradeço à Cecilia Farias, pela cumplicidade, por seu carinho autêntico, e por ser a pessoa com quem posso contar em todos os momentos. Obrigado por estar presente em minha vida. Com você, aprendo a ser uma pessoa melhor (pelo menos, eu me esforço). Espero, um dia, ser forte e livre como você. 
Agradeço aos meus demais amigos, com quem dividi momentos muito felizes, e que foram pacientes, compreendendo meus momentos de ausência durante esses quatro anos. Espero que nós possamos recuperar esses momentos em suspenso e viver juntos outros tantos mais, André Castro, Carol Simões, Livia Oushiro, Mytia Privoznov, Regina Szwadzka, Lara Frutos, Marcus Lunguinho e Guilherme Beltrami.

Por fim, agradeço aos meus irmãos Guilherme e Gustavo, e ao Tufão, minha alegria de viver, pelo apoio indireto no meu trabalho, e por representarem uma parte tão querida de mim. Um agradecimento especial à minha Tia Cida e à minha prima Ana Paula Tardivo, que me incentivaram tanto e que me auxiliaram em um momento sensível para o desenvolvimento dos meus estudos. Sem sua intervenção e seu apoio não teria chegado até aqui. 
"We are certainly not to relinquish evidence of experiments for the sake of dreams and vain fictions of our own devising; nor are we to recede from the analogy of Nature, which is wont to be simple and always consonant to itself".

Sir Isaac Newton — Principia Mathematica (1690) 


\section{Resumo}

NÓBREGA, Vitor Augusto. Abordagem Isomórfica: A Articulação entre o Léxico e a Sintaxe na Emergência da Linguagem. 2018. 268 f. Tese (Doutorado) — Faculdade de Filosofia, Letras e Ciências Humanas, Universidade de São Paulo, São Paulo, 2018.

Investigamos, nesta tese, as bases filogenéticas do léxico humano e o modo como elas foram articuladas às habilidades combinatoriais no curso da evolução. Partimos de uma avaliação da interação entre o léxico e a sintaxe com o intuito de determinar quanto da derivação sintática é dependente de informações lexicais e, em que medida, as propostas disponíveis são coerentes com o desenvolvimento evolutivo humano. Nosso objetivo principal é fornecer uma hipótese para a interface entre o léxico e a sintaxe que seja explicativa e evolutivamente adequada. Para esclarecer as discordâncias empíricas e teóricas observadas, propomos, em contrapartida, uma nova abordagem para a gramática, a Abordagem Isomórfica. Argumentamos que o léxico humano decorre do agrupamento de um conjunto de sistemas pré-adaptados que evoluíram separadamente —um sistema conceitual-intencional, um sistema sensório-motor e um sistema funcional—, cuja integração é um produto direto da emergência de um sistema combinatorial recursivo. Operacionalmente, buscamos, com essa abordagem, reduzir a influência lexical na formação de um objeto linguístico, na tentativa de assegurar uma isonomia funcional entre o léxico e a sintaxe. Motivamos, adicionalmente, a exaptação de um sistema responsável por derivar as unidades discretas empregadas pelo sistema combinatorial, a que damos o nome de sistema funcional. Compartilhado com primatas não humanos, o sistema funcional justifica-se pelo paralelismo entre a denotação rígida das vocalizações de alerta de primatas não humanos e o conteúdo fixo das unidades funcionais da linguagem humana. Propomos, com base nessa correlação, que os mecanismos cognitivos subjacentes aos sistemas de vocalização primata, instanciados pelo sistema funcional, correspondem aos precursores filogenéticos dos traços formais. Funcionalmente, essa nova abordagem incorpora a visão neoconstrucionista de que a derivação da estrutura sintática independe de informações codificadas nas entradas lexicais. Tal conjectura assegura a autonomia funcional da sintaxe, o que, como resultado, nos aproxima do caminho para se ir "além da adequação explicativa". 
Palavras-chave: linguística evolucionária; biolinguística; léxico; sintaxe; comunicação animal; Abordagem Isomórfica. 


\section{Abstract}

\section{NÓBREGA, Vitor Augusto. Isomorphic Approach: Articulating the Lexicon and Syntax}

in the Emergence of Language. 2018. 268 f. PhD dissertation - Faculty of Philosophy, Letters, and Human Sciences, University of São Paulo, São Paulo, 2018.

We investigate, in this dissertation, the phylogenetic bases of human lexicon and how they were articulated with combinatorial abilities in evolution. We begin with an evaluation of the interaction between lexicon and syntax to determine how much of the syntactic derivation is dependent on lexical information, and to which extent the available proposals are consistent with human evolutionary development. Our main goal is to come up with an account for the lexicon-syntax interface that is both explanatory and evolutionarily adequate. In an attempt to eliminate the observed empirical and theoretical divergences, we propose a new approach to grammar, the Isomorphic Approach. We claim the human lexicon arouse from the assemblage of a set of pre-adapted systems that evolved separately - viz., a conceptual-intentional, a sensory-motor, and a functional system - , whose integration is a by-product of the emergence of a recursive combinatorial system. Operationally, we seek, with this approach, to reduce the burden of lexical influence in the derivation of a linguistic object, with the view to establish a functional isonomy between lexicon and syntax. Furthermore, we motivate the exaptation of a pre-adapted system responsible for deriving the discrete units that feed the combinatorial engine, which we call functional system. Shared with non-human primates, the functional system finds justification in the parallel between the rigid denotation of non-human primate alert calls and the fixed content of human language functional units. We propose, based on this conjecture, that the cognitive mechanisms underlying non-human primate alarm-calling systems, suggestively made available by the functional system, comprise the phylogenetic precursors of human language formal features. Functionally, this new approach incorporates the neo-constructionist view that the derivation of a syntactic structure is independent of lexically encoded instructions. With this premise, we aim to ensure the establishment of an autonomous syntax, which, as a result, brings us closer to the road toward a level of explanation that goes "beyond explanatory adequacy." 
Keywords: evolutionary linguistics; biolinguistics; lexicon; syntax; animal communication; Isomorphic Approach. 


\section{Lista de Figuras}

Figura 1 Representação esquemática dos fatores internos ao organismo relacionados à FL.

Figura 2 Espectrogramas das vocalizações de alarme de macacos-vervet 85 (Chlorocebus pygerythrus) em resposta às suas três principais classes de predadores, notadamente: leopardos, águias e cobras.

Figura 3 Representações das táticas antipredatórias dos macacos-vervet 86

Figura 4 Espectrogramas das vocalizações de alarme de macacos diana (Cercopithecus diana diana) machos e fêmeas em resposta às suas duas principais classes de predadores, águias e leopardos.

Figura 5 Propriedades referenciais das representações simbólicas de primatas não humanos e humanos.

Figura 6 Espécies de aves que motivaram a produção da vocalização para 103 águias por macacos vervet infantes, juvenis e adultos.

Figura 7 Integração entre FLB e FLN de acordo com a AI.

Figura 8 Relações filogenéticas dos componentes da FL com a espécie humana.

Figura 9 Diagramas arbóreos representando as relações filogenéticas de autapomorfia, sinapomorfia e homoplasia.

Figura 10 Típico exemplar de um núcleo para corte vinculado à indústria lítica Olduvaiense, encontrada no Valle del Duero (Espanha).

Figura 11 Típico exemplar de um "machado de mão" vinculado à indústria lítica Acheulense, encontrado no Valle del Duero (Espanha).

Figura 12 Placa de ocre com inscrições geométricas encontrada na caverna de Blombos, África do Sul.

Figura 13 Árvore evolucionária da família Hominidae. 


\section{Lista de Quadros}

Quadro 1 Amostra das abordagens empíricas utilizadas para se determinar os componentes da FL.

Quadro 2 Animais que provocaram a produção de vocalizações de alarme por macacos-vervet.

Quadro 3 Palavras formadas a partir da raiz $\sqrt{K B}_{\mathrm{K} \int}$ do hebraico.

Quadro 4 Taxonomia dos morfemas estipulados pela AI. 188

Quadro 5 Principais eventos evolutivos envolvidos na emergência da FL. 


\section{Lista de Abreviaturas e Siglas}

\begin{tabular}{|c|c|}
\hline $\mathrm{A} / \mathrm{ADJ}$ & Adjetivo \\
\hline$a$ & Categorizador adjetival \\
\hline $\mathrm{AC}$ & Átomo conceitual \\
\hline $\mathrm{A} / \mathrm{C}$ & Agente/Causa \\
\hline AExt & Argumento externo \\
\hline AI & Abordagem Isomórfica \\
\hline AInt & Argumento interno \\
\hline Asp & Aspecto \\
\hline ATR & Atributo \\
\hline AUX & Auxiliar \\
\hline $\mathrm{BEC}$ & Become \\
\hline$c$ & Categoria funcional particular a uma língua \\
\hline $\mathrm{C}$ & Sistema combinatorial \\
\hline $\mathrm{C}$ & Núcleo complementizador \\
\hline C-I & Sistema conceitual-intencional \\
\hline CL & Classificador \\
\hline $\mathrm{CP}$ & Sintagma complementizador \\
\hline $\mathrm{D}$ & Determinante \\
\hline DEF & Definitude \\
\hline DEM & Demonstrativo \\
\hline DIR & Direto \\
\hline DP & Sintagma determinante \\
\hline DS & Estrutura profunda \\
\hline EPP & Princípio da Projeção Estendida \\
\hline ERG & Ergativo \\
\hline$f_{0}$ & Interface com o sistema funcional \\
\hline$F$ & Especificação funcional \\
\hline $\mathrm{F}$ & Sistema funcional \\
\hline FEM & Feminino \\
\hline
\end{tabular}


Camada flexional

IMP Imperativo

INV

Inverso

Caso

Língua (genérico)

Forma Lógica

Lexical Functional Grammar

Entrada lexical

LOC

Locativo

MD

Morfologia Distribuída

$n$

Categorizador nominal

$\mathrm{N}$

Nome

NP

Sintagma nominal

Num

Numeral

$\mathrm{O}$

Organismo

OS

Objeto sintático

1P

2P

$3 P$

$1^{a}$ pessoa

$2^{\mathrm{a}}$ pessoa

PASS

$\mathrm{PF}$

$3^{\mathrm{a}}$ pessoa

Semântica lexical de uma entrada lexical

Preposição

Passado

PHON

Forma Fonética

Interface com o sistema sensório-motor 


\begin{tabular}{|c|c|}
\hline PL & Plural \\
\hline PM & Programa Minimalista \\
\hline POSS & Possessivo \\
\hline PP & Sintagma preposicionado \\
\hline PROX & Proximal \\
\hline Q & Quantificador \\
\hline $\mathrm{R}_{\mathrm{K}}$ & Representação estrutural \\
\hline $\mathrm{T}$ & Tempo \\
\hline TA & Transitivo animado \\
\hline TRANS & Transitivo \\
\hline SEM & Interface com o sistema conceitual-intencional \\
\hline SG & Singular \\
\hline S-M & Sistema sensório-motor \\
\hline SMT & Tese Minimalista Forte \\
\hline SS & Estrutura superficial \\
\hline Spec & Especificador \\
\hline SUBJ & Sujeito \\
\hline $\mathrm{UdL}$ & Unidade da Linguagem \\
\hline$u \mathrm{~F}$ & Traço não interpretável \\
\hline $\mathrm{V}$ & Verbo \\
\hline $\mathrm{v}$ & Categorizador verbal \\
\hline$v$ & Núcleo funcional introdutor de argumento externo \\
\hline VAL & Valor \\
\hline VP & Sintagma verbal \\
\hline $\mathrm{XS}$ & Modelo Exoesqueletal \\
\hline WH & Item $w h$ \\
\hline
\end{tabular}




\title{
Lista de Símbolos
}

\author{
Raiz lexical \\ Domínio interpretativo \\ Categoria universal \\ Traços de número, gênero e pessoa \\ Unidade fonológica \\ Conteúdo semântico \\ Marcação temática \\ Equivalência à substância \\ Equivalência a extensível no tempo
}

[N]

[V]

[A]

Equivalência à propriedade 


\section{Sumário}

\section{Capítulo 1 \\ Introdução}

1.1 As contradições no tratamento dado ao léxico e à sintaxe 25

1.2 Questões de pesquisa, hipóteses e domínio empírico 30

1.3 Visão geral dos capítulos $\quad 35$

\section{Capítulo 2}

Desiderata para uma sintaxe autônoma $\quad 37$

2.1 Introdução 37

2.2 Em defesa de uma sintaxe ab ovo

2.3 Em defesa de uma sintaxe como único componente gerativo 52

2.3.1 Sintetizando a GU: Considerações sobre ontogenia 53

2.3.2 Sintetizando a GU: Considerações evolutivas 60

2.4 Diretrizes para uma teoria sintática explicativa e evolutivamente adequada $\quad 71$

$\begin{array}{ll}2.5 \text { Resumo } & 78\end{array}$

\section{Capítulo 3}

O sistema funcional $\quad 81$

3.1 Introdução $\quad 81$

3.2 A referencialidade funcional do repertório vocal primata $\quad 83$

3.3 As bases filogenéticas do léxico funcional humano 96

$\begin{array}{ll}3.3 .1 \text { A natureza rígida das categorias referenciais primatas } & 100\end{array}$

3.3.2 A natureza flexível das raízes lexicais 104

$\begin{array}{ll}3.3 .3 \mathrm{O} \text { sistema funcional } & 110\end{array}$

3.4 Fatores biológicos que restringem a ampliação do repertório primata 117

3.4.1 Restrições neurofisiológicas que limitam o repertório primata 119

3.4.2 Restrições representacionais que limitam o repertório primata 124

$\begin{array}{ll}3.5 \text { Resumo } & 127\end{array}$

\section{Capítulo 4}

A Abordagem Isomórfica 128

4.1 Introdução 128

4.2 A Abordagem Isomórfica e a arquitetura da gramática 133

4.3 A base universal das categorias funcionais $\quad 145$

$\begin{array}{ll}\text { 4.3.1 Hipótese da ausência de uma base universal } & 147\end{array}$

$\begin{array}{lr}\text { 4.3.2 Hipótese da Base Universal } & 150\end{array}$

4.3.3 Hipótese da Coluna Universal 155 
4.4 O molde isomórfico do léxico funcional humano 164

4.4.1 Etapas de formação de uma categoria funcional 167

4.4.2 A instalação da multiplicidade dos traços formais $\quad 174$

4.5 A emergência do léxico conceitual humano 188

4.6 A Abordagem Isomórfica e o ideal de uma sintaxe autônoma 200

$\begin{array}{ll}4.7 \text { Resumo } & 210\end{array}$

\section{Capítulo 5}

Evolução, contrastes e conclusões 213

5.1 Evolução humana e os primeiros registros de uma consciência simbólica 213

$\begin{array}{ll}5.2 \text { Contrastes } & 225\end{array}$

5.3 Conclusões $\quad 231$

Referências Bibliográficas $\quad 234$ 



\section{Capítulo 1}

Introdução

Investigamos, nesta tese, as bases filogenéticas do léxico humano e o modo como elas foram articuladas às habilidades combinatoriais no curso da evolução. Partimos de uma avaliação da interação entre o léxico e a sintaxe com o intuito de determinar quanto da derivação sintática é dependente de informações lexicais e, em que medida, as propostas disponíveis são coerentes com o desenvolvimento evolutivo humano. Nosso objetivo principal é fornecer uma hipótese para a interface entre o léxico e a sintaxe que seja explicativa e evolutivamente adequada. Para esclarecer as discordâncias empíricas e teóricas observadas, propomos, em contrapartida, uma nova abordagem para a gramática, a Abordagem Isomórfica. Argumentamos que o léxico humano decorre do agrupamento de um conjunto de sistemas que evoluíram separadamente e cuja integração é um produto direto da emergência de um sistema combinatorial recursivo. Operacionalmente, buscamos, com essa abordagem, reduzir a influência lexical na formação de um objeto linguístico, na tentativa de assegurar uma isonomia funcional entre o léxico e a sintaxe.

\subsection{As contradições no tratamento dado ao léxico e à sintaxe}

Há um certo consenso de que a capacidade para adquirir e processar uma língua diz respeito a um caractere biológico circunscrito à espécie humana. Visto sincronicamente, todo caractere biológico exclusivo a uma única espécie pode parecer, a princípio, uma inovação evolutiva, ou seja, um caractere sui generis sem correlatos estruturais em espécies ancestrais. Porém, caracteres sugestivamente inovadores não emergem do nada. Uma inovação evolutiva decorre, comumente, da reorganização de estruturas e de componentes preexistentes que, uma 
vez recrutados para uma nova função, acabam dando origem a um conjunto de propriedades inesperadas. Tendo em vista a longa história evolutiva que antecede o aparecimento do Homo sapiens, é razoável presumir que as bases cognitivas que propiciaram o desenvolvimento de uma competência linguística evoluíram independentemente em outras espécies.

Assim, a natureza inovadora da Faculdade da Linguagem (FL) - i.e., do caractere que capacita a espécie humana com a aptidão para adquirir, produzir e compreender uma ou mais línguas - deriva, teoricamente, de uma reestruturação de componentes mais elementares, os quais já estavam disponíveis na natureza muito antes de seu aparecimento. Considerando-se que a competência linguística compreende um conjunto de associações entre um significado e um som ou sinal, conectados por meio de uma estrutura sintática, podemos admitir que a FL inclui, pelo menos, um léxico, uma sintaxe, um sistema para externalização - i.e., sensóriomotor (S-M) - e um sistema para interpretação - i.e., conceitual-intencional (C-I). Em vista disso, esclarecer o surgimento da FL implica determinar como esses quatro componentes foram reunidos durante a evolução humana e quais dentre eles preexistem à linguagem.

Ao analisar, em particular, o léxico e a sintaxe, percebemos que a linguística teórica os descreve, tradicionalmente, como dois módulos independentes da FL. Sua interação é o que promove a formação das expressões linguísticas. Dada a centralidade desses dois módulos, Berwick e Chomsky (2016, p. 66) sugerem que a tarefa central das investigações acerca da emergência da FL reside em "explicar os 'átomos da computação sintática', os itens lexicais" e em "descobrir as propriedades computacionais da FL". ${ }^{1}$ Contudo, somente essa segunda tarefa tem recebido atenção. Isso decorre, em grande medida, da necessidade de se elucidar a conjectura de que a recursividade sintática representa o único componente humano da FL (HAUSER; CHOMSKY; FITCH, 2002). As origens evolutivas do léxico carecem ainda de uma explicação pormenorizada, biológica e cognitivamente fundamentada.

Em linhas gerais, a explanação para o desenvolvimento evolutivo do léxico reduz-se a duas conjecturas, as quais são apresentadas na forma de menções isoladas. A parte conceitual do léxico é descrita como um produto de mecanismos mentais de domínio geral, associados à aquisição e à memorização de palavras (HAUSER; CHOMSKY; FITCH, 2002, p. 1576). Já a parte funcional é atribuída às competências fornecidas pela Gramática Universal (GU) - i.e., pela porção da FL correspondente aos componentes exclusivos à espécie- (CHOMSKY, 2000, 2001, 2007). Essa última conjectura é um reflexo da alta especificidade das categorias

\footnotetext{
${ }^{1}$ Trecho original: "[To account for the emergence of the language faculty - hence to the existence of at least one language - we have to face to basic tasks. One is] to account for the "atoms of computation," the lexical items $[. .$.$] [The second is] to discover the computational property of the language faculty".$
} 
funcionais que, por terem ocupações circunscritas à linguagem, impedem que correspondentes filogenéticos sejam encontrados nos sistemas de comunicação animal ou mesmo em outros domínios cognitivos.

Por exemplo, as entradas lexicais regularmente abrigam um conjunto de diacríticos ou de traços formais que servem como instruções para as operações sintáticas. Tais instruções são capazes de projetar uma estrutura argumental, de desencadear movimentos, de determinar a organização de hierarquias funcionais, entre outros encargos. Até a variação translinguística resulta, na visão mais bem aceita, do modo como o léxico funcional é definido (Cf. BORER, 1984; CHOMSKY, 1995, 2001, 2004; BAKER, 2008; RIZZI, 2009, 2014; CINQUE, 2016). Essas funções são, essencialmente, restritas à linguagem. Pinker e Jackendoff (2005) chamam a atenção para a especificidade das entradas lexicais, cuja natureza é tão exclusiva à espécie quanto a própria recursividade sintática.

Em suas palavras:

\begin{abstract}
"[Qual é] a fonte e a natureza das entradas lexicais, as quais fazem um trabalho considerável na teoria (definindo estruturas sintagmáticas, desencadeando movimento), e que, portanto, são muito mais abstratas e específicas da linguagem do que simples pareamentos entre som e significado[?]" (PINKER; JACKENDOFF, 2005, p. 220, tradução nossa). ${ }^{2}$
\end{abstract}

Entretanto, atribuir o léxico —ou, no mínimo, sua parcela funcional—à GU não nos parece uma solução razoável. Isso se deve, fundamentalmente, ao provável desenvolvimento recente da FL, cuja fixação, inferida a partir da datação dos primeiros registros arqueológicos explicitamente simbólicos, ocorreu há, pelo menos, 80.000-100.000 anos (HENSHILWOOD et al., 2002; HENSHILWOOD et al., 2004; VANHAEREN et al., 2006; BOUZZOUGAR et al., 2007). Esse recorte temporal é um piscar de olhos tanto com relação ao tempo geológico quanto com relação aos 6-7 milhões de anos da evolução humana. Tal intervalo implica que a seleção natural não teria tempo hábil de produzir a complexidade verificada internamente à FL. Como resultado, a interferência de caracteres exclusivos ao genótipo humano -i.e., determinados pela GU— no surgimento da FL deve ser mínima (CHOMSKY, 2007, 2010a, 2013a, 2016).

\footnotetext{
${ }^{2}$ Trecho original: "[...] the source and nature of lexical entries, which do considerable work in the theory (defining phrase structures, triggering movement), and which therefore are far more abstract and languagespecific than mere sound-meaning pairings".
} 
Não seria adequado, portanto, assumir que a GU está a cargo tanto da determinação das habilidades combinatoriais associadas à sintaxe quanto das entradas lexicais, em especial, de diacríticos ou de feixes de traços formais. Tal conjectura sobrecarrega consideravelmente a GU e, como consequência, torna a explicação para o suposto desenvolvimento recente da FL infactível. Como assinala Chomsky (2013a, p. 37):

\begin{abstract}
"O alvo para a explicação da evolução da linguagem é a GU; foi isso o que evoluiu. [...] As evidências são bastante fortes de que, desde a partida de nossos ancestrais para fora da África, há cerca de 50.000 anos atrás, a GU não sofreu nenhuma mudança significativa, e antes disso (no tempo evolucionário) não há evidências de que ela tenha existido. Quanto mais simples a GU, maior a esperança de que a evolução da linguagem [...] pode algum dia ser pelo menos parcialmente compreendida" (CHOMSKY, 2013a, p. 37, tradução nossa). ${ }^{3}$
\end{abstract}

Em vista disso, nós devemos repensar o papel e a especificidade do léxico, juntamente com sua articulação com a sintaxe, reavaliando seus primitivos e o empacotamento arbitrário de informações em entradas lexicais. Essa estratégia nos permitirá chegar a uma hipótese sobre a GU que seja evolutivamente adequada, isto é, coerente com o desenvolvimento evolutivo humano. A nosso ver, o pouco entendimento das bases biológicas e cognitivas do léxico é o que permite um tratamento imprudente para a relação entre o léxico e a sintaxe, pois, na ausência de uma hipótese restritiva e bem fundamentada sobre os primitivos lexicais, em particular, sobre os diacríticos e os traços formais, torna-se trivial consentir que entradas lexicais altamente específicas estejam presentes na gramática, sem a necessidade de se justificar como elas foram estabelecidas e quais seriam suas possíveis origens biológicas (e.g., se elas apresentam algum precursor filogenético ou não).

Além desse descompasso evolutivo envolvendo a especificidade do léxico, devemos considerar também quão explicativa é a assunção de entradas lexicais altamente informativas. $\mathrm{O}$ encapsulamento de propriedades combinatoriais na forma de instruções predeterminadas em um léxico pré-sintático é um problema da mesma forma que o pouco conhecimento sobre suas origens. Essa concepção de léxico nos faz questionar em que medida estamos, realmente, explicando os fenômenos linguísticos ou simplesmente arranjando artifícios para assegurar o

\footnotetext{
${ }^{3}$ Trecho original: "The target of an account of language evolution is UG; that is what has evolved. [...] The evidence is quite strong that since the departure of our ancestors from Africa about 50,000 years ago it has undergone no significant change, and not very long before (in evolutionary time) there is no evidence that it existed. The simpler UG, the greater the hope that evolution of language [...] might some day be at least partially understood".
} 
estabelecimento de uma determinada configuração estrutural. Borer (2005a, 2013) e Boeckx (2010, 2015) destacam que um léxico internamente complexo nos impossibilita de alcançar um nível de adequação explicativa que seja capaz de esclarecer por que as estruturas geradas são do modo como são (mas não de outro). Ao postular que instruções lexicais conduzem as operações sintáticas, estamos reproduzindo, irrefletidamente, uma determinada observação empírica. Além do mais, ao relegar entradas lexicais internamente complexas ao genótipo humano - i.e., à GU—, tal como feixes de traços formais ou mesmo hierarquias funcionais, inviabilizamos ainda mais um tratamento adequado para a emergência da FL.

É com base nesses apontamentos que construímos a proposta desta tese. Nos próximos capítulos, propomos uma nova abordagem para a gramática, em que a influência do léxico na derivação de um objeto linguístico reduz-se significativamente e, ao mesmo tempo, contribui para uma supressão de suas especificidades. A ela, damos o nome de Abordagem Isomórfica. Argumentamos, adicionalmente, que as bases evolutivas do léxico não decorrem da GU, mas de sistemas externos à FL. Assumimos uma orientação biolinguística, isto é, interessada em desvendar as fundações biológicas da competência linguística humana. Procuramos, através dessa orientação, não apenas chegar a uma melhor compreensão das origens do léxico, como também fornecer uma explicação mais bem fundamentada sobre sua articulação com a sintaxe. Como apontado por Lenneberg (1964, p. 76), ainda no começo do empreendimento biolinguístico, "nada se ganha rotulando a propensão para a linguagem como biológica, a menos que possamos usar esse insight para novas direções de pesquisa". ${ }^{4}$

Ao abordar a relação entre o léxico e a sintaxe através dessa orientação biolinguística, focada em uma linguística evolucionária, buscamos igualmente demonstrar a relevância de se admitir um critério de adequação evolutiva, ou seja, de se elaborar hipóteses para a gramática que sejam condizentes com o percurso evolutivo humano. Por meio desse critério, seremos capazes de alinhar a linguística teórica aos ideais que subjazem às teorias naturalistas. Assim, seguindo a advertência de Jackendoff (2011, p. 588), procuramos fazer com que a linguística teórica "[faça] contato com a biologia, levando o estudo da linguagem para além da descrição e dos universais linguísticos". Em nossa visão, um maior conhecimento sobre a natureza biológica dos primitivos e dos componentes da gramática irá nos assegurar a elaboração de hipóteses explicativamente mais adequadas. Para levar a cabo essas pretensões, apresentamos,

\footnotetext{
${ }^{4}$ Trecho original: "nothing is gained by labeling the propensity for language as biological unless we can use this insight for new research directions $[\ldots]$ ".

${ }^{5}$ Trecho original: "linguistics must make contact with biology, taking the study of language beyond just the description of languages and language universals".
} 
no que segue, as três questões de pesquisa desta tese, nossas hipóteses, o domínio empírico explorado e uma visão geral dos capítulos que a constituem.

\subsection{Questões de pesquisa, hipóteses e domínio empírico}

Vimos, nesta primeira exposição, que há uma contradição no tratamento teórico e no tratamento evolutivo dado ao léxico e à sintaxe, bem como à sua articulação internamente à FL. Nesta tese, pretendemos eliminar essas contradições e abrir caminho para um tratamento da interface entre o léxico e a sintaxe que produza resultados explicativos e que se alinhe a uma orientação biolinguística, preocupada em gerar hipóteses coerentes com o conhecimento atual sobre a história evolutiva humana. Para alcançar esses objetivos, nós investigamos três questões, cujas explicações compõem os eixos temáticos dos capítulos que virão a seguir.

\section{* Questão \#1:}

Qual a razoabilidade de se admitir que o funcionamento sintático depende diretamente de informações lexicais?

A sintaxe, em uma abordagem lexicocêntrica, como a descrita acima, não desfruta de autonomia funcional, visto que ela apenas implementa uma planta estrutural predeterminada nas entradas lexicais. Há, contudo, dúvidas tanto no que concerne ao caráter explicativo dessa abordagem, quanto no que diz respeito à sua validade evolutiva, já que a FL parece ser um desenvolvimento recente. Assim, a premissa de que a estrutura sintática está pré-moldada em núcleos lexicais representa, em nosso entendimento, uma estratégia descritiva provisória, que, embora tenha propiciado um avanço na investigação do conhecimento linguístico humano, encontra-se, atualmente, ultrapassada. Se nosso objetivo é, de fato, ir "além da adequação explicativa", ou seja, esclarecer por que as propriedades e as estruturas da linguagem são do modo como são, tal como sugere Chomsky (2007), torna-se imperativo repensar o papel do léxico internamente à FL.

Observem que o que estamos colocando em pauta é a plausibilidade de se relegar a distribuição das entradas lexicais e a derivação de uma estrutura sintática a instruções lexicais, como se tais instruções fossem uma exigência da GU, e, nesse sentido, decorressem de uma condição biológica da espécie humana, que, até o momento, não apresenta uma justificativa evidente. Dessa forma, não consideramos procedente assumir que o funcionamento sintático 
seja um reflexo de informações codificadas em entradas lexicais. Em contraposição a essa assunção, procuramos desenvolver uma abordagem para gramática em que a sintaxe desfruta de liberdade combinatorial ab ovo, ou seja, desde o início da derivação. A sintaxe, em nossa perspectiva, dispõe de total autonomia combinatorial para gerar diferentes arranjos estruturais a partir de um conjunto uniforme de entradas lexicais, cujo conteúdo não apresenta nenhum efeito estrutural. A aceitabilidade das representações geradas é determinada pelo sistema interpretativo C-I, pós-sintaticamente, e não previamente através de imposições feitas por instruções lexicais.

Para se atingir esse modelo ideal acerca da articulação entre o léxico e a sintaxe, nós reunimos, no Capítulo 2, um conjunto de desiderata metodológicos, que nos servirão como critérios para assegurar que não estamos atribuindo aos primitivos lexicais propriedades que deveriam ser de responsabilidade ou da sintaxe ou do sistema C-I. Esses desiderata são:

\section{- Desideratum \#1:}

As entradas lexicais não devem ser as responsáveis por projetar a estrutura sintática.

\section{- Desideratum \#2:}

Informações lexicais não devem ser pré-empacotadas arbitrária e gratuitamente em um léxico pré-sintático.

\section{- Desideratum \#3:}

Hierarquias de primitivos funcionais devem ser emergentes, não predeterminadas.

\section{- Desideratum \#4:}

A GU deve fornecer à $\mathrm{FL}$ apenas um único sistema combinatorial, implementado pela operação Merge, isto é, pela operação sintática responsável por combinar primitivos lexicais em estruturas hierarquicamente arranjadas.

\section{- Desideratum \#5:}

As aplicações da operação Merge devem estar dissociadas da satisfação de exigências lexicais. 
Acreditamos que, ao satisfazer esse grupo de desiderata, seremos capazes de elaborar uma teoria da gramática livre de empacotamento ad hoc de informações combinatoriais em entradas lexicais e, paralelamente, de abordar o conhecimento linguístico humano sem reduzir as propriedades combinatoriais das línguas naturais a instruções preestabelecidas. Além disso, esses desiderata visam garantir que as propriedades do léxico não sobrecarreguem o aparato genético da espécie, ou seja, a GU, uma vez que eles removem a necessidade de se admitir um léxico altamente estruturado como parte de suas atribuições.

\section{Questão \#2:}

O léxico humano evoluiu independentemente das habilidades sintáticas?

Em conformidade com o desideratum 4, reunimos evidências que nos mostram que as bases filogenéticas do léxico são dissociadas do desenvolvimento da sintaxe e que, portanto, devem ter evoluído de modo independente. Argumentamos que, semelhantemente à própria FL, o léxico resulta da reunião entre caracteres que evoluíram em separado, notadamente: um sistema S-M, um sistema C-I e um sistema funcional. Especificamente, sugerimos que as bases cognitivas do inventário lexical humano foram fixadas quando esses três sistemas préadaptados passaram a ser mediados através de um sistema combinatorial recursivo, a sintaxe, instanciado teoricamente por Merge. Esse último sistema representa um caractere exclusivo ao genótipo humano, uma vez que ele não apresenta correspondentes homólogos ou análogos no mundo natural, como revelam Hauser, Chomsky e Fitch (2002), Yip (2006), Berwick et al. (2011), Heinz e Idsardi (2013), Samuels (2009, 2011, 2015), entre outros. ${ }^{6}$

Em nossa perspectiva, portanto, o léxico não é um caractere monolítico ao qual vieram se aplicando modificações graduais, nem mesmo uma expressão de habilidades determinadas pela GU. Ele corresponde, por hipótese, a um efeito colateral da combinação dos sistemas pré-adaptados que deram origem à FL. Sendo assim, o léxico não deve ser visto como um módulo da FL, mas como um produto da interação da FL com esses três diferentes sistemas externos. No que concerne à porção funcional, argumentamos em favor da exaptação de um sistema pré-adaptado, a que damos o nome de sistema funcional. Compartilhado com primatas não humanos, esse sistema justifica-se pelo paralelismo entre a denotação rígida das vocalizações de alerta de primatas não humanos e o conteúdo fixo das unidades funcionais da

\footnotetext{
${ }^{6}$ Caracteres homólogos são aqueles que evoluíram a partir de um ancestral comum. Já os caracteres análogos são aqueles que apresentam uma função semelhante, porém, emergiram independentemente em espécies sem relação evolutiva próxima.
} 
linguagem humana. Propomos, a partir dessa correspondência, que os mecanismos cognitivos subjacentes aos sistemas de vocalização primata, bem como de outros animais não humanos, instanciados pelo sistema funcional, correspondem aos precursores filogenéticos dos traços formais.

Por outro lado, nós propomos que a porção conceitual do léxico humano decorre das competências perceptuais instauradas pelo sistema C-I e da maneira como esse sistema passou a interagir com o componente sintático, ou seja, com a operação Merge, após a reorganização física e mental que deu origem à FL. Mais precisamente, nós conjecturamos que a porção conceitual do léxico humano foi fixada no momento em que Merge passou a delimitar conjuntos vazios em uma estrutura sintática, os quais passaram a ser preenchidos pelas representações conceituais extraídas da percepção, alocadas em C-I. Internamente à FL, esse grupo de representações conceituais foi atomizado em itens linguísticos e passou a constituir o conhecimento de mundo de um falante. Posteriormente, esses itens foram associados a uma forma fonológica e externalizados por meio do sistema S-M. Veremos que uma das principais consequências da associação entre Merge e o sistema C-I foi uma ampliação considerável do repertório lexical humano.

Tendo em mente essas considerações, propomos que as competências que integram o repertório lexical humano — conteúdos funcionais e conceituais e formas fonológicas - estão distribuídas pela FL na forma de três listas dissociadas, todas elas não gerativas e constituídas por informações relativas a cada um dos sistemas externos dos quais elas derivam, em consonância com o que sugere a visão canônica apresentada pela Morfologia Distribuída (Cf. MARANTZ, 1995, 1997; EMBICK; NOYER, 2007; HARLEY, 2014), a saber:

- Léxico-I(nterno), que abriga o banco de primitivos linguísticos oriundos da interface com o sistema funcional, ou seja, o conjunto de traços formais de uma dada língua L;

- Léxico-C(onceitual), que abriga as representações conceituais extraídas da percepção, atomizadas na forma de instruções linguísticas, as quais interagem com o sistema C-I;

- Léxico-E(xterno), que abriga as regras que associam tanto os primitivos do Léxico-I quanto as representações conceituais lexicalizadas a instruções fonológicas.

Considerando-se essas assunções, a GU reduz-se, em nossa perspectiva, a um sistema combinatorial recursivo, responsável por formar expressões hierarquicamente estruturadas, e 
às interfaces com os três sistemas externos: funcional, C-I e S-M. Tal posicionamento alinhase diretamente com o que pretende a Tese Minimalista Forte (do inglês Strong Minimalist Thesis, SMT; CHOMSKY, 2000, 2001, 2004, 2010a), o que nos permite afirmar que a Abordagem Isomórfica aproxima-se de uma hipótese evolutivamente adequada. Em linhas gerais, as expressões linguísticas são derivadas a partir dos primitivos que integram o sistema funcional, presentes no Léxico-I. Em nossa abordagem, apenas traços formais servem como primitivos da gramática. As estruturas sintáticas formadas a partir desses traços serão, no caminho para o sistema C-I, vinculadas a uma dada instrução conceitual, presente no LéxicoC, a qual será responsável por buscar um conceito relevante na memória de longo prazo. Essa mesma estrutura irá receber, no caminho para S-M, instruções fonológicas para que ela possa, então, ser externalizada, as quais estão alocadas no Léxico-E.

\section{* Questão \#3:}

Como o léxico e a sintaxe foram integrados no curso da evolução?

Tendo em vista que as bases cognitivas dos primitivos manipulados pela sintaxe, isto é, dos traços formais, são externas à FL, conjecturamos que sua integração se dá por meio de uma interface, a que chamamos de interface $f_{0}$.

Propomos que a articulação entre o sistema funcional, que dá origem aos primitivos da gramática, e a sintaxe implementa-se de modo semelhante à Tese da Raiz Zero, sugerida por Sigurđsson (2012). Sua integração processa-se do seguinte modo: a interface $f_{0}$ corresponde a uma célula interna à FL, destituída de conteúdo, e que será arbitrariamente preenchida por um primitivo do sistema funcional. No momento em que $f_{0}$ é atrelada a uma primitivo do sistema funcional, ela produz um traço formal internamente à $\mathrm{FL}, f_{1}$, em uma dada língua L. Esse traço $f_{1}$ será armazenado em um Léxico-I, mais especificamente, em uma lista não ordenada de primitivos disponíveis para a operação Merge. Em seguida, a FL cria uma cópia de $f_{0}$, tornando essa interface disponível novamente. A nova cópia será preenchida por outro primitivo oriundo do sistema funcional e o procedimento se repete. A hipótese de que os primitivos do Léxico-I ingressam na FL através de uma interface com o sistema funcional nos permite assegurar a simplicidade da GU pretendida pela SMT, tornando a integração entre os primitivos lexicais e a sintaxe coerente com o percurso evolutivo humano.

Para motivar as hipóteses descritas nesta introdução, empregamos, como domínio empírico, trabalhos em que são descritas observações naturalísticas e experimentais sobre os sistemas de vocalização de alerta de animais não humanos, em especial, de primatas 
antropoides - i.e., macacos do Velho e do Novo mundo e grandes símios-, bem como sobre seu comportamento, desenvolvimento e percepção vocal. Para motivar o caráter inato dos conteúdos veiculados pelos traços formais e endossar sua correlação com o comportamento vocal primata, recorremos ao domínio empírico explorado por Wiltschko (2014, 2015), bem como a uma série de trabalhos que investigaram a universalidade das categorias funcionais. É importante destacar que esta tese não tem por objetivo uma explicação detalhada de um dado fenômeno linguístico ou da organização da gramática de uma determinada língua. Nosso foco é reavaliar o estabelecimento das competências atreladas ao léxico e à sintaxe na evolução da espécie, a partir da descrição de fenômenos linguísticos já bem conhecidos e descritos pela literatura linguística.

\subsection{Visão geral dos capítulos}

No Capítulo 2, apresentamos uma caracterização do lexicocentrismo dominante nos modelos gerativistas, dando atenção especial aos modelos minimalistas, e os empecilhos que esse posicionamento coloca para a descrição e para a explicação dos fenômenos linguísticos. Destacamos que uma perspectiva lexicocêntrica para a gramática nos impede de desenvolver teorias explicativamente adequadas e nos afasta de uma explicação evolutivamente adequada sobre a competência linguística humana. Para elaborar uma abordagem para a gramática livre da influência lexical no funcionamento sintático, tal como pretende a Abordagem Isomórfica, exploramos um conjunto de desiderata metodológicos fundamentais para assegurar uma sintaxe operacionalmente independente.

No Capítulo 3, nós motivamos a existência de um sistema funcional em primatas não humanos e humanos. Reunimos, primeiramente, evidências em favor da natureza referencial das vocalizações de alerta. Caracterizamos, logo depois, o mecanismo cognitivo subjacente às vocalizações e o modo pelo qual ele corresponde à base filogenética do léxico funcional humano. Listamos evidências em favor da natureza inata e referencialmente rígida das representações subjacentes a esses sinais vocais e comparamos tais características com as propriedades dos primitivos lexicais, raízes -i.e., os primitivos geralmente atrelados à porção conceitual do léxico- e traços formais. É a partir dessa analogia que propomos o sistema funcional. Elencamos ainda os motivos que teriam impulsionado a seleção desse sistema. Para chegar a um maior entendimento acerca da expansão do repertório lexical humano, 
apontamos os fatores biológicos que possivelmente limitam a ampliação do inventário vocal primata de um ponto de vista ontogenético.

No Capítulo 4, apresentamos os pressupostos gerais da Abordagem Isomórfica. Nele, exploramos seus componentes e seu funcionamento. Descrevemos a arquitetura da gramática concebida por essa abordagem e o modo como o sistema funcional se integra à FL. Discutimos em que medida é possível argumentar em favor da universalidade de categorias funcionais, a fim de identificar a natureza dos primitivos que integram o sistema funcional humano. Apresentamos a estrutura elementar do molde isomórfico - i.e., dos primitivos do sistema funcional - a partir do qual os traços formais são derivados. Mostramos como esse molde isomórfico dá origem à variedade de traços formais observada translinguisticamente. Descrevemos, adicionalmente, como se deu a emergência da porção conceitual do léxico humano sob a ótica da Abordagem Isomórfica. Por fim, ilustramos como essa abordagem satisfaz os desiderata para uma sintaxe autônoma, indicados no Capítulo 2.

No Capítulo 5, localizamos a emergência da FL, vinculando-a a uma espécie, a um local e a um dado ponto no tempo. Argumentamos que a FL é um caractere, sugestivamente, exclusivo ao $H$. sapiens, muito embora as bases cognitivas para o desenvolvimento de uma consciência simbólica já estivessem minimamente organizadas desde o surgimento do Homo heidelbergensis, o provável ancestral comum entre o Homo neanderthalensis e o H. sapiens. Discutimos, em seguida, um grupo de análises que divergem dos pressupostos globais da Abordagem Isomórfica e, por fim, reunimos as considerações finais desta tese. 


\section{Capítulo 2}

\section{Desiderata para uma sintaxe autônoma}

As entradas lexicais constituem-se, tipicamente, por um conjunto de informações prédeterminadas responsáveis por guiar a projeção de uma estrutura sintática. Essa perspectiva acerca da interação entre o léxico e a sintaxe pressupõe, em certo sentido, que a estrutura sintática já está pré-formatada na entrada lexical antes mesmo da derivação se iniciar. Embora tal assunção assegure a reprodução dos arranjos estruturais observados na empiria, ela não explica por que geramos tais arranjos e não outros. Com o intuito de ir "além da adequação explicativa" - ou seja, com o intuito de esclarecer por que as propriedades da linguagem são do modo como são-, reunimos, neste capítulo, um conjunto de desiderata metodológicos para abordar o conhecimento linguístico humano sem reduzir as propriedades combinatoriais das línguas naturais a instruções lexicais. Para tanto, investigamos quanto da computação sintática pode ser, efetivamente, dependente de informação lexical.

\subsection{Introdução}

A competência linguística da espécie humana compreende, minimamente, um sistema combinatorial recursivo - i.e., uma sintaxe-, e um conjunto finito de elementos discretos i.e., um léxico-, os quais, uma vez integrados, são capazes de dar origem a um número ilimitado de expressões internamente estruturadas e interpretáveis. Tradicionalmente, as teorias linguísticas estabelecem uma divisão operacional entre as funções atribuídas à sintaxe e ao léxico, caracterizando-os como dois módulos gramaticais substancialmente distintos. Tal hipótese sobre a organização interna da FL nos sugere, de um ponto de vista evolutivo, que o desenvolvimento de cada um desses módulos ocorreu autonomamente e por circunstâncias independentes. 
Essa é a conclusão de diversos trabalhos interdisciplinares de viés gerativista que buscam esclarecer as origens da linguagem humana. Neles, há uma notável primazia da sintaxe em oposição ao léxico, uma vez que a sintaxe é definida como o caractere central, unicamente humano, responsável por promover o surgimento da linguagem. O léxico, apesar de apresentar propriedades exclusivas à espécie, é descrito como produto de mecanismos mentais de domínio geral, os quais subsidiariam a aquisição e a memorização de palavras (HAUSER; CHOMSKY; FITCH, 2002, p. 1576). Entretanto, quando considerada de um ponto de vista estritamente formal, tal assimetria entra a sintaxe e o léxico se inverte: o léxico passa a ter precedência sobre a sintaxe, já que informações lexicais operam induzindo e conduzindo as operações sintáticas.

Com o objetivo de avaliar a autonomia da sintaxe com relação ao léxico, investigamos (i) em que medida, (ii) em quais circunstâncias e (iii) quais são os impasses colocados pela conjectura de que a computação sintática é regida por instruções lexicais. Argumentamos que uma abordagem lexicocêntrica para a gramática é contraproducente, pois ela impede o desenvolvimento de uma teoria explicativa e evolutivamente adequada sobre o conhecimento linguístico humano, em consonância com as posições de Borer (2003, 2005a, 2005b, 2013), Fujita (2009, 2017), Boeckx (2010, 2013a, 2015) e Sigurđsson (2012). Como resultado, apresentamos um conjunto de desiderata metodológicos que nos permitirá isentar a sintaxe da influência lexical e, consequentemente, repensar o impacto e a articulação de cada um desses módulos na emergência da competência linguística.

Este capítulo está organizado do seguinte modo: na seção 2.2, caracterizamos o lexicocentrismo dominante nos modelos gerativistas, com atenção especial aos modelos minimalistas, e os empecilhos que esse posicionamento teórico coloca para a descrição e para a explicação dos fenômenos linguísticos. Em seguida, na seção 2.3, mostramos que assunções lexicocêntricas não somente nos impedem de desenvolver uma teoria explicativamente adequada, como também nos afasta de uma explicação evolutivamente adequada sobre a capacidade linguística humana, condizente com a história evolutiva da espécie. Por fim, na seção 2.4, elencamos os desiderata metodológicos decorrentes das considerações feitas no capítulo, os quais são - em nosso entendimento - essenciais para se chegar a uma teoria da gramática livre de empacotamento ad hoc de informações combinatoriais. 


\subsection{Em defesa de uma sintaxe $a b$ ovo}

A caracterização das entradas lexicais e de sua articulação em uma estrutura sintática representa o principal objeto de investigação de diversas abordagens gerativistas para a gramática. Essas abordagens comumente delimitam as tarefas atribuídas às entradas lexicais e à estrutura sintática na forma de dois módulos independentes: o léxico e a sintaxe. Em linhas gerais, o léxico corresponde a um repositório de entradas lexicais, normalmente constituídas de uma associação arbitrária entre som e significado e de um conjunto de diacríticos ou traços formais que servem como instruções para as operações sintáticas. A sintaxe, por sua vez, desempenha as propriedades combinatoriais da gramática, concatenando entradas lexicais em uma estrutura hierarquicamente organizada.

A interação entre esses dois módulos segue o pressuposto de que as possibilidades combinatoriais verificadas nas línguas naturais decorrem de informações pré-codificadas nas entradas lexicais. Por exemplo, a entrada lexical ler, além de descrever o pareamento entre uma representação fonológica e uma representação semântica, contém, adicionalmente, diacríticos ou traços formais que especificam suas propriedades categoriais e predicativas, ou seja, sua distribuição sintática e a natureza sintático-semântica dos argumentos aos quais pode se concatenar. Tais informações indicam que ler é um verbo e deve ser combinado a nomes, uma vez que requer argumentos que satisfaçam suas exigências temáticas.

Esse posicionamento teórico é assumido, em particular, pelos modelos de Government and Binding (GB; e.g., GRIMSHAW, 1979; CHOMSKY, 1981, 1986; PESETSKY, 1982), Head-Driven Phrase Structure Grammar (HPSG; e.g., POLLARD; SAG, 1994; SAG; WASOW, 1999) e Lexical Functional Grammar (LFG; e.g., BRESNAN; KARNEVA, 1989; KAPLAN; BRESNAN, 1995; BRESNAN et al., 2016). É válido salientar que os modelos minimalistas também partilham dessa assunção, uma vez que partem de informações lexicais para determinar a concatenação e as relações de dependência entre as entradas lexicais, bem como eventuais transformações estruturais (e.g., CHOMSKY, 1995, 2000; ADGER, 2003; HORNSTEIN; NUNES; GROHMANN, 2005; BOECKX, 2011a; WURMBRAND, 2014, dentre outros). ${ }^{7}$

\footnotetext{
${ }^{7}$ Chomsky (1995) fornece uma formalização dissociativa para o processo lexical de pareamento entre traços formais e entradas lexicais. Os traços formais formam, de acordo com o autor, um subconjunto do léxico e são pareados às entradas lexicais somente após terem sido selecionados para compor uma Numeração. Para essa perspectiva, traços formais não constituem propriedades inerentes às entradas lexicais, já que devem ser associados a elas no curso da derivação, especialmente o que o autor chama de "traços opcionais" (Cf. CHOMSKY, 1995, p. 231). O que explicitamos, em nossa discussão, é a assunção canônica de que traços formais integram as entradas lexicais de uma língua, tal como caracterizado inicialmente em Chomsky (1965);
} 
Exemplos da codificação de informações distribucionais —mais especificamente, argumentais - na forma de diacríticos ou de traços formais estão ilustrados nas entradas lexicais em (1), cada qual correspondente a um dos modelos de gramática mencionados acima. Notem que a codificação de propriedades argumentais é elaborada de diferentes maneiras: pelas características semânticas dos argumentos, tal como em (1a); por sua função sintática, como em (1b) e (1c); ou por suas propriedades formais, como em (1d), em que os traços $\varphi$ (viz., traços associados a informações flexionais, como número, pessoa e gênero) sinalizam que o argumento interno deve ser um nome.

(1) Diacríticos e traços formais codificados nas entradas lexicais

a. Em GB (MARANTZ, 1984, p. 18)

$\begin{array}{lll}\text { i. } & \text { give 'dar' } & \text { (tema, alvo) } \\ \text { ii. } & \text { put 'colocar' } & \text { (tema, localização) } \\ \text { iii. } & \text { steal 'roubar' } & \text { (tema }, \text { fonte })\end{array}$

b. Em HPSG (LEVINE; MEURERS, 2006, p. 238)

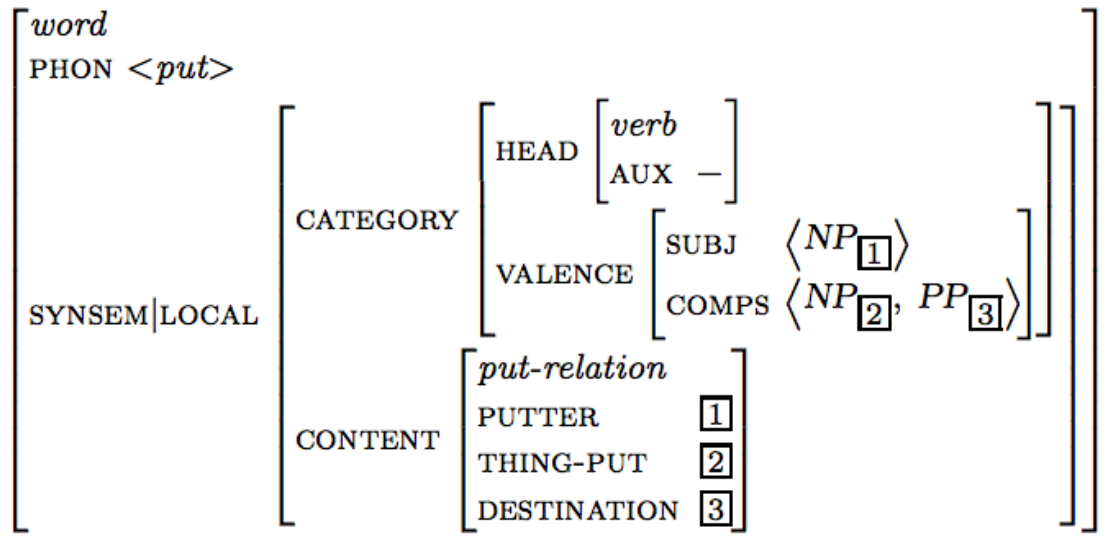

c. Em LFG (KAPLAN; BRESNAN, 1995, p. 59)

$$
\begin{aligned}
\text { hands 'entregar' } \mathrm{V} \quad & (\uparrow \text { TENSE })=\text { PRES } \\
& (\uparrow \text { SUB NUM })=\mathrm{SG} \\
& (\uparrow \mathrm{PRED})=\text { 'hand' }((\uparrow \mathrm{SUBJ}),(\uparrow \mathrm{OBJ}),(\uparrow \mathrm{OBJ} 2)),
\end{aligned}
$$

d. Em uma abordagem minimalista (WURMBRAND, 2014, p. 171)
i. wear 'usar'
[uT:
, $u v$ :
$, u \varphi:$
ii. call 'chamar'
[uT:
,$u v$ :
[uT:
$, u v:$

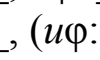
iii. laugh 'rir'

$$
\text { (u) }
$$

uma assunção que foi amplamente assumida pelas abordagens gerativistas posteriores. Chomsky (1965, p. 214) sugere que "[...] uma entrada lexical [é] simplesmente um conjunto de traços, alguns sintáticos, alguns fonológicos, alguns semânticos" [Trecho original: "[We might, then, take] a lexical entry to be simply a set of features, some syntactic, some phonological, some semantic"]. Veremos, no desenvolvimento deste capítulo, que mesmo uma abordagem dissociativa entre traços formais e entradas lexicais, como a de Chomsky (1995), parte de uma perspectiva teórica em que a sintaxe é vista como um coadjuvante na derivação dos objetos linguísticos. 
Ao examinar as entradas lexicais representadas em (1), percebemos que, para esses modelos, propriedades fundamentalmente formais reduzem-se a instruções lexicais. Do modo como estão descritas, as entradas lexicais em (1) são inseridas no componente sintático com lacunas a serem saturadas, as quais devem ser preenchidas por outras entradas lexicais no curso da derivação. Boeckx (2015) rotula tais modelos de gramática de "queijo suíço" ou "lego", ${ }^{8}$ enquanto Rappaport Hovav e Levin $(1995,1998)$ e Levin e Rappaport Hovav (2005) os classificam como modelos "projecionistas", pois são as propriedades lexicais que projetam a estrutura sintática. Borer (2003, 2005a, 2005b, 2013) semelhantemente descreve essa visão de gramática como "endoesqueletal”, uma vez que a entrada lexical serve como um esqueleto em torno do qual a sintaxe é construída.

Esquematicamente, essa hipótese acerca da articulação entre as funções do léxico e da sintaxe pode ser sintetizada através da equação em (2), elaborada em Borer (2005a, p. 5):

(2) $\mathrm{P}\left(\mathrm{L}_{\mathrm{K}}\right)+\mathrm{C} \rightarrow \mathrm{R}_{\mathrm{K}}$

Em (2), $\mathrm{L}_{\mathrm{K}}$ corresponde a uma entrada lexical; $\mathrm{P}$ corresponde à sua semântica lexical — traduzida em termos de uma relação predicado-argumento-; $\mathrm{C}$ ao sistema combinatorial implementado pela sintaxe e, $\mathrm{R}_{\mathrm{K}}$, a uma representação estrutural. As propriedades codificadas em $\mathrm{L}_{\mathrm{K}}$ devem ser mapeadas em uma $\mathrm{R}_{\mathrm{K}}$ por intermédio de C. Por exemplo, o verbo ler, seguindo esse esquema, tem listado em P dois argumentos a serem saturados, um agente (i.e., quem lê) e um paciente (i.e., o que é lido), bem como instruções que indicam que o paciente deve ser concatenado em uma relação estrutural mais interna do que o agente. $\mathrm{C}$, com base nessas instruções gera a $\mathrm{R}_{\mathrm{K}}$ em (3):

(3) $[\mathrm{vp}$ agente $\quad[\mathrm{v}$, ler paciente $]$

Uma vez que $\mathrm{C}$ instancia as propriedades combinatoriais da gramática, é plausível admitir, de um ponto de vista gerativo, que outras $R_{K}$ poderiam ser igualmente derivadas tomando o verbo ler como seu núcleo. Exemplos são as $\mathrm{R}_{\mathrm{K}}$ listadas em (4). No entanto, essas $\mathrm{R}_{\mathrm{K}}$ são descartadas da maneira como são geradas. Nas abordagens projecionistas, o descarte não toma por base questões de agramaticalidade, mas a incompatibilidade das $R_{K}$ em (4) com

\footnotetext{
${ }^{8}$ Tendo em vista a ideia de que as entradas lexicais são defectivas, já que elas somente se tornam plenas quando "preenchidas" por outras entradas lexicais específicas. Em termos técnicos, a nomenclatura figurativa sugerida por Boeckx (2015) recupera a ideia de quadros de subcategorização, que descrevem as necessidades formais de uma entrada lexical.
} 
as instruções presentes na entrada lexical do verbo ler, tal como ressalta Borer $(2005$, p. 6). Há, nesse sentido, um sistema de checagem que requer uma obediência da sintaxe com relação às prescrições distribucionais feitas por uma entrada lexical.

(4) a. *[vp paciente [v,ler agente]

b. $*[\mathrm{vP} \quad[\mathrm{v}, \operatorname{ler}[\mathrm{PP} \mathrm{P}$ agente $][\mathrm{pP} \mathrm{P}$ paciente $]]]$

A influência das informações lexicais na estruturação sintática não se restringe a propriedades argumentais. Nos modelos minimalistas, por exemplo, movimentos sintáticos ocorrem a fim de satisfazer as exigências lexicais de um determinado núcleo, as quais estão codificadas na forma de primitivos atratores, como os traços de borda, os traços- $w h$, os traços $\mathrm{EPP}^{9} \mathrm{e}$ os traços não valorados/não interpretáveis. ${ }^{10}$ Para explicar a derivação de uma sentença interrogativa envolvendo deslocamento de constituinte, tal como Quem o Pedro disse que a Maria encontrou __ ?, os modelos minimalistas geralmente assumem que o constituinte deslocado - i.e., o pronome interrogativo quem - é realizado em uma posição estrutural periférica (viz., [Spec, CP]), pois o núcleo complementizador C, alocado nessa posição, apresenta uma exigência lexical que somente é satisfeita quando uma entrada lexical contendo um traço-wh for concatenada em seu especificador (Cf. RIZZI, 1990, 1997; CHOMSKY, 1995, 2000).

Se observarmos os modelos minimalistas mais atentamente, verificaremos que essa perspectiva projecionista serve como um alicerce para sua concepção de gramática, o que, consequentemente, exacerba a dependência da sintaxe com relação ao léxico. Neles, os traços formais não apenas determinam propriedades argumentais e deslocamentos estruturais, como também são os responsáveis por desencadear a aplicação da operação sintática elementar, a operação Merge, cuja finalidade principal é concatenar entradas lexicais em uma disposição hierárquica. Exemplos são as concepções de Merge presentes em Chomsky (2000), Pesetsky e Torrego (2006) e Wurmbrand (2014), ilustradas abaixo, bem como as concepções paralelas fornecidas nas referências que se seguem (Cf. WATANABE, 1996; COLLINS, 1997, 2002; CHOMSKY, 2004; ABELS, 2003; BOECKX, 2015, entre outros).

\footnotetext{
${ }^{9}$ Do inglês, Extended Projection Principle, Princípio da Projeção Estendida (Cf. CHOMSKY, 1981, para a caracterização do princípio; CHOMSKY, 2001, para sua caracterização em termos de um traço formal).

${ }^{10}$ Ver também formalizações paralelas empregadas nas primeiras versões minimalistas, tais como Greed (CHOMSKY, 1993, p. 33), Attract (CHOMSKY, 1995, p. 297) e Suicidal Greed (CHOMSKY, 2000, p. 135).
} 
"Set-Merge apresenta, tipicamente, uma assimetria inerente. Quando $\alpha, \beta$ se concatenam, essa operação satisfaz requerimentos (selecionais) de um (o seletor), mas não de ambos [...] Set-Merge de $(\alpha, \beta)$ tem algumas propriedades de Agree: um traço F de um dos elementos concatenados (diga-se $\alpha$ ) deve ser satisfeito para que a operação se aplique" (CHOMSKY, 2000, p. 133-134, tradução nossa). ${ }^{11}$

"Requerimento veicular sob o Merge: Se $\alpha$ e $\beta$ se concatenam, algum traço F de $\alpha$ deve sondar um traço F em $\beta$ ” (PESETSKY; TORREGO, 2006, p. 25, tradução nossa). ${ }^{12}$

"Condição sob o Merge: Concatene $\alpha$ e $\beta$ se $\alpha$ puder valorar um traço de $\beta$ " (WURMBRAND, 2014, p.130, tradução nossa). ${ }^{13}$

Os traços formais também são os responsáveis por determinar a variação superficial atestada entre as línguas, como bem recupera Boeckx (2015, p. 9). A hipótese mais difundida é a de que o conjunto de parâmetros que especifica uma dada língua corresponde às entradas lexicais de seu léxico funcional (Cf. BORER, 1984; CHOMSKY, 1995, 2001; BAKER, 2008; RIZZI, 2009, 2014; CINQUE, 2016, entre outros). Rizzi (2014, p. 22), por exemplo, define um parâmetro como "uma instrução para determinada ação sintática, expressa na forma de um traço presente em um item do léxico funcional". ${ }^{14} \mathrm{Na}$ perspectiva do autor, os parâmetros circunscrevem-se aos traços formais capazes de desencadear operações sintáticas, tais como traços envolvendo a aplicação de Merge e traços envolvendo movimento. Percebam que essa hipótese acerca da variação, e igualmente acerca das etapas da aquisição da linguagem, segue a assunção de que as operações sintáticas são guiadas por traços formais, reafirmando o prescritivismo lexical sobre o funcionamento sintático.

Fica evidente, portanto, que há, nas abordagens gerativistas, um amplo domínio das propriedades lexicais na delimitação do curso das operações sintáticas. Dito de outra maneira, a sintaxe é regida pelo léxico. Boeckx $(2010,2015)$ caracteriza esse posicionamento teórico, compartilhado por modelos de gramática que relegam grande parte das funções sintáticas às instruções lexicais, como lexicocentrismo, definido em (5), abaixo:

\footnotetext{
${ }^{11}$ Trecho original: "Set-Merge typically has an inherent asymmetry. When $\alpha, \beta$ merge, it is to satisfy (selectional) requirements of one (the selector) but not both [...] Set-Merge of $(\alpha, \beta)$ has some of the properties of Agree: a feature F of one of the merged elements (say, $\alpha$ ) must be satisfied for the operation to take place".

${ }^{12}$ Trecho original: "Vehicle Requirement on Merge: If $\alpha$ and $\beta$ merge, some feature F of $\alpha$ must probe F on $\beta$ ".

${ }^{13}$ Trecho original: "Merge Condition: Merge $\alpha$ and $\beta$ if $\alpha$ can value a feature of $\beta$ ".

${ }^{14}$ Trecho original: "[A parameter] is an instruction for a certain syntactic action expressed as a feature on an item of the functional lexicon".
} 
(5) Lexicocentrismo (BOECKX, 2010, 2015)

Posição teórica que toma por base a assunção de que as entradas lexicais codificam a maioria (ou todas) as propriedades centrais da FL.

Como destaca o autor, o lexicocentrismo reflete, em grande medida, a influência do Princípio da Projeção na organização sintática, o qual está recuperado no exemplo (6), através das citações de Chomsky (1981, 1986):

(6) Princípio da Projeção

a. “[...] as propriedades de marcação- $\theta$ de cada item lexical devem estar representadas categorialmente em cada nível sintático: em LF, SS [estrutura superficial], e DS [estrutura profunda]" (CHOMSKY, 1981, p. 8, tradução nossa). ${ }^{15}$

b. "Representações em cada nível sintático (i.e., LF, e D- e SS) são projetadas a partir do léxico, uma vez que respeitam as propriedades de subcategorização dos itens lexicais" (CHOMSKY, 1986, p. 29, tradução nossa). ${ }^{16}$

Em linhas gerais, o Princípio da Projeção assinala que toda informação contida na entrada lexical "deve ser projetada sintaticamente" (DEN DIKKEN, 2013, p. 20), o que faz com que as "informações lexicais determinem a estrutura sintática" (HAEGEMAN, 1994, p. 55). Essas diretrizes são tidas como um axioma sobre o funcionamento da gramática e são assumidas pela quase totalidade dos modelos gerativistas. Nos modelos minimalistas, em particular, podemos observá-las, mais diretamente, na endocentricidade atribuída à operação Merge, cuja formalização mais comum implica a presença de um núcleo projetor, como sugere a definição no exemplo (7). As entradas lexicais, $\alpha$ e $\beta$, encontram-se em uma relação assimétrica — muito embora estejam simetricamente arranjadas—, já que apenas uma delas será identificada como núcleo e, por consequência, responsável por rotular a estrutura formada (Cf. CHOMSKY, 1995, 2000, 2004).

\footnotetext{
${ }^{15}$ Trecho original: "[...] the $\theta$-marking properties of each lexical item must be represented categorially at each syntactic level: at LF, S-Structure, and D-Structure".

${ }^{16}$ Trecho original: "Representations at each syntactic level (i.e., LF, and D- and S-Structure) are projected from the lexicon, in that they observe the subcategorization properties of lexical items".
} 
(7) Merge (CHOMSKY, 1995, p. 243)

a. Entradas lexicais são objetos sintáticos.

b. $K=\{\gamma,\{\alpha, \beta\}\}, \alpha$ é um objeto sintático, $\beta$ é um objeto sintático, e $\gamma$ é o rótulo de $\mathrm{K}$.<smiles>CC(C)=O</smiles>

Entretanto, apesar de verificarmos um apelo irrestrito ao léxico, não há, em nenhum dos modelos gerativistas apontados até o momento, uma teoria restritiva e biologicamente fundamentada sobre a natureza das entradas lexicais e sobre o que pode vir a ser considerado um traço formal (Cf. BOECKX, 2010, 2015; SIGURĐSSON, 2012). Tal lacuna teórica revela um sério problema metodológico: esses modelos de gramática fornecem explicações sobre o conhecimento linguístico humano sem uma concepção clara de quais são as propriedades elementares dos átomos que participam das computações sintáticas (Cf. MYUSKEN; VAN RIEMSDIJK, 1986; ZEIJLSTRA, 2008, 2012; KIBORT; CORBETT, 2010; ADGER, 2010; ADGER; SVENONIUS, 2011; SIGURĐSSON, 2012). Como assinala Sigurđsson (2012, p. 368 ), tal conduta seria equivalente a fazer química sem qualquer conhecimento ou teoria do que seja um elemento químico.

A ausência de uma teoria explícita sobre a natureza dos traços formais nos chama a atenção para o seu caráter paliativo, isto é, são dispositivos que nos auxiliam na identificação e na caracterização dos fenômenos linguísticos, mas que, ao mesmo tempo, mascaram nosso entendimento sobre esses fenômenos (Cf. ŠIMÍK, 2012, p. 1). Isso se nota, por exemplo, na facilidade com que novos traços formais podem ser postulados com o intuito de se obter um determinado efeito ou arranjo estrutural. Essa é uma estratégia teórica que abre precedentes altamente indesejáveis. Exemplos são facilmente encontrados nos círculos minimalistas, em que a presunção de um novo traço formal resolve impasses estruturais colocados por um fenômeno linguístico específico (e.g., traço EPP, CHOMSKY, 2000, 2001; traço pied-piper, WATANABE, 2006; traço speech act, MUNARO, 2010).

Além do pouco entendimento sobre a natureza dos traços formais, as propostas minimalistas assumem que as unidades elementares da gramática não são os traços por si só —independentes e isolados_-, mas feixes de traços formais. Esses feixes correspondem a um 
conjunto particular de traços agrupados de modo sistemático, os quais seriam hipoteticamente fornecidos pela GU, como sugere Chomsky $(2007$, p. 6$):{ }^{17}$

\begin{abstract}
"Além de Merge que se aplica ilimitadamente, a GU deve fornecer os elementos atômicos, itens lexicais IL, cada qual um arranjo estruturado de propriedades (traços) aos quais Merge e outras operações se aplicam para formar expressões" (CHOMSKY, 2007, p. 6, tradução nossa). ${ }^{18}$
\end{abstract}

A hipótese de que os feixes de traços constituem unidades elementares da gramática configura-se igualmente como um inconveniente metodológico, pois a assunção de um feixe de traços implica necessariamente que seus traços foram combinados em um determinado momento da derivação. Considerando-se, por razão de simplicidade, que a operação Merge representa o único mecanismo formal capaz de combinar objetos linguísticos internamente à gramática (Cf. CHOMSKY, 2000, 2004, 2010a, 2015, 2016, 2017), seria esperado que Merge também fosse responsável por gerar os feixes de traços formais. Dadas essas observações, temos em mãos um paradoxo, notado primeiramente por Boeckx (2015, p. 8), uma vez que "Merge precisa de feixes de traços formais para se aplicar e feixes de traços formais precisam de Merge para existir". ${ }^{19}$

Esse antagonismo teórico nos mostra que a assunção de feixes de traços formais como primitivos da gramática é uma estipulação mal fundamentada. A falta de uma explicação plausível para sua formação faz com que seus arranjos regulares sejam relegados cegamente às competências fornecidas pela $\mathrm{GU}$, sem qualquer explicação adicional sobre quais são suas bases cognitivas e biológicas. Além do mais, se admitirmos que as aplicações de Merge são desencadeadas pela valoração de traços, como mencionado acima, a formação desses feixes torna-se ainda mais especulativa (BOECKX, 2015, p. 7). Finalmente, a assunção de feixes de traços juntamente com a hipótese de que a sintaxe - mais especificamente Merge, e apenas Merge - tenha sido o epicentro da gramática é contraditória, uma vez que tal hipótese ignora as circunstâncias envolvendo o surgimento dos feixes; isto é, unidades formais internamente complexas que implicam a combinação de unidades mais elementares.

\footnotetext{
${ }^{17}$ Ver também Chomsky $(2000,2001,2004)$.

${ }^{18}$ Trecho original: "In addition to Merge applicable without bounds, UG must at least provide atomic elements, lexical items LI, each a structured array of properties (features) to which Merge and other operations apply to form expressions".

${ }^{19}$ Trecho original: "[in the following loop]: merge requires feature bundles to apply, and feature bundles require merge to exist".
} 
É importante salientar ainda que os feixes de traços formais correspondem a uma premissa teórica generalizada nos círculos minimalistas, pois são assumidos não somente por propostas lexicalistas - i.e., propostas em que o léxico pré-sintático é composto por regras independentes - (Cf. CHOMSKY, 1995, 2000; ACKEMA; NEELEMAN, 2004; DI SCIULLO, 2005; WILLIAMS, 2007, 2012, entre outros), como também em propostas não lexicalistas - i.e., propostas em que o léxico pré-sintático não apresenta qualquer propriedade combinatorial- (Cf. HALLE; MARANTZ, 1994; MARANTZ, 1997; BORER, 2003, 2005a, 2005b, 2013; ACEDO-MATELLÁN; REAL-PUIGDOLLERS, 2014, entre outros). ${ }^{20}$ Podemos afirmar, nesse sentido, que a proposta de feixes de traços formais acirra ainda mais a interdependência entre o léxico e a sintaxe, o que, como consequência, torna a natureza tanto dos feixes quanto de seus traços obscura, bem como a própria articulação entre as funções atribuídas ao léxico e à sintaxe.

A mesma argumentação desenvolvida sobre a implausibilidade dos feixes de traços aplica-se, de igual modo, à ideia de que o ordenamento hierárquico das categorias funcionais decorre de uma determinação estabelecida pela GU, como descrevem a hipótese da projeção estendida e o programa cartográfico. A hipótese da projeção estendida, por exemplo, sugere que os "constituintes nucleados por verbos e os constituintes nucleados por nomes formam projeções [estendidas], as quais incluem tanto a projeção de seus núcleos lexicais quanto a camada funcional que circunda a projeção lexical” (GRIMSHAW, 1991, p. 2). ${ }^{21}$ Dessa maneira, a projeção de uma entrada lexical verbal ou nominal está amalgamada às categorias funcionais com as quais pode interagir, já que ambas partilham os mesmos traços categoriais, como ilustrado no esquema em (8) (Cf. a Tese da Identidade Categorial; do inglês Categorial Identity Thesis; VAN RIEMSDIJK, 1998, p. 4). Essa hipótese pressupõe obrigatoriamente um ordenamento predeterminado da estruturação sintática, o qual está fundamentalmente atrelado a informações codificadas nas entradas lexicais. ${ }^{22}$

\footnotetext{
${ }^{20}$ Nas propostas lexicalistas, as regras combinatoriais restringem-se à formação de palavras, não à reunião de traços formais em feixes. Boeckx $(2015$, p. 8) comenta que a postulação de uma nova operação específica à formação de feixes seria redundante. $\mathrm{O}$ autor observa que, uma vez que essa nova operação daria origem a conjuntos semelhantes àqueles derivados por Merge, não haveria razão para se admitir que essa operação não fosse também Merge. Além disso, quando considerada de um ponto de vista evolutivo, a assunção de dois módulos gramaticais com propriedades combinatoriais — viz., o léxico e a sintaxe - nos afasta de uma explicação condizente com o que se sabe até o momento sobre o desenvolvimento evolutivo da espécie, tal como assinalam Fujita (2009, 2017), Ott (2009), Sigurđsson (2012), Nóbrega e Miyagawa (2015), entre outros. Esse último argumento ficará mais evidente na próxima seção deste capítulo.

${ }^{21}$ Trecho original: "[Extended projections involve an extended notion of an X-bar theoretic projection,] in which noun-headed constituents and verb-headed constituents form (extended) projections, which include both the projection of their lexical heads and the functional shell which surrounds the lexical projection".

${ }^{22}$ Há hipóteses paralelas que poderiam ser igualmente mencionadas. Por exemplo, em GB, Guéron e Hoekstra (1988) propuseram a hipótese de cadeias-T (do inglês, $T$-chain), em que o verbo serve como núcleo para uma
} 
(8) Exemplo esquemático de projeção estendida (GRIMSHAW, 1991, p. 4)

a. Projeção estendida do núcleo lexical verbal:

$\{\mathrm{V}, \mathrm{I}, \mathrm{C}\}$, que estão amalgamados pelo traço verbal $[+\mathrm{V},-\mathrm{N}]$

b. Projeção estendida do núcleo lexical nominal:

$\{\mathrm{N}, \mathrm{D}, \mathrm{P}\}$, que estão amalgamados pelo traço nominal $[-\mathrm{V},+\mathrm{N}]$

c. Especificações categoriais e funcionais

$\begin{array}{lll}\mathrm{V} & {[+\mathrm{V},-\mathrm{N}]} & F 0 \\ \mathrm{I} & {[+\mathrm{V},-\mathrm{N}]} & F 1 \\ \mathrm{C} & {[+\mathrm{V},-\mathrm{N}]} & F 2 \\ \mathrm{~N} & {[-\mathrm{V},+\mathrm{N}]} & F 0 \\ \mathrm{D} & {[-\mathrm{V},+\mathrm{N}]} & F 1 \\ \mathrm{P} & {[-\mathrm{V},+\mathrm{N}]} & F 2^{23}\end{array}$

A Cartografia, por sua vez, postula a existência de uma estrutura rica, constituída de um conjunto variado de núcleos funcionais que estariam presentes em todo domínio oracional derivado pela sintaxe (Cf. RIZZI, 1997, 2004; CINQUE, 1999, 2002, 2006; BELLETTI, 2004, entre outros). Mais especificamente, a proposta parte do pressuposto de que as orações seriam formadas por "um sistema constante de núcleos funcionais em todas as línguas, cada qual responsável por projetar uma subárvore que se realiza em uma hierarquia sintática fixa, independentemente da manifestação morfológica de seu núcleo" (RIZZI, 2004, p. 4). ${ }^{24}$ Essas hierarquias universais de projeções funcionais —exemplificadas em (9), através da porção correspondente à periferia esquerda, e em (10), com a porção correspondente ao domínio funcional envolvendo a camada flexional - seriam, por estipulação, primitivos fornecidos pela GU (CINQUE, 1999, p. 135), semelhantemente ao que Chomsky (2007, p. 6) propõe para os arranjos sistemáticos dos feixes de traços formais.

cadeia de projeções funcionais, incluindo concordância, tempo e um núcleo complementizador. Mais recentemente, dentro de uma abordagem nanossintática, Starke $(2001,2009)$ sugere a ideia de sequências funcionais, que se assemelha em grande medida às projeções estendidas.

23 Neste exemplo, $\mathrm{V}=$ =erbo, $\mathrm{I}=$ camada flexional, $\mathrm{C}=$ complementizador, $\mathrm{N}=$ nome, $\mathrm{D}=$ determinante, $\mathrm{P}=$ preposição, e $\mathrm{F}=$ especificação funcional. $\mathrm{F}$ indica a localização de cada um dos núcleos em uma projeção de mesma especificação categorial.

${ }^{24}$ Trecho original: "[...] clauses should be formed by a constant system of functional heads in all languages, each projecting a sub-tree occurring in a fixed syntactic hierarchy, irrespective of the actual morphological manifestation of the head." 
(9) Estrutura da periferia esquerda, antigo Comp (RIZZI, 1997, p. 297)

[...[Força [Tópico [Foco [Tópico [Fin(itude) [...]]]]]]]

(10) Estrutura do campo médio, antigo Infl (CINQUE, 1999, 106)

$\left[\right.$ Modo $_{\text {atodefala }}\left[\right.$ Modo $_{\text {avaliativo }}\left[\right.$ Modo $\left._{\text {evidencial }}\right]$ [Modalidade epistêmica $_{[}\left[\mathrm{T}_{\text {passado }}\left[\mathrm{T}_{\text {futuro }}\right.\right.$ [Modo $_{\text {irrealis }}\left[\right.$ Modalidade $_{\text {necessidade }}\left[\right.$ Modalidade $_{\text {possibilidade }}\left[\right.$ Asp $_{\text {habitual }} \quad\left[\right.$ Asp $_{\text {repetitivo(I) }}$ $\left[\mathrm{Asp}_{\text {frequentativo(I) }}\left[\mathrm{Modalidade}_{\text {volitiva }}\left[\mathrm{Asp}_{\text {acelerativo(I) }}\left[\mathrm{T}_{\text {anterior }}\left[\mathrm{Asp}_{\text {terminativo }}\left[\mathrm{Asp}_{\text {continuativo }}\right.\right.\right.\right.\right.\right.$ $\left[\mathrm{Asp}_{\text {perfeito(?) }}\left[\mathrm{Asp}_{\text {retrospectivo }}\left[\mathrm{Asp}\right.\right.\right.$ proximativo $\left[\mathrm{Asp}_{\text {durativo }}\left[\mathrm{Asp}_{\text {genérico/progressivo }}\left[\mathrm{Asp}_{\text {prospectivo }}\right.\right.\right.$

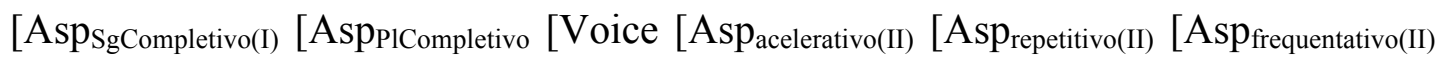

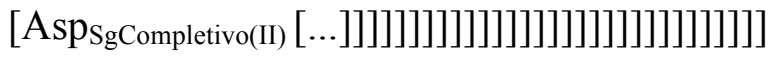

Reparem que essas hipóteses acerca do ordenamento das categorias funcionais, apesar de estarem voltadas para uma porção maior da estrutura sintática, acarretam, cada uma a seu modo, os mesmos problemas colocados pelos feixes de traços formais, notadamente: (i) a premissa de que a estrutura sintática encontra-se pré-moldada nos núcleos lexicais e (ii) a ideia de que seu arranjo regular é determinado por imposições feitas pela GU. No entanto, para assegurar que a sintaxe desfrute de independência funcional e para que as análises sobre os fenômenos linguísticos não se circunscrevam a um nível descritivo é imprescindível que as restrições combinatoriais e o ordenamento das categorias funcionais sejam efetivamente explicados e não somente reiterados na forma de estruturas templáticas (FORTUNY, 2008; BOECKX, 2008, 2015).

Essa crítica não diz respeito aos resultados empíricos obtidos pelas propostas listadas acima, em especial, pelo programa cartográfico. O que está em pauta é a razoabilidade de se relegar os ordenamentos estruturais observados na empiria a uma exigência imposta pela GU, como se tais ordenamentos decorressem de uma condição biológica, a qual, até o momento, não apresenta uma justificativa evidente. Como alternativa, Cinque e Rizzi (2010) aventam a possibilidade de que as cartografias estruturais poderiam ser resultado de determinações feitas pelos sistemas externos, especificamente, pelo sistema interpretativo C-I. Essa possibilidade é defendida nos trabalhos de Fortuny (2008) e Boeckx (2015), em que os autores sugerem que os mapas estruturais não nos fornecem um primitivo do componente sintático, mas uma indicação de como o sistema C-I está organizado.

Como salienta Fortuny (2008, p. 91):

"Embora estejamos longe de chegar a um bom entendimento das restrições que o sistema C-I impõe sobre a combinação das categorias funcionais, não há nenhuma razão convincente para se pensar que as cartografias pertençam ao conjunto de 
elementos primitivos da faculdade da linguagem, bem como não há nenhuma razão convincente para se pensar que um entendimento mais aprofundado não possa ser alcançado ao reduzir uma propriedade aparente da cartografia a princípios de ordem superior (FORTUNY, 2008, p. 91, tradução nossa). ${ }^{25}$

Tendo em mente os impasses descritivos e analíticos colocados por essas conjecturas lexicocêntricas, vê-se que é indiscutível que o léxico, da maneira como está definido, impede que a sintaxe opere de maneira autônoma. Figurativamente, a derivação sintática inicia-se in media res, isto é, com parte de seu trabalho pré-elaborado nas entradas lexicais, como bem descreve Boeckx (2015, p. 5) no trecho abaixo:

“[...] o que torna as análises minimalistas pouco convincentes [...] é o fato de que, no momento em que a derivação sintática se inicia, toda a ação já ocorreu, da forma como está. Ela foi cuidadosamente pré-empacotada (pré-concatenada) nas entradas lexicais. E, uma vez no léxico, elas são tomadas por certas. Não são derivadas, não são construídas. São simplesmente assumidas como uma questão de necessidade conceitual. [...] Em vez de "abordarem a sintaxe (e a GU) de baixo" (Chomsky, 2007), os sintaticistas minimalistas a abordam a partir do léxico, in media res, e por esse motivo afastam-se da prática minimalista” (BOECKX, 2015, p. 5, tradução nossa). ${ }^{26}$

Compartilhamos com o autor, integralmente, essa posição. A justificativa é a seguinte: ao listar nas entradas lexicais os passos computacionais que a sintaxe deve tomar, ameaçamos sua independência combinatorial e, por conseguinte, a criatividade linguística. A sintaxe, em uma perspectiva lexicocêntrica, passa a ser um mero assistente na derivação de um objeto linguístico, já que as instruções lexicais direcionam e, ao mesmo tempo, restringem sua aplicação. Se nosso objetivo é elaborar uma teoria sobre a gramática que seja não apenas descritiva e explicativamente adequada, mas também evolutiva e biologicamente adequada,

\footnotetext{
${ }^{25}$ Trecho original: "Although we are far from a good understanding of the restrictions the C-I system imposes on the combination of functional categories, there is no compelling reason to think that cartographies belong to the set of primitive elements of the faculty of language, as there is no compelling reason to think that a deeper understanding of a phenomena cannot be attained by reducing an apparent property of it to higher order principles".

${ }^{26}$ Trecho original: "[...] what makes minimalist analyses unconvincing [...] is that by the time such analyses begin, all the action has already taken place, as it were. It has been carefully pre-packaged (pre-merged) into lexical entries. And once in the lexicon, it's taken for granted. It's not derived, it's not constructed. It is simply assumed as a matter of virtual conceptual necessity. [...] Instead of "approaching syntax (and UG) from below" (Chomsky, 2007), minimalist syntacticians approach it from the lexicon, in media res, and as such they do not depart at all from pre-minimalist practices."
} 
será preciso explicitar derivacionalmente —em vez de listar nas entradas lexicais — por que as propriedades da linguagem são do modo como são.

Como recomenda Chomsky (2004, p. 105), é indispensável buscar um esclarecimento que vá "além da adequação explicativa", a fim de se chegar a um conhecimento amplo da competência linguística humana, integrado às demais ciências cognitivas: ${ }^{27}$

(11) Ir além da adequação explicativa (CHOMSKY, 2004, p. 105, tradução nossa)

"Podemos buscar um nível de explicação mais profundo do que a adequação explicativa, indagando não somente quais são as propriedades da linguagem, mas por que elas são do modo como são". ${ }^{28}$

Com base no que vimos até aqui, podemos concluir que o lexicocentrismo coloca inúmeros obstáculos no caminho para se "ir além da adequação explicativa" (BORER, 2003, 2005a, 2005b, 2013; FUJITA, 2009, 2017; BOECKX, 2010, 2015; SIGURĐSSON, 2012; RAMCHAND, SVENONIUS, 2014; BIBERAUER; ROBERTS, 2015). Em vista disso, o que defendemos — com base em problemas já apontados na literatura- é uma liberdade combinatorial para a sintaxe ab ovo, ou seja, desde o início da derivação, possibilitando que ela disponha de autonomia funcional para criar diferentes representações estruturais a partir de um conjunto uniforme de entradas lexicais, e que a validade dessas representações seja determinada pelos sistemas interpretativos, não por imposições feitas por instruções lexicais. Dadas essas considerações, podemos admitir que o primeiro passo para se ir "além da adequação explicativa" é redefinir a interação entre o léxico e a sintaxe, na tentativa de abolir a subordinação funcional da sintaxe com relação às prescrições lexicais.

Para caracterizar melhor o impacto que o léxico apresenta no funcionamento sintático, exploramos, na seção seguinte, os impasses que uma perspectiva lexicocêntrica coloca para os critérios de adequação explicativa e evolutiva. Discutimos questões concernentes à ontogenia da competência linguística -i.e., ao seu desenvolvimento em um indivíduo, o Problema de Platão- e à sua filogenia —i.e., ao seu desenvolvimento na história evolutiva da espécie, o

\footnotetext{
${ }^{27}$ Para que se estabeleça um contraponto, Chomsky (1965, p. 63) define adequação explicativa do seguinte modo: "[...] uma teoria linguística que tem por objetivo adequação explicativa está interessada na estrutura interna desse dispositivo, ou seja, ela busca fornecer uma base bem fundamentada e independente de qualquer língua particular para a seleção da gramática descritivamente adequada de cada língua" [Trecho original: [...] a linguistic theory that aims for explanatory adequacy is concerned with the internal structure of the device; that is, it aims to provide a principled basis independent of any particular language, for the selection of the descriptively adequate grammar of each language].

${ }^{28}$ Trecho original: "We can seek a level of explanation deeper than explanatory adequacy, asking not only what the properties of language are but why they are that way".
} 
Problema de Wallace-Darwin. As considerações feitas nesta seção e na seção seguinte nos permitirão apresentar, no final deste capítulo, os desiderata metodológicos mencionados no Capítulo 1, os quais servirão como diretrizes para a elaboração de nossa hipótese sobre a articulação entre as competências lexical e sintática na emergência da linguagem, a Abordagem Isomórfica.

\subsection{Em defesa de uma sintaxe como único componente gerativo}

Após termos examinado os impasses colocados pela assunção de um léxico altamente estruturado, avaliamos, nesta seção, as implicações que essa posição teórica coloca para a representação da GU e para as hipóteses envolvendo o surgimento da competência linguística na evolução. Para tanto, revisitamos o modo como a complexidade inerentemente atrelada à linguagem humana foi repensada teoricamente na transição para o PM. Ao ter em mente uma concepção da GU radicalmente empobrecida, tal como a defendida por Chomsky (1995, 2000, 2005, 2007, 2013a, 2015, 2016, 2017), poderemos avaliar, com maior precisão, as razões pelas quais a assunção de uma hipótese lexicocêntrica inviabiliza uma explicação coerente com o problema lógico para a emergência da linguagem, o Problema de WallaceDarwin.

Dividimos esta seção em duas partes: na subseção 2.3.1, contrastamos as propriedades atribuídas à GU nos modelos pré-minimalistas e sua versão empobrecida no PM. Estarão em pauta as estratégias utilizadas para se defender que a complexidade vinculada à GU é, na realidade, aparente. Veremos que essa complexidade resume-se, presumivelmente, a um epifenômeno da interação entre uma competência recursiva, determinada geneticamente, e princípios físicos, não biológicos, responsáveis por reger o mundo natural. Na subseção 2.3.2, incorporamos a essa discussão a hipótese de que as propriedades unicamente humanas da FL são mínimas, dado que grande parte de seus componentes seriam compartilhados com animais não humanos, tal como apontam Hauser, Chomsky e Fitch (2002), Fitch, Hauser e Chomsky (2005), Samuels (2011, 2012, 2015), Fitch (2010, 2017), Bolhuis et al. (2014), entre outros, uma assunção que colabora com uma visão reducionista da GU. 


\subsubsection{Sintetizando a $G U$ : Considerações sobre ontogenia}

Como já pôde ser notado na última seção, o PM promoveu uma revisão considerável das principais assunções teóricas desenvolvidas pelo empreendimento gerativista. Um dos impactos mais perceptíveis dessa revisão está na caracterização da GU. Nas abordagens préminimalistas —em especial, na abordagem avançada em GB-, a GU era descrita como (i) um sistema cognitivo inato, (ii) internamente complexo, (iii) determinado geneticamente, (iv) exclusivo à espécie humana e (v) autônomo com relação aos demais sistemas cognitivos (Cf. CHOMSKY, 1980a, 1981, 1986, 1988). Essa perspectiva acerca da GU visava diminuir a influência do ambiente como fonte primária para o desenvolvimento de um conhecimento linguístico complexo em um curto intervalo de tempo; o chamado problema lógico da aquisição da linguagem, o Problema de Platão (CHOMSKY, 1986, p. xxv).

Assim, com o intuito de esclarecer o descompasso entre o conhecimento adquirido rapidamente no processo de aquisição da linguagem e a escassez de informações disponíveis no ambiente, Chomsky (1968, p. 79) sugere que a GU é constituída por "uma estrutura inata que é rica o suficiente para explicar a disparidade entre experiência e conhecimento". ${ }^{29}$ Essa hipótese ficou conhecida como o argumento da pobreza de estímulos (Cf. CHOMSKY, 1986, 1988). ${ }^{30}$ Em termos gerais, o raciocínio subjacente a esse argumento é o seguinte: quanto maior for o número de propriedades inatas atreladas à competência linguística humana, menor será a dependência do ambiente para o seu desenvolvimento. Essa hipótese descreve o pensamento nativista de Chomsky — em contraposição à postura empiricista do behaviorismo (Cf. LAURENCE; MARGOLIS, 2001, p. 219-220)—, que associa a competência linguística à dotação genética da espécie, como sugerido na citação abaixo:

\footnotetext{
“O argumento da pobreza de estímulos não deixa uma alternativa razoável, a não ser supor que essas propriedades são, de algum modo, determinadas pela gramática universal, como parte do genótipo" (CHOMSKY, 1980a, p. 66, tradução nossa). ${ }^{31}$
}

Conforme recuperam Chomsky (2007), Hornstein (2009), Fujita (2009), Berwick (2011a), Al-Mutairi (2014) e Boeckx (2015), a dotação genética supostamente tinha como seu fenótipo - i.e., como produto de sua expressão - uma GU rica, que conferia ao indivíduo um

\footnotetext{
${ }^{29}$ Trecho original: "[...] an innate structure that is rich enough to account for the disparity between experience and knowledge".

${ }^{30}$ Para mais detalhes, ver Lasnik e Lidz (2016).

${ }^{31}$ Trecho original: "The argument from the poverty of the stimulus leaves us no reasonable alternative but to suppose that [language] properties are somehow determined in universal grammar, as part of the genotype".
} 
conjunto de módulos com funções distintas e cuja interação era caracterizada por uma série de relações complexas (Cf. CHOMSKY, 1981, 1986, 1988). Entre eles, podemos citar a Teoria X-Barra, a Teoria Temática, o Filtro do Caso e a Teoria da Ligação. ${ }^{32}$ Tal substrato genético, associado às particularidades dos módulos que compunham a GU, limitavam a FL a um caractere biológico exclusivamente humano.

Embora Chomsky (1980a, p. 57) tenha especulado sobre a possibilidade dos grandes símios compartilharem certas propriedades do sistema conceitual com a espécie humana, a alta especificidade dos módulos estipulados em GB restringia a FL —e por conseguinte, a GU- a uma capacidade integralmente determinada pelo genótipo da espécie. Da mesma maneira, a especificidade desses módulos em GU afastava a possibilidade de que partes da competência linguística pudessem ser observadas em outras habilidades cognitivas. Tais posicionamentos podem ser verificados, por exemplo, nos dois trechos recuperados abaixo:

"É também importante ter em mente que a faculdade da linguagem parece, de fato,
ser uma dotação unicamente humana. Outros organismos têm seus sistemas próprios
de comunicação, mas as propriedades desses sistemas são radicalmente distintas da
linguagem humana, e a linguagem humana é muito mais do que um sistema de
comunicação" (CHOMSKY, 1988, p. 37-38, tradução nossa). ${ }^{33}$

"Parece haver pouca razão para se supor, por enquanto, que existem princípios gerais da estrutura cognitiva ou mesmo da cognição humana, expressos em algum nível superior, a partir dos quais as propriedades particulares de "órgãos mentais" específicos, como a faculdade da linguagem, poderiam ser deduzidas, ou mesmo que haja analogias elucidativas entre esses vários sistemas" (CHOMSKY, 1980a, p. 215, nossa tradução). ${ }^{34}$

Ao longo dos anos, uma estrutura interna cada vez mais elaborada foi sendo atribuída à GU com o objetivo de reduzir as tarefas indutivas que a criança deveria desempenhar no

\footnotetext{
${ }^{32}$ É válido salientar que a caracterização dessas teorias como módulos está intimamente relacionada aos diferentes princípios que guiavam seu funcionamento. Por exemplo, o Filtro do Caso apresentava um domínio de atuação específico (viz., verificar se os sintagmas nominais possuíam um traço de Caso, fosse ele determinado por um verbo, por uma preposição ou por um núcleo flexional); semelhantemente, a Teoria da Ligação parte de domínios de licenciamento específicos (viz., o Princípio A, relacionado a anáforas; o Princípio B, relacionado a pronomes; e o Princípio C, relacionado a expressões referenciais).

${ }^{33}$ Trecho original: "It is also worth bearing in mind that the language faculty does appear to be a unique human possession. Other organisms have their own systems of communication, but these have properties radically different from human language, and human language is far more than a system of communication".

${ }^{34}$ Trecho original: "There seems little reason to suppose, for the moment, that there are general principles of cognitive structure, or even of human cognition, expressible at some higher level, from which the particular properties of particular "mental organs," such as the language faculty, can be deduced, or even that there are illuminating analogies among these various systems".
} 
processo de aquisição da linguagem. Chomsky (2007, p. 3) nomeou essa postura com relação à GU de abordagem "de cima para baixo", pois a questão central, nesse momento, era determinar "quão rica a GU deveria ser para dar conta da aquisição da linguagem em um curto intervalo de tempo". ${ }^{35}$ Al-Mutairi (2014, p. 35) recupera uma analogia feita em Chomsky (1971, p. 189) que ilustra muito bem como o problema da aquisição da linguagem era concebido por essa perspectiva:

\begin{abstract}
"Chomsky (1971) [...] nos pede para imaginar um engenheiro que enfrenta o problema de construir uma teoria dos estados internos de um dispositivo, estudando suas relações de entrada e de saída. Nesse contexto, o engenheiro é o linguista e o dispositivo é um "dispositivo de aquisição da linguagem", cuja entrada e saída são, respectivamente, os dados linguísticos primários e as gramáticas postuladas. A analogia continua: o linguista não entende bem a função do dispositivo, mas a partir das informações obtidas sobre suas relações de entrada e de saída, ele constrói uma teoria de sua estrutura interna. O linguista — para completar a analogia — observa a disparidade entre a entrada e a saída do dispositivo e conclui que, para que o dispositivo execute sua função, ele deve conter uma estrutura interna rica [...] Assim, a tarefa para o linguista seria determinar quão rica a estrutura interna deve ser para que o dispositivo execute sua função" (AL-MUTAIRI, 2014, p. 35, tradução nossa). ${ }^{36}$
\end{abstract}

Na transição para o PM, há uma inversão dessa lógica ao se tentar demonstrar que grande parte da complexidade associada à linguagem não é inerente à GU. Passa-se a questionar, a partir de então, "quão pouco pode ser atribuído à GU e ainda sim ser possível explicar a variedade de línguas obtidas" (CHOMSKY, 2007, p. 4). ${ }^{37}$ Grosso modo, a guinada teórica promovida pelo PM leva-nos a abandonar uma abordagem para a GU "de cima para baixo" e a assumir uma posição reducionista, analisando-a "de baixo para cima", ou seja, atribuindo a ela o mínimo necessário para se explicar o processo de aquisição da linguagem.

\footnotetext{
${ }^{35}$ Trecho original: "How much must be attributed to UG to account for language acquisition?".

${ }^{36}$ Trecho orininal: "Chomsky (1971) [...] asks us to imagine an engineer who is faced with the problem of constructing a theory of the internal states of a device by studying its input-output relations. Thus the engineer is the linguist, and the device is a "language acquisition device," the input and output to which are the primary linguistic data and the postulated grammars, respectively. The analogy continues; the linguist does not quite understand the function of the device, but from the information about its input-output relations, he constructs a theory of the internal structure of the device. The linguist - to complete the analogy - observes the disparity between the input and output of the device, and concludes that, in order for the device to perform its function, it must have a rich internal structure [...] Thus the task for the linguist is to determine how rich the internal structure must be in order for the device to perform its function".

${ }^{37}$ Trecho original: "How little can be attributed to UG while still accounting for the variety of I-languages attained".
} 
Ao sintetizar a GU, há evidentemente uma diminuição da influência da determinação genética no desenvolvimento do conhecimento linguístico humano, fato que permite que mecanismos não específicos à linguagem possam ser considerados nos procedimentos empregados para se fixar uma língua.

A noção "de baixo para cima" recupera a assunção defendida no âmbito do PM de que a FL deve ser um sistema ótimo para satisfazer as condições de legibilidade impostas pelos sistemas externos com os quais interage, notadamente, o sistema associado à externalização —viz., o sistema S-M- e o sistema associado à interpretação — viz., o sistema C-I (Cf. CHOMSKY, 1995, 2000, 2005). Dado que, no minimalismo, o "engenheiro" da analogia de Chomsky (1971, p. 189) já detém um conhecimento prévio do dispositivo sob análise -i.e., da organização interna e do funcionamento da GU—, Chomsky (2007, p. 4) propõe, nessa abordagem, uma caracterização da GU com foco em suas interfaces. Basicamente, o autor endossa a redução do aparato formal creditado à GU e busca garantir que, com esse aparato mínimo, ela ainda seja capaz de gerar expressões legíveis pelos sistemas externos. ${ }^{38}$

Fica evidente que, com a abordagem "de baixo para cima", o PM passa a representar a GU como um sistema cognitivo simples. Duas mudanças de perspectiva contribuem para o estabelecimento dessa nova conjectura, a saber, a postulação de que a linguagem apresenta competências identificáveis (i) em outros aspectos da cognição humana, bem como (ii) em outras espécies de animais não humanos. Essa tentativa de reduzir a influência da GU no desenvolvimento da linguagem pode ser percebida, de modo mais notório, no modelo dos três fatores (Cf. CHOMSKY, 2005, 2007, 2008, 2010a). Nesse modelo, Chomsky sugere que três fatores subjazem ao desenvolvimento da competência linguística em um indivíduo humano, nomeadamente:

(12) Modelo dos três fatores (CHOMSKY, 2005, p. 6)
a. Primeiro Fator: dotação genética - i.e., a GU-;
b. Segundo Fator: experiência;
c. Terceiro Fator: princípios não específicos à FL/GU.

Observem que a influência da dotação genética reduz-se a um terço. Seu papel é tornar a aquisição possível e, ao mesmo tempo, delimitar o número de línguas, ou seja, de estados

\footnotetext{
${ }^{38}$ É válido salientar que essa redução da GU é o que caracteriza, em grande medida, a transição para o PM, verificada, por exemplo, na eliminação de níveis de representação, na limitação da multiplicidade de operações e de passos computacionais, etc.
} 
mentais atingidos. O segundo fator, em (12b), corresponde aos estímulos do ambiente que, uma vez convertidos em experiência, fazem com que a GU seja modelada em uma dada língua natural. Por sua vez, o terceiro fator, em (12c), representa restrições biofísicas atreladas à regulação do crescimento de qualquer organismo no mundo natural. No que concerne à linguagem, Chomsky (2005, p. 6) circunscreve o terceiro fator a duas categorias: (i) eficiência computacional e (ii) princípios de processamento de dados e de regulação estrutural. Qualquer uma dessas categorias resulta de leis naturais, não específicas à linguagem, e sua atuação internamente à FL asseguraria, por hipótese, sua determinação como um caractere biológico ótimo para os propósitos que visa desempenhar. ${ }^{39}$

De maneira ampla, o terceiro fator recupera as tentativas de D’Arcy Thompson e de Alan Turing de evidenciar que muitas propriedades dos organismos não resultam de seleção natural, mas decorrem diretamente do modo como o mundo físico funciona. Uma vez que a GU é descrita como uma categoria pertencente ao mundo natural, devemos partir da premissa de que ela deve ser estudada igualmente a qualquer outro sistema biológico (Cf. CHOMSKY, 2000; MARTIN; URIAGEREKA, 2000), sob os quais os princípios biofísicos associados ao terceiro fator também estão em jogo (GOULD, 2002). ${ }^{40}$ Isso implica que há, internamente aos mecanismos da GU, certas propriedades que derivam do funcionamento do mundo físico, e não somente de caracteres determinados através do genótipo humano. Vemos, portanto, que a estratégia subjacente ao modelo dos três fatores, em (12), é reduzir a complexidade da GU transferindo um conjunto de propriedades presumivelmente determinadas pelo genótipo da espécie a princípios mais gerais, não específicos à linguagem.

Como resultado, podemos perceber que a complexidade da competência linguística, atribuída integralmente à GU em GB, torna-se aparente quando incorporamos a abordagem "de baixo para cima" ao modelo dos três fatores. A competência linguística deixa de ser

\footnotetext{
${ }^{39} \mathrm{O}$ papel do terceiro fator no desenvolvimento da linguagem vem sendo assinalado desde o início do empreendimento gerativista, muito embora tenha encontrado espaço somente no minimalismo. Em Chomsky (1965, p. 59), por exemplo, já é possível observar a menção a "princípios de organização neural que poderiam estar profundamente arraigados em leis físicas" [Trecho original: "principles of neural organization that may be even more deeply grounded on physical law"]. Al-Mutairi $(2014$, p. 50) aponta que apesar da influência da dotação genética ter figurado como o argumento principal nos trabalho de Chomsky, as considerações que hoje compõem os princípios do terceiro fator estiveram servindo como pano de fundo ao seu pensamento desde os primeiros anos da teoria. Sua revisão após o advento do PM se inicia em Chomsky (2004, p. 104-105), tornando-se célebre com a publicação de Chomsky (2005).

${ }^{40} \mathrm{Um}$ exemplo elucidativo da influência do terceiro fator é fornecido por Berwick e Chomsky (2011, p. 22), a saber: a impossibilidade da evolução de rodas para locomoção animal. Tendo em vista as dificuldades físicas de se fornecer um sistema nervoso e abastecimento sanguíneo a um objeto que se locomove rodando, leis físicas estariam em jogo impedindo que um sistema locomotor com tais características fosse desenvolvido por qualquer organismo animal. Da mesma forma, o formato de uma célula não é resultado de uma lei biológica, mas de pressões físicas que forçam a determinação desse formato (EPSTEIN; KITAHARA; SEELY, 2017, p. 52).
} 
descrita como uma consequência única e exclusiva da expressão genética da espécie, cuja manifestação fenotípica daria origem a um sistema internamente complexo. Em vez disso, ela passa a ser caracterizada como o produto da interação entre (i) uma determinação genética mínima - i.e., a GU - e (ii) leis biofísicas que regem o mundo natural. Com bem aponta AlMutairi (2014, p. 22), no PM, “o que é inato à linguagem, opostamente ao que é aprendido, corresponde ou a uma manifestação de nossos genes ou a uma consequência de leis físicas, não biológicas". 41

Essa sintetização da GU, fortemente pretendida pelo PM, cristaliza-se na chamada Tese Minimalista Forte (SMT; CHOMSKY, 2001), que, em sua formulação geral, estipula que a linguagem humana nada mais é do que uma solução ótima para satisfazer as condições de legibilidade impostas pelas interfaces com os sistemas S-M e C-I:

(13) Tese Minimalista Forte (CHOMSKY, 2001, p. 1, tradução nossa)

"A tese minimalista mais forte deve assegurar que a linguagem é uma solução ótima para condições de legibilidade". ${ }^{4}$

Notamos que, como consequência dessa nova abordagem para a GU, os módulos postulados em GB são sugestivamente descartados e grande parte de suas funções passa a ser explicada na forma de condições impostas pelas interfaces com os sistemas externos. Através da SMT, podemos afirmar que a GU reduz-se, em tese, a um sistema combinatorial recursivo -implementado teoricamente pela operação Merge-, o qual é responsável por formar expressões hierarquicamente estruturadas, e a princípios de eficiência computacional que assegurariam a legibilidade dessas expressões pelos sistemas interpretativos. Em decorrência desse reducionismo, a GU pode ser sintetizada na forma de uma simples equação, tal como argumenta Chomsky (2010a, p. 46):

(14) GU: Recursividade + Interfaces $=$ Linguagem

Contudo, é importante lembrar que Chomsky $(2000,2001,2007)$ também relega à GU o fornecimento de entradas lexicais altamente estruturadas. Esse posicionamento teórico contradiz a abordagem "de baixo para cima" e coloca em questão a validade da equação em

\footnotetext{
${ }^{41}$ Trecho original: "[...] what is innate in language, as opposed to what is learned, is either a manifestation o four genes or a consequence of non-biological, physical law".

${ }^{42}$ Trecho original: "Strong Minimalist Thesis: The strongest minimalist thesis would hold that language is an optimal solution to legibility conditions".
} 
(14). Se o propósito do PM é sintetizar a GU atribuindo a ela o mínimo necessário para se desenvolver uma língua, não seria adequado enriquecê-la, paralelamente, com as propriedades que compõem as entradas lexicais, ou seja, com feixes de traços formais ou hierarquias funcionais. Como vimos na última seção, as entradas lexicais são comumente constituídas de uma grande quantidade de informações, cujo intuito é diminuir a influência da sintaxe na construção de um objeto linguístico. Se nós admitirmos que tais informações também são determinadas geneticamente, a redução da GU pretendida pela SMT torna-se ilusória.

Tal incongruência endossa a afirmação de Boeckx (2015, p. 19) de que a sintaxe minimalista nada mais é do que "GB disfarçada". Isso de deve à manutenção de uma GU composta por um conjunto massivo de informações - dessa vez, codificadas na forma de feixes de traços formais ou de hierarquias funcionais-, a fim de garantir que a criança desenvolva a(s) língua(s) a que é exposta. ${ }^{43}$ Poderíamos, por outro lado, repensar a validade da equação em (14) e considerar, paralelamente, uma hipótese alternativa que inclua o léxico (e.g., "Léxico + Recursividade + Interfaces = Linguagem”). Entretanto, com essa hipótese alternativa, acabamos mantendo as redundâncias colocadas pela assunção de um léxico complexo e de um sistema recursivo, uma vez que a complexidade das entradas lexicais torna-se casual e o sistema recursivo coadjuvante, tal como discutido na última seção. ${ }^{44}$

Vejam que, cada vez mais, torna-se inequívoca a necessidade de diminuir a influência do léxico na computação sintática e de determinar de que modo as propriedades que são tidas como "fornecidas pelo léxico" estão diluídas pela gramática. Sugerimos que, para se chegar a uma teoria próxima àquela vislumbrada pela SMT e, ao mesmo tempo, a uma teoria coerente com a abordagem "de baixo para cima", é imprescindível reduzir a complexidade atribuída às entradas lexicais, relegando suas restrições combinatoriais à sintaxe. Devemos também averiguar em que medida as competências associadas ao léxico são, realmente, exclusivas à

\footnotetext{
${ }^{43}$ Boeckx (2015) levanta esse argumento por outras razões. Ele nota que os traços gramaticais apresentam, de certo modo, o mesmo grau de especificidade que os módulos assumidos em GB. O autor ressalta também que contrapartes desses módulos podem ser encontradas na forma de traços no PM, o que nos sugere que sua eliminação também é aparente no modelo.

${ }^{44}$ Uma terceira alternativa seria admitir um léxico simplificado, sem estruturação em feixes, em vez de um léxico complexo tal como aquele assumido pelas principais abordagens minimalistas. Porém, como veremos na próxima subseção, a suposta emergência recente da competência linguística também nos força a reduzir os aspectos unicamente humanos da FL. Até o momento, esses aspectos circunscrevem-se às propriedades combinatoriais, as quais são consideravelmente distintas daquelas observadas nos sistemas de comunicação de animais não humanos. Sendo assim, é fundamental averiguar em que medida as propriedades do léxico são exclusivamente humanas. Há evidências indicando que a riqueza conceitual da espécie é compartilhada com outros animais não humanos (Cf. SPELKE, 2003; CARRUTHERS, 2006; HURFORD, 2007), o que nos sugere que a lexicalização desses conceitos - i.e., a transformação desses conceitos em entradas lexicaisdeve corresponder a um evento evolutivo mínimo, possivelmente um efeito colateral da emergência de um sistema recursivo. Voltaremos a essa questão no Capítulo 4.
} 
espécie e passíveis de serem incluídas na equação em (14). Desenvolveremos essas sugestões no Capítulo 4, quando explorarmos os pressupostos globais da Abordagem Isomórfica.

Essa mesma conclusão a que chegamos acima é obtida quando avaliamos o percurso evolutivo da espécie humana. Discutiremos, na próxima subseção, que a suposta emergência recente da competência linguística nos leva a manter uma descrição da GU tal como sugerido na equação em (14) e a considerar mais enfaticamente que sua complexidade é aparente. Em nossa discussão, apontamos que a complexidade comumente atribuída à linguagem humana é aparente não apenas devido à influência de leis biofísicas em seu funcionamento, mas também devido ao fato de que a maior parte dos componentes que constituem a FL - incluindo as propriedades associadas ao léxico - é compartilhada, hipoteticamente, com outras espécies de animais não humanos, tendo sido presumivelmente cooptados para dar origem à capacidade linguística da espécie.

\subsubsection{Sintetizando a $G U$ : Considerações evolutivas}

Na medida em que a organização interna da GU foi se tornando cada vez mais clara, o empreendimento gerativista passou a investigar não somente a parametrização da GU em uma língua particular, como também questões relativas à emergência da competência linguística na história evolutiva da espécie. O raciocínio subjacente a essas duas questões é correlato, pois compreende essencialmente um descompasso entre complexidade e tempo. Apontamos que o problema lógico da aquisição da linguagem está em esclarecer a riqueza do conhecimento linguístico adquirido pela criança em um curto intervalo de tempo, e a partir de estímulos restritos. Por outro lado, veremos, nesta subseção, que o problema lógico inerente à evolução da linguagem concentra-se em explicar o surgimento de uma faculdade cognitiva, composta de diferentes habilidades, tendo em conta sua manifestação recente.

Desde muito antes das publicações seminais sobre a teoria da evolução através de seleção natural (Cf. DARWIN, 1869, 1871), diferentes disciplinas já indagavam quais teriam sido os eventos evolutivos que propiciaram o surgimento da FL na evolução. A questão é de grande interesse não apenas pela influência da linguagem no desenvolvimento da cognição e do comportamento humanos, como também pela natureza singular dessa inovação evolutiva, que se distingue por ser uma autapomorfia, ou seja, por se configurar como um caractere exclusivo à espécie humana (CHOMSKY, 1980a, 1988, 2000, 2007, 2017; TALLERMAN; GIBSON, 2012), e por seu desenvolvimento evolutivo recente, cuja fixação, deduzida a partir 
dos primeiros registros arqueológicos explicitamente simbólicos, ocorreu por volta de 80.000 100.000 anos atrás (Cf. HENSHILWOOD et al., 2002; HENSHILWOOD et al., 2004; d'ERRICO et al, 2005; HOFFMANN; STANDISH et al., 2018, entre outros). ${ }^{45}$

Quando avaliamos a complexidade da linguagem de um ponto de vista evolutivo, notamos que sua singularidade e sua suposta manifestação recente desafiam uma explicação em termos de seleção natural, um fato que se atrela à descontinuidade entre as capacidades cognitivas humanas e a de animais não humanos. Evolução através de seleção natural exige fundamentalmente modificações graduais que partem de um caractere precursor, somado a uma série de caracteres intermediários — decorrentes de pressões adaptativas—, os quais dão origem paulatinamente a um órgão complexo. ${ }^{46}$ Porém, não se observa na natureza espécies intermediárias que evidenciem uma gradação intelectual entre animais não humanos e os humanos modernos, capazes de indicar não apenas graus moderados de uma competência linguística, como também de autoconsciência, abstração, inovação e criatividade artística.

Esse descompasso foi apontado pela primeira vez por Alfred R. Wallace, cofundador da teoria da seleção natural, que, em sua revisão, destacou que "a seleção natural somente poderia ter capacitado nossos ancestrais com um cérebro um pouco superior àquele de um primata" $\left(1869\right.$, p. 392). ${ }^{47}$ Nesse contexto, a linguagem humana, bem como outras faculdades cognitivas, constituem caracteres biológicos que fogem às expectativas teóricas de Darwin. $\mathrm{O}$ problema que Wallace nota é o seguinte: se complexidade é resultado de um processo gradual e se a seleção natural somente responde às pressões adaptativas impostas pelo ambiente aos organismos, seria esperado que os humanos modernos apresentassem divergências cognitivas

\footnotetext{
${ }^{45}$ Desenvolveremos, nesta subseção, a hipótese mais bem aceita até o momento nos círculos gerativistas (Cf. CHOMSKY, 2000, 2005, 2010a, 2015, 2016; HORNSTEIN, 2009; BOECKX, 2009; 2011b, 2011c, 2013a, 2015; FUJITA, 2009, 2017; BERWICK; CHOMSKY, 2011, 2016, dentre outros), bem como por paleoantropólogos (Cf. MITHEN, 1996; TATTERSALL, 1998, 2008, 2010, 2012, 2016a, 2016b, 2017; KLEIN, 2009, dentre outros) e por geneticistas (Cf. PÄÄBO, 2014a, 2014b; REICH, 2018) que investigam a evolução humana. Descobertas recentes nos sugerem, porém, que os neandertais também eram dotados de uma consciência simbólica, um caractere fundamental para se desenvolver uma competência linguística (Cf. HOFFMANN; STANDISH et al., 2018; HOFFMANN; ANGELUCCI et al., 2018). Possivelmente, a hipótese de que raciocínio simbólico surgiu exclusivamente na linhagem sapiens, como sugeriam os autores acima, será repensada. No Capítulo 5, ao discutir os registros arqueológicos utilizados para se chegar a essas datações, apresentamos uma hipótese alternativa: argumentamos que as bases cognitivas para raciocínio simbólico emergiram, presumivelmente, em um ancestral comum entre neandertais e sapiens — possivelmente o Homo heidelbergensis — há 600.000 anos atrás, muito embora sua expressão tenha se dado tardiamente em ambas as espécies descendentes, por volta de 80.000-100.000 anos atrás. Um intervalo de tempo ainda restrito para o desenvolvimento das habilidades específicas que compõem a FL.

${ }^{46}$ O termo "adaptação", como descreve Hauser (1996, p. 3), diz respeito a um determinado caractere que evoluiu como resposta a um problema sócio-ecológico. Os traços que compõem esse caractere estão intrinsecamente relacionados à probabilidade de sobrevivência ou sucesso reprodutivo de um organismo e representam a melhor solução para um problema sócio-ecológico.

${ }^{47}$ Trecho original: "Natural selection could only have endowed the savage with a brain a little superior to that of an ape".
} 
pontuais com relação a seus ancestrais não humanos, o que, ao que tudo indica, não é o caso (Cf. MITHEN, 1996; TATTERSALL, 1998, 2008, 2010, 2012, 2016a, 2016b, 2017; KLEIN, 2009; LALAND, 2017).

Como argumenta Wallace (1870, p. 351-352):

\begin{abstract}
“Como poderia a 'seleção natural', ou a sobrevivência dos mais aptos na luta pela existência, favorecer o desenvolvimento de poderes mentais tão inteiramente removidos das necessidades materiais dos homens selvagens, e que mesmo agora, com nossa civilização relativamente desenvolvida, ainda [...] parecem ter relação mais com o futuro da raça do que com seu status atual? (WALLACE, 1870: 351352, tradução nossa). ${ }^{48}$
\end{abstract}

Esse impasse acabou sendo rotulado por Bickerton (2014, p. 1) como o Problema de Wallace. ${ }^{49}$ Tal problema exige uma explicação para a lacuna cognitiva existente entre animais não humanos e humanos, que identifique qual a fonte da capacidade intelectual humana. Mais especificamente, o Problema de Wallace busca desvendar por que a mente humana configurase como um desenvolvimento evolutivo inesperado, uma vez que ela excede as habilidades cognitivas que a espécie necessitaria para sobreviver. ${ }^{50}$ De acordo com esse raciocínio, a competência linguística passa a ser "um constrangimento para a teoria evolutiva, pois é muito mais poderosa do que se poderia explicar em termos de forças seletivas", tal como assinala Premack (1986, p. 133). ${ }^{51}$ Sendo assim, o Problema de Wallace exige que nós averiguemos a existência de estruturas cognitivas subjacentes à FL em diferentes grupos de animais não humanos, capazes de indicar uma potencial cumulatividade em seu aparecimento.

Intrínseco ao Problema de Wallace é o intervalo de tempo que demarca as primeiras expressões de raciocínio simbólico. Como destacamos, a FL é frequentemente descrita como um caractere biológico de desenvolvimento recente, e cujas primeiras expressões materiais, verificadas tangencialmente em registros arqueológicos, concentram-se há 80.000-100.000 anos atrás. Tal janela temporal é um piscar de olhos em termos evolutivos e, como tal, implica

\footnotetext{
${ }^{48}$ Trecho original: "How could "natural selection," or survival of the fittest in the struggle for existence, at all favor the development of mental powers so entirely removed from the material necessities of savage men, and which even now, with our comparatively high civilization, are, [in their in advance of the age], and appear to have relation rather to the future of the race than to its actual status?".

${ }^{49}$ Cf. Chomsky (2010a) para uma primeira apreciação do dilema colocado por Wallace.

${ }^{50}$ Wallace (1871, p. 334) não conseguia vislumbrar vantagens adaptativas para a "natureza intelectual e moral" humanas [moral and intelectual nature], tais como a linguagem, cooperação, criatividade artística e musical, etc. Em sua visão, a mente humana é composta por competências que vão muito além do que seria exigido pela natureza para a manutenção da espécie.

${ }^{51}$ Trecho original: "[Human language is] an embarrassement for evolutionary theory because it vastly is more powerful than one can account in terms of selective forces".
} 
que a seleção natural não teria tido tempo hábil para produzir a complexidade verificada internamente à $\mathrm{FL}^{52}$ Esse descompasso com os pressupostos da teoria da seleção natural nos faz colocar em perspectiva o modo como a FL tornou-se um caractere biológico passível de emergir; um questionamento que ficou conhecido como o Problema de Darwin (Cf. FUJITA, 2002, 2009; HORNSTEIN, 2009; BOECKX, 2009).

Embora esses dois problemas tenham sido definidos separadamente pela literatura, eles podem ser reduzidos a um único dilema, a saber:

\section{(15) Problema de Wallace-Darwin}

De que modo a complexidade atribuída à competência linguística foi alcançada na evolução tendo em vista a aparente pobreza de precursores e o curto intervalo de tempo para o seu desenvolvimento?

Com base nessas observações, podemos dizer que o "Problema de Wallace-Darwin", assim amalgamado, nos antecipa que somente seremos capazes de alcançar uma explicação adequada sobre a emergência da FL se admitirmos como premissas gerais que (i) adaptação através de seleção natural pode não corresponder a toda a explicação para o seu surgimento e que (ii) a competência linguística humana não diz respeito a um sistema cognitivo complexo, constituído por um conjunto de módulos e princípios específicos à linguagem; caso contrário, a FL se torna um caractere biológico totalmente anômalo no mundo natural, sem correlatos no desenvolvimento evolutivo de qualquer outro organismo. ${ }^{53 / 54}$

Ao contrastar essa discussão com o que vimos na última subseção, verificamos que as estratégias de sintetização da GU, empreendidas pelo PM nos últimos anos, estão alinhadas às considerações colocadas pelo Problema de Wallace-Darwin. Fica evidente que a sintetização da GU é de interesse não somente das investigações sobre a ontogenia da linguagem, como

\footnotetext{
${ }^{52}$ Notem que é dessa correlação entre complexidade e tempo, mencionada no início desta subseção, que podemos notar uma isomorfia entre o problema lógico da aquisição da linguagem —o Problema de Platão- e o problema lógico da emergência da linguagem - o Problema de Wallace-Darwin. No primeiro caso, o fator temporal é determinado pela experiência, enquanto no segundo, o fator temporal é determinado pela seleção natural (Cf. HORNSTEIN, 2009; BOECKX, 2011c; AL-MUTAIRI, 2014).

${ }^{53}$ Essa última premissa parte da assunção de que a formação de módulos específicos implica, necessariamente, um grau de complexidade que não seria biologicamente possível em um curto intervalo de tempo. Como destaca Fodor (1998, p. 210), módulos contêm uma série de informações altamente especializadas, comumente destinadas a resolver problemas específicos. Tal grau de elaboração exige, em termos adaptativos, um tempo considerável para sua fixação, o que contradiz os fatos observados até o momento para o desenvolvimento da competência linguística.

${ }^{54}$ Uma extensão desse problema seria esclarecer quais foram as pressões seletivas que favoreceram os genes implicados na competência linguística, bem como quais vantagens adaptativas esse caractere teria conferido, inicialmente, à espécie. Para o leitor interessado nessa discussão, ver Pinker e Bloom (1990), Laland (2017), Miyagawa, Lesure e Nóbrega (2018).
} 
também das investigações sobre sua filogenia. Como discutimos anteriormente, a redução dos mecanismos da GU e a influência exercida pelos princípios do terceiro fator fazem com que o papel do genótipo humano - i.e., das competências exclusivas à espécie - seja limitado; tal limitação, consequentemente, torna o assunto da emergência da linguagem mais palatável e passível de ser explorado. ${ }^{55}$ Como aponta Chomsky (2007, p. 4):

\begin{abstract}
"A tarefa de explicar a emergência da linguagem também seria igualmente facilitada pelas mesmas razões que se colocam para a investigação sobre a evolução de modo geral, a saber: quanto menos for atribuído à informação genética (no nosso caso, a GU) para se determinar o desenvolvimento de um organismo, mais viável se torna o estudo de sua evolução" (CHOMSKY, 2007, p. 4, tradução nossa). ${ }^{56}$
\end{abstract}

A sintetização da GU é reiterada quando consideramos a hipótese de que o surgimento da competência linguística representa um evento relativamente recente. Essa assunção nos leva a presumir que a inovação evolutiva ocorrida na espécie, responsável por dar origem ao caractere para linguagem, deve ter sido geneticamente mínima, muito embora seu fenótipo corresponda paradoxalmente a um sistema complexo, o que se observa, por exemplo, na descontinuidade cognitiva estabelecida entre animais não humanos e humanos. Levando-se em consideração a limitação de caracteres exclusivos ao genótipo humano na emergência da linguagem, a complexidade observada fenotipicamente deve, por hipótese, estar associada a componentes da FL que não são exclusivos à espécie e à linguagem humanas. Para identificálos, é preciso definir quais são os componentes elementares da FL. (Cf. CHOMSKY, 2010a, 2013a, 2016, 2017; BERWICK; CHOMSKY, 2016; BERWICK, 2017).

\footnotetext{
${ }^{55}$ A tentativa de se identificar o componente unicamente humano da linguagem tem como objetivo central explicar por que somente humanos, opostamente a animais não humanos, são dotados de uma competência linguística. Para Chomsky, deve haver um componente biológico exclusivo à espécie, o qual não seria, a princípio, resultado de exaptação, ou seja, selecionado por razões independentes em outras espécies e cooptado para linguagem. Essa não é, obviamente, a única hipótese para o surgimento da FL. Tendo em vista que caracteres aparentemente inovadores geralmente resultam da reorganização de estruturas e componentes preexistentes na natureza (Cf. WEST-EBERHARD, 2005; MOCZEK, 2008), alguns autores sugerem que o mesmo poderia ser esperado do componente sintático, apesar de sua aparente singularidade. Por exemplo, o componente sintático poderia corresponder à exaptação de habilidades motoras recrutadas de outros domínios cognitivos (Cf. FUJITA, 2009, 2017) ou da integração casual de dois sistemas de expressão animal encontrados separadamente na natureza (Cf. MIYAGAWA; BERWICK; OKANOYA, 2013; MIYAGAWA et al., 2014; NÓBREGA; MIYAGAWA, 2015). Chomsky, por sua vez, mantém a visão de que há algo especial na espécie humana a fim de assegurar a validade da GU; caso contrário, se for possível demonstrar que Merge resulta de uma reorganização entre sistemas primitivos, então a hipótese de que há uma GU cai por terra.

${ }^{56}$ Trecho original: "The task of accounting for the evolution of language would also be correspondingly eased, for the same reasons that hold for inquiry into evolution generally: the less attributed to genetic information (in our case, the topic of UG) for determining the development of an organism, the more feasible the study of its evolution".
} 
Tomando por base os avanços teóricos obtidos pelo empreendimento gerativista nos últimos sessenta anos, Berwick e Chomsky (2016, p. 1) e Chomsky (2016, p. 4) fornecem uma definição concisa para esse caractere, partindo de sua propriedade elementar: a conjectura de que a competência linguística humana compreende somente um sistema de associações entre som e significado, conectados através de uma estrutura sintática. Os autores rotulam tal propriedade de "Propriedade Básica", descrita no trecho abaixo:

\footnotetext{
“A linguagem é um sistema computacional finito capaz de produzir uma infinidade de expressões, cada uma das quais com uma interpretação definida nos sistemas semântico-pragmático e sensório-motor (informalmente, pensamento e som) (BERWICK; CHOMSKY, 2016, p. 1, tradução nossa)". 57
}

Assumindo-se a validade da definição colocada pela "Propriedade Básica", podemos dizer que a FL compõe-se, minimamente, de três componentes: (i) um sistema combinatorial, (ii) um sistema S-M e (iii) um sistema C-I. Para determinar quais dentre esses sistemas não são exclusivos à espécie humana, Berwick e Chomsky (2016, p. 2) recomendam a abordagem “dividir para conquistar". Sua metodologia é consideravelmente simples. Os autores propõem que, em um primeiro momento, devemos fragmentar o caractere sob análise em componentes mais elementares, tal como fizemos na identificação da lista de componentes acima, e, em um segundo momento, devemos contrastar suas propriedades com um conjunto de propriedades paralelas constatadas no comportamento e na expressão genética de animais não humanos.

Hauser, Chomsky e Fitch (2002) desenvolveram grande parte dessa tarefa.

Aplicando o método comparativo, os autores verificaram que muitas das propriedades que compõem os sistemas S-M e C-I são averiguadas em animais não humanos e, portanto, seriam anteriores ao surgimento da competência linguística. Por exemplo, os autores revelam que características articulatórias e perceptuais, como partes da anatomia do aparelho vocal, controle motor, percepção rítmica e imitação vocal são amplamente encontradas em outros vertebrados. O mesmo paralelo é observado nas capacidades conceituais e interpretativas, já que percepção, planejamento, cardinalidade/numerosidade, identificação de objetos, aquisição de representações conceituais não linguísticas, entre outras, são atestadas no comportamento de diferentes espécies. ${ }^{58}$ Porém, diferentemente do que se observa com esses dois sistemas, as

\footnotetext{
${ }^{57}$ Trecho original: "Basic Property of language: that a language is a finite computational system yielding an infinity of expressions, each of which has a definite interpretation in semantic-pragmatic and sensorimotor systems (informally, thought and sound)".

${ }^{58}$ Essas observações são endossadas em trabalhos posteriores. Para o sistema S-M, Samuels (2009, 2011), Pfenning et al. (2014), Comins e Gentner (2015), Engesser et al. (2015), Spierings e ten Cate (2016), Roberts
} 
propriedades do sistema combinatorial, em especial, sua recursividade, seriam sugestivamente exclusivas à espécie humana. Em decorrência disso, as características desse sistema recursivo corresponderiam à inovação evolutiva manifestada pelo genótipo humano. ${ }^{59}$

Um resumo das correlações feitas pelos autores e dos tipos de estudos analisados para o estabelecimento dessas correlações pode ser visto no Quadro 1, abaixo, adaptado de Hauser, Chomsky e Fitch (2002, p. 1573). Neste quadro, optamos por apontar apenas as correlações estabelecidas para os sistemas S-M e C-I:

et al. (2017), dentre outros. Para o sistema C-I: Spelke (2003), Povinelli (2004), Carruthers (2006), Hurford (2007), Carey (2009), Emonds (2011), Fitch e Zuberbühler (2013), entre outros.

59 Berwick et al. (2011) e Berwick et al. (2012) mostram que as características combinatoriais dos sistemas de comunicação animal, em especial, do canto dos pássaros, diferem daquelas que observamos na linguagem humana. Enquanto o canto dos pássaros comumente restringe-se a gramáticas de estado finito, a linguagem humana é essencialmente uma gramática de estado não finito. Ver também Yip (2006), Samuels (2009, 2011, 2016) e Heinz e Idsardi (2013). 
Quadro 1. Amostra das abordagens empíricas utilizadas para se determinar os componentes da FL.

Problema empírico

\begin{tabular}{|c|c|}
\hline \multicolumn{2}{|c|}{ Sistema S-M } \\
\hline Invenção e imitação vocal & $\begin{array}{l}\text { Estudos sobre a tutoria de pássaros canoros, análises dos } \\
\text { dialetos vocais de baleias, imitação espontânea de sons } \\
\text { criados artificialmente por golfinhos. }\end{array}$ \\
\hline Neurofisiologia dos sistemas de ação-percepção & $\begin{array}{l}\text { Estudos que avaliam se neurônios-espelho, responsáveis por } \\
\text { fornecem o substrato nuclear para os sistemas de ação- } \\
\text { percepção, podem auxiliar na imitação gestual e } \\
\text { (possivelmente) na imitação vocal. }\end{array}$ \\
\hline Restrições impostas pela anatomia do trato vocal & $\begin{array}{l}\text { Estudos sobre a extensão do trato vocal e dispersão de } \\
\text { formantes em pássaros e primatas. }\end{array}$ \\
\hline Biomecanismos da produção sonora & $\begin{array}{l}\text { Estudos da produção vocal de primatas, incluindo o papel } \\
\text { das oscilações mandibulares. }\end{array}$ \\
\hline Modalidades de produção e percepção linguística & $\begin{array}{l}\text { Percepção trans-modular e língua de sinais em humanos } \\
\text { versus comunicação unimodal em animais. }\end{array}$ \\
\hline \multicolumn{2}{|c|}{ Sistema C-I } \\
\hline Teoria da Mente, atribuição de estados mentais & Estudos sobre a distinção entre ver e saber em chimpanzés. \\
\hline $\begin{array}{l}\text { Capacidade para adquirir representações } \\
\text { conceituais não linguísticas }\end{array}$ & Estudos com macacos rhesus e o conceito objeto/tipo. \\
\hline Sinais vocais referenciais & $\begin{array}{l}\text { Estudos das vocalizações de primatas empregadas para } \\
\text { designar predadores, alimentos e relações sociais. }\end{array}$ \\
\hline Imitação como um processo intencional, racional & $\begin{array}{l}\text { Estudos comparativos entre chimpanzés e humanos infantes } \\
\text { sugerindo que somente esses últimos percebem } \\
\text { intencionalidade em ações e, portanto, extraem intenções } \\
\text { racionais não observadas. }\end{array}$ \\
\hline $\begin{array}{l}\text { Controle voluntário da produção vocal como } \\
\text { evidência para intenção comunicativa }\end{array}$ & $\begin{array}{l}\text { Estudos comparativos que exploram a relação entre a } \\
\text { produção de sinais e a composição de uma audiência social. }\end{array}$ \\
\hline
\end{tabular}

Fonte: Hauser, Chomsky e Fitch (2002, p. 1573).

Tendo em mente essas observações, Hauser, Chomsky e Fitch (2002, p. 1570-1571) cindem a FL em duas categorias, notadamente: (i) uma Faculdade da Linguagem no sentido estrito (FLN, do inglês Faculty of Language in the narrow sense), que inclui propriedades únicas à espécie e à linguagem humanas —em outras palavras, a GU—, e (ii) uma Faculdade da Linguagem no sentido amplo (FLB, do inglês Faculty of language in the broad sense), que inclui propriedades exaptadas para a linguagem, sendo, portanto, compartilhadas com outras 
espécies de animais não humanos, bem como propriedades recrutadas de outros domínios cognitivos. ${ }^{60} \mathrm{Na}$ Figura 1, apresentamos uma representação esquemática da cisão estabelecida pelos autores.

Figura 1. Representação esquemática dos fatores internos ao organismo relacionados à FL. ${ }^{61}$

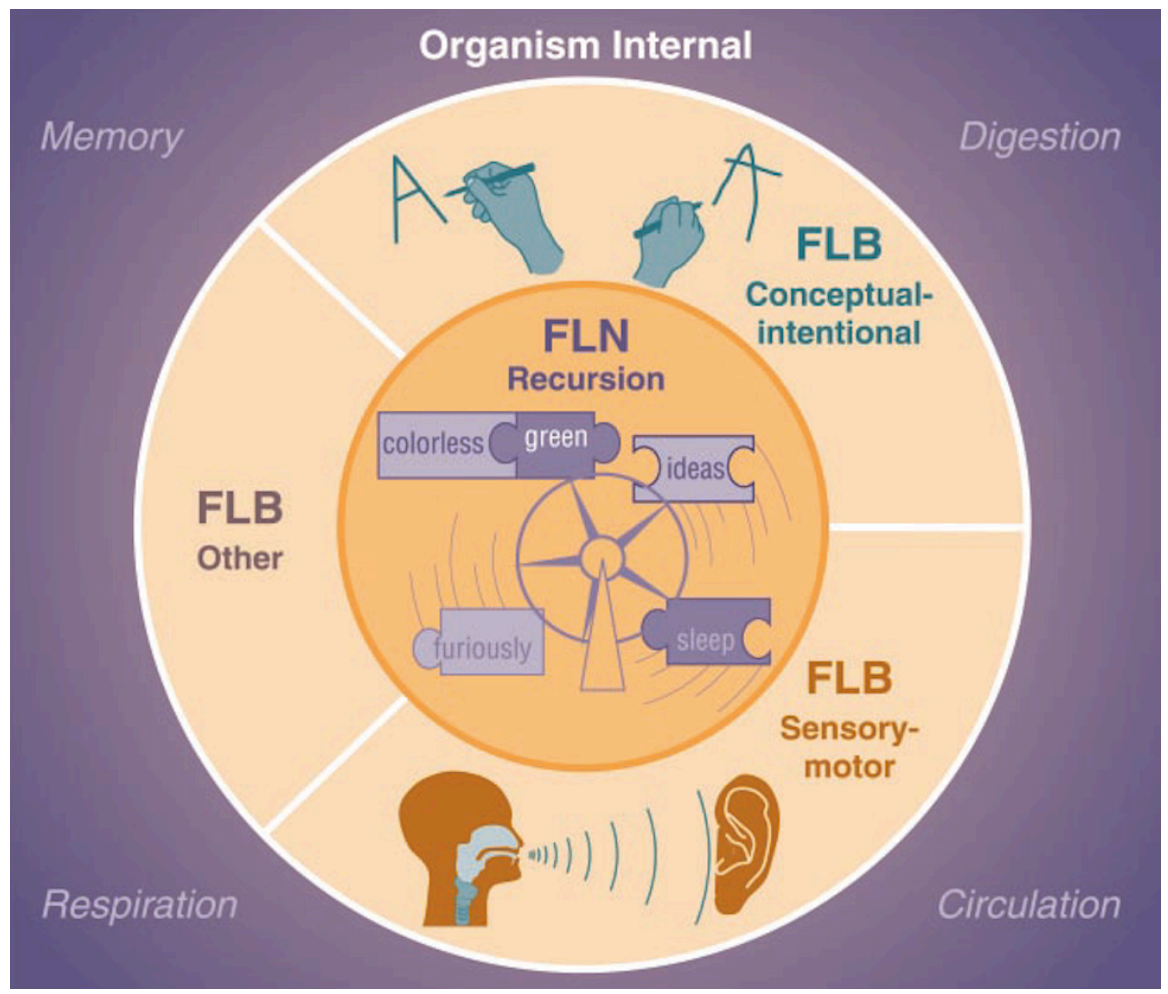

Fonte: Hauser, Chomsky e Fitch (2002, p. 1570).

Reparem que, na Figura 1, a FLB inclui a FLN. De acordo com Hauser, Chomsky e Fitch (2002, p. 1571), foi através da integração entre a FLB e a FLN que as capacidades preexistentes dos sistemas S-M e C-I passaram a ser mediadas por um sistema combinatorial recursivo. ${ }^{62}$ Como resultado dessa integração, verificamos que grande parte da complexidade observada no fenótipo linguístico não está diretamente codificada no genoma humano, mas decorre dos componentes periféricos da FLB, especialmente daqueles que subjazem aos sistemas S-M e C-I. Essa assunção explica grande parte do Problema de Wallace-Darwin. O

\footnotetext{
${ }^{60}$ Exaptação diz respeito a uma adaptação biológica cujas pressões seletivas para sua manutenção não estão relacionadas à sua função atual (GOULD; VRBA, 1982; BUSS et al., 1998). Em linhas gerais, uma adaptação biológica é recrutada para funções distintas daquelas de sua origem. Por exemplo, as penas das aves surgiram originalmente para agir como isolamento térmico, tendo sido exaptadas, posteriormente, para o voo.

${ }^{61}$ Memória, digestão, respiração e circulação representam sistemas internos ao organismo, não necessariamente associados à FL.

${ }^{62}$ Considerações sobre quando e como essa integração pode ter ocorrido serão discutidas no Capítulo 4, quando justificarmos empiricamente os argumentos em favor da Abordagem Isomórfica.
} 
que haveria de unicamente humano na linguagem reduz-se, de acordo com essa visão, "aos mecanismos computacionais da recursividade, tal como eles aparecem na sintaxe estrita, e aos mapeamentos para as interfaces" (2002, p. 1573). ${ }^{63}$ Essa conclusão dialoga, diretamente, com a SMT descrita pela equação em (14).

Há, entretanto, que se levar em consideração a influência do léxico na emergência da linguagem, como destacam Pinker e Jackendoff (2005, p. 212-215). O léxico humano tem sido subestimado pelas abordagens gerativistas interessadas na evolução da linguagem e, muito embora os autores tenham consciência dessa negligência, "como [explicar o seu surgimento], ninguém tem ideia" (BERWICK; CHOMSKY, 2011, p. 40). ${ }^{64}$ Com base no que vimos até aqui, podemos afirmar que seria inapropriado atribuir entradas lexicais ou feixes de traços formais à GU/FLN — contra Chomsky (2000, 2001, 2004, 2007)—, pois isso contradiz as recomendações feitas pelo Problema de Wallace-Darwin. Tal assunção faria com que as propriedades exclusivamente humanas da competência linguística deixassem de ser mínimas, sobrecarregando o papel do genótipo da espécie. Dadas essas circunstâncias, devemos esperar que o léxico humano decorre de propriedades externas à FLN, que foram supostamente cooptadas de outras espécies e/ou de domínios cognitivos, tal como os sistemas S-M e C-I.

Além disso, é importante frisar que o léxico não é interpretado somente como um repositório de entradas lexicais, mas como um módulo gerativo em diversas concepções da GU, sendo frequentemente caracterizado como um componente autônomo, responsável pela formação de palavras (Cf. CHOMSKY, 1970; HALLE; 1973; ARONOFF, 1976; SCALISE, 1984; DI SCIULLO; WILLIAMS, 1989; LIEBER, 1992, entre outros). Porém, dados os critérios colocados pelo Problema de Wallace-Darwin, podemos afirmar que essa hipótese é evolutivamente inconsistente, pois ela enriquece sobremaneira a GU. Isso se justifica pela seguinte razão: a hipótese lexicalista parte do pressuposto de que a dotação genética confere ao indivíduo dois módulos combinatoriais dissociados, cada qual destinado à formação de um conjunto específico de objetos linguísticos, um para a formação de palavras e outro para a formação de sintagmas e de sentenças. Em decorrência dessa assunção, a inovação evolutiva passa a ser caracterizada por um conjunto de informações altamente especializadas, cujo alto grau de elaboração inviabiliza o surgimento da competência linguística em um curto intervalo de tempo.

\footnotetext{
${ }^{63}$ Trecho original: "[FLN] comprises only the core computational mechanisms of recursion as they appear in narrow syntax and the mappings to the interfaces".

${ }^{64}$ Trecho completo: "Essas propriedades dos itens lexicais parecem ser únicas à linguagem e ao pensamento humanos e devem ser explicadas de algum modo no estudo de sua evolução. Como, ninguém tem ideia". [These properties of lexical items seem to be unique to human language and thought and have to be accounted for somehow in the study of their evolution. How, no one has any idea.]
} 
Esse descompasso levou alguns autores a defender uma abordagem antilexicalista para o surgimento da linguagem (Cf. FUJITA, 2009, 2017; OTT, 2009; BOECKX, 2009, 2011c, 2015; SIGURĐSSON, 2012; NÓBREGA; MIYAGAWA, 2015; MURPHY, 2016). Por exemplo, Fujita (2009) busca evitar o enriquecimento da GU distribuindo as propriedades do léxico aos demais componentes da gramática. De acordo com o autor, as propriedades do léxico deveriam ser decompostas entre a sintaxe e os sistemas interpretativos. Ecoando as abordagens não lexicalistas (Cf. HALLE; MARANTZ, 1993; 1994; MARANTZ, 1995; 1997; BORER, 2003; 2005a; 2005b, entre outras), Fujita (2009, p. 143) defende que a GU compreende apenas um único sistema combinatorial —ou seja, Merge-, responsável pela formação tanto de palavras quanto de sintagmas e de sentenças, e que questões associadas à forma e à interpretação estariam a cargo dos sistemas S-M e C-I.

As premissas da perspectiva antilexicalista elaborada pelo autor estão resumidas em (16): ${ }^{65 / 66}$

(16) Premissas antilexicalistas (FUJITA, 2009, p. 143)

a. Palavras são geradas pela sintaxe;

b. O léxico gerativo pode ser decomposto entre FLN (a operação Merge) e FLB (som e significado);

c. Consequentemente, não há nenhum léxico gerativo.

Por fim, é relevante apontar que o léxico apresenta peculiaridades que desafiam a hipótese de que o sistema combinatorial é o único caractere exclusivo à espécie humana. Entre elas, podemos citar (i) sua extensão, que excede em dezenas de milhares os sinais referenciais empregados por animais não humanos (MARLER; TENAZA, 1977; GOODALL, 1986); (ii) sua aquisição ilimitada, que não se restringe ao período crítico da aquisição da linguagem (TALLERMAN, 2009, 2012) e (iii) seu caráter dependente de aprendizado, opostamente aos sinais inatos atestados em animais não humanos (HOCKETT, 1960a, 1960b; PINKER; JACKENDOFF, 2005; entre outros). Embora sejam propriedades desafiadoras, veremos, no Capítulo 4, que elas podem ser analisadas como epifenômenos da emergência da operação Merge, o que asseguraria a validade da SMT.

\footnotetext{
${ }^{65}$ É importante salientar que essa posição teórica —apesar de receber outro nome no âmbito da emergência da linguagem - nada mais é do que uma ampliação da hipótese não lexicalista defendida por Halle e Marantz (1993, 1994), Marantz $(1995,1997)$ e Borer $(2003,2005$ a, 2005b, 2013).

${ }^{66}$ No Capítulo 4, veremos que, embora tal perspectiva nos aproxime de uma explicação coerente com o Problema de Wallace-Darwin, ela não é suficiente para esclarecer o surgimento do léxico humano, uma vez que não fornece uma hipótese acerca da origem das peças a serem combinadas pelo sistema combinatorial.
} 
Com esse conjunto de considerações em mente, iremos, na próxima seção, reunir um grupo de desiderata para se desenvolver uma teoria sintática isenta de prescrições lexicais.

\subsection{Diretrizes para uma teoria sintática explicativa e evolutivamente adequada}

Exploramos, ao longo das últimas seções, os empecilhos que a assunção de um léxico altamente estruturado colocam para a teoria da gramática, não apenas no que concerne à adequação explicativa como também à adequação evolutiva. Nesta seção, reunimos os desiderata metodológicos, derivados dos apontamentos feitos neste capítulo, os quais nos colocam, em nosso entendimento, no caminho para se ir "além da adequação explicativa". Esses desiderata caracterizam-se como pressupostos desejáveis por aqueles que buscam desenvolver uma teoria sobre a gramática em que (i) o funcionamento da sintaxe independe de instruções arbitrariamente empacotadas em entradas lexicais, e em que (ii) as propriedades do léxico não sobrecarregam o aparato genético da espécie, mas correspondem, a princípio, a um produto da influência de componentes compartilhados com outras espécies e/ou com outros domínios cognitivos.

Embora tenhamos criticado a postulação indiscriminada de traços formais, não defendemos que os traços devem ser excluídos como primitivos da gramática, contra Boeckx (2010, 2015). Pelo contrário, nosso intuito é fornecer uma hipótese restritiva e biologicamente plausível para o seu surgimento, sua articulação com o sistema combinatorial e para a criação de qualquer novo traço formal. Sendo assim, julgamos ser necessária a adoção dos desiderata aqui elencados, pois eles podem nos servir como critérios para assegurar que não estamos atribuindo às entradas lexicais propriedades que deveriam ser explicadas ou pela sintaxe ou pelos sistemas interpretativos. É importante mencionar que esses desiderata foram elaborados por diferentes autores e por razões distintas, apesar de apresentarem uma motivação comum, a saber: indicar que a influência do léxico na computação sintática é radicalmente restrita.

Com base no que discutimos até aqui, pudemos extrair cinco desiderata, decorrentes de um mesmo pressuposto global, todos listados individualmente abaixo: 
* Pressuposto Global

A sintaxe não deve seguir, cegamente, instruções lexicais.

\section{- Desideratum \#1:}

As entradas lexicais não devem ser as responsáveis por projetar a estrutura sintática — antiprojecionismo (MARANTZ, 1997, 2013; BORER, 2003, 2005a, 2005b, 2013).

- Desideratum \#2:

Informações lexicais não devem ser pré-empacotadas arbitrária e gratuitamente anti-estruturação em feixes (BOECKX, 2010, 2015).

\section{- Desideratum \#3:}

Hierarquias funcionais devem ser emergentes, não predeterminadas (FORTUNY, 2008; BOECKX, 2008, 2010, 2015).

\section{- Desideratum \#4:}

A aplicação de Merge deve estar dissociada da valoração de traços (CHOMSKY, 2008, 2013a, 2015).

\section{- Desideratum \#5:}

A GU deve conter apenas um único sistema combinatorial, implementado pela operação Merge — antilexicalismo (FUJITA, 2009, 2017; OTT, 2009; BOECKX, 2009，2011c，2015; SIGURĐSSON，2012; NÓBREGA; MIYAGAWA，2015; MURPHY, 2016).

Iniciemos pelo desideratum 1. Tal desideratum nos sugere que, para se obter uma sintaxe operacionalmente autônoma, é fundamental impedir que ela sirva apenas como um tradutor de instruções lexicais. Em vez de partir da premissa de que o léxico projeta a estrutura sintática e de que a sintaxe segue, irrefletidamente, as orientações dos traços formais, devemos assumir que a distribuição das entradas lexicais é uma propriedade da estrutura sintática em que elas estão inseridas. Em outras palavras, as estruturas sintáticas devem ser geradas independentemente das entradas lexicais que irão realizá-las. Isso implica que as entradas lexicais não devem conter propriedades funcionais inerentes (e.g., 
propriedades categoriais ou argumentais), capazes de guiar a derivação da estrutura. As características funcionais das entradas lexicais devem, em vez disso, ser determinadas pelo ambiente sintático em que elas estão alocadas.

O desideratum 1 recomenda, portanto, a assunção de uma teoria exoesqueletal, antiprojecionista, neoconstrucionista para a gramática, a fim de assegurar que a computação sintática usufrua de autonomia funcional. A perspectiva exoesqueletal corresponde a um conjunto variado de abordagens que, embora divirjam em detalhes técnicos, compartilham a hipótese de que a estrutura sintática é responsável por determinar as características distribucionais e funcionais das entradas lexicais. Suas versões mais conhecidas são a Morfologia Distribuída (MD; Cf. MARANTZ, 1997, 2013; HALLE, 1997; HARLEY; EMBICK, 2000; NOYER 1999, 2000; ALEXIADOU, 2001; EMBICK; NOYER, 2007) e o modelo Exoesqueletal (XS; Cf. BORER, 2003, 2005a, 2005b, 2013). Podemos incluir ainda os trabalhos desenvolvidos por van Hout (1996), Pietroski (2005, 2008, 2010, 2011, 2012), Ramchand (2008), Lohndal (2012, 2014, 2017), Adger (2013), entre outros.

Vejamos uma breve ilustração dessa perspectiva. Tomemos, para tanto, a entrada lexical ler, como na sentença $O$ aluno leu o livro. De acordo com a proposta exoesqueletal, a entrada lexical ler é interpretada como um verbo não porque contenha uma instrução categorial, mas porque ela foi concatenada como parte de uma categoria funcional que a verbaliza (e.g., complemento de v, MARANTZ, 1997; ou complemento de T, BORER, 2003, 2005b). Da mesma forma, a entrada lexical livro é interpretada como argumento interno do verbo ler não devido a uma exigência imposta pela entrada lexical ler, mas porque livro ocupa uma posição estrutural que a faz ser lida dessa maneira (viz., complemento de uma $\sqrt{ }$ RAIZ categorizada por v; MARANTZ, 1997; ou especificador de AspP, BORER, 2003, 2005b). Assim sendo, para a perspectiva exoesqueletal, uma entrada lexical será interpretada como argumento externo ou interno a depender da estrutura funcional que a circunda.

Uma extensão do desideratum 1 é o desideratum 2, que nos aconselha a eliminar qualquer pré-empacotamento arbitrário de informações na forma de instruções lexicais. Um fenômeno linguístico que sinaliza a irrelevância desse pré-empacotamento é a promiscuidade estrutural das entradas lexicais. Marantz (1995, 1997), Borer (2003, 2005a, 2005b), Pietroski (2005, 2008, 2010, 2011, 2012), entre vários outros autores, nos chamam a atenção para uma assimetria presente entre a estrutura sintática e o conteúdo conceitual a ela associado. Enquanto a estrutura sintática apresenta uma interpretação rígida, a entrada lexical detentora de conteúdo conceitual é altamente flexível. Um conjunto clássico de sentenças utilizadas 
para se ilustrar tal promiscuidade é o uso verbal do nome siren 'sirene' no inglês, recuperado nos exemplos em (17):

(17) Inglês (CLARK; CLARK, 1979, p. 803)

a. The fire stations sirened throughout the raid.

'As estações de bombeiros soaram durante todo o ataque'.

b. The factory sirened midday and everyone broke for lunch.

'A fábrica [soou o alarme] ao meio-dia e todos pararam para o almoço'.

c. The police sirened the Porsche to a stop.

'A polícia [sinalizou com a sirene] para que o Porsche parasse'.

d. The police car sirened up to the accident.

'A viatura [se deslocou com a sirene ligada] até o local do acidente'.

e. The police car sirened the daylights out of me.

'A viatura [me assustou com o som da sirene]'.

As sentenças acima nos indicam que a entrada lexical siren pode ocorrer com um número variável de argumentos e que seu conteúdo nuclear — viz., produzir um som de alarme - pode ser recuperado em todas elas, apesar de ser influenciado pelo significado das demais entradas no contexto. Isso nos indica que a distribuição e o significado de siren não resultam apenas das especificações contidas em sua entrada lexical, mas do ambiente sintático em que ela está inserida. Tal flexibilidade nos aponta que o pré-empacotamento de informações distribucionais, seja através de diacríticos ou de traços formais, é um equívoco, já que as entradas lexicais podem apresentar diferentes padrões argumentais. Dessa forma, podemos afirmar, no que diz respeito às propriedades argumentais, que as entradas lexicais não devem conter um conjunto de informações distribucionais predeterminadas e, da mesma forma, não devem projetar a estrutura sintática.

Curiosamente, embora as abordagens exoesqueletais tenham defendido um empobrecimento informacional das entradas lexicais, nem todas efetivaram essa tese na prática. Por exemplo, a MD admite feixes de traços formais como um de seus primitivos. A assunção de feixes, como vimos, é uma conjectura altamente arbitrária. Não fica evidente nem para a MD, nem para os demais modelos minimalistas, como esses feixes de traços foram arranjados independentemente de um mecanismo combinatorial. Tendo em vista o caráter pouco explicativo dos feixes, devemos presumir que a estrutura sintática é, na realidade, composta por entradas lexicais sem uma estrutura interna, em que um traço formal 
corresponde a um núcleo sintático independente, como indica o princípio "um traço, um núcleo" (KAYNE, 2005). Essa assunção se alinha ao que é assumido pelo modelo XS, pela cartografia e pela abordagem nanossintática (Cf. STARKE, 2001, 2009; CAHA, 2009). ${ }^{67}$

Lembrem-se, por outro lado, que os mesmos impasses colocados pelos feixes de traços estendem-se às hierarquias funcionais. O pré-ordenamento de categoriais funcionais é o que o desideratum 3 busca evitar. Devemos enfatizar novamente que não estamos colocando em questão a validade dos mapeamentos estruturais, mas a maneira como eles são caracterizados, ou seja, como uma determinação estabelecida pela GU. O desideratum 3 nos convida a averiguar em que medida as hierarquias funcionais podem ser derivadas pelas interfaces com os sistemas externos. Se obtivermos um resultado positivo, seremos então capazes de explicar efetivamente as restrições estruturais, em vez de apenas listá-las. É válido ressaltar que a influência dos sistemas interpretativos na disposição das categorias funcionais somente pode ser avaliada se abrirmos espaço para interdisciplinaridade. Nesta tese, nós consideramos o desideratum 3 como uma conjectura. Estamos cientes de que mais trabalhos devem ser desenvolvidos para elucidar essa questão.

O desideratum 4, por sua vez, busca não apenas endossar a visão antiprojecionista defendida pela perspectiva exoesqueletal como também assegurar que a inovação evolutiva responsável por dar origem à competência linguística humana —ou seja, a implementação de um sistema combinatorial recursivo - seja mínima. De acordo com a hipótese geral assumida pela teoria gerativa, a recursividade está imbricada nas regras que geram as estruturas sintáticas, e, por conseguinte, o poder gerativo da FL está codificado em suas regras estruturais. Chomsky $(1994,1995)$ propõe que a recursividade pode ser reduzida a um único mecanismo combinatorial, a operação Merge, tal como apontamos anteriormente. Esse mecanismo gera representações estruturais através da combinação de duas unidades discretas na forma de um conjunto.

Resíduos do Princípio da Projeção, destacado anteriormente, vinculam à Merge um caráter endocêntrico, exigindo que a simetria inerente aos membros dos conjuntos formados, $\{\alpha, \beta\}$, seja substituída por uma relação assimétrica, em que um dos membros figura como núcleo do objeto formado, ou $\alpha$ ou $\beta$. Isso levou Chomsky $(2000,2001,2004)$ a sugerir uma formalização para a operação Merge em que a identificação do núcleo ocorresse de forma determinística, através de instruções lexicais. Para tanto, o autor sugeriu que o núcleo de um

\footnotetext{
${ }^{67}$ É importante salientar que núcleos contendo mais de um traço formal podem ser formados internamente à sintaxe; entretanto, eles não devem ser vistos como primitivos da gramática (KAYNE, 2005; CINQUE; RIZZI, 2010).
} 
objeto sintático como $\{\alpha, \beta\}$ fosse determinado pela entrada lexical cujos traços gramaticais tivessem sido valorados; tal como mencionamos brevemente na seção 2.2. Assim, se $\beta$ satura um traço gramatical de $\alpha$, então $\alpha$ será o núcleo da combinação $\{\alpha, \beta\}$ e o objeto sintático resultante deverá ter a composição $\{\alpha,\{\alpha, \beta\}\}$, tal como ilustrado na representação em (18).

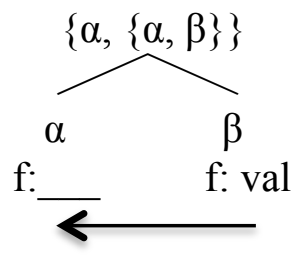

Chomsky (2000, 2001) correlaciona a identificação do núcleo a uma dependência sonda-alvo entre $\alpha$ e $\beta$, a qual é descrita como uma relação de seleção. No entanto, atrelar um mecanismo de seleção/sondagem à operação Merge nos afasta de uma teoria próxima àquela pretendida pela SMT, uma vez que ela enriquece a GU. Além disso, essa solução recorre a uma estratégia lexicalista, em que são os traços formais que guiam a computação sintática. Merge, assim definida, é uma operação complexa, já que se compõe de (i) um mecanismo combinatorial, de (ii) um mecanismo de valoração e de (iii) um mecanismo de rotulação; uma explicação incoerente com as considerações feitas pelo Problema de Wallace-Darwin. ${ }^{68} \mathrm{~A}$ complexidade inerente a essa concepção de Merge fez com que Chomsky (2008, p. 145) removesse seleção/sondagem do sistema computacional. $\mathrm{O}$ autor substituiu esse mecanismo direcional por um algoritmo de rotulação independente do mecanismo combinatorial, o qual operaria de acordo com as especificações em (19):

(19) Algoritmo de rotulação (CHOMSKY, 2008, p. 145, tradução nossa)

a. Em $\{H, \alpha\}, H$ é um item lexical, $H$ é o núcleo.

b. Se $\alpha$ é internamente concatenado a $\beta$, formando $\{\alpha, \beta\}$ então o núcleo de $\beta$ é o núcleo de $\{\alpha, \beta\}$.

A estrutura sintática deixa, então, de ser endocêntrica e passa a ser exocêntrica, uma vez que seu núcleo é determinado por um algoritmo alheio às propriedades lexicais, ou seja, alheio aos traços que constituem os objetos combinados. Essa mudança de perspectiva diminui os aspectos lexicocêntricos da sintaxe. Chomsky (2013a, 2015) radicaliza a hipótese

\footnotetext{
${ }^{68}$ Além disso, a assunção de rótulos em conjuntos fere a Condição de Inclusividade (CHOMSKY, 1995), a qual determina que nenhum elemento além daqueles fornecidos pela Numeração sejam incluídos na derivação sintática (Cf. COLLINS, 2002; SEELY, 2006).
} 
da exocentricidade estrutural ao propor que a identificação do núcleo de um objeto sintático pode ocorrer epifenomenalmente, através de um sistema de busca mínima decorrente de princípios do terceiro fator. De acordo com essa formulação, o núcleo da estrutura sintática é determinado pelo tipo da unidade combinada, não pelo algoritmo em (18). Assim sendo, dada uma combinação $\{\alpha, \alpha \mathrm{P}\}$, a mais comum entre as línguas, $\alpha$ será imediatamente identificado como o núcleo da estrutura, não $\alpha \mathrm{P}$.

Essa última formulação nos fornece um mecanismo combinatorial básico e genérico, fundamental para se chegar a uma explicação adequada para o Problema de Wallace-Darwin. Ao dissociar Merge de valoração, asseguramos uma descrição mínima para a GU/FLN. Notem que a inovação evolutiva passa a ser descrita apenas por um mecanismo combinatorial binário. A endocentricidade dos objetos linguísticos deixa de ser uma propriedade de Merge e passa a ser atribuída a mecanismos de eficiência computacional, que buscam por objetos não sintagmáticos. A operação Merge, como definida em Chomsky (2013a, 2015), torna possível a assunção de que a FL é um desenvolvimento evolutivo recente, visto que o caractere inovador limita-se à implementação de uma capacidade combinatorial irrestrita, a qual opera através da combinação recursiva de unidades discretas em conjuntos. ${ }^{69}$

Portanto, para satisfazer o desideratum 4 acima, assumimos a definição de Merge apresentada em (20), descrita com base nas posições de Chomsky (2013a, 2015). Percebam que essa versão de Merge está dissociada de qualquer influência lexical, seja em termos de desencadeamento para sua aplicação ou em termos de rotulação. A nosso ver, essa operação corresponde ao mecanismo mais simples para se derivar os encaixamentos hierárquicos observados nas palavras e nas sentenças da linguagem humana:

(20) Merge

Dados dois objetos sintáticos $\alpha$ e $\beta$ —atômicos ou derivados a partir de Merge—, forme um conjunto $\{\alpha, \beta\}$.

$$
\mathrm{M}(\alpha, \beta)=\{\alpha, \beta\}
$$

\footnotetext{
${ }^{69}$ A operação Merge, entretanto, aplica-se de duas maneiras no sistema computacional (CHOMSKY, 2000, 2004): como set-Merge, concatenando dois objetos $\alpha$ e $\beta$ em um conjunto $\{\alpha, \beta\}$, e como pair-Merge, em que $\alpha$ e $\beta$ são concatenados na forma de um par ordenado, $<\alpha, \beta>$. Se set-Merge e pair-Merge correspondem a duas operações distintas, sua emergência paralela enfraquece o argumento de que a FL surgiu abruptamente. Se setMerge é uma "mutação" e se a GU reduz-se, simplesmente, à operação Merge somada a princípios do terceiro fator interagindo com as interfaces, é preciso explicar a relação entre set-Merge e pair-Merge. Uma possível alternativa é reduzir pair-Merge a uma notação de conjuntos, tal como demonstrado por Wiener-Kuratowski, em que $<\alpha, \beta>$ equivale a $\{\alpha,\{\alpha, \beta\}\}$ (Cf. LANGENDOEN, 2003; ZWART, 2010). Para se chegar a uma conclusão positiva de que pair-Merge pode ser implementado em termos de conjuntos, é necessário avaliar se os resultados obtidos com conjuntos são os mesmos quando analisados como pares ordenados.
} 
Dado esse conjunto de estratégias para se reduzir a estrutura interna da GU/FLN, não seria esperado sobrecarregá-la com as propriedades do léxico humano, tal como frisamos diversas vezes. O desideratum 5 tem o propósito de impedir tal sobrecarga. Por esse motivo, argumentamos em favor de uma hipótese antilexicalista para a emergência da linguagem humana, juntamente com Fujita (2009, 2017), Ott (2009), Nóbrega e Miyagawa (2015), Boeckx (2010, 2013a, 2015) e Murphy (2016). Ao assumir uma perspectiva antilexicalista, asseguramos a diminuição da influência lexical na explicação dos fenômenos linguísticos e garantimos, ao mesmo tempo, que a sintaxe disponha de autonomia gerativa. Isso se deve ao fato de que o antilexicalismo circunscreve a competência gerativa humana a um único sistema combinatorial, Merge, responsável pela formação de qualquer objeto linguístico, desde palavras a sentenças.

Com isso em mente, podemos dizer que nossa tarefa, de agora em diante, será desenvolver uma teoria sintática a partir da operação Merge, tal como definida em (20). Devemos assegurar, para tanto, que esse mecanismo combinatorial mínimo seja capaz de gerar diferentes tipos de objetos linguísticos, tal como vislumbrado pelo antilexicalismo e pelas abordagens não lexicalistas elencadas acima, e de explicar não somente as propriedades combinatoriais da gramática, como também as circunstâncias que levaram ao surgimento de um léxico consideravelmente amplo, estruturalmente promíscuo, cuja aquisição é ilimitada, e adequado para ser interpretado pelos componentes interpretativos pós-sintaticamente.

\subsection{Resumo}

Neste capítulo, defendemos uma liberdade combinatorial para a sintaxe $a b$ ovo, com o intuito de combater a ideia projecionista de que as propriedades formais da gramática estão predeterminadas em instruções lexicais. Argumentamos que, para se ir "além da adequação explicativa", é preciso repensar a interação entre o léxico e a sintaxe, seja na forma de uma reavaliação dos primitivos da gramática, que ainda carecem de um respaldo biológico, seja no empacotamento arbitrário de informações funcionais em entradas lexicais. Acreditamos que o pouco entendimento das bases biológicas do léxico humano é o que permite um tratamento imprudente para a relação entre o léxico e a sintaxe. Além disso, esse pouco entendimento, atrelado à grande influência que o léxico apresenta na FL, colocam em questão a validade 
explicativa das análises sobre os fenômenos linguísticos, sobre a variação, sobre a aquisição e sobre a emergência da linguagem.

Vimos que a assunção de um léxico altamente estruturado sobrecarrega a GU. Além disso, tal posicionamento impossibilita que as competências exclusivamente humanas da FL sejam, de fato, reduzidas. De um ponto de vista evolutivo, há um grande interesse em se mostrar que os componentes únicos à espécie são mínimos, pois isso tornaria a FL um sistema integrado ao mundo natural e coerente com as teorias sobre o desenvolvimento evolutivo de um organismo. Quanto menores forem as características unicamente humanas da FL, maiores serão as chances de se explicar o surgimento da competência linguística em um indivíduo e na história evolutiva da espécie. As ponderações feitas no âmbito da ontogenia e da filogenia da linguagem nos levam a considerar que as propriedades do léxico humano não são exclusivas à espécie, mas decorrem, presumivelmente, de habilidades exaptadas de outros animais e/ou de outros sistemas cognitivos.

É preciso ter em mente que a caracterização da FL como um órgão biológico nos deixa reféns de uma concepção de sua organização interna que seja coerente com as restrições colocadas pelo Problema de Wallace-Darwin, e que, por essa razão, a explicação de sua estrutura interna está inevitavelmente sujeita a essas restrições. Nesse sentido, qualquer hipótese acerca da emergência do léxico humano deve ser guiada não apenas por princípios teóricos de adequação descritiva e explicativa, como frisou Chomsky (1965), como também por um critério de adequação evolutiva, como salientaram Longobardi (2004) e Fujita (2007, 2009), condizente com o desenvolvimento evolutivo da espécie humana. ${ }^{70}$ Sendo assim, para elaborar uma teoria evolutivamente adequada sobre a GU será preciso "explicar como foi possível que a FL [com destaque para o léxico] tenha emergido durante nossa história evolutiva" (FUJITA, 2009, p. 129). ${ }^{71}$

No próximo capitulo, desenvolvemos o primeiro passo para se chegar a uma teoria da gramática condizente com essas considerações. Com a Abordagem Isomórfica, redefinimos a interação entre o léxico e a sintaxe. Propomos que os traços formais decorrem de um sistema compartilhado com animais não humanos, um sistema funcional. Destacaremos, para tanto, as evidências para se considerar o sistema funcional como um precursor filogenético para as categoriais funcionais da linguagem humana. Veremos que a fixação dos traços formais deriva de um mecanismo cognitivo verificado em outras espécies, em especial, nos sistemas

\footnotetext{
${ }^{70}$ Ver também adequação filogenética, em Richards (2008), e adequação natural, em Boeckx e Uriagereka (2007).

${ }^{71}$ Trecho original: "[...] explains how it was possible for the human faculty of language (HFL) to emerge during our evolutionary history".
} 
de vocalização de alerta de primatas não humanos. Ao estabelecer um paralelo entre os traços formas e o mecanismo subjacente às vocalizações de alerta, poderemos também avaliar as razões que impediram o desenvolvimento lexical de primatas não humanos. 


\section{Capítulo 3}

\section{O sistema funcional}

Uma novidade evolutiva normalmente resulta da reorganização de caracteres preexistentes. A FL, enquanto caractere inovador, não é diferente. Vimos que dois de seus componentes elementares são compartilhados com animais não humanos, os sistemas S-M e C-I. Neste capítulo, argumentamos em favor da exaptação de um terceiro componente, responsável por derivar as unidades discretas empregadas pelo sistema combinatorial, a que damos o nome de sistema funcional (F). Compartilhado com primatas não humanos, o sistema $\mathrm{F}$ justifica-se pelo paralelismo entre a denotação rígida das vocalizações de alerta e o conteúdo fixo das unidades funcionais da linguagem humana. Propomos, com base nessa correlação, que os mecanismos cognitivos subjacentes aos sistemas de vocalização primata, instanciados em nossa perspectiva por $\mathrm{F}$, correspondem aos precursores biológicos dos traços formais.

\subsection{Introdução}

As reformulações dos primitivos da gramática, sobretudo após o advento do PM, não promoveram um avanço das investigações sobre as bases biológicas do léxico humano. $\mathrm{Na}$ realidade, por falta de uma hipótese mais convincente, parte das entradas lexicais —viz., os traços formais e seu agrupamento em feixes - foram relegados à GU (Cf. CHOMSKY, 2000, 2001, 2007). Essa assunção, além de não fornecer uma explicação biológica e cognitivamente fundamentada acerca das origens do léxico, apresenta um impacto negativo quando considerada sob a ótica do Problema de Wallace-Darwin e das expectativas teóricas para se ir “além da adequação explicativa". Isso se deve ao fato de que, ao atribuir os átomos da computação sintática à GU, sobrecarregamos a influência do genótipo humano no desenvolvimento da linguagem, tal como vimos no Capítulo 2. 
Com o objetivo de fornecer uma hipótese sobre a emergência do léxico coerente com as diretrizes para uma sintaxe autônoma e condizente com as considerações colocadas pelo Problema de Wallace-Darwin, sugerimos, neste capítulo, que as bases filogenéticas do léxico humano estão presentes na linhagem primata e, muito possivelmente, são anteriores à separação dos primatas como uma ordem independente. Para firmar essa correlação, comparamos as propriedades do léxico humano com o comportamento vocal e as habilidades perceptuais de primatas não humanos, cujas relações filogenéticas com a espécie humana são bem estabelecidas. Através do exame de registros disponíveis em observações naturalísticas e em trabalhos experimentais desenvolvidos pela primatologia, inferimos a presença de precursores evolutivos para as entradas lexicais, mais especificamente, para os mecanismos cognitivos encarregados de fixar os traços formais.

Verificamos que, contrariamente ao que assumem trabalhos em teoria linguística e em comunicação animal, a correlação referencial entre as vocalizações de alerta e as palavras da linguagem humana não reside em sua porção conceitual, mas em sua porção funcional. ${ }^{72} \mathrm{~A}$ denotação rígida das vocalizações de alerta assemelha-se à natureza semanticamente fixa das unidades funcionais da linguagem humana, tendo em vista que ambas não estão sujeitas à variação de conteúdo. Tal característica é diametralmente oposta ao que observa nas unidades detentoras de conteúdo conceitual — viz., as raízes—, as quais são definidas por sua natureza altamente polissêmica. Defendemos, nesse sentido, que primatas não humanos e humanos são dotados de um sistema $\mathrm{F}$ responsável por extrair do mundo informações sobre um conjunto predeterminado de categorias, o qual é privilegiado para externalização.

Em outras palavras, o sistema $\mathrm{F}$ é composto por categorias pré-adaptadas, específicas da espécie, que um organismo está geneticamente predisposto a categorizar. Tal assunção parte do pressuposto de que a biologia de um indivíduo determina aquilo que pode compor sua experiência (Cf. CHOMSKY, 1966, 1975; GOULD; MARLER, 1987; GALLISTEL, 2010; EPSTEIN, 2016). Desse modo, o sistema F compreende os aspectos do mundo a serem necessariamente categorizados por uma espécie e convertidos em conhecimento. Enquanto em primatas não humanos essas categorias correspondem a classes de predadores, distúrbios, alimentos e relações sociais, na linguagem humana, elas dizem respeito aos atributos que derivam os traços formais, tais como classificação categorial, quantidade, espaço, vinculação

\footnotetext{
${ }^{72}$ Seguindo Schlenker et al. (2016, p. 5), empregamos o termo "vocalização de alerta" em um sentido amplo, referindo-nos não apenas a vocalizações atreladas a um contexto predatório, tal como é o caso das "vocalizações de alarme", mas também a vocalizações para movimento de grupo, alimentos, urgência, relações sociais (e.g., encontro intergrupal, conciliação entre indivíduos) e a vocalizações utilizadas como alertas gerais (e.g., queda de árvores, distúrbio não especifico nas imediações).
} 
discursiva, entre outros. Admitimos que o caráter predeterminado dessas categorias é o que promove a uniformidade dos domínios funcionais observados entre as línguas.

Para desenvolver a hipótese acima, organizamos o capítulo do seguinte modo: na seção 3.2, discutimos o caráter referencial das vocalizações de alerta. Na seção 3.3, caracterizamos o mecanismo cognitivo subjacente às vocalizações e o modo pelo qual ele figura como a base filogenética do léxico funcional humano. Apresentamos evidências para a natureza inata e referencialmente rígida das representações subjacentes a esses sinais vocais e comparamos tais características com as propriedades dos primitivos lexicais, raízes e traços formais. É a partir dessa analogia que propomos o sistema F. Em seguida, apontamos os motivos que teriam impulsionado a seleção desse sistema. Por fim, na seção 3.4, elencamos os fatores biológicos que possivelmente limitam a ampliação do repertório vocal primata de um ponto de vista ontogenético.

\subsection{A referencialidade funcional do repertório vocal primata}

Darwin $(1859,1871)$ argumentava que o curso da evolução poderia ser mapeado através do contraste entre caracteres semelhantes em espécies filogeneticamente relacionadas, o chamado "método comparativo". Caracteres semelhantes podem ser contrastados através da comparação entre suas características comuns, entre suas diferenças e entre suas possíveis ramificações. Quando o caractere sob investigação é a FL, procuramos intuitivamente estabelecer uma correlação entre as propriedades de seus componentes elementares e os aspectos funcionais dos sistemas de vocalização de alerta de primatas não humanos, nossos ancestrais vivos mais próximos. Isso se deve ao fato de que a espécie humana, bem como diversas espécies de primatas não humanos, fazem uso de recursos vocais como uma de suas principais estratégias comunicativas.

Sistemas de vocalização de alerta são empregados pela grande maioria dos primatas não humanos, tendo sido verificados não apenas em primatas antropoides —e.g., em monos e em macacos do Velho e do Novo mundo- (Cf. ZUBERBÜHLER, 2003, 2009; CÄSAR; ZUBERBÜHLER, 2012), bem como em prossímios - e.g., lêmures- (Cf. MACEDONIA, 1990; ODA, 2008). ${ }^{73}$ Como apontam Fedurek e Slocombe (2011, p. 154), muitas espécies de primatas não humanos vivem em ambientes arbóreos de baixa visibilidade e seus

\footnotetext{
${ }^{73} \mathrm{O}$ termo "mono" refere-se aos grandes símios. Quando necessário, empregaremos a expressão "pequenos monos" para gibões, e a expressão "grandes monos" para gorilas, chimpanzés e bonobos.
} 
coespecíficos ficam geralmente separados enquanto viajam ou forrageiam. ${ }^{74}$ As vocalizações de alerta servem, nesse contexto, como um meio ideal para a transmissão de informações. Ao analisá-las acusticamente, em paralelo com as circunstâncias em que são eliciadas, é possível elaborar hipóteses acerca do conteúdo veiculado por cada sinal vocal.

Entre os trabalhos naturalísticos e experimentais mais conhecidos sobre o repertório vocal primata estão aqueles que exploraram as vocalizações antipredatórias. Destaca-se o sistema de vocalizações de alarme dos macacos-vervet do leste africano (Chlorocebus pygerythrus; anteriormente Cercopithecus aethiops), cujos primeiros estudos impulsionaram as investigações sobre o comportamento vocal primata e sobre sua natureza referencial. A depreensão de propriedades referenciais nos sinais vocais empregados por populações selvagens de macacos-vervet foi o que promoveu uma primeira aproximação entre as habilidades referenciais das palavras e o conteúdo sugestivamente simbólico atrelado a cada vocalização (Cf. MARLER; EVANS; HAUSER, 1992; SEYFARTH; CHENEY, 1993, 1997, 2003; EVANS; MARLER, 1995; HAUSER, 1996, entre outros).

Descrito, inicialmente, por Struhsaker (1967), esse sistema de vocalizações de alarme constitui-se basicamente de três sinais vocais acusticamente distintos, cada qual produzido em resposta a uma determinada classe de predadores, a saber: um sinal vocal que indica a presença de leopardos (Panthera pardus), um que indica a presença de águias-belicosas (Polemaetus bellicosus) e um que indica a presença de pítons africanas (Python sebae). No restante deste capítulo, iremos nos referir a esses sinais vocais como vocalização para leopardos, vocalização para águias e vocalização para cobras, respectivamente. Cada uma dessas vocalizações está representada nos espectrogramas que compõem a Figura $2:^{75}$

\footnotetext{
74 "Forragear" corresponde às atividades relacionadas à busca de alimentos, as quais lançam mão de estratégias específicas atreladas à espécie e ao seu espaço ecológico.

${ }^{75}$ Como apontam Seyfarth, Cheney e Marler (1980a, p. 210), “as características acústicas dessas vocalizações são tais que elas poderiam ser atribuídas inequivocamente para um tipo [de predador], tanto por espectrografia sonora no laboratório quanto de ouvido em campo" [The acoustical features of the calls were such that they could be assigned unambiguously to one type, both by sound spectography in the laboratory and by ear in the field]. Seyfarth, Cheney e Marler (1980b, p. 1073) mencionam também que essas vocalizações são totalmente arbitrárias, ou seja, elas não constituem uma imitação onomatopaica das vocalizações do predador.
} 
Figura 2. Espectrogramas das vocalizações de alarme de macacos-vervet (Chlorocebus pygerythrus) em resposta às suas três principais classes de predadores, notadamente: leopardos, águias e cobras.

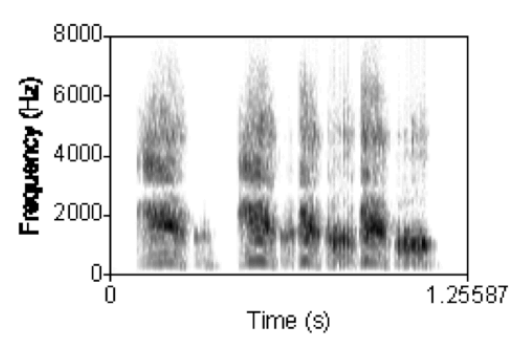

Vocalização para leopardos

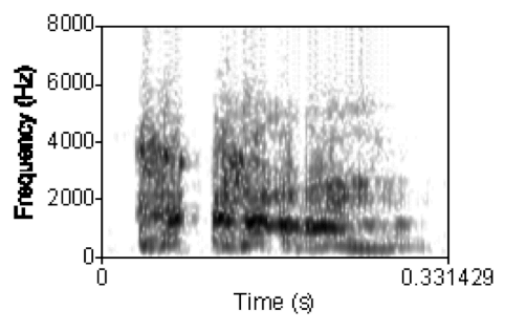

Vocalização para águias

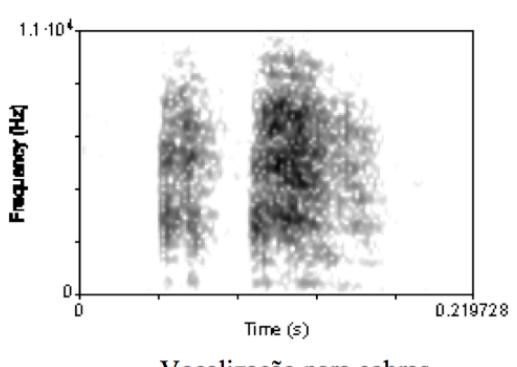

Vocalização para cobras

Fonte: http://web.sas.upenn.edu/seyfarth/vocalizations/vervet-monkey-vocalizations/.

As correlações estabelecidas entre um sinal vocal e uma dada classe de predadores foram inferidas através da observação das estratégias de fuga empreendidas pelo bando. Struhsaker (1967) notou que a vocalização para leopardos fazia com que o bando subisse em uma árvore e se escondesse em sua copa. A vocalização para águias, por sua vez, fazia com que o bando olhasse para cima, descesse da árvore ou se escondesse em galhos de vegetação densa. Já a vocalização para cobras fazia com que muitos ficassem em pé e passassem a olhar cuidadosamente para a área que o circundava. A título de ilustração, cada uma dessas táticas antipredatórias está caracterizada na Figura 3, em que há um macaco-vervet, uma classe de predadores e a reação adaptativa correspondente: 
Figura 3. Representações das táticas antipredatórias dos macacos-vervet.

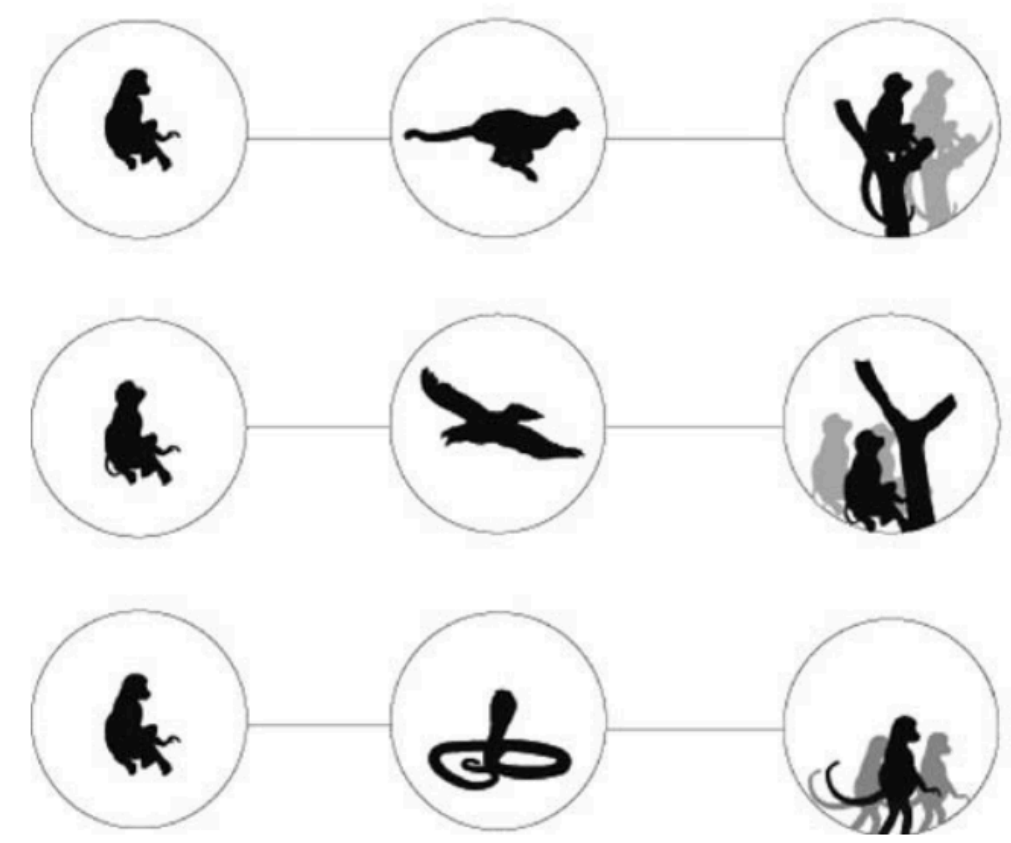

Fonte: Queiróz e El-Hani (2006, p. 187).

Em decorrência do caráter inferencial das interpretações atribuídas ao comportamento vocal primata, há uma série de controvérsias envolvendo o conteúdo manifestado pelas vocalizações. Marler (1980) foi um dos primeiros a reacender o debate sobre as motivações que subjazem à produção vocal primata e sobre a qualidade das informações veiculadas a seus coespecíficos. O principal impasse está em determinar se as vocalizações de alarme -e, em um sentido amplo, as vocalizações de alerta - correspondem à expressão dos estados emocionais do sinalizador, tal como sugeriu Darwin (1872), ou se elas estariam associadas a um componente simbólico, expressando referentes específicos no mundo. O autor descreve essas duas hipóteses do seguinte modo:

(21) Conteúdo informacional associado às vocalizações de alarme

a. Hipótese \#1: Vocalizações são afetivas (i.e., expressam excitação)

As vocalizações seriam um reflexo do estado interno do animal, como uma expressão de seu grau de excitação;

b. Hipótese \#2: Vocalizações são simbólicas (i.e., expressam um referente) As vocalizações estariam relacionadas a fenômenos externos, em virtude de uma motivação referencial. Elas serviriam para designar referentes específicos. 
De acordo com a hipótese em (21a), cada vocalização denota um grau de afetação do sinalizador em relação ao risco apresentado pelo predador. As vocalizações de alarme indicariam, nesse sentido, a urgência de uma estratégia antipredatória. Por exemplo, uma vocalização poderia apontar que há tempo suficiente para recolher informações sobre o tipo, a localização e o comportamento do predador antes de se recorrer a um plano de fuga, ao passo que outra vocalização poderia indicar a necessidade de uma resposta imediata. A hipótese em (21b), por sua vez, admite que o sinalizador denota, através de cada vocalização, uma classe distinta de predadores. De acordo com essa alternativa, as vocalizações de alarme designam um conjunto particular de entidades ou de eventos no mundo e, por essa razão, devem ser analisadas como sinais referenciais.

As primeiras avaliações acústicas feitas por Struhsaker (1967) não foram suficientes para determinar qual das duas hipóteses listadas acima melhor define o conteúdo informacional das vocalizações de alarme. Para esclarecer esse impasse, Seyfarth, Cheney e Marler (1980a, 1980b) desenvolveram novos trabalhos experimentais com populações selvagens de macacos-vervet, avaliando as ações do bando que se sucediam à produção de uma dada resposta vocal. Em seus experimentos, havia um detalhe fundamental: os autores reproduziram para o grupo gravações de vocalizações de seus coespecíficos sem qualquer pista ou distúrbio que pudesse suscitar um contexto predatório nas imediações. Como resultado, eles verificaram que as vocalizações de alarme por si só são suficientes para provocar reações adaptativas específicas, tal como ilustrado na Figura 3.

As descobertas de Seyfarth, Cheney e Marler (1980a, 1980b) foram interpretadas como uma evidência em favor da hipótese em (21b), pois, dada a ausência de um contexto predatório, não seria possível afirmar que diferentes graus de excitação estariam em jogo na escolha de uma determinada estratégia de fuga. Logo, o sistema de vocalizações dos macacosvervet deveria operar de modo referencial e cada uma de suas vocalizações deveria estar atrelada a um conteúdo semântico distinto, já que desencadeiam diferentes efeitos nos receptores. Embora tenha havido variação nas reações comportamentais do bando, a correlação entre um estímulo vocal e uma classe de predadores foi estatisticamente significativa (SEYFARTH; CHENEY; MARLER, 1980a, p. 210). ${ }^{76}$ Tais resultados levaram

\footnotetext{
${ }^{76}$ Esses resultados não excluem, entretanto, a existência de sistemas de vocalização de alarme cujo conteúdo é expressar urgência, ou seja, sistemas compostos por vocalizações que distinguem situações de alto e baixo risco, tal como é o caso dos roedores (WHELLER; FISCHER, 2012, p. 195). O que eles nos mostram é que as vocalizações de alarme de primatas não humanos apresentam um conteúdo sugestivamente referencial. É possível encontrar ainda espécies dotadas de um sistema vocal cujas vocalizações denotam ao mesmo tempo
} 
os autores a concluir que "[...] as vocalizações de alarme dos macacos-vervet designam referentes externos particulares" (1980b, p. 1090). ${ }^{77 / 78}$

Entretanto, mesmo após essa descoberta, a atribuição de habilidades referenciais a primatas não humanos permaneceu controversa. Owren e Rendall (1997, 2001), por exemplo, insistem na hipótese em (21a). Os autores defendem que as vocalizações de alarme não contêm necessariamente um componente referencial. Eles argumentam que primatas não humanos produzem esses sinais vocais com o intuito de extrair respostas afetivas de seus coespecíficos, fazendo com que eles alterem seu comportamento. Em sua perspectiva, "certas propriedades acústicas das vocalizações podem ser utilizadas para induzir uma resposta do sistema nervoso dos receptores" (2001, p. 61). ${ }^{79}$ As reações adaptativas observadas seriam, de acordo com esse raciocínio, um reflexo da estrutura acústica do sinal vocal. Para Owren e Rendall (1997, 2001), a afetação emocional do animal age como a principal variável mediando estímulo vocal e comportamento.

Contrariamente à conjectura desses autores, Zuberbühler, Cheney e Seyfarth (1999) revelam, em um trabalho experimental com macacos diana (Cercopithecus diana diana), que o comportamento antipredatório de primatas não humanos não é regido pelas propriedades acústicas do estímulo vocal, mas por uma representação mental das classes de predadores a que esses estímulos se associam. Os macacos diana, semelhantemente aos macacos-vervet, produzem vocalizações de alarme acusticamente distintas para, pelo menos, dois grupos de predadores, águias-coroadas (Stephanoaetus coronatus) e leopardos (Panthera pardus). Além disso, essa espécie apresenta uma característica comportamental particular: toda vez que um macho adulto produz uma vocalização de alarme, as fêmeas respondem, em seguida, com uma vocalização sexualmente dimórfica -i.e., acusticamente distinta da vocalização dos machos - correspondente à mesma classe de predadores.

Na Figura 4, abaixo, é possível observar as vocalizações produzidas pelos machos, na primeira fileira, e as vocalizações produzidas pelas fêmeas, na segunda fileira, para cada uma das classes de predadores.

um referente e a urgência para se tomar uma decisão, tal como é o caso dos suricates (SEYFARTH; CHENEY, 2003, p. 150).

${ }^{77}$ Trecho original: "[...] it seems appropriate to conclude that the alarm calls of vervet monkeys designate particular external referents".

${ }^{78}$ Price et al. (2015) reanalisaram a produção vocal de macacos-vervet, incluindo os materiais coletados por Struhsaker, Seyfarth e Cheney. Os autores observaram que, quando considerados apenas os contextos predatórios, as fêmeas produziram vocalizações de alerta esperadas para o tipo do predador em $98.7 \%$ dos casos, enquanto os machos produziram em $93.2 \%$ dos casos.

${ }^{79}$ Trecho original: "[...] particular acoustic properties of vocalizations can be used to induce nervous-system responses in receivers". 
Figura 4. Espectrogramas das vocalizações de alarme de macacos diana (Cercopithecus diana diana) machos e fêmeas em resposta às suas duas principais classes de predadores, águias e leopardos.

To Crowned Eagle

Males
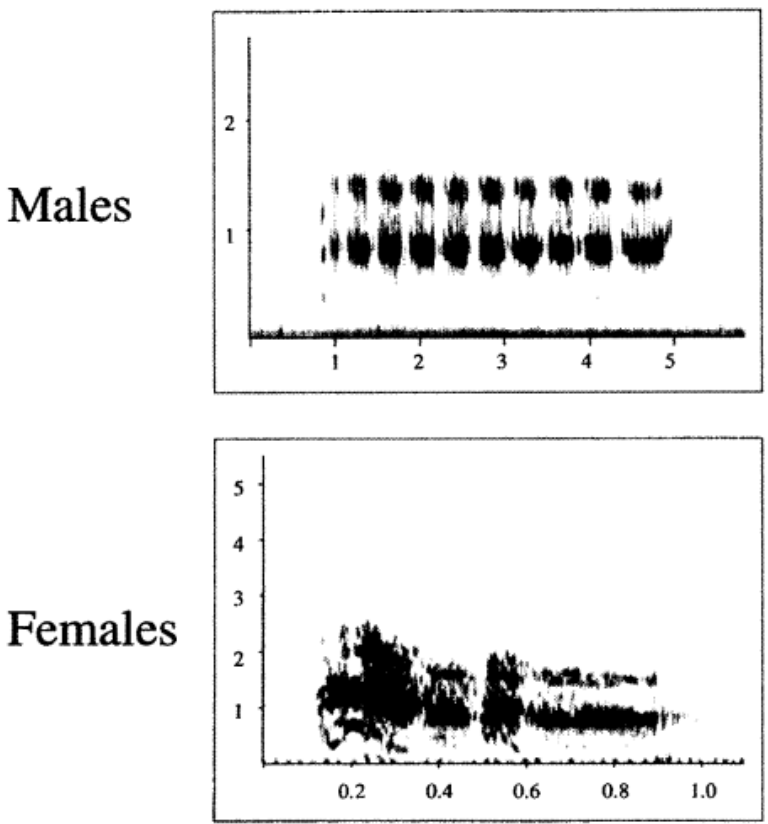

Time (s)
To Leopard

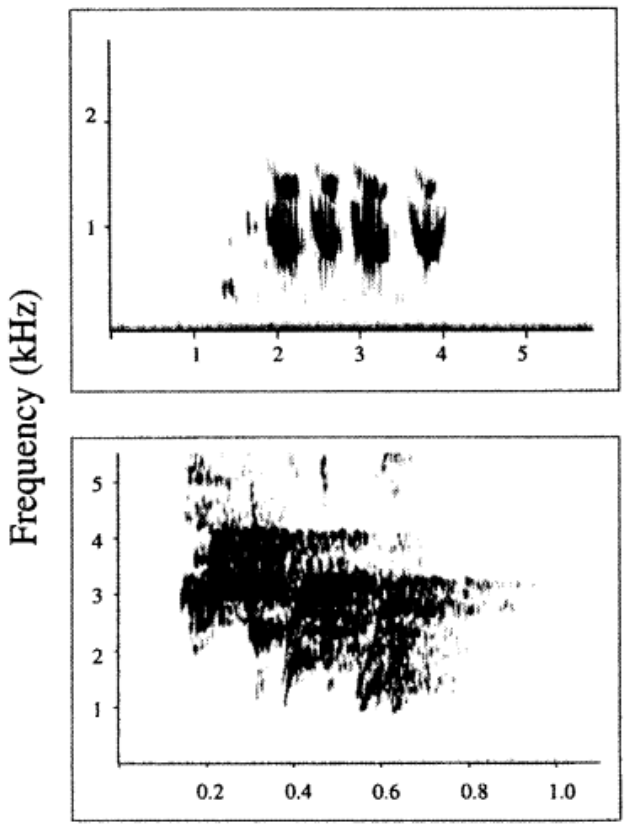

Time (s)

Fonte: Zuberbühler, Cheney e Seyfarth (1999, p. 34).

Fazendo uso de um experimento elaborado com base em técnicas de habituaçãodesabituação - i.e., técnicas em que se mede o grau de afetação dos indivíduos com relação a um determinado estímulo sensorial—, os autores avaliaram a natureza do fator responsável por incitar a resposta vocal das fêmeas. Mais especificamente, Zuberbühler, Cheney e Seyfarth (1999) investigaram se (i) as fêmeas de macacos diana respondem às vocalizações produzidas pelos machos ao acessar uma representação mental do predador ou se (ii) as fêmeas respondem a essas vocalizações como um ato reflexo de suas características acústicas, tal como conjecturaram Owren e Rendall $(1997,2001)$.

Para testar essas duas hipóteses, os autores analisaram o comportamento vocal das fêmeas em diferentes contextos predatórios. Seu experimento foi estruturado do seguinte modo: quatro tipos de estímulos vocais foram apresentados às fêmeas, a saber, rosnados de leopardos, guinchos de águias, vocalizações para leopardos produzidas pelos machos e vocalizações para águias produzidas pelos machos. Gravações desses quatro estímulos foram reproduzidas em três contextos. Em cada contexto, um grupo de fêmeas ouvia dois estímulos 
em sequência, um estímulo inicial e um estímulo de sondagem, separados por um intervalo de cinco segundos de silêncio. Esses contextos continham diferentes arranjos de estímulos, cada qual com um conjunto de expectativas relacionadas às duas hipóteses acima.

Em (22), descrevemos os três contextos de avaliação e as expectativas com relação a essas duas hipóteses:

(22) Contextos e expectativas para o experimento (ZUBERBÜHLER; CHENEY; SEYFARTH, 1999, p. 35)

a. Condição de base. As fêmeas eram expostas à vocalização de um predador (e.g., o rosnado de um leopardo ou o guincho de uma águia) e, em seguida, a gravação com a vocalização desse mesmo predador era reproduzida. Uma vez que esses dois estímulos apresentam características acústicas e semânticas idênticas, seria esperado um efeito de habituação, isto é, as fêmeas deveriam responder intensamente ao estímulo acústico inicial (i.e., produzindo muitas vocalizações) e responder em menor intensidade ao estímulo de sondagem (i.e., produzindo menos vocalizações).

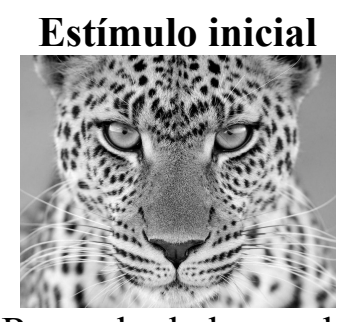

Rosnado de leopardo

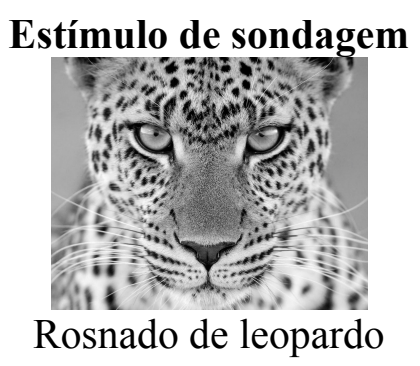

Estímulo de sondagem

Rosnado de leopardo

b. Condição de teste. As fêmeas ouviam primeiramente a vocalização de alarme produzida por um macho e, em seguida, ouviam a vocalização do predador correspondente àquele alarme. Uma vez que as características semânticas dos dois estímulos são idênticas, mas não suas características acústicas, seria esperado que as fêmeas respondessem intensamente ao estímulo inicial e, por sua vez, (a) respondessem intensamente ao estímulo de sondagem, caso fossem guiadas pelas características acústicas da vocalização, ou (b) respondessem em menor intensidade, caso fossem guiadas pelas características semânticas do predador. 

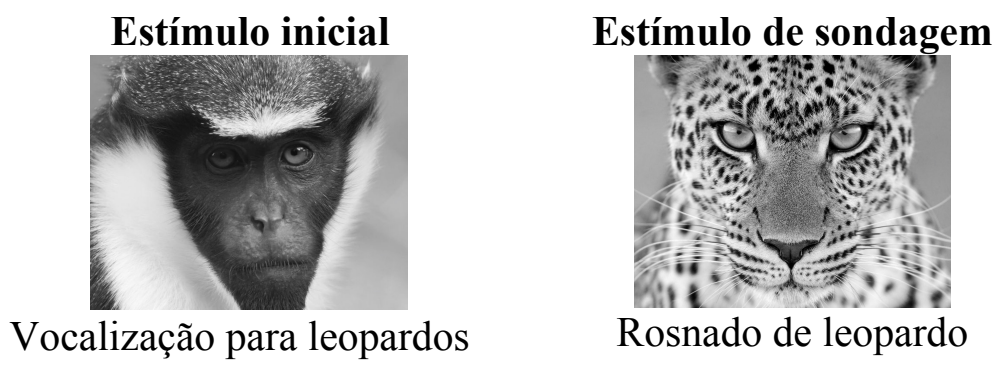

c. Condição de controle. As fêmeas eram expostas à vocalização de alarme de um macho para um dado predador e, em seguida, ouviam a vocalização de um predador distinto (e.g., vocalização para águias produzida pelo macho seguida de um rosnado de leopardo). Uma vez que tanto as características acústicas quanto as características semânticas dos estímulos são distintas, seria esperado que as fêmeas respondessem intensamente nos dois contextos de exposição.
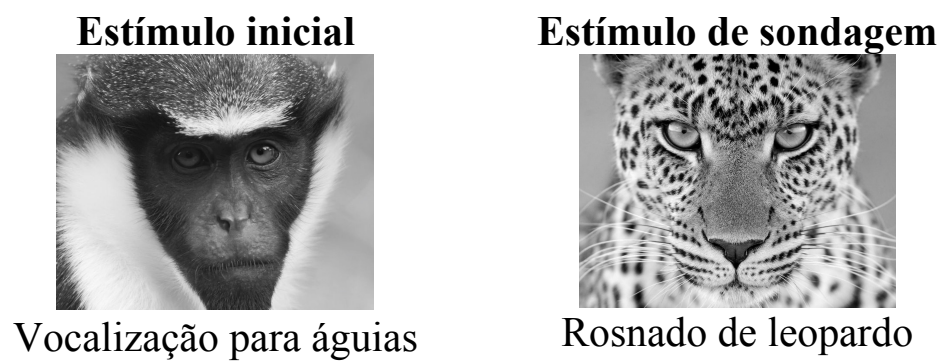

Os resultados obtidos foram os seguintes. Para a condição de base, descrita em (22a), verificou-se o esperado, as fêmeas produziram respostas vocais intensas no estímulo inicial e respostas vocais amenas no estímulo de sondagem, já que as características acústicas e semânticas mantiveram-se constantes. Na condição de teste, a de maior interesse, observou-se que as fêmeas produziram respostas vocais intensas no estímulo inicial e responderam em menor intensidade no estímulo de sondagem, privilegiando a expectativa (b), detalhada em (22b). O efeito de habituação reportado na condição de teste nos indica que o fator responsável por eliciar uma resposta menos intensa das fêmeas foram as características semânticas do estímulo inicial e não suas características acústicas, contrariamente ao que propuseram Owren e Rendall (1997, 2001).

Com base nos resultados obtidos na condição de teste, a hipótese (ii) é favorecida, pois os rosnados de leopardos e os guinchos de águias perdem a eficácia de provocar uma resposta vocal das fêmeas nos contextos em que elas foram expostas a vocalizações de alarme correspondentes a esses predadores. Zuberbühler, Cheney e Seyfarth (1999, p. 40) comentam que as fêmeas interpretam as vocalizações dos machos como uma evidência para a presença 
do predador e, por essa razão, não ficam surpresas ao ouvir as vocalizações reais do predador posteriormente. Dito de outro modo, as fêmeas interpretam a vocalização do predador como uma informação redundante. Finalmente, na condição de controle, em (22c), averiguou-se as expectativas iniciais: respostas vocais intensas para os dois estímulos, uma vez que ambos diferem semântica e acusticamente. ${ }^{80}$

Esses resultados nos indicam que a percepção vocal primata não está restrita às propriedades acústicas de uma vocalização. Na verdade, o que se nota com esse experimento é o oposto: a percepção vocal primata está intimamente associada a uma avaliação conceitual de uma determinada situação predatória; uma conclusão que endossa a hipótese em (21b). É possível conjecturar ainda que a produção vocal primata também resulta do acesso a uma representação conceitual, já que as fêmeas de macacos diana avaliam os estímulos vocais dos machos com base em um critério de redundância antes de insistir em suas repostas vocais. Em resumo, podemos dizer que os macacos diana associam uma mesma representação conceitual a sinais vocais acusticamente distintos, sejam eles produzidos por seus coespecíficos ou pelos próprios predadores. $^{81}$

Uma explicação parcimoniosa para o comportamento vocal primata, tendo em vista essas circunstâncias, deve partir do pressuposto de que as vocalizações de alarme transmitem informações aos receptores e que as reações adaptativas observadas são desencadeadas por essas informações. Parece ser razoável admitir que primatas não humanos são capazes de representar mentalmente classes de entidades, eventos e situações a partir da exposição a um dado estímulo vocal, o que nos sugere que seus sistemas de vocalização estão ancorados em um componente referencial. Obviamente, as representações mentais de primatas não humanos não se equiparam às representações mentais humanas; porém, sua capacidade de abstração e, em certo sentido, de referencialidade são um indicativo de que os precursores evolutivos da competência semântica e, como veremos, de parte da competência lexical, derivam dessas representações mentais não humanas pré-adaptadas e pré-linguísticas. ${ }^{82}$

\footnotetext{
${ }^{80}$ Zuberbühler, Cheney e Seyfarth $(1999$, p. 40) comentam ainda que não é possível descrever as vocalizações de alarme como "perigo vindo de cima" ou "perigo vindo de baixo", como sugeriu posteriormente Bickerton (2007, 2009), já que nas florestas tropicais do oeste africano, habitat desses primatas, águias podem ser encontradas no chão e leopardos podem ser encontrados no dossel superior da floresta (i.e., em áreas mais altas que as do bando).

${ }^{81}$ Esse experimento também foi aplicado em macacos de Campbell (Cercopithecus campbelli), espécie que apresenta o mesmo comportamento vocal dos macacos diana (ZUBERBÜHLER, 2001, 2003). Os resultados obtidos são paralelos aos que Zuberbühler, Cheney e Seyfarth (1999) obtiveram.

${ }^{82}$ Essas conclusões estão presentes também nos trabalhos de Cheney e Seyfarth (1990a), Hauser (2001), Spelke (2003), Carruthers (2006), Hurford (2007, 2012), Carey (2009) e Emonds (2011).
} 
Nesta tese, compartilhamos essa assunção. Assumimos que os sistemas de vocalização de alarme estão atrelados a um componente referencial —a ser melhor caracterizado-, o qual permite que primatas não humanos denotem um conjunto limitado de entidades e eventos no mundo. Isso não implica necessariamente que a produção vocal primata envolve um ato voluntário ou que os sinalizadores ajam com o intuito de influenciar os estados mentais e o comportamento de seus coespecíficos (CHENEY; SEYFARTH, 1990b, 2000; SEYFARTH; CHENEY, 1993, 2003; FITCH; ZUBERBÜHLER, 2013). A transmissão de informações em primatas parece decorrer de um processo epifenomenal, não comunicativo e que se estabelece de maneira indireta. ${ }^{83}$ Como apontam Seyfarth e Cheney (2003, p. 148), "a seleção natural parece ter favorecido receptores capazes de extrair informações e sinalizadores cujo comportamento facilitasse a extração de informações pelos receptores". ${ }^{84}$

Embora partilhemos da hipótese de que primatas não humanos sejam dotados de um componente referencial, não assumimos que tal componente corresponda aos precursores evolutivos das habilidades referenciais atreladas à porção conceitual das palavras. ${ }^{85} \mathrm{Na}$ realidade, entendemos que as vocalizações de alarme operam como se fossem referenciais, seguindo o conceito de "referencialidade funcional" proposto por Macedonia e Evans (1993). Tal assunção atenua os aspectos linguísticos associados ao termo "referência" e o caráter deliberado da produção vocal primata. Em linhas gerais, interpretamos o componente referencial dos sistemas de vocalização de alarme como um mecanismo de mapeamento restrito e unidirecional entre uma categoria referencial predeterminada geneticamente -

\footnotetext{
${ }^{83}$ Quando consideramos o comportamento vocal primata, percebemos que o significado e a função de seus sinais vocais não são os mesmos para os sinalizadores e para os receptores (Cf. MARLER, 1961; MARLER; HAUSER; EVANS, 1992; MACEDONIA; EVANS, 1993; SEYFARTH; CHENEY, 2003; FITCH; ZUBERBÜHLER, 2013, entre outros). A produção vocal - i.e., a perspectiva do sinalizador- ainda suscita questionamentos, como quais são as motivações que levam um primata a produzir uma vocalização e se essas motivações carregam alguma intenção informativa, decorrente de uma Teoria da Mente, isto é, de uma habilidade para atribuir estados mentais (e.g., pensamentos, desejos, crenças, conhecimento, etc.) a outros indivíduos (Cf. PREMACK; WOODRUFF, 1978). Trabalhos experimentais nos mostram que macacos, de modo geral, não agem com o intuito de alterar o conhecimento de seus coespecíficos (Cf. CHENEY; SEYFARTH, 1990b, 2005; SEYFARTH; CHENEY, 1993, 2003). Grandes monos, em especial, chimpanzés, apresentam sugestivamente rudimentos dessa habilidade (Cf. CROCKFORD et al., 2012; SCHEL et al. 2013). É por essa razão que apontamos que a transmissão de informações opera de forma indireta em primatas não humanos. Nesse sentido, o componente referencial sob investigação é inferido, fundamentalmente, a partir das observações feitas acerca da percepção vocal primata -i.e., da perspectiva do receptor-, a qual nos indica que as vocalizações de alarme são interpretadas como uma expressão informativa e funcionalmente referencial.

${ }^{84}$ Trecho original: " [...] selection appears to have favored recipientes who are skilled in extracting information and signalers whose behavior makes it easy for them to do so".

${ }^{85}$ Uma posição semelhante é assumida por autores que discutem a emergência da linguagem humana a partir de uma perspectiva gradualista, em especial, o gradualismo lexical, tais como Bickerton (2007) e Tallerman (2012, 2017). Opostamente a essa assunção, alguns adeptos do gradualismo holístico, como Wray $(1998,2000$, 2001) e Mithen $(2005,2009)$, defendem que as palavras da linguagem humana resultam de modificações graduais aplicadas aos sistemas de vocalização primata. Como veremos mais adiante, essas expectativas não são comprovadas empiricamente, tendo em vista as diferenças funcionais e de mapeamento entre as vocalizações de alarme e a porção conceitual do léxico humano.
} 
certamente selecionada for pressões adaptativas (ZUBERBÜHLHER, 2003, 2009)—, e uma classe específica de entidades ou de eventos no mundo.

Em contrapartida, propomos que as habilidades referenciais associadas à porção conceitual do léxico humano decorrem de competências perceptuais instauradas pelo sistema C-I e do modo como esse sistema passou a interagir com o componente sintático -e, de maneira indireta, com o sistema S-M - após a reorganização mental que deu origem à FL. Como veremos na seção 3.4, a percepção primata é extremamente rica, o que nos sugere que primatas não humanos extraem uma vasta quantidade de informações do mundo (CHENEY; SEYFARTH, 1990a, 2005, 2007; SPELKE, 2000, 2003; CARRUTHERS, 2006; HURFORD, 2007, 2012; BURGE, 2010; EMONDS, 2011). No entanto, embora esses sujeitos sejam capazes de depreender diferentes tipos de informações, possivelmente traduzidas em termos de representações conceituais, eles não são capazes de manipulá-las e de externalizá-las.

Admitindo que tal capacidade perceptual seja compartilhada pela espécie humana, ${ }^{86}$ argumentamos que, diferentemente de primatas não humanos, humanos modernos são capazes de manipular representações conceituais na forma de entidades linguísticas. Nesse sentido, conjecturamos que as propriedades referenciais das entradas lexicais emergiram quando as representações conceituais extraídas da percepção — dissociadas das categorias pré-adaptadas das vocalizações de alarme- , tornaram-se entidades linguísticas através da integração entre o sistema C-I e o componente sintático. Uma vez lexicalizadas, ou seja, uma vez atomizadas em objetos linguísticos, essas representações conceituais passaram, então, a ser empregadas referencialmente pelo sistema S-M; o que, como consequência, provocou uma ampliação do inventário lexical humano.

Para diagnosticar quais sistemas de vocalização de alerta estão ancorados em um componente funcionalmente referencial, empregamos os critérios estipulados por Macedonia e Evans (1993), descritos em (23):

\footnotetext{
${ }^{86}$ Tal assunção foi primeiramente sugerida por Hauser, Chomsky e Fitch (2002, p. 1573), quando os autores discutiram a aquisição de representações conceituais não linguísticas por primatas não humanos. Dentre os exemplos explorados, os autores mencionam os trabalhos experimentais com macacos rhesus (Macaca mulata) envolvendo a depreensão dos conceitos como objeto e tipo (Cf. SHETTLEWORTH, 1998; HEYES, HUBER, 2000).
} 
(23) Referência funcional (MACEDONIA; EVANS, 1993, p. 179-180)

Um sinal vocal é funcionalmente referencial se e somente se:

a. Critério da produção: Exibe certo grau de especificidade a um determinado contexto;

b. Critério da percepção: Elicia respostas comportamentais dos receptores independentemente de um contexto predatório.

O critério da produção, em (23a), está atrelado à perspectiva do sinalizador. Ele determina que as vocalizações devem ser acusticamente distintas e que os estímulos associados à sua produção devem pertencer a uma categoria de entidades ou de eventos uniforme. A expectativa com relação a esse critério é que as vocalizações não sejam produzidas em taxas consideráveis em contextos inapropriados (e.g., na ausência de um predador). ${ }^{87} \mathrm{O}$ critério da percepção, em (23b), está atrelado à perspectiva do receptor. Esse critério demanda que a resposta adaptativa seja provocada independentemente do contexto em que o indivíduo está inserido, tal como vimos na descrição do experimento de Seyfarth, Cheney e Marler (1980a, 1980b). Isso significa que uma vocalização por si só deve ser suficiente para evocar uma reação comportamental apropriada no receptor.

A avaliação de diferentes sistemas vocais com base nos critérios em (23) possibilitou que sinais funcionalmente referenciais fossem atestados em outras espécies de primatas não humanos, incluindo antropoides e prossímios (Cf. ZUBERBÜHLER; NÖE; SEYFARTH, 1997; ZUBERBÜHLER, 2001; ARNOLD; ZUBERBÜHLER， 2006a; KIRCHHOF; HAMMERSCHIMIDT, 2006; OUATTARA; LEMASSON; ZUBERBÜHLER, 2009a, entre outros), bem como em roedores e aves (Cf. WHEELER; FISCHER, 2012; TOWNSEND; MANSER, 2013). Além disso, é importante mencionar que as vocalizações de alerta também satisfazem os critérios em (23) e, por essa razão, devem ser vistas como funcionalmente referenciais (Cf. DI BITETTI, 2003; SLOCOMBE et al, 2010; FEDUREK; SLOCOMBE,

\footnotetext{
${ }^{87}$ Wheeler e Fischer (2012), Fischer e Price (2016) e Fischer (2017) apresentam diversas críticas com relação à noção de "referencialidade funcional". Sua principal discordância está na plausibilidade do critério da produção. Eles argumentam que algumas vocalizações parecem se sobrepor a mais de um contexto, o que colocaria em jogo a validade da especificidade contextual. Por exemplo, Price et al. (2015, p. 2), ao revisar os contextos que eliciam as vocalizações de macacos-vervet, notam que a vocalização para cobras também é produzida quando há agressão intergrupal. O mesmo se observa com a vocalização para águias, a qual é produzida quando há agressão intragrupal. A distinção feita pelas populações selvagens de macacos-vervet decai minimamente quando são contrastados esses dois contextos. Porém, Price et al. $(2015$, p. 6) assinalam a possibilidade de que os pesquisadores podem não ter identificado alguma característica acústica da vocalização saliente para os macacos, a qual os permitiria distinguir essas (quatro) vocalizações. Por essa razão, insistimos na validade do critério da produção, embora estejamos cientes de que novos trabalhos podem refiná-lo ou reelaborá-lo posteriormente.
} 
2011). Esses resultados nos indicam que os mecanismos cognitivos subjacentes a esses sistemas vocais devem ter se estabelecido anteriormente à separação dos primatas como uma ordem independente; portanto, anteriormente, há 65 milhões de anos atrás.

Tendo em mente o caráter funcionalmente referencial dos sistemas de vocalização de alerta, podemos comparar, na próxima seção, suas características elementares com as propriedades funcionais e semânticas do léxico humano. Consideramos, para tanto, apenas as vocalizações de alerta que atendem aos critérios em (23). Notamos que o repertório vocal primata é geneticamente determinado, tanto no que concerne às categorias veiculadas quanto à estrutura acústica de suas vocalizações. Trabalhos que investigaram o desenvolvimento vocal primata nos revelam que as categorias expressas são fixas e atreladas a uma única classe de entidades no mundo. Isso impede, consequentemente, uma aproximação evolutiva com a porção conceitual do léxico humano, como é comumente sugerido. Será a partir dessas considerações que delinearemos as bases do sistema F.

\subsection{As bases filogenéticas do léxico funcional humano}

As habilidades referenciais dos sistemas de vocalização de alerta nos sugerem, à primeira vista, que haveria um continuísmo entre o comportamento vocal primata e a porção conceitual do léxico humano. Contudo, ao analisar esses dois caracteres mais atentamente, percebemos que eles não apresentam características paralelas capazes de indicar um eixo de gradação evolutiva. A correlação geralmente estabelecida decorre de leituras antropocêntricas e metafóricas atribuídas às vocalizações, frequentemente ancoradas em termos linguísticos. Se tal continuísmo fosse verdadeiro, deveríamos esperar que a contraparte humana, ou seja, as raízes lexicais — viz., unidades que abrigam o conteúdo semântico-conceitual das palavrasexibissem propriedades sutilmente distintas daquelas observadas nas categorias referenciais primatas, considerando-se sua proximidade evolutiva. ${ }^{88}$

Entretanto, as raízes da linguagem humana apresentam propriedades diametralmente opostas àquelas inferidas sobre as categorias primatas, sendo que muitas dessas propriedades

\footnotetext{
${ }^{88}$ Para o contraste que visamos estabelecer, consideramos apenas as categorias mentais envolvidas na veiculação de informações em primatas não humanos e em humanos modernos: no caso dos primatas, temos as categorias referenciais - um termo neutro para indicar aquilo que corresponderia a um primitivo de seu componente referencial-, e no caso dos humanos, as raízes. Deixamos de lado, no momento, outras diferenças. Por exemplo, diferenças envolvendo as motivações que subjazem à produção vocal, tais como a ausência de intencionalidade explícita em primatas. Retornaremos a essa e outras diferenças na seção 3.4, quando discutirmos os fatores que impedem a ampliação do repertório vocal primata de um ponto de vista ontogenético.
} 
são específicas da espécie, notadamente: (i) sua extensão, que excede em dezenas de milhares os sinais referenciais empregados por primatas não humanos (MARLER; TENAZA, 1977; GOODALL, 1986); (ii) sua aquisição ilimitada, que não se restringe ao período crítico da aquisição da linguagem (TALLERMAN, 2009, 2012); (iii) seu caráter dependente de aprendizado (HOCKETT, 1960a, 1960b; SEYFARTH; CHENEY; MARLER, 1980a, 1980b; BICKERTON, 2007) e (iv) sua natureza polissêmica, tendo em vista que uma mesma raiz pode ser associada a diferentes conteúdos, muitas vezes idiossincráticos (ARAD, 2003, 2005; HARLEY, 2014).

O comportamento vocal primata, por sua vez, é severamente restrito no que concerne aos mapeamentos entre conteúdo e vocalização. Tanto o inventário de categorias referenciais quanto a estrutura acústica das vocalizações são determinadas geneticamente, dois fatores que limitam a extensão e a expansão do repertório primata (SNOWDOW; ELOWSON; ROUSH, 1997; SEYFARTH; CHENEY, 1997, 2010; FITCH; ZUBERBÜHLER, 2013). O caráter inato dessas categorias e de seus correspondentes vocais nos indicam que as habilidades referenciais de primatas não humanos se estabelecem de modo coextensivo e unidirecional. ${ }^{89}$ Ou seja, cada categoria veiculada por uma vocalização recupera uma classe específica de entidades ou de eventos no mundo, definida adaptativamente. Em decorrência disso, não é possível admitir que essas categorias sejam polissêmicas tal como são as raízes.

Podemos caracterizar esse antagonismo funcional do seguinte modo: as categorias referenciais expressas pelas vocalizações seguem, essencialmente, uma correspondência de um-para-um, em que todo elemento do conjunto das categorias referenciais pré-adaptadas é pareado exatamente com apenas um único elemento do conjunto das entidades ou dos eventos. ${ }^{90}$ As raízes lexicais, por outro lado, são altamente polissêmicas (Cf. MARANTZ, 1995; ARAD, 2003, 2005; ACQUAVIVA; PANAGIOTIDIS, 2012; PANAGIOTIDIS, 2014, 2015; HARLEY, 2014, entre outros). Isso nos sugere que, ao contrário das categorias referenciais primatas, as raízes apresentam uma correspondência de um-para-muitos, uma vez que um mesmo exemplar pode ser associado livremente a mais de um elemento do conjunto das entidades ou dos eventos.

Na Figura 5, abaixo, ilustramos o contraste de mapeamento entre as categorias préadaptadas dos sistemas de comunicação primata $(\mathrm{S})$ e as raízes lexicais ( $\sqrt{ } \mathrm{RAIZ})$ :

\footnotetext{
${ }^{89}$ Ver também Chomsky (2010a, 2013b, 2016) para uma argumentação nesses termos.

${ }^{90}$ Trabalhos que investigaram os gestos icônicos de primatas não humanos sugerem que, semelhantemente às vocalizações, esses gestos teriam uma denotação rígida, designando ações específicas (Cf. TANNER; BYRNE, 1996; DOUGLAS; MOSCOVICE, 2015). Esses fatos endossam a hipótese de as categorias expressas por primatas não humanos seguem uma correspondência de um-para-um.
} 
Figura 5. Propriedades referenciais das representações simbólicas de primatas não humanos e humanos. ${ }^{91}$
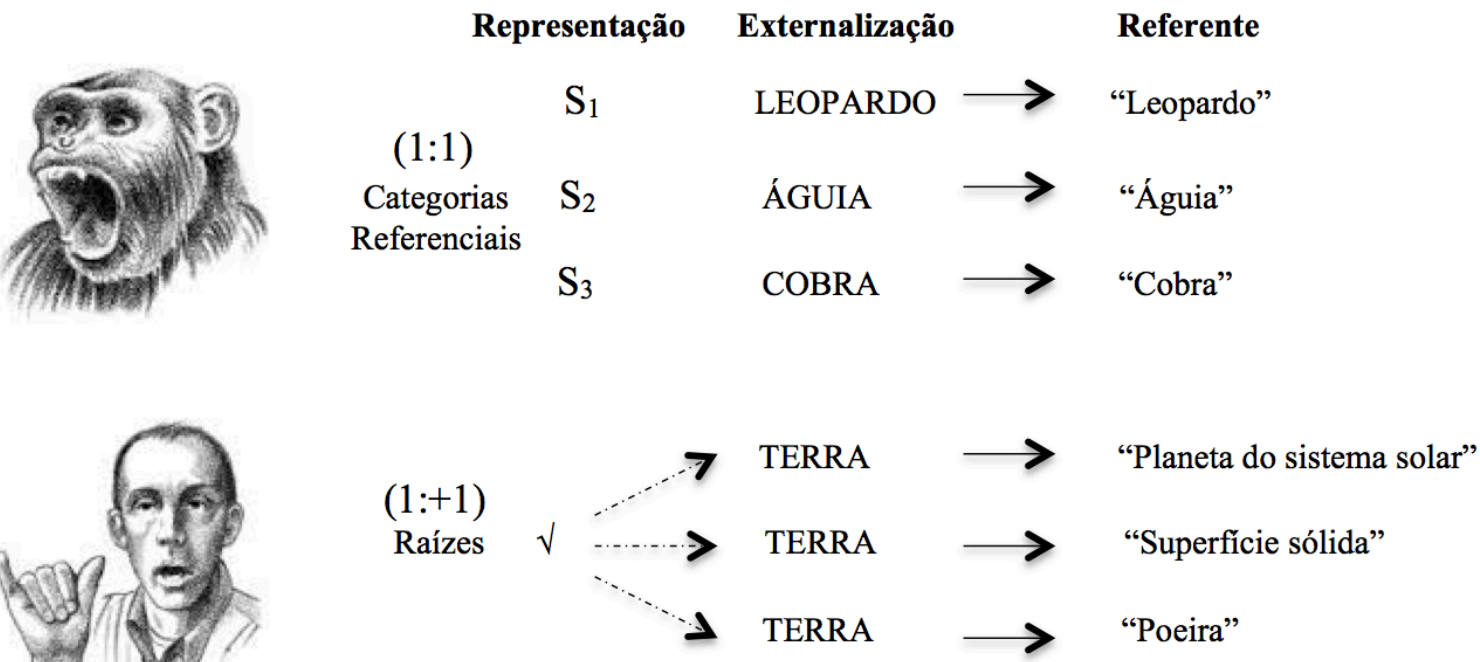

Tendo em mente essa assimetria, percebemos que a natureza coextensiva e inata das categorias referenciais primatas não apresentam equivalentes na porção conceitual do léxico humano. Assim sendo, não vemos como justificar um continuísmo entre os mecanismos cognitivos subjacentes aos sistemas de vocalização de alerta e as raízes lexicais, tal como proposto - através de metalinguagens distintas - por Marler, Evans, Hauser (1992), Seyfarth e Cheney (1993, 1997, 2003, 2010), Hauser (1996), Evans e Marler (1995), Evans (1997), Miyagawa, Berwick e Okanoya (2013), Miyagawa et al. (2014), Nóbrega e Miyagawa (2015), Miyagawa (2017), entre inúmeros outros autores. É preciso, em vista disso, repensar o impacto que o componente referencial primata pode ter tido no desenvolvimento da FL e a qual de suas competências esse componente estaria, possivelmente, atrelado.

Apesar dessa divergência funcional entre o componente referencial primata e as raízes lexicais, há ainda uma parte do léxico humano que deve ser considerada nesses estudos contrastivos —e que estranhamente não recebeu nenhuma atenção até o momento-, a saber: sua porção funcional. Curiosamente, a natureza coextensiva e unidirecional das vocalizações de alerta correlaciona-se de modo direto com as propriedades do léxico funcional humano, instanciado teoricamente pelos traços formais. Semelhantemente às categorias subjacentes às vocalizações de alerta, um traço formal expressa um único conteúdo, caracterizado pela classe gramatical a que ele pertence, e esse conteúdo não está sujeito à polissemia. Além disso, as

\footnotetext{
${ }^{91}$ As ilustrações da Figura 5 foram retiradas do artigo de Hauser, Chomsky e Fitch (2002, p. 1569).
} 
classes gramaticais tendem a ser restritas e uniformes na espécie, paralelamente ao que se observa no inventário de categorias manipuladas pelo repertório vocal primata. ${ }^{92}$

Por exemplo, um traço formal especificado com o conteúdo [plural], não pode, abstratamente, recuperar o conteúdo [singular], ou mesmo um conteúdo idiossincrático como

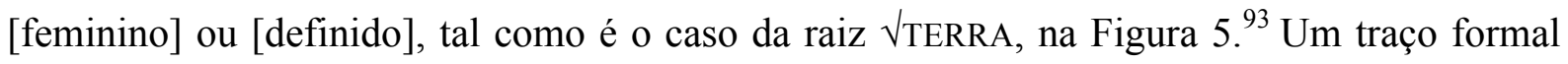
está restrito ao conteúdo que veicula e não está sujeito à variação, pois sua contribuição semântica é universal de um ponto de vista lógico. ${ }^{94}$ Esse raciocínio parte do pressuposto de que as bases cognitivas do léxico funcional humano são universais e de que a gramática opera de modo realizacional, ou seja, seus primitivos são abstratos e somente passam a ser associados a um expoente fonológico tardiamente (Cf. HALLE; MARANTZ, 1994; BEARD, 1995). Dadas essas semelhanças, conjecturamos que os mecanismos cognitivos subjacentes aos sistemas de vocalização primata correspondem aos precursores filogenéticos do léxico funcional humano. ${ }^{95}$ Tais mecanismos compreendem, em nosso entendimento, o sistema F.

No desenvolvimento desta seção, apresentamos, na subseção 3.3.1, evidências para a natureza semanticamente rígida das categoriais representacionais de primatas não humanos, com base em observações naturalísticas sobre a ontogenia do uso vocal de macacos-vervet. Na subseção 3.3.2, justificamos o caráter altamente flexível das raízes a partir de dados de diferentes línguas. Esses levantamentos servem para corroborar a assunção de que as habilidades referenciais primatas não apresentam correspondentes na porção conceitual do

${ }^{92}$ Veremos, no Capítulo 4, que as classes gramaticais da linguagem humana decorrem de categorias mais primitivas, tal como sugerido por Wiltschko (2014), a partir das quais classes específicas a uma língua são derivadas. Nesse sentido, algumas divergências de classes gramaticais observadas translinguisticamente decorrem do modo como essas categorias universais são fixadas individualmente por cada sistema linguístico. Por exemplo, de acordo com Wiltschko, o domínio nominal conta com uma categoria genérica "ponto de vista", a qual é universal. No português, essa categoria é fixada pela classe corresponde aos morfemas de número, enquanto, no chinês, ela é fixada na forma de classificadores. Em ambas as línguas, essas classes desempenham a mesma função (Cf. BORER, 2005a).

${ }^{93}$ Embora estejamos descrevendo os traços formais ilustrativamente como unidades putativas, é importante ressaltar que o mesmo raciocínio se aplica a uma descrição dos traços em termos de valores binários ou multivalorados. Se caracterizássemos a distinção singular vs. plural na forma de um traço binário [ \pm singular], a concepção subjacente ao conteúdo [+singular] contribuiria semanticamente de modo uniforme entre as línguas e não seria capaz de extrair uma interpretação [-singular] de um ponto de vista lógico. Uma raiz, entretanto, a depender do contexto morfossintático ou sintático em que está inserida, pode extrair diferentes interpretações, muitas vezes idiossincráticas (Cf. ARAD, 2003, 2005; BORER, 2003, 2005a, 2005b, 2013; ACQUAVIVA; PANAGIOTIDIS, 2012; PANAGIOTIDIS, 2014, 2015; HARLEY, 2014, entre outros).

${ }^{94}$ Isso garante, por exemplo, que a contribuição semântica de um mesmo traço formal seja equivalente em qualquer sistema linguístico. Não é possível argumentar razoavelmente que a concepção e o papel formal do traço [singular] empregado por um falante de português divirja ou varie sutilmente do traço [singular] manipulado abstratamente por um falante de suaíli ou kadiwéu.

${ }^{95}$ É importante não confundir o caráter semanticamente rígido dos traços formais com casos de homofonia e gramaticalização, em que um mesmo expoente fonológico corresponde a diferentes conteúdos gramaticais, tal como é o caso do segmento /-z/ em inglês, que pode dizer respeito tanto ao morfema de plural quanto a um morfema sincrético indicando $3^{\mathrm{a}}$ pessoa do singular. O que observamos nesses casos é uma questão de forma e não do conteúdo veiculado pelo(s) traço(s) abstratamente. Do ponto de vista computacional, um traço formal é uniforme e interpretado pelo componente semântico da gramática do mesmo modo translinguisticamente. 
léxico humano. Finalmente, na subseção 3.3.3, descrevemos o sistema F, os mecanismos cognitivos que o integram e seu funcionamento em primatas não humanos. Em nossa perspectiva, esses mecanismos estão implicados na determinação das categorias referenciais das vocalizações primatas e na fixação dos traços formais da linguagem humana.

\subsubsection{A natureza rígida das categorias referenciais primatas}

Nesta subseção, evidenciamos que as categorias referenciais subjacentes às vocalizações primatas detêm uma correspondência de um-para-um com a entidade ou com o evento denotados. Para tanto, discutimos o desenvolvimento vocal dos macacos-vervet, em especial, a ontogenia de sua produção vocal. Avaliamos observações naturalísticas sobre o comportamento de macacos infantes (i.e., sujeitos com menos de 12 meses de idade), juvenis (i.e., sujeitos com idade entre 1-5 anos de idade) e adultos (i.e., sujeitos com mais de 5 anos de idade). Veremos que, embora macacos infantes e juvenis produzam vocalizações de alarme para espécies não predadoras, sua produção vocal não é aleatória. As espécies que provocam respostas vocais dos macacos-vervet apresentam semelhanças físicas e comportamentais com suas três principais classes de predadores.

Como vimos na última seção, os macacos-vervet produzem vocalizações de alarme acusticamente distintas para, pelo menos, três classes de predadores: leopardos, águiasbelicosas e pítons africanas. Contudo, em seu habitat natural, esses sujeitos encontram mais de 150 espécies de pássaros e mamíferos, dentre as quais apenas algumas espécies oferecem um risco predatório. Isso exige dos macacos infantes duas tarefas cruciais: primeiramente, eles devem aprender quais espécies são, de fato, predadoras. Em um segundo momento, eles devem associar essas espécies às vocalizações disponíveis. É válido apontar, nesse contexto, que as vocalizações de alarme produzidas por macacos infantes e juvenis são acusticamente semelhantes às vocalizações produzidas por macacos adultos (SEYFARTH; CHENEY, 1997, p. 250), o que nos sugere que a estrutura acústica dessas vocalizações é inata à espécie. ${ }^{96}$

Seyfarth, Cheney e Marler (1980b) e Seyfarth e Cheney (1986) perceberam que uma variedade considerável de animais é capaz de incitar a produção vocal de macacos-vervet, notadamente, as espécies de predadores elencadas acima, bem como potenciais predadores i.e., animais que atacam espécies do tamanho de macacos-vervet, mas que, a princípio, não

\footnotetext{
${ }^{96}$ Essa mesma conclusão se amplia a outras espécies de macacos, bem como a pequenos e grandes monos (Cf. HAMMERSCHMIDT; FISCHER, 2008). Iremos discutir mais detidamente os aspectos inatos da estrutura acústica das vocalizações primatas na próxima seção.
} 
seriam seus predadores-, e animais não predadores. Um resumo das espécies e dos objetos que provocaram a produção vocal das populações observadas está apresentado no Quadro 2, abaixo, retirado de Seyfarth, Cheney e Marler (1980b, p. 1072-1073).

Quadro 2. Animais que provocaram a produção de vocalizações de alarme por macacos-vervet.

\begin{tabular}{|c|c|c|c|}
\hline & Predadores reais & Predadores potenciais & Não predadores \\
\hline Vocalização para & Leopardo & Leão & Javali-africano \\
\hline \multirow[t]{7}{*}{ leopardos } & (Panthera pardus) & (Panthera leo) & (Phacochoerus \\
\hline & & Hiena & aethiopicus) \\
\hline & & (Crocuta crocuta) & \\
\hline & & Guepardo & \\
\hline & & (Acinonyx jubatus) & \\
\hline & & Chacal & \\
\hline & & (Canis mesomelas) & \\
\hline \multirow[t]{19}{*}{ Vocalização para águias } & Águia-belicosa & Águia-dominó & Açor-africano \\
\hline & (Polemaetus bellicosus) & (Hieraetus spilogaster) & (Accipiter tachiro) \\
\hline & & Águia-cobreira-de-peito- & Águia-sem-rabo \\
\hline & & preto & (Teranthopius ecaudatus) \\
\hline & & (Circaetus pectoralis) & Ganso-do-egito \\
\hline & & Águia-rapace & (Alopochen aegyptiacus) \\
\hline & & (Aquila rapax) & Garça-real-europeia \\
\hline & & Bufo-de-verraux & (Ardea cinerea) \\
\hline & & (Bubo lacteus) & Calau-gigante \\
\hline & & & (Bucorvus leadbeateri) \\
\hline & & & Rolieiro-de-peito-lilás \\
\hline & & & (Coracias caudata) \\
\hline & & & Pomba \\
\hline & & & (Streptopelia ssp.) \\
\hline & & & Colhereiro-africano \\
\hline & & & (Platalea alba) \\
\hline & & & Abutre-de-cabeça-branca \\
\hline & & & (Trigonoceps occipitalis) \\
\hline & & & Folha caindo \\
\hline \multirow[t]{4}{*}{ Vocalização para cobras } & Píton-africana & Naja & Jabuti \\
\hline & (Python sebae) & (Naja ssp.) & (fam. Testudinidae) \\
\hline & & Mamba-preta & Rato \\
\hline & & (Dendroaspis polylepis) & (Arvicanthus ssp.) \\
\hline
\end{tabular}

Fonte: Seyfarth, Cheney e Marler (1980b, p. 1072-1073). 
Os autores apontaram que os desvios vocais retratados no Quadro 2, ou seja, a produção de vocalizações para espécies que não representam um perigo aparente, foram cometidos apenas por infantes e juvenis. Se olharmos, cuidadosamente, para o conjunto de espécies e objetos que incitaram a produção vocal desses sujeitos, notaremos que suas características físicas e/ou comportamentais se assemelham àquelas dos predadores reais. Essas correspondências nos revelam que, embora os macacos-vervet pratiquem suas vocalizações durante os primeiros cinco anos de vida, restringindo-as paulatinamente, os infantes comportam-se como se fossem predispostos, desde o nascimento, a dividir diferentes espécies em categoriais predeterminadas, a saber: predadores vs. não predadores, e em carnívoros terrestres, águias e cobras (SEYFARTH; CHENEY, 1997, p. 252; 2010, p. 94).

Por exemplo, macacos infantes emitem a vocalização para águias para uma variedade considerável de pássaros (e.g., diferentes espécies de águias, aves de grande porte e pombas), bem como para objetos suspensos no ar, tal como uma folha caindo. No entanto, esses indivíduos nunca produzem a vocalização para águias para animais que estão no solo. Semelhantemente, macacos infantes emitem a vocalização para leopardos para animais inofensivos (e.g., javalis-africanos). Entretanto, essa vocalização somente é empregada nos contextos em que há mamíferos terrestres nas adjacências (e.g., leões, hienas, guepardos, chacais). Já a vocalização para cobras é eliciada apenas nos contextos em que os infantes avistam uma entidade que se assemelha comportamentalmente a uma cobra (e.g., jabuti) (Cf. SEYFARTH; CHENEY; MARLER, 1980b, p. 1072-1073).

Ao avaliar, especificamente, a produção da vocalização para águias, Seyfarth e Cheney $(1986,1997)$ reiteraram suas observações iniciais. Os autores notaram adicionalmente que os macacos adultos são extremamente seletivos. Sujeitos acima dos cinco anos produzem a vocalização para águias em maior quantidade para aves de rapina (da família Falconidae), em particular, para águias-belicosas e, em alguns contextos, para águias-coroadas. Macacos juvenis, por sua vez, são menos seletivos; porém, mais propensos a produzir a vocalização para águias a espécies predadoras. Já os macacos infantes são os menos seletivos, pois não são capazes de distinguir aves predadoras de aves não predadoras. Na Figura 6, é possível observar o grau de seletividade dos macacos-vervet com relação à produção da vocalização para águias. 
Figura 6. Espécies de aves que motivaram a produção da vocalização para águias por macacos-vervet infantes, juvenis e adultos. A espessura das linhas indica o número de vocalizações produzidas: linhas tracejadas, menos de 5; linhas únicas, 6-10; linhas duplas, 11-15; linhas grossas, mais de 15.
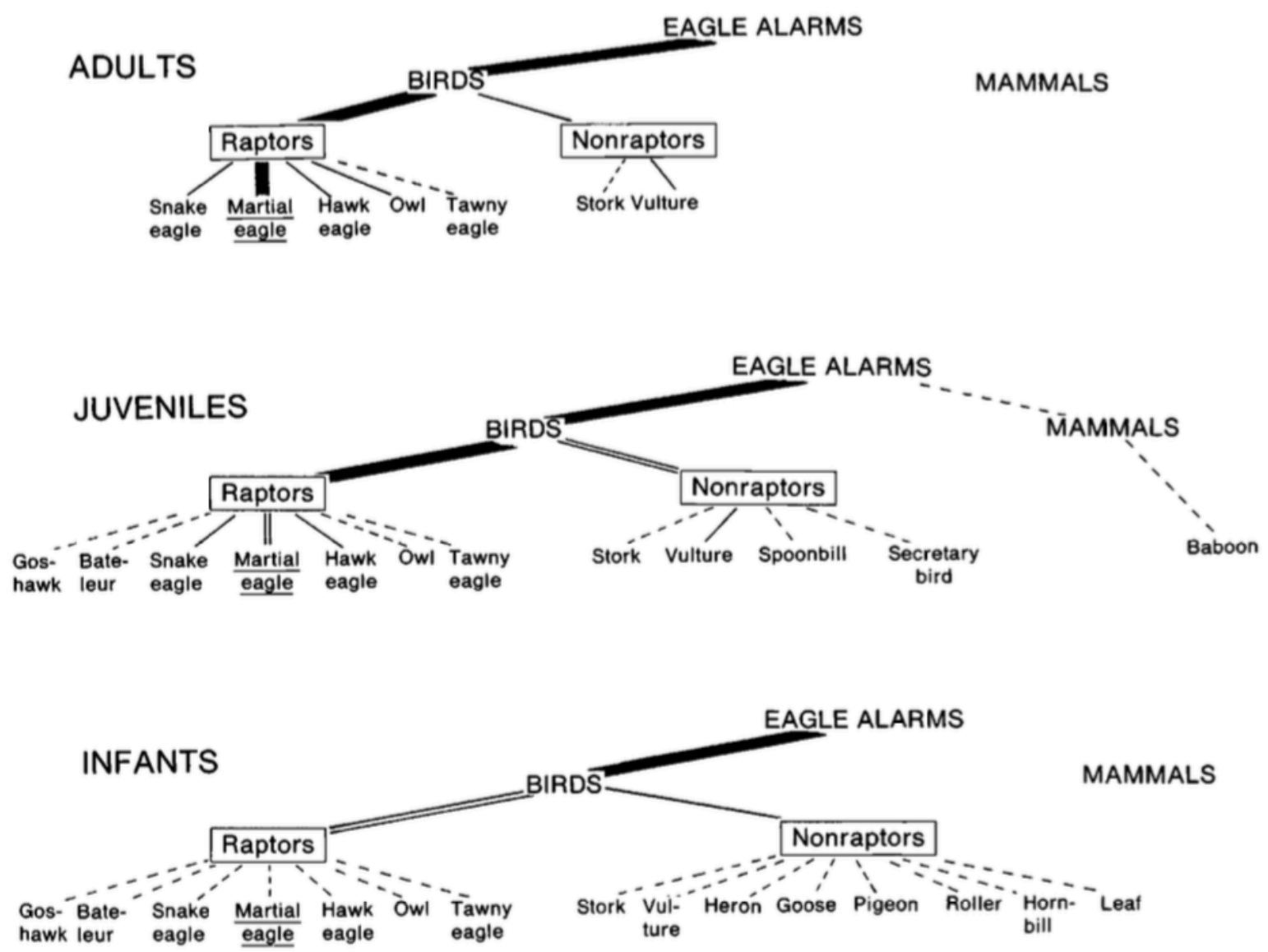

Fonte: Seyfarth e Cheney (1997, p. 253).

Com base na distribuição representada na Figura 6, bem como nos demais resultados apresentados por Seyfarth e Cheney $(1986,1993,1997,2010)$, é razoável postular que as categorias referenciais associadas às vocalizações dos macacos-vervet são coextensivas com as classes de predadores que elas denotam. Uma vez que uma vocalização para águias não é eliciada fora de um contexto em que a entidade no mundo contenha características físicas e/ou comportamentais associadas a essa classe, não podemos afirmar que tais categorias dão margem à polissemia, tal como é o caso das raízes. Apesar da fixação dessas categorias referenciais primatas depender substancialmente da experiência do indivíduo, as entidades no mundo que podem servir como potenciais referentes são consideravelmente restritas e, de certo modo, uniformes.

Como assinalam Seyfarth e Cheney (1986, p. 1645): 


\begin{abstract}
"Embora muitas espécies induzissem à produção de vocalizações de alarme, infantes e juvenis foram seletivos na produção de suas vocalizações: a vocalização para águias foi produzida apenas para aves e, dentro dessa classe geral, mais de 30 espécies de aves foram vistas regularmente durante o estudo; porém, não incitaram vocalizações. A vocalização para águias foi produzida com maior frequência para aves de rapina (família Falconidae), um grupo cujos membros distinguem-se das outras aves por seu tamanho relativamente grande, bico curvo e garras" (SEYFARTH; CHENEY, 1986, p. 1645, tradução nossa). ${ }^{97}$
\end{abstract}

Essas observações nos servem como evidência para sustentar a hipótese de que as categorias referenciais atreladas às vocalizações primatas apresentam uma denotação rígida. Seu caráter restrito deve-se certamente ao fato de que essas categorias resultam de pressões adaptativas, o que torna os mapeamentos entre conteúdo e vocalização uma propriedade inata. Estudos adicionais endossaram a assunção de que o uso das vocalizações é altamente limitado e que, durante a infância, o papel do aprendizado na determinação da relação entre um conteúdo e uma vocalização é reduzido. Isso se verifica, por exemplo, no desenvolvimento vocal de macacos nemestrinos (Macaca nemestrina; GOUZOULES; GOUZOULES, 1989); de macacos rhesus (OWREN et al., 1993); de sifakas (Propithecus verrauxi; FICHTEL; VAN SCHAIK, 2006) e de outras espécies de primatas não humanos (SEYFARTH; CHENEY, 1997).

\title{
3.3.2 A natureza flexível das raízes lexicais
}

Ao analisar as propriedades das raízes, percebemos um amplo contraste com as representações envolvendo as vocalizações primatas. Um deles é a possibilidade de associar um novo conceito a uma raiz a qualquer momento. Um exemplo ilustrativo são os modificadores comparativos do português. Os nomes cavalo, porco, burro, criança, banana, mala, xarope, monstro, espada, laranja, entre outros, adquirem um significado alternativo na posição de modificador nominal, tal como se verifica nos sintagmas menino cavalo, homem porco, marido banana, criança xarope, etc. Quando concatenados na posição de modifícador,

\footnotetext{
${ }^{97}$ Trecho original: "Although many species elicited alarm calls, infants and juveniles were nevertheless selective in their alarm-calling:eagle alarms were given only to birds, and within this general class over 30 avian species were seen regularly during the study but did not elicit alarms. Eagle alarms were given most often to raptors (family Falconidae), a group whose members are distinguished from other birds by their relatively large size, curved beak and talons".
} 
suas raízes deixam de se referir às entidades comumente denotadas e passam a recuperar um conteúdo idiossincrático, porém, inerentemente associado às propriedades do referente de seu uso nominal. $^{98}$

Essa capacidade que as raízes têm de recuperar diferentes significados é observada amplamente entre as línguas. Arad $(2003,2005)$ aponta que um grupo de raízes do hebraico pode dar origem a uma extensa família de palavras, cujo parentesco semântico é facilmente reconhecível. O significado dessas raízes não é determinado isoladamente, mas depende do contexto morfossintático em que elas estão inseridas, um fenômeno que a autora rotula de “significados múltiplos contextualizados". Por exemplo, a raiz tri-consonantal $\sqrt{Q L T}$ apresenta uma ampla gama de interpretações em domínios verbais (v) e nominais (n). Esses domínios categoriais estão caracterizados pelos padrões vocálicos listados em (24), em que "C" está para uma das três consoantes da raiz.

(24) Hebraico $\sqrt{ } \mathrm{QLT}$ (ARAD, 2005, p. 97)

$\begin{array}{lll}\text { a. } \operatorname{CaCaC}(\mathrm{v}) & \text { qalat } & \text { 'absorver, receber' } \\ \text { b. } \operatorname{hiCCiC}(\mathrm{v}) & \text { hiqlit } & \text { 'gravar' } \\ \text { c. } \operatorname{miCCaC}(\mathrm{n}) & \text { miqlat } & \text { 'um abrigo' } \\ \text { d. } \operatorname{maCCeC}(\mathrm{n}) & \text { maqlet } & \text { 'um receptor' } \\ \text { e. } \operatorname{taCCiC}(\mathrm{n}) & \text { taqlit } & \text { 'uma gravação' } \\ \text { f. } \mathrm{CaCCeCet}(\mathrm{n}) & \text { qaletet } & \text { 'uma fita-cassete' } \\ \text { g. } \mathrm{CeCeC}(\mathrm{n}) & \text { qelet } & \text { 'input' }\end{array}$

Na tentativa de explicar esses múltiplos significados, Arad $(2003,2005)$ propõe que as raízes são radicalmente subespecificadas semanticamente. Isso significa que elas não apresentam um conteúdo inerente, plenamente determinado. Pelo contrário, as raízes contêm, em sua perspectiva, um núcleo conceitual empobrecido, a partir do qual outros significados podem ser recuperados. Dito de outro modo, as raízes operam como "potencialidades", pois são capazes de apontar para diferentes referentes no mundo. O licenciamento dessas diferentes interpretações é regulado pelo contexto morfossintático, tal como se observa na

\footnotetext{
${ }^{98}$ Foltran e Nóbrega (2017), ao investigarem as propriedades dos modificadores comparativos, mostram que eles preservam a categoria nominal, o que se justifica pela ausência de concordância em gênero e pela impossibilidade de se formarem advérbios com o sufixo -mente, características comuns à classe dos adjetivos. Os autores mostram também que o uso desses modificadores dá origem a sintagmas nominais e não a compostos, uma vez que há a possibilidade de intervenções sintáticas como modificação (e.g., um homem bem mala), fronteamento (e.g., Mala(s) $)_{i}$ ele tem uns três amigos ala(s) $\left.{ }_{i}\right)$ e coordenação (e.g., homem banana e preguiçoso).
} 
distribuição dos padrões vocálicos em (24). Assim sendo, o caráter subespecificado das raízes é o que promove a materialização de seu conteúdo de diferentes modos.

Há, por outro lado, raízes lexicais que não apresentam um significado coerente a partir do qual possamos derivar um significado nuclear. Aronoff (2007 apud HARLEY, 2014, p. 238-239) ${ }^{99}$ assinala, também com base em dados do hebraico, que há raízes com pouca ou nenhuma relação com um significado, como é o caso da raiz $\sqrt{K B}_{\mathrm{K}}$, a qual dá origem a uma grande família de palavras, listada no Quadro 3, abaixo. Como se observa, é difícil admitir que a raiz $\sqrt{\mathrm{KB}} \int$ contenha um significado nuclear a partir do qual "fruta em conserva", "rolo compressor" e "fornalha" são derivados. Vale ressaltar que a raiz $\sqrt{ } \mathrm{KB} \int$ é armazenada como um elemento sincrônico da língua hebraica, e que a família de palavras representada no Quadro 3 não corresponde a um mero caso de homofonia entre suas consoantes.

Quadro 3. Palavras formadas a partir da raiz $\sqrt{\mathrm{KB}} \int$ do hebraico.

\begin{tabular}{|c|c|}
\hline $\mathbf{R a i z}=\sqrt{\mathbf{K B} \boldsymbol{\int} \sim} \sim$ 'apertar' & Mudança sincrônica \\
\hline \multicolumn{2}{|l|}{ Nomes } \\
\hline keves & 'passagem, passo, grau, fruta em conserva' \\
\hline$k v i f$ & 'estrada pavimentada, rodovia' \\
\hline$k v i f a$ & ‘compressão’ \\
\hline kivfan & 'fornalha, estufa' \\
\hline maxbef & 'prensa, rolo compressor' \\
\hline mixbafa & 'loja de decapagem' \\
\hline \multicolumn{2}{|l|}{ Verbos } \\
\hline$k a v a \int$ & $\begin{array}{l}\text { 'conquistar, subjugar, apertar, pavimentar, conservar em vinagre, preservar, } \\
\text { armazenar, esconder' }\end{array}$ \\
\hline kibes & 'conquistar, subjugar, apertar, pavimentar, conservar em vinagre, preservar' \\
\hline hixbif & ‘subjugar’ \\
\hline \multicolumn{2}{|l|}{ Adjetivos } \\
\hline kavus & 'subjugado, conquistado, preservado, apertado, pavimentado' \\
\hline$k v u \int i m$ & ‘conservado, preservado’ \\
\hline mexubaf & 'apertado, preenchido' \\
\hline
\end{tabular}

Acquaviva e Panagiotidis (2012, p. 10) fornecem um exemplo adicional: a raiz $\sqrt{E S T H}$, do grego. Em (25), reproduzimos a família de palavras associada a essa raiz. Apesar das afinidades semânticas sugeridas pelas glosas em (25), a raiz $\sqrt{E S T H}$ expressa referentes muito

\footnotetext{
${ }^{99}$ ARONOFF, M. In the beginning was the word. Language, v. 83, n. 4, 2007, p. 803-830.
} 
variados. De acordo com os autores, a maleabilidade semântica dessa raiz, bem como de outras raízes do grego e do italiano, inviabiliza a determinação de um núcleo conceitual coerente, não importando quão subespecificado ele seja. Os autores sugerem, em contrapartida, uma proposta mais radical que a de Arad (2003, 2005), argumentando que as raízes são desprovidas de um núcleo conceitual predeterminado. Em outras palavras, os autores defendem que as raízes lexicais são destituídas de significado.

(25) Grego VESTH (ACQUAVIVA; PANAGIOTIDIS, 2012, p. 10)
a. esth-an-o-me 'tato'
b. esth-is-i 'sentido'
c. sin-esth-is-i 'realização, consciência'
d. esth-i-ma 'sentimento, caso amoroso, namorado(a)'
e. sin-esth-i-ma 'emoção'
f. esth-is-iaz-mos 'sensualidade'
g. esth-an-tik-os 'sensível, emotivo'
h. esth-it-os 'perceptível, tangível'
i. an-esth-it-os 'inconsciente, insensível'
j. esth-it-ir-ios 'sensorial'
k. esth-it-ik-os 'estético, esteticista'

Harley (2014, p. 240) endossa essa conclusão com base na distribuição das raízes latinas no inglês, as quais também resistem a uma individuação semântica. As raízes em (26) não apresentam um significado fora de um contexto morfossintático, ou seja, não é possível determinar, por exemplo, qual o significado da raiz $\sqrt{ }$ CEIVE isoladamente. Além disso, essas raízes dão origem a uma família de palavras semanticamente fluida, impedindo a atribuição de um significado nuclear. Vale mencionar que as raízes em (26), apesar de semanticamente vagas, são claramente diagnosticadas como um primitivo independente no inglês. Como ressalta Harley (2014, p. 240-241), as raízes latinas apresentam identidade fonológica, desencadeiam o mesmo padrão de alomorfia contextual e têm as mesmas restrições de seleção morfológica. ${ }^{100}$

\footnotetext{
${ }^{100}$ Por exemplo, a raiz $\sqrt{ }$ CEIVE alterna entre os alomorfes ceice $\sim$ cept e seleciona o sufixo -ion para nominalizações, ao passo que a raiz $\sqrt{ }$ POSE alterna entre os alomorfes pose $p o s$ e seleciona para nominalizações o sufixo -ition, mas não -ion ou -ation.
} 
(26) Inglês (HARLEY, 2014, p. 240)

a. $\sqrt{ }$ CEIVE

deceive 'enganar', receive 'receber', conceive 'conceber', perceive 'perceber'

b. $\sqrt{\text { HERE }}$

adhere 'aderir', inhere 'pertencer'

c. $\sqrt{ }$ PORT

comport 'comportar', deport 'deportar', report 'reportar', import 'importar', support 'apoiar'

d. $\sqrt{ }$ POSE

suppose 'supor', depose 'depor', compose 'compor', repose 'hesitar', propose 'propor'

Harley (2014, p. 241) aponta, ainda, outros exemplos que desafiam a individuação semântica das raízes: os itens caboodle (e.g., kit and caboodle 'tudo', run the gamut 'inclui uma ampla variedade', vim and vigor 'vitalidade', etc.). A interpretação das raízes caboodle, gamut e vim é dependente do contexto sintático, ou seja, de todo o sintagma, diferentemente das raízes em (24), (25) e (26), cuja interpretação depende do contexto morfossintático. Esses itens caboodle correspondem a casos em que o falante aprende uma expressão e seu conteúdo como um sintagma, sem ter aprendido um significado independente para suas partes. Embora esses itens representem um bloco semântico, eles são transparentes morfossintaticamente, tal como é o caso de jinks (e.g., I don't care for these/*this high jinks lit. eu não me importo com essa algazarra; Cf. HARLEY, 2014, p. 242). A possibilidade de recuperar um conteúdo não composicional só é possível devido à ausência de um significado predeterminado nas raízes. O mesmo pode ser observado em compostos não composicionais e expressões idiomáticas. A atribuição de um significado não composicional aos compostos samba-canção e caixa-preta, bem como às expressões idiomáticas chutar o balde e engolir sapos, só é possível porque suas raízes não detêm uma associação rígida com um conteúdo. Isso permite que essas raízes passem a designar um referente distinto daqueles comumente expressos por suas partes individualmente (BORER, 2014a; NÓBREGA, 2015a, 2016).

Tais fatos empíricos nos sugerem que as raízes da linguagem humana são desprovidas de informação conceitual enquanto um objeto isolado. Sua defectividade semântica permite que elas possam fazer referência a diferentes entidades ou eventos no mundo. Em qualquer uma das perspectivas descritas acima, a conclusão é a mesma: uma raiz não apresenta uma relação intrínseca, predeterminada, com um conteúdo. Na realidade, as raízes constituem um 
dispositivo interno à FL, capaz de recuperar diferentes conceitos armazenados em nossa memória de longo prazo (PIETROSKI, 2008, 2012; BOECKX, 2015). De acordo com essa hipótese, a associação desses diferentes conceitos a uma raiz é o que permite que eles sejam empregados de modo referencial. Para a segunda perspectiva acima — da vacuidade semântica das raízes-, as raízes são individualizadas somente por meio de um índice alfanumérico, que está vinculado a um conjunto de instruções conceituais em LF (HARLEY, 2014, p. 243-247).

Essas instruções basicamente listam os conceitos recuperados por uma mesma raiz nos diversos contextos morfossintáticos e sintáticos em que ela aparece. Além disso, o número de instruções conceituais atrelados a uma raiz pode ser ampliado através da indexação de um conceito adicional. Em (27), apresentamos as instruções recuperadas pela raiz hipotética $\sqrt{ }_{243}$, conectada ao segmento fonológico /sãm.ba/ no português. Notem que, ao lado direito das instruções, os significados apresentam um contexto morfossintático explícito. Logo, cada um dos itens listados nas instruções em (27) competem entre si, como propõe Harley (2014, p. 244-245), e o mais especificado acaba atribuindo um conceito à raiz. Esse dispositivo não se equipara, de modo algum, ao funcionamento das categorias referenciais primatas, tal como veremos na subseção seguinte.

(27) Instruções conceituais atreladas à raiz $\sqrt{243}_{24}(/$ sãm.ba/)

$$
\begin{aligned}
& \sqrt{ }_{243} \leftarrow \rightarrow \text { "samba" } \\
& \leftarrow \rightarrow \text { "ser preso"/ [v[_ ] ] } \quad \text { (e.g., } x \text { sambou) } \\
& \leftarrow \rightarrow \text { "folgado"/ [[v [[estar }] \mathrm{v}[\mathrm{v}[\ldots] \text { ] }]]_{\mathrm{vP}} \quad \text { (e.g., } x \text { está sambando) } \\
& \leftarrow \rightarrow \text { “problema"/ [v [[dar] }[\mathrm{n}[\ldots] \rrbracket]]_{\mathrm{vP}} \\
& \leftarrow \rightarrow \text { "cueca"/ [[n[__ ] ] [canção }] \mathrm{n}]_{\mathrm{nP}}
\end{aligned}
$$

Percebemos, com os dados elencados acima, que o caráter semanticamente defectivo das raízes difere da denotação rígida das categorias referenciais primatas. Sua maleabilidade referencial — dissociada de uma predeterminação genética — coloca a emergência das raízes em um ramo evolutivo diferente. Em nossa visão, as raízes parecem estar mais intimamente associadas ao desenvolvimento da percepção. Especificamente, elas parecem derivar do modo como as representações conceituais extraídas das habilidades perceptuais da espécie humana, presumivelmente compartilhadas através da exaptação do sistema C-I, foram transformadas em objetos linguísticos, tal como comentamos anteriormente. O estabelecimento de raízes na FL — ou melhor, de um item vazio de conteúdo - foi, em nosso entendimento, a inovação evolutiva que possibilitou a atomização das representações conceituais extraídas da percepção 
em entidades linguísticas, bem como sua posterior manipulação pela gramática. Voltaremos a esse tópico no próximo capítulo.

Em resumo, as divergências apontadas nas duas últimas subseções corroboram a dissociação entre as categorias referenciais primatas e as propriedades referenciais da porção conceitual do léxico humano. Buscamos demonstrar que esses dois caracteres decorrem de percursores evolutivos distintos. Na próxima subseção, apontamos aquilo que presumimos ser o desdobramento do componente referencial primata, a que chamamos de sistema F. Veremos que seus primitivos elementares, rotulados provisoriamente de categorias referenciais, operam sugestivamente de modo paralelo aos traços formais. Para tanto, descrevemos o mecanismo cognitivo subjacente ao sistema $\mathrm{F}$, seu funcionamento em primatas não humanos e apontamos de que modo ele pode figurar como a base filogenética do léxico funcional humano.

\subsubsection{O sistema funcional}

Para caracterizar o sistema F, partimos da premissa de que a dotação biológica de um organismo determina o que pode compor sua experiência (CHOMSKY, 1966, 1975; GOULD; MARLER, 1987; JACKENDOFF, 1994; LUST, 2006; LEWONTIN, 2008; GALLISTEL, 2010; EPSTEIN, 2016). Isso significa que os estímulos do ambiente passíveis de serem experienciados são delimitados em função das estruturas cognitivas expressas por seu genótipo. Por exemplo, uma abelha pode desempenhar suas "danças" a um indivíduo humano milhares de vezes. No entanto, os limites da experiência humana não permitem que esse indivíduo seja capaz de traduzir, em circunstâncias naturais, as imagens dessa agitação em termos de representações mentais sobre a distância e a direção da fonte de alimento. Da mesma forma, perturbações acústicas ultrassônicas podem ser experienciadas por um cachorro, mas não pela espécie humana (EPSTEIN, 2016, p. 197).

Há, nesse sentido, certos domínios da experiência que são construídos através de propriedades inatas. Segundo a abordagem racionalista, a experiência constitui-se de aspectos do ambiente circunscritos pela composição anatômica e cognitiva de uma espécie, a qual restringe aquilo que a espécie pode experienciar e, então, converter em conhecimento. $\mathrm{O}$ desenvolvimento do comportamento vocal primata é um excelente exemplo. Vimos que os macacos-vervet são predispostos, desde o nascimento, a extrair das perturbações acústicas e visuais que experienciam três categorias específicas do mundo: carnívoros terrestres, águias e cobras. Isso se justifica pela uniformidade das características físicas e comportamentais das 
entidades capazes de incitar suas vocalizações, as quais, desde tenra idade, não são produzidas aleatoriamente (SEYFARTH; CHENEY; MARLER, 1980b; SEYFARTH; CHENEY, 1986; 1993; 1997).

Em linhas gerais, essa premissa racionalista acerca da constituição do sistema $\mathrm{F}$ basicamente estipula que parte dos dados da experiência, suscetíveis a serem traduzidos em conhecimento, são predeterminados geneticamente. Dito em outras palavras, nurture is nature. Isso implica, no que concerne à competência linguística, que o papel da experiência no desenvolvimento da linguagem não deve ser concebido em termos de uma influência externa e elegível pelo indivíduo (EPSTEIN, 2016, p. 198). De acordo com essa perspectiva, os fatores ambientais capazes de influenciar o desenvolvimento de um organismo e de seus órgãos —e.g., FL— não correspondem a construtos externos, selecionáveis e, principalmente, homogêneos aos órgãos sensoriais das espécies. É preciso, nesse sentido, determinar o tipo de experiência que cada espécie está predisposta a experimentar. Porém, somente poderemos identificar quais estímulos do ambiente são relevantes para o desenvolvimento de uma determinada espécie, se, em primeiro lugar, conhecermos suas propriedades cognitivas e anatômicas.

Como bem descreve Descartes (1648/1985, p. 303-304 apud EPSTEIN, 2016, p. 199): $:^{101}$

\footnotetext{
"Nada dos objetos externos atinge nossa mente através dos órgãos sensoriais, exceto certos movimentos corpóreos [...] Mas nem os próprios movimentos nem as figuras que deles emergem são concebidas por nós exatamente como ocorrem nos órgãos dos sentidos [...]. Segue-se que as próprias ideias dos movimentos e das figuras [que são evocadas] são inatas para nós" (DESCARTES, 1648/1985, p. 303-304, tradução nossa). ${ }^{102}$
}

O sistema $\mathrm{F}$ instancia, em nosso entendimento, um domínio desse recorte inato da experiência. Argumentamos que o sistema F é composto por um conjunto de categorias préadaptadas capazes de serem experienciadas - i.e., categorizadas - por um organismo, as quais são privilegiadas para externalização. O termo "funcional" diz respeito à função

\footnotetext{
${ }^{101}$ DESCARTES, R. Comments on a certain broadsheet. In COTTINGHAM, J.; STOOTHOFF, R.; MURDOCH, D. (orgs.) The philosophical writings of Descartes. Vol. 1. Cambridge: Cambridge University Press, 1648/1985.

${ }^{102}$ Trecho original: "Nothing reaches our mind from external objects through the sense organs except certain corporeal motions [...] But neither the motions themselves nor the figures arising from them are conceived by us exactly as they occur in the sense organs [...] Hence it follows that the very ideas of the motions themselves and of the figures are innate in us"
} 
referencial que essas categorias adquirem quando externalizadas, fato que, consequentemente, acaba conferindo vantagens adaptativas a seus coespecíficos. Conjecturamos que o sistema $\mathrm{F}$ compreende um número restrito de categorias referenciais, as quais devem ser entendidas como seus primitivos. Hipotetizamos ainda que cada uma dessas categorias foi selecionada por pressões adaptativas e, por essa razão, são específicas de cada espécie. Para evitar que a externalização dessas categorias seja interpretada como um ato deliberado, tendo em vista o que apontamos sobre a produção vocal primata, passaremos a chamá-las de "células" do sistema F. ${ }^{103}$

Em termos estruturais, cada célula de F relaciona-se a uma classe de entidades ou de eventos no mundo que, necessariamente, devem compor a experiência de um organismo. Dado seu caráter pré-adaptado, admitimos que uma célula é constituída por uma estrutura interna rígida, a qual faz com que os mapeamentos decorrentes de sua externalização sigam uma correspondência de um-para-um com as entidades ou com os eventos denotados, tal como ilustramos na Figura 5. Para descrever sua rigidez estrutural, sugerimos que toda célula consiste de um par ordenado. Os membros desse par ordenado são: um atributo (ATR), correspondente à categoria que irá determinar a experiência do organismo; e um valor (VAL), correspondente às informações extraídas das perturbações sensoriais acessíveis à experiência, delimitada por um ATR. Notem que a determinação de VAL está, intimamente, vinculada às considerações feitas por um ATR, em uma relação parte-todo.

Para ilustrar como as células do sistema F operam, tomemos, como exemplo, o sistema de vocalizações de alarme dos macacos-vervet, descrito na seção 3.2. Cada uma das categorias de entidades que esses indivíduos estão predispostos a categorizar instanciam, em nossos termos, um ATR e, por consequência, uma célula de seu sistema F. As entidades no mundo sujeitas a serem experienciadas correspondem a seus VAL. VAL está para a parte da célula que resulta da experiência do indivíduo. No caso dos macacos-vervet, diferentes espécies podem servir como um VAL, tal como vimos na descrição de seu desenvolvimento vocal, na seção 3.3.1. Entretanto, os macacos-vervet vão gradativamente fixando um VAL para cada ATR, assim que identificam quais espécies do ambiente são, de fato, predadoras. Podemos dizer que, para um macaco-vervet infante, se $A T R=V O A R$, então VAL=qualquer entidade que satisfaça esse ATR.

\footnotetext{
${ }^{103}$ Não queremos atrelar ao sistema $\mathrm{F}$ qualquer intenção comunicativa. Esse sistema abriga essencialmente um conjunto de categorias determinadas adaptativamente, as quais conferem vantagens aos coespecíficos que são capazes de extrair informações de sua externalização. Intenções comunicativas, envolvendo uma Teoria da Mente, somente serão associadas ao sistema F quando esse passar a ser empregado pela FL na espécie humana.
} 
Em (28), fornecemos uma formalização das células que compõem o sistema $F$ e de que modo elas recortam a experiência de um organismo:

\section{(28) Célula em F}

a. Uma célula $\mathrm{C}$ em $\mathrm{F}$ é um par ordenado $<\mathrm{ATR}, \mathrm{VAL}>$ que satisfaz:

(i) ATR pertence ao conjunto finito A das categorias referenciais determinadas pela dotação biológica de uma espécie;

(ii) VAL corresponde a um elemento de ATR (i.e., VAL pertence a ATR).

b. Assim, dado que A é o conjunto das categorias referenciais, então o conjunto de todas as células $\mathrm{C}$ em $\mathrm{F}$ de um organismo $\mathrm{O}$ é dado por $\{<\mathrm{ATR}, \mathrm{VAL}>=\mathrm{ATR} \in$ A e VAL $\in$ ATR $\}$.

c. Denotamos uma célula arbitrária $\mathrm{C}$ por $<$ ATR, VAL $>$ (i.e., $\mathrm{C}=<\mathrm{ATR}, \mathrm{VAL}>$ ) e o conjunto das células $\mathrm{C}$ de $\mathrm{F}$ de um organismo $\mathrm{O}$ por $=\{<\mathrm{ATR}, \mathrm{VAL}>\mid \mathrm{ATR} \in$ A e VAL $\in$ ATR $\}^{104}$

O conjunto finito das categorias referenciais das quais um ATR pode ser retirado é específico à cada espécie e representa as determinações genéticas que recortam parte de sua experiência. Os ATR selecionados para constituir uma célula são aqueles passíveis de serem atrelados a um expoente fonológico, seja uma vocalização ou um gesto. Vale assinalar que o caráter variável de VAL apresenta vantagens adaptativas, uma vez que os ambientes mudam. As espécies dotadas de um sistema $\mathrm{F}$ devem ser capazes de identificar outras espécies que, porventura, passem a atuar como seus predadores. Por exemplo, macacos-vervet têm como um de seus principais predadores espécies aviárias. Porém, as espécies de aves e suas aparências físicas variam consideravelmente de um habitat para outro (GARGETT, 1971). O fato de VAL ser variável permite que um macaco-vervet possa identificar novas espécies aviárias, fisicamente distintas, através de um mesmo ATR.

Dada essa organização do sistema F, uma espécie irá naturalmente extrair informações do ambiente em que está inserida - i.e., atribuir VAL aos ATR - e, gradativamente, irá fixar um determinado VAL a um ATR durante seu desenvolvimento. No caso dos macacos-vervet, a variabilidade de VAL verificada em seu uso vocal nos indica que os ATR de suas células não correspondem a uma classe de entidades em si (e.g., "LEOPARDO”; “ÁGUIA”; “COBRA”),

\footnotetext{
${ }^{104}$ As notações em (28) devem ser lidas do seguinte: $\epsilon$ "pertence a", | "tal que".
} 
mas a um tipo de comportamento/ataque (e.g., "CAMINHAR"; "VOAR"; "RASTEJAR"). ${ }^{105}$ Isso explicaria por que javalis, uma folha caindo e jabutis também são capazes de incitar a produção vocal de um infante. Por essa razão, propomos que o conjunto de ATR de primatas não humanos pode ser traduzido em termos das generalizações acerca do comportamento do predador — no que diz respeito às vocalizações de alarme-, mas não em termos de uma classe de entidades específicas.

Essa nossa assunção está descrita em (29), através do conjunto de células que compõe parte do sistema F dos macacos-vervet:

(29) Conjunto de células que compõe parte do sistema F dos macacos-vervet
a. $\quad$ CAMINHAR vervet,$x>$
b. $<\operatorname{VOAR}_{\text {vervet }}, x>$
c. $<$ RASTEJAR $_{\text {vervet }}, x>$
$=$ em que $x$ corresponde a VAL, uma variável a ser determinada através da experiência do indivíduo com base nas delimitações impostas por um ATR.

Outro ponto que deve ser discutido são as origens evolutivas do sistema F. Para abordar essa questão, devemos considerar a assimetria entre a produção e a percepção vocal de animais não humanos, visto que o significado e a função de uma vocalização não são os mesmos para os sinalizadores e para os receptores (MARLER, 1961; MARLER; HAUSER; EVANS, 1992; MACEDONIA; EVANS, 1993; SEYFARTH; CHENEY, 2003; FITCH; ZUBERBÜHLER, 2013). ${ }^{106}$ Essa assimetria nos faz questionar quais foram as razões que teriam impulsionado a seleção do sistema $\mathrm{F}$ em animais não humanos — tendo em vista que esse sistema é anterior à fixação dos primatas-, e qual componente de seu comportamento vocal teria propiciado seu desenvolvimento, isto é, o sistema F corresponde a (i) um subproduto das pressões seletivas que incidiram sobre o comportamento dos sinalizadores ou a (ii) um subproduto das pressões associadas ao comportamento dos receptores?

Enquanto as motivações subjacentes à produção vocal animal ainda são pouco evidentes, as características extraídas da percepção nos fornecem indícios de que animais não

\footnotetext{
${ }^{105}$ Deve ficar claro que essa descrição é apenas uma aproximação daquilo que seria a representação mental de um ATR no sistema $\mathrm{F}$ de um macaco-vervet. Certamente, há filigranas dessa representação que não são abarcadas por essa descrição, mas isso não impede que forneçamos uma caracterização da generalização que ela abrange.

${ }^{106}$ Como apontamos no final da seção 3.2, roedores e aves também produzem sinais vocais funcionalmente referenciais (Cf. WHEELER; FISCHER, 2012; TOWNSEND; MANSER, 2013) e, por extensão, também devem ser dotados de um sistema F.
} 
humanos —não apenas primatas — atribuem uma interpretação específica às respostas vocais dos sinalizadores. A relação entre um estímulo sensorial e uma vocalização permite que os receptores interpretem um sinal vocal como uma unidade funcionalmente referencial, atrelando-a, possivelmente, a uma representação mental do predador ou de um evento (ZUBERBÜHLHER; CHENEY; SEYFARTH, 1999; SEYFARTH; CHENEY, 1993, 1997, 2003; FEDUREK; SLOCOMBE, 2011). Seyfarth e Cheney (2003, p. 168) caracterizam essas divergências de estímulos envolvendo a produção e a percepção vocal de animais não humanos do seguinte modo:

\begin{abstract}
"A incapacidade dos animais para reconhecer os estados mentais de outros indivíduos coloca restrições importantes em sua comunicação e distingue a comunicação animal da linguagem humana. Com a possível exceção dos chimpanzés, animais não humanos não são capazes de representar os estados mentais de outros indivíduos. Como resultado, enquanto os sinalizadores podem vocalizar para alterar o comportamento de um receptor, eles não vocalizam com o objetivo específico de informar os demais ou em resposta à percepção da ignorância dos demais. Da mesma forma, enquanto os receptores extraem informações sutis das vocalizações, isso não inclui informações sobre o conhecimento do sinalizador. Os receptores adquirem informações de sinalizadores que, em um sentido humano, não têm a intenção de fornecê-las" (SEYFARTH; CHENEY, 2003, p. 168, tradução nossa). ${ }^{107}$
\end{abstract}

É bem sabido que a produção de vocalizações configura-se como uma atividade de risco, pois, ao vocalizar, um animal pode acabar revelando sua localização e a localização de seu grupo (SHERMAN, 1977; 1980; ZUBERBÜHLER; NÖE; SEYFARTH, 1997). Contudo, apesar do risco envolvido, diversos tipos de sistemas de vocalização foram selecionados em diferentes espécies. Sherman $(1977,1985)$ argumenta que a seleção desses sistemas está atrelada ao fato de que a produção vocal aumenta as chances de sobrevivência dos descendentes, uma vez que os sinais vocais podem alertar sobre a iminência de um ataque predatório. $\mathrm{O}$ autor argumenta também que a variedade acústica dos sinais vocais seria igualmente um produto de pressões decorrentes da seleção por parentesco, já que

\footnotetext{
${ }^{107}$ Trecho original: "The inability of animals to recognize the mental states of others places important constraints on their communication and distinguishes animal communication most clearly from human language. With the possible exception of chimpanzees, animals cannot represent the mental state of another. As a result, whereas signalers may vocalize to change a listener's behavior, they do not call with the specific goal of informing others or in response to the perception of ignorance in another. Similarly, whereas listeners extract subtle information from vocalizations, this does not include information about the signaler's knowledge. Listeners acquire information from signalers who do not, in the human sense, intend to provide it".
} 
vocalizações acusticamente distintas transmitem informações mais precisas acerca das estratégias de fuga a serem empreendidas.

No entanto, uma vez que não há por parte do sinalizador qualquer intenção de influenciar os estados mentais e o comportamento de seus coespecíficos, devemos presumir que a percepção vocal foi selecionada por razões distintas daquelas envolvendo a produção vocal. Seyfarth e Cheney (2003, p. 156) sugerem que deve ter havido uma coevolução de sinalizadores e receptores. Para os autores, a seleção natural favoreceu sinalizadores capazes de vocalizar de modo a alterar o comportamento dos receptores, embora não haja intenção comunicativa envolvida. Isso se deve ao fato de que as vocalizações conferem vantagens evolutivas ao sinalizadores de maneira indireta, pois quanto mais descendentes sobrevivem, maior é o compartilhamento de seu material genético. Simultaneamente, a seleção natural favoreceu receptores capazes de detectar correlações entre um sinal vocal e um evento no mundo, extraindo, assim, informações relevantes para sua sobrevivência.

Com base na hipótese da coevolução, de Seyfarth e Cheney (2003), conjecturamos que o sistema F configura-se como um subproduto das pressões seletivas que agiram sobre o comportamento dos receptores. Ao favorecer indivíduos capazes de extrair informações sobre entidades, eventos e situações, a seleção natural acabou tornando-os paulatinamente sensíveis a perceber esses grupos de categorias e, igualmente, a vocalizar nas circunstâncias em que eles se apresentam. Gradativamente, a percepção dessas categorias tornou-se uma propriedade inata à espécie. Elas passaram, então, a compor aquilo que nós caracterizamos como os ATR das células do sistema F. No caso de primatas não humanos, as informações transformadas em ATR compreendem classes de predadores, urgência para se empreender uma estratégia de fuga, movimentos de grupo, interações intergrupais e identidades em uma hierarquia social (SEYFARTH; CHENEY, 2003; CHENEY; SEYFARTH, 2005; DI BITETTI, 2003; SLOCOMBE et al., 2010; FEDUREK; SLOCOMBE, 2011).

Por fim, tratemos, brevemente, do papel do sistema F na espécie humana. Admitindose a validade da perspectiva racionalista subjacente à assunção desse sistema, devemos esperar que a espécie humana também apresenta um conjunto de ATR e que parte de sua experiência é circunscrita por suas categorias. Argumentamos, nesta tese, que o sistema F foi exaptado pela FL, na reorganização mental de que ela mesma resulta. Sendo assim, F compõe a FLB da mesma forma que os sistemas C-I e S-M. Conjecturamos que, após ser associado à FLN, F passou a fixar aquilo que entendemos como "traços formais", os quais servem como primitivos para o sistema combinatorial. Os ATR humanos não correspondem, obviamente, às categorias pré-adaptadas de primatas não humanos. Hipotetizamos que os ATR que integram 
o sistema $\mathrm{F}$ humano representam um conjunto de categorias mais genéricas, envolvendo, por exemplo, classificação categorial, quantidade, espaço, vinculação discursiva, as quais foram também, presumivelmente, selecionadas. Tal assunção explicaria a uniformidade dos domínios sintáticos que abrigam o léxico funcional humano translinguisticamente.

Veremos, no próximo capítulo, que o léxico funcional humano parece ser derivado de um conjunto restrito de categorias universais, as quais, a depender do modo como são fixadas por um sistema linguístico, acabam adquirindo características específicas a esse sistema (e.g., número vs. classificadores; tempo vs. aspecto, todos decorrentes de uma categoria universal, a ser melhor descrita). Essa assunção corresponde, essencialmente, à "Hipótese da Coluna Universal", proposta por Wiltschko $(2014,2015)$, a qual tomamos como um indicativo para a plausibilidade de um sistema $\mathrm{F}$ na espécie humana. Antes de passar a esclarecer como $\mathrm{F}$ foi integrado à FL e como ele opera fixando traços formais, iremos, no que resta deste capítulo, explorar quais são os fatores biológicos que impedem a expansão do repertório vocal primata de um ponto de vista ontogenético.

\subsection{Fatores biológicos que restringem a ampliação do repertório primata}

Bloom (2000, p. 242) comenta que a vida mental relativamente limitada de animais não humanos está associada à ausência de "palavras" em seus sistemas de comunicação. De fato, uma das inovações evolutivas que caracterizam a lacuna cognitiva entre a espécie humana e animais não humanos é o domínio de um extenso vocabulário. Diferentemente dos sistemas de vocalização animal, o léxico humano é consideravelmente mais extenso e elaborado, tendo em vista que suas entradas podem denotar uma ampla gama de conteúdos, que vão desde referentes concretos a referentes abstratos, eventos e propriedades. Entretanto, tendo em conta as características do comportamento vocal animal, quais fatores biológicos restringem, de um ponto de vista ontogenético, a ampliação de seu repertório vocal? Ou seja, o que impede que animais não humanos, em especial, primatas não humanos, sejam capazes de expressar conceitos além daqueles predeterminados geneticamente?

Para fornecer uma explicação a esse lacuna evolutiva, caracterizada por alguns autores como o Paradoxo de Hauser (2008 apud OTT, 2009, p. 260) ${ }^{108 / 109}$, exploramos, nesta seção,

\footnotetext{
${ }^{108}$ HAUSER, M. D. Humaniqueness. Annual meeting of the American Association for the Advancement of Science, 2008.

${ }^{109} \mathrm{O}$ Paradoxo de Hauser corresponde à assimetria entre as competências compartilhadas com animais não humanos e os impedimentos que bloqueiam sua ampla expressividade. Nas palavras de Hauser (2008): “Os animais compartilham muitas das peças que compõem o pensamento humano, mas, paradoxalmente, há uma
} 
propriedades da produção vocal primata e de sua percepção, avaliada agora de modo amplo. Restringimos nossa atenção ao comportamento de primatas não humanos devido à sua proximidade evolutiva com a espécie humana, pois isso nos fornece, paralelamente, uma dimensão aproximativa do que promoveu a ampliação do léxico humano. Argumentamos que há, pelo menos, dois fatores biológicos responsáveis por limitar a expansão do repertório vocal primata. O primeiro deles subdivide-se em duas restrições neurofisiológicas, as quais impedem, de um lado, a aquisição de novas vocalizações e, de outro, o estabelecimento de novos estímulos vocais como unidades referenciais. Essas duas restrições neurofisiológicas estão descritas em (30):

(30) Restrições neurofisiológicas que impedem a ampliação repertório vocal primata

a. Ausência da capacidade de aprendizagem vocal em primatas não humanos

Essa restrição impede a aquisição de novas vocalizações, somada à incapacidade de modificar e inventar novas vocalizações (Cf. FITCH; HAUSER, 1995; SEYFARTH; CHENEY, 1997; FISCHER et al., 2002; FITCH, 2004; FITCH; ZUBERBÜHLER, 2013, entre outros);

\section{b. Dotação de uma Teoria da Mente rudimentar}

Essa restrição impede a atribuição de estados mentais a outros indivíduos, impossibilitando, consequentemente, que eles tenham consciência das relações entre comportamentos e crenças de seus coespecíficos (Cf. SPERBER; WILSON, 1986; CHENEY; SEYFARTH，1990b，1997，2005; SEYFARTH; CHENEY, 1993, 1997, 2003; TOMASELLO et al. 2005, entre outros).

Já o segundo fator corresponde ao caráter predeterminado do repertório conceitual primata, o qual é circunscrito, em nossos termos, pelo número de ATR de seu sistema F. Como vimos na última seção, o conjunto das categorias conceituais passíveis de serem externalizadas é uma característica inata à espécie e, por essa razão, limitado pelo seu genótipo. A percepção primata, em contrapartida, é consideravelmente rica: primatas não humanos, bem como outras espécies de animais não humanos, são capazes de correlacionar amplamente estímulos vocais e não vocais a um conteúdo (CHENEY; SEYFARTH, 2005, p. 142). Isso nos indica que, embora primatas não humanos depreendam informações do mundo,

grande lacuna cognitiva entre humanos e animais." [Trecho original: "Animals share many of the building blocks that comprise human thought, but paradoxically, there is a great cognitive gap between humans and animals"]. 
presumivelmente na forma de representações conceituais, eles não são dotados de um dispositivo cognitivo que lhes permita manipulá-las. Acreditamos que esse dispositivo somente irá aparecer na espécie humana, através do surgimento de uma entidade vazia de conteúdo, o que equivale às raízes lexicais.

Para desenvolver essas nossas considerações, reunimos, no restante dessa seção, evidências que corroboram os dois grupos de fatores biológicos elencados acima. Para tanto, apresentamos, na subseção 3.4.1, evidências extraídas de trabalhos experimentais que endossam e, ao mesmo tempo, esclarecem as duas restrições neurofisiológicas apontadas em (30). Na subseção 3.4.2, listamos evidências retratadas em observações naturalísticas, bem como em resultados de trabalhos experimentais, as quais nos revelam a abrangência da percepção primata. Com esse conjunto de informações em mãos, será possível entender os limites do repertório vocal de primatas não humanos e, de maneira indireta, de outras espécies de animais não humanos.

\subsubsection{Restrições neurofisiológicas que limitam o repertório primata}

Iniciemos pela restrição neurofisiológica em (30a): a ausência de aprendizagem vocal em primatas não humanos. Em linhas gerais, essa restrição nos indica que a estrutura acústica das vocalizações primatas são inatas, ou seja, uma vocalização não se desenvolve a partir de estímulos externos ou através de instruções pedagógicas dos genitores e/ou de outros macacos adultos.

Uma das principais evidências que embasam a validade dessa assunção é a qualidade das vocalizações de alarme produzidas por macacos "Kaspar Hauser", ou seja, macacos criados em isolamento ou por mães mudas. Apesar de não receberem nenhum estímulo acústico do ambiente, esses indivíduos produzem naturalmente as vocalizações de alarme de sua espécie, nas circunstâncias esperadas (Cf. HARLOW et al., 1965; WINTER et al., 1973). Outra evidência para a estrutura inata das vocalizações está no comportamento de macacos criados por espécies adotivas, tal como observado em um experimento envolvendo macacos rhesus e macacos-japonês (Macaca fuscata). A espécie adotada —os macacos rhesus — não apresentou nenhuma alteração nas propriedades acústicas de suas vocalizações, produzindo-as 
com as mesmas características verificadas em sua espécie, quando em contexto isolado, e nas mesmas situações (OWREN et al., 1993; SEYFARTH; CHENEY, 1997). ${ }^{110}$

Além do caráter inato das vocalizações, primatas não humanos não são capazes de adquirir novos sinais vocais, ou seja, eles não dotados de aprendizagem vocal, tal como são os pássaros canoros, algumas espécies de cetáceos e os humanos modernos (NOTTEBOHM, 1975; OKANOYA, 2002, 2007; WILBRECHT; NOTTEBOHM, 2003; OKANOYA; MERKER, 2007, entre outros). Primatas não humanos raramente modificam seu repertório vocal através da aquisição de novas vocalizações. Algumas espécies são capazes de modificar sutilmente seus sinais; porém, essa habilidade não promove uma ampliação de seu repertório vocal (HAUSER, 1989, 1992; ELOWSON; SNOWDON, 1994; MITANI; BRANDT, 1994; SEYFARTH; CHENEY, 1997; CROCKFORD et al., 2004). Como destacam Cheney e Seyfarth (2005, p. 143), um babuíno no Quênia produz praticamente as mesmas vocalizações, nos mesmos contextos, que um babuíno em Botswana.

A rigidez da estrutura acústica das vocalizações primatas não impede, contudo, que eles tenham controle sobre sua produção vocal, ou seja, sobre quando vocalizar ou não. Tal afirmação contradiz a tese de Tallerman $(2007,2012)$, que argumenta que as vocalizações de alarme são eliciadas somente em contextos de pressão emocional, tal como na iminência de um ataque predatório. A autora sugere que vocalizações dessa natureza não são produzidas intencionalmente e não podem ser suprimidas. Contrariamente às expectativas da autora, Cheney e Seyfarth (1985a) mostram que os macacos-vervet deixam de produzir vocalizações de alarme quando estão sozinhos em contexto predatório. Além disso, macacos-vervet são capazes de alterar suas vocalizações a depender do grau de parentesco dos indivíduos nas proximidades (CHENEY; SEYFARTH, 1985b, 1988). ${ }^{111}$

Por exemplo, Cheney e Seyfarth (1985b) apontam que macacos-vervet fêmeas tendem a produzir maiores taxas de vocalizações de alarme quando estão na presença de sua prole do que quando estão na presença da prole de outras fêmeas. Nesse segundo contexto, as fêmeas podem ou (i) suprimir sua vocalização, ou (ii) realizá-las em menor intensidade. Da mesma forma, macacos-vervet machos tendem a produzir vocalizações de alarme em maior intensidade quando estão próximos a fêmeas do que quando estão próximos a outros machos dominantes, sendo que, nesse último contexto, eles mais as suprimem do que as realizam. $\mathrm{O}$

\footnotetext{
${ }^{110}$ Uma terceira evidência são as semelhanças acústicas entre as vocalizações de macacos-vervet infantes e a de macacos-vervet adultos, apontada na subseção 3.3.1 (SEYFARTH; CHENEY, 1986; 1997).

${ }^{111} \mathrm{O}$ mesmo comportamento foi observado em galos (Gallus gallus). Eles produzem vocalizações para aves predadoras apenas quando há um macho ou uma fêmea de sua espécie nas imediações (GYGER et al., 1986; KARAKASHIAN et al., 1988).
} 
que podemos inferir desse conjunto de observações é que a produção vocal primata não pode ser caracterizada meramente como um ato reflexo e involuntário, tal como sugere Tallerman $(2007,2012)$, muito embora suas vocalizações sejam extremamente rígidas no que concerne à sua estrutura acústica. ${ }^{112}$

Outra restrição neurofisiológica que engessa a ampliação do repertório vocal primata é a ausência de uma Teoria da Mente, apontada em (30b). Essa restrição indica que, embora as vocalizações sejam interpretadas como expressões funcionalmente referencias, elas não são produzidas com o intuito de modificar os estados mentais dos receptores. Como comentam Cheney e Seyfarth (1990a, 1997), uma vocalização de alerta diz respeito ao conhecimento do sinalizador, mas não a um conhecimento que ele pretende transmitir a seus coespecíficos. Por exemplo, macacos-vervet adultos não fazem qualquer esforço para corrigir infantes que recorrem a estratégias comportamentais antipredatórias equivocadas. Seyfarth e Cheney (1986, 1997) observaram que as estratégias empreendidas por macacos-vervet infantes normalmente os deixavam vulneráveis. ${ }^{113}$ Curiosamente, esse comportamento de risco não provocou qualquer reação instrutiva da mãe ou de algum outro macaco adulto, ou seja, não foi verificada nenhuma estratégia de pedagogia ativa por parte desses sujeitos a fim de instruir o infante.

A falta de pedagogia ativa decorre, de acordo com Seyfarth e Cheney $(1986,1997)$, do fato de que primatas não humanos não reconhecem as diferenças entre o que eles sabem e o que o infante sabe, e por essa razão, eles não buscam ensiná-los sobre os diferentes tipos de ataque dos predadores e sobre quais seriam as respostas comportamentais apropriadas para cada vocalização. Consequentemente, os infantes só irão passar a desempenhar um comportamento antipredatório adequado através da observação do comportamento de macacos adultos. Isso faz com que o processo de aprendizado evolua mais lentamente e com menor eficiência do que se envolvesse um sistema de transmissão de informações. Macacosvervet infantes apenas deixam de correr para a mãe ou de apresentar um comportamento de

\footnotetext{
${ }^{112}$ Os resultados obtidos no experimento de Zuberbühler, Cheney e Seyfarth (1999) fornecem evidências adicionais para a assunção de que vocalizações de alarme não constituem um ato reflexo, tendo em vista que as fêmeas produzem respostas mais amenas quando as características acústicas e semânticas do predador mantêm-se constantes. Caso contrário, toda vocalização produzida por um macho eliciaria a mesma taxa de respostas das fêmeas.

${ }^{113}$ Por exemplo, ao ouvir uma vocalização de alarme, os infantes ou corriam em direção às suas mães ou desempenhavam uma ação que os expunha aos predadores, tal como olhar para cima logo após a produção de uma vocalização para cobras, ou correr para um arbusto logo após a produção de uma vocalização para leopardos.
} 
risco por volta dos 4 meses de idade, um tempo considerável, como apontam os autores $(\mathrm{Cf}$. SEYFARTH; CHENEY, 1997, p. 254-255). ${ }^{114}$

Da mesma forma, primatas não humanos não buscam informar seus coespecíficos quando esses desconhecem a presença de alimento ou de perigo nas imediações. Cheney e Seyfarth (1990b) aplicaram um teste de transmissão de informações em macacos rhesus e em macacos-japonês, a fim de verificar se eles apresentavam algum nível de Teoria da Mente. Macacos rhesus e macacos-japonês, de acordo com os autores, normalmente produzem vocalizações de alerta quando se deparam com técnicos carregando redes —o que indica, metaforicamente, um distúrbio nas imediações_-, e quando são alimentados com suas frutas preferidas (e.g., maçãs). Para esse experimento, foram selecionados dois macacos, uma mãe e sua prole, e, para sua aplicação, esses sujeitos foram colocados em um local separado da arena onde estavam alocados; porém, permaneceram com total acesso visual à arena.

Em uma primeira situação, caracterizada como "situação de conhecimento", a mãe e a prole ficavam próximos um do outro. Eles podiam ver um ao outro, bem como podiam visualizar a arena vazia. Nessa situação, ambos observavam um técnico colocando maçãs em um cesto de alimentos na arena. Após a colocação das frutas, a prole era solta, passando a ter acesso ao cesto de alimentos. Em uma segunda situação, caracterizada como "situação de ignorância", a mãe e sua prole ficavam separados por um anteparo de aço, impedidos de ter contato físico. Nesse segundo contexto, somente a mãe podia ver as maçãs sendo colocadas no cesto. Em seguida, a prole era liberada na arena. O mesmo teste foi aplicado em uma condição de "perigo", em que, em vez de se colocar alimentos em um cesto, um técnico aparecia usando uma máscara cirúrgica, carregando uma rede e se escondendo atrás de uma árvore.

O raciocínio subjacente a esse experimento é o seguinte: se primatas não humanos, em particular, macacos, são sensíveis aos estados mentais de seus coespecíficos, ou seja, se eles levam em consideração o conhecimento daqueles que estão próximos quando produzem vocalizações de alarme ou vocalizações para alimentos, seria esperado que as mães produzissem uma maior taxa de vocalizações, ou alterassem de algum modo seu comportamento, nos contextos em que sua prole não tinha conhecimento daquilo que ela já sabia. Por outro lado, se esses indivíduos não são afetados pelos estados mentais daqueles que

\footnotetext{
${ }^{114}$ Outra observação que parece indicar a inabilidade de macacos em reconhecer os estados mentais de seus coespecíficos é a perpetuação da produção de vocalizações de alarme mesmo quando todos os membros do bando já avistaram o predador (CHENEY; SEYFARTH, 1981; 1985b). Se macacos fossem capazes de inferir os estados mentais e o conhecimento de seus coespecíficos, seria esperado que as taxas de vocalizações diminuíssem ou cessassem assim que todos estivessem cientes da presença de um predador nas proximidades.
} 
estão próximos, o comportamento das mães deveria ser similar nos dois contextos avaliados, independentemente de sua prole ter ou não conhecimento da presença de alimento ou de perigo nas imediações.

Em ambos os contextos investigados, verificou-se que o comportamento das mães permaneceu inalterado pelo conhecimento de sua prole. No experimento com as maçãs, as mães e as proles trocaram poucas vocalizações e não houve diferença na taxa de vocalizações produzidas pelas mães cujas proles tinham ou não conhecimento de alimento no cesto (CHENEY; SEYFARTH, 1990b, p. 745). No experimento com o "predador" (i.e., com o técnico carregando uma rede), as mães não produziram vocalizações de alarme em taxas mais altas do que nos contextos em que sua prole desconhecia a presença de perigo, nem mesmo buscaram orientá-las indicando a localização do técnico (CHENEY; SEYFARTH, 1990b, p. 745). O que se conclui com esses resultados, de acordo com os autores, é que, embora as mães reconheçam um descompasso entre seu conhecimento e aquele de sua prole, elas não desempenham nenhuma ação significativa para informá-la.

Cheney e Seyfarth (1990b, p. 745-746) ressaltam que os resultados negativos obtidos nesse experimento não levam a uma conclusão definitiva de que primatas não humanos não são dotados de uma Teoria da Mente; eles teriam, em vez disso, uma Teoria da Mente rudimentar. A justificativa é a seguinte: por mais que primatas não humanos reconheçam, em certo grau, a diferença entre seu conhecimento com relação ao dos demais, eles não alteram seu comportamento a fim de modificar seus estados mentais, ou seja, eles não buscam transmitir informações. Grosso modo, macacos não demonstram qualquer intenção de se comunicar. Tal característica, associada à sua incapacidade de aprendizagem e inovação vocal, inviabilizam as condições minimamente necessárias para que uma nova vocalização seja estabelecida e adotada pelo grupo, aumentando, desse modo, seu repertório vocal. Para que uma nova vocalização seja adotada, tanto os sinalizadores quanto os receptores devem ser capazes de atribuir intenções e crenças, uns aos outros, e de transmiti-las.

Cheney e Seyfarth (1997, p. 182) elaboraram um pequeno exercício para ilustrar a relevância de uma Teoria da Mente na formação e na aquisição de um vocabulário, o qual pode ser sintetizado da seguinte forma: imaginem, por exemplo, uma sociedade composta por dois indivíduos. Um deles vê uma borboleta pela primeira vez e produz um som ao olhar para ela, "kipepeo". O segundo indivíduo, ao observar a atitude do primeiro, conclui que a sequência de sons "kipepeo" refere-se à representação mental BORBOLETA. Sendo assim, a adoção de "kipepeo", seja por aprendizado associativo ou por uma convenção, irá exigir que ambos reconheçam que o outro indivíduo recupera a representação mental BORBOLETA toda 
vez que se enuncia "kipepeo". O que se observa é que a associação entre um estímulo acústico e uma representação mental, bem como sua transmissão entre os membros de uma comunidade, está intimamente associada à atribuição de estados mentais entre seus indivíduos.

Em resumo, podemos concluir que primatas não humanos apresentam impedimentos de diversas ordens para a ampliação de seu repertório vocal. A restrição neurofisiológica envolvendo aprendizagem vocal, apontada em (30a), proíbe que primatas não humanos sejam capazes de externalizar outros conceitos por meio da aquisição de novos sinais vocais. Já a restrição neurofisiológica atrelada à capacidade de atribuir estados mentais e de depreender o conhecimento de coespecíficos, em (30b), impede que um sinal vocal sutilmente modificado acabe adquirindo um valor comunicativo durante a ontogenia vocal, diferentes dos valores já determinados pré-adaptativamente. Acreditamos que essas duas restrições, em conjunto, impossibilitam que novos sinais vocais sejam empregados e interpretados referencialmente por primatas não humanos. Há ainda um fator representacional que deve ser levado em consideração, o qual será explorado mais detalhadamente na próxima subseção.

\subsubsection{Restrições representacionais que limitam o repertório primata}

É um fato bem conhecido que diferentes espécies de animais não humanos são capazes de associar um estímulo vocal a uma determinada representação conceitual. Darwin (1871, p. 83) já salientava essa capacidade, assinalando que, embora animais não humanos possam atrelar representações conceituais a estímulos sonoros, eles não são capazes de produzi-los na mesma escala. Enquanto o número de vocalizações emitidas por animais não humanos é altamente restrito, o número de representações conceituais que eles podem evocar é consideravelmente amplo. Por exemplo, os comportamentos que um cachorro exibe ao ouvir os estímulos sonoros "carro", "bola", "passear", "banho", sugerem que o animal atribui a cada uma dessas instruções vocais uma representação distinta (THOMPSON, 1995; KAMINSKI et al., 2004; CHENEY; SEYFARTH, 2005).

Primatas não humanos aprendem novas associações entre som e conteúdo, da infância à fase adulta, e esse aprendizado pode ser modificado durante o desenvolvimento do animal (CHENEY; SEYFARTH, 2005, p. 142). Tal habilidade é um dos exemplos mais notórios da assimetria entre produção e percepção vocal em primatas não humanos, pois, embora eles sejam capazes de depreender diversas representações conceituais do ambiente, eles não 
possuem habilidades de manipulá-las e de externalizá-las, tal como vimos na última subseção. Há, além dos impedimentos neurofisiológicos descritos, um impedimento representacional, o qual impede que as representações extraídas da percepção sejam empregadas pelo animal, tal como o são as categorias pré-adaptadas do sistema F. Grosso modo, "primatas não humanos dominam muitos conceitos para os quais eles não têm nenhuma palavra" (CHENEY; SEYFARTH, 2005, p. 149). ${ }^{115}$

Uma primeira evidência para a maleabilidade da percepção primata nos é fornecida pelos experimentos com macacos adotados por outras espécies. Embora os sujeitos adotados não adquiram as vocalizações da espécie adotiva, tanto a espécie adotada quanto a espécie adotiva aprendem a reconhecer e a responder às vocalizações um dos outros (SEYFARTH; CHENEY, 1997). De modo semelhante, macacos-vervet aprendem a distinguir e a responder às vocalizações de alarme produzidas por espécies distintas, tais como pássaros e ungulados (HAUSER, 1998; CHENEY, SEYFARTH, 1990a). A mesma habilidade foi observada em macacos diana e em macacos de Campbell (SNOWDON, 1990; ZUBERBÜHLER, 2002). Além disso, infantes e juvenis aprendem, durante seu desenvolvimento vocal, a distinguir quais espécies são perigosas e quais espécies são inofensivas, atrelando-as às vocalizações disponíveis (CHENEY; SEYFARTH, 1990, 2005; FISCHER; CHENEY; SERYFARTH, 2000). Isso nos sugere que eles são capazes de classificar, através de processos associativos, diferentes espécies em um conjunto de categorias, notadamente: predadores/não predadores, carnívoros terrestres, águias e cobras.

Cheney e Seyfarth (2005, p. 145-146) apontam também que primatas não humanos são extremamente sensíveis aos estímulos sonoros, vocais e não vocais, emitidos por outros indivíduos. Essas habilidades perceptuais permitem que primatas não humanos -e animais não humanos de modo geral — adquiram informações sobre a identidade do sinalizador e o contexto em que seus estímulos sonoros são eliciados. Por exemplo, quando capturados, primatas não humanos aprendem rapidamente a distinguir as vozes de seus tratadores e os possíveis significados atrelados a um novo estímulo acústico (e.g., o chacoalhar de chaves). Além da capacidade de associar estímulos vocais a uma representação conceitual, trabalhos experimentais nos revelam que primatas não humanos depreendem conceitos de diversas ordens, não apenas aqueles associados às vocalizações.

Emonds (2011, p. 56), ao revisar a literatura sobre a percepção primata, aponta que primatas não humanos são capazes de identificar entidades vivas e entidades de sua própria

\footnotetext{
${ }^{115}$ Trecho original: "Monkeys and apes have many concepts for which they have no words".
} 
espécie (i.e., animacidade), de distinguir ações de estados e de distinguir agregados sem forma aparente dentro de um conjunto de unidades discretas. Primatas não humanos também são capazes de distinguir quantificadores universais de quantificadores existenciais, locativos orientados para o sujeito (e.g., de dentro para fora, de cima para baixo) e são capazes de fazer operações aritméticas simples. Por exemplo, através de um trabalho experimental, Hauser, McNeilage e Ware (1996) revelam que os macacos rhesus da ilha de Porto Rico apresentam um sistema de quantificação espontâneo, o qual pode ser traduzido como representações conceituais dos números um, dois, três e muitos. ${ }^{116}$

Esse conjunto de informações acerca da percepção primata nos mostra que esses indivíduos são capazes de atrelar diversos estímulos vocais e não vocais a uma representação conceitual, e de extrair diferentes tipos de informações do mundo, além daquelas que são predeterminadas pelo seu sistema F. Possivelmente, tais habilidades perceptuais compõem parte de seu sistema C-I, tal como sugeriram Hauser, Chomsky e Fitch (2002). No entanto, embora primatas não humanos depreendam essas variadas informações, eles não são capazes de manipulá-las na forma de objetos simbólicos. Falta-lhes, em nosso entendimento, um dispositivo cognitivo, que os permita transformar as representações conceituais extraídas da percepção em entidades operáveis. A essa lacuna, soma-se (i) a natureza inata da estrutura acústica de suas vocalizações, (ii) a ausência de habilidades para aprendizagem vocal e (iii) uma Teoria da Mente desenvolvida, as quais engessam sobremaneira as possibilidade de expansão do repertório vocal primata.

É por essa razão que conjecturamos que a emergência da porção conceitual do léxico decorre de um dispositivo capaz de tornar as representações conceituais extraídas da percepção em objetos manipuláveis. Admitimos que esse dispositivo corresponde, grosso modo, às raízes lexicais. As raízes, unidades destituídas de conteúdo, passaram a ser associadas às representações conceituais da percepção, disponíveis no sistema C-I. Isso permitiu que essas representações fossem atreladas a uma estrutura sintática e, então, externalizadas através do sistema S-M. No próximo capítulo, veremos que esse item vazio

\footnotetext{
${ }^{116} \mathrm{O}$ experimento aplicado para se chegar a essa conclusão foi o seguinte: valendo-se da técnica da quebra de expectativa, foi apresentada a um grupo de macacos rhesus selvagens da ilha de Porto Rico uma beringela roxa e, em seguida, essa beringela era escondida atrás de um anteparo. Um dos pesquisadores implantava outra beringela atrás do anteparo e o removia, permitindo que o macaco pudesse contemplar as duas beringelas. Esperava-se, nesse experimento, que o macaco olhasse por mais tempo para casos em que havia uma alteração no número de beringelas do que quando o número mantinha-se o mesmo, antes e depois da remoção do anteparo. Os autores observaram que os macacos rhesus tendem a olhar por mais tempo quando o número de beringelas atrás do anteparo se altera. Nos diversos contextos em que o experimento foi aplicado, os autores puderam notar que esses macacos eram capazes de compreender as seguintes equações aritméticas: $1+1=2,2$ $+1=3,2-1=1$ e $3-1=2$, mas falhavam quando a soma é $2+2=4$.
} 
semanticamente pode ser derivado através da operação Merge, o que nos sugere que a emergência de um sistema combinatorial recursivo teria tido um papel fundamental na ampliação do léxico humano, bem como no aparecimento de expressões linguísticas idiossincráticas e não composicionais. ${ }^{117}$

\subsection{Resumo}

Propusemos que primatas não humanos e os humanos modernos compartilham um sistema $\mathrm{F}$ que os capacita a extrair informações de um conjunto predeterminado de categorias, as quais são privilegiadas para externalização. Dado o caráter inato desse conjunto de categorias, admitimos que elas recortam parte da experiência dessas espécies, fazendo com que suas habilidades sensoriais sejam sensíveis à conversão das categorias experienciadas em conhecimento. Em primatas não humanos, elas correspondem ao conjunto de entidades denotadas por suas vocalizações (e.g., classes de predadores, urgência para se empreender uma estratégia de fuga, movimentos de grupo, interações intergrupais e identidades hierárquicas), ao passo que, na espécie humana, elas correspondem às categorias que derivam os traços formais (e.g., classificação categorial, quantidade, espaço, vinculação discursiva).

Ao atrelar o sistema $\mathrm{F}$ ao léxico funcional, colaboramos para uma expansão dos estudos envolvendo as bases biológicas do léxico humano e, ao mesmo tempo, fornecemos uma hipótese alternativa à assunção de que os átomos da computação sintática decorrem da GU. Com isso, evitamos sobrecarregar a influência do genótipo humano no desenvolvimento da linguagem. Argumentamos, no próximo capítulo, que a competência lexical humana não é um produto de modificações graduais aplicadas a um único precursor filogenético, nem mesmo resulta de um caractere específico ao genótipo humano. Pelo contrário, a competência lexical humana decorre das habilidades que compõem os sistemas pré-adaptados presentes na FLB, notadamente, os sistema F, C-I e S-M, e de sua associação à operação Merge.

Os detalhes técnicos da integração entre esses sistemas, bem como a formação e expansão do repertório lexical humano serão discutidos em detalhes a seguir.

\footnotetext{
${ }^{117} \mathrm{O}$ raciocínio é basicamente o seguinte: se as raízes fossem plenamente especificadas, ou seja, se cada raiz correspondesse a uma representação conceitual particular — tal como é o caso dos sistemas de vocalização primata-, não atestaríamos palavras com significados polissêmicos e não composicionais na linguagem humana, como discutimos na subseção 3.3.2.
} 


\section{Capítulo 4}

\section{A abordagem isomórfica}

A Abordagem Isomórfica (AI) compreende uma nova perspectiva sobre a interface entre o léxico e a sintaxe. Ela se fundamenta na hipótese de que esses dois componentes da gramática evoluíram separadamente. As bases filogenéticas do léxico humano são analisadas como sendo externas à $\mathrm{FL}$, tendo sido cooptadas no evento evolutivo que deu origem à sintaxe, mais especificamente, à operação Merge. Essa assunção reduz o papel do genótipo humano -i.e., da GU — no desenvolvimento da FL, satisfazendo o critério de adequação evolutiva colocado pelo Problema de Wallace-Darwin. Do ponto de vista operacional, a AI incorpora a visão neoconstrucionista de que a derivação da estrutura sintática independe de informações codificadas nas entradas lexicais. Tal conjectura assegura a autonomia funcional da sintaxe, o que, consequentemente, nos aproxima do caminho para se ir "além da adequação explicativa".

\subsection{Introdução}

A AI é uma proposta antilexicalista e neoconstrucionista acerca da articulação entre o léxico e a sintaxe. Ela assume que há uma única classe de primitivos lexicais disponíveis para a computação sintática —os traços formais—, os quais procedem de um molde isomórfico fornecido por um sistema externo à FL, o sistema F. Disso deriva o seu nome. Para essa proposta, a estrutura interna da FL segue, estritamente, as diretrizes colocadas pela SMT (CHOMSKY, 2000, 2001, 2004, 2010a), compondo-se apenas de um sistema combinatorial recursivo, Merge, e das interfaces com os sistemas externos. Tais assunções representam as bases epistemológicas dessa nova abordagem para a gramática, a ser descrita neste capítulo. Serão explorados seu escopo evolutivo, ou seja, como a AI se alinha ao critério de adequação 
evolutiva, e seu escopo explicativo, isto é, como ela atua na descrição e na explicação dos fenômenos linguísticos.

Para iniciar nossa discussão, iremos, primeiramente, descrever os cinco pressupostos gerais que fundamentam a organização interna e o funcionamento da arquitetura da gramática vislumbrada pela AI. Esses cinco pressupostos foram elaborados com base nos desiderata elencados no Capítulo 2 e estão definidos em (31):

(31) Pressupostos gerais da Abordagem Isomórfica

- Pressuposto \#1

Os sistemas cognitivos subjacentes ao léxico humano são externos à FL.

* Pressuposto \#2

A FL compõe-se unicamente de Merge e dos mapeamentos para as interfaces.

- Pressuposto \#3

Merge é o único mecanismo gerativo capaz de derivar objetos linguísticos.

\section{* Pressuposto \#4}

Traços formais são os únicos primitivos da gramática.

\section{* Pressuposto \#5}

As estruturas derivadas por Merge têm seus nós terminais associados tardiamente a um conteúdo fonológico.

Seguindo o pressuposto 1, postulamos que as bases cognitivas do léxico humano são compartilhadas com animais não humanos. No que concerne à porção funcional do léxico, admitimos que há um sistema externo à $\mathrm{FL}$, o sistema $\mathrm{F}$, que, uma vez exaptado, passou a fixar os traços formais da linguagem. Já a porção conceitual do léxico deriva da integração entre a operação Merge e o sistema C-I, o qual também foi exaptado (HAUSER; CHOMSKY; FITCH, 2002; BOLHUIS et al., 2014; BERWICK; CHOMSKY, 2016). A primeira aplicação de Merge dá origem a uma posição estrutural vazia - i.e., a um conjunto vazio-, que será associada a um conteúdo conceitual na interface com o sistema C-I. Em outras palavras, para a AI, as raízes são definidas estruturalmente, em paralelo às propostas de de Belder (2011) e de Belder e van Craenenbroeck (2015). Essa nossa formalização leva em conta a vacuidade semântica das raízes, tal como idealizada por Harley (2014).

À posição estrutural que abriga o conteúdo conceitual da estrutura sintática -i.e., ao nó terminal comumente ocupado pelas raízes_-, damos o nome de "átomo conceitual", definido em (32): 
(32) Átomo conceitual

Átomo conceitual (AC) é um conjunto vazio resultante da primeira aplicação da operação Merge. Esse conjunto corresponde a um nó terminal da estrutura sintática, a ser preenchido por um conteúdo conceitual pós-sintaticamente.

O pressuposto 2 reflete as diretrizes colocadas pela SMT. Seu propósito é assegurar uma caracterização mínima da GU e, com isso, diminuir a influência de caracteres exclusivos ao genótipo humano no desenvolvimento da linguagem. É válido observar que, para se obter uma sintetização efetiva da GU, devemos considerar os pressupostos 1 e 2 em conjunto. Será através deles que seremos capazes de eliminar a sobrecarga imposta pelo léxico. Além disso, a inovação evolutiva instanciada pela GU, Merge, deve corresponder a um mecanismo combinatorial simples, cuja aplicação está dissociada da valoração de traços. Merge aplica-se ilimitadamente. Em conformidade com Chomsky (2013a, 2015), assumimos também que o núcleo de um objeto linguístico derivado por Merge é determinado através de um sistema de busca mínima, decorrente de princípios do terceiro fator. Essa simplificação de Merge nos fornece uma representação da GU coerente com o desenvolvimento recente da FL.

Em (33), fornecemos a definição de Merge adotada pela AI, a qual foi apresentada parcialmente no Capítulo 2. A definição integral em (33) contempla, em (33b), a formação de um AC. Em (34), definimos quais itens gramaticais servem como um objeto sintático (OS) para as aplicações de Merge, com base nas considerações de Hornstein (2017, p. 74) e Collins (2017, p. 50). Percebam que, de acordo com as estipulações em (34), tanto primitivos lexicais, em (34a), quanto expressões complexas, em (34b), podem servir como um OS. Tais estipulações caracterizam a natureza recursiva dessa operação, uma vez que, ao poder se aplicar sobre os próprios objetos gerados, Merge é capaz de dar origem a um número irrestrito de estruturas sintáticas.

(33) Merge

a. Dados dois OS $\alpha$ e $\beta$, forme um conjunto $\{\alpha, \beta\}$. $\mathrm{M}(\alpha, \beta)=\{\alpha, \beta\}$

b. Na ausência de um OS servindo como input, forme um conjunto vazio. $\mathrm{M} \rightarrow\{\}=\varnothing$. 
(34) Domínios para as aplicações de Merge
a. Se $\alpha$ é um primitivo lexical, então $\alpha$ é um OS.
b. Se $\alpha$ é um OS e $\beta$ é um OS, então $\{\alpha, \beta\}$ é um OS.
c. Para $\alpha, \beta$, e o conjunto de OS derivados por Merge, $\mathrm{M}(\alpha, \beta)=\{\alpha, \beta\}$.

O pressuposto 3 determina que encaixamento estrutural somente pode ser estabelecido através de Merge. Isso implica que a FL inclui um único mecanismo gerativo, responsável por derivar tanto a estrutura interna das palavras quanto a estrutura interna das sentenças. Tal premissa define o caráter antilexicalista da AI, paralelo ao que propõem a MD (HALLE; MARANTZ, 1993; MARANTZ, 1997) e o modelo XS (BORER, 2003, 2005a, 2005b, 2013). Ainda, o pressuposto 3 impede que haja encaixamento de entradas lexicais internamente ao léxico. Essa conjectura inibe a formação de hierarquias funcionais pré-sintáticas, de entradas lexicais complexas e de feixes de traços formais. Em nossa perspectiva, o léxico humano deve ser interpretado como uma lista de primitivos isolados e desprovidos de uma estrutura interna, os quais, uma vez inseridos no espaço computacional, servem como um núcleo sintático independente; nos moldes de XS, do programa cartográfico e da abordagem nanossintática.

Assumimos, adicionalmente, que a FL contém apenas uma única classe de primitivos gramaticais: traços formais. Essa assunção está caracterizada no pressuposto 4. Sendo assim, a AI não estabelece uma diferença entre lexical versus funcional no que diz respeito aos nós sintáticos. Todos os nós terminais são funcionais, sintaticamente ativos e interpretáveis. Esse posicionamento parte de considerações feitas nos trabalhos de Marantz (1995), de Belder (2011), Acedo-Mattelán e Real-Puigdollers (2014) e de Belder e van Craenenbroeck (2015). Os AC, em (32), não devem ser entendidos como um primitivo da gramática, tal como são as raízes para a MD e os listemas para o modelo XS. Um AC tem somente o papel de delimitar um espaço da estrutura sintática a ser preenchido por um conteúdo conceitual na interface interpretativa. Dado que esse conteúdo conceitual não influencia o funcionamento sintático, ele não deve estar presente pré-sintaticamente, como assinalam Marantz (1995), Acquaviva (2009a), Acquaviva e Panagiotidis (2012), Harley (2014), entre outros.

A premissa de que a sintaxe opera concatenando apenas traços formais alinha-se à hipótese de que a linguagem humana emergiu como um sistema do pensamento (CHOMSKY, 2011, 2015, 2016). De acordo com essa hipótese, a competência linguística humana reside na capacidade de organizar símbolos em arranjos estruturais legíveis pelo sistema interpretativo C-I. Nos termos da AI, a emergência de Merge possibilitou que as células pré-adaptadas do sistema $\mathrm{F}$, as quais tomam a forma de traços formais internamente à FL, fossem combinadas 
em estruturas sintáticas hierarquicamente arranjadas. Essas estruturas passaram a integrar uma linguagem internalizada, semanticamente rígida. Sua rigidez semântica resulta do conteúdo fixo atrelado aos traços formais. Paralelamente, a operação Merge deu origem a nós terminais destituídos de conteúdo, os quais permitiram que um mesmo arranjo de informações formais pudesse ser associado a diferentes conteúdos conceituais pós-sintaticamente.

Essa hipótese está ilustrada na estrutura em (35). O conteúdo fixo dos traços formais promove uma leitura invariável da estrutura derivada. A presença de um AC possibilita que esse mesmo arranjo seja atrelado a mais de um conteúdo conceitual na interface interpretativa (e.g., cachorro, livro, filho, etc.). ${ }^{118}$ Em vista disso, a AI hipotetiza que Merge tenha dotado os primeiros humanos modernos de um sistema do pensamento altamente composicional e uniforme de um ponto de vista interpretativo. Esses indivíduos passaram a manipular o conhecimento extraído de seus ATR e a associá-los estruturalmente. Os AC, por sua vez, possibilitaram que os arranjos derivados pudessem incorporar os conteúdos extraídos da percepção, atomizando-os na forma de objetos linguísticos. A integração entre as estruturas semanticamente rígidas derivadas por Merge e os conteúdos conceituais disponíveis em C-I ampliou enormemente o poder expressivo da espécie.

$$
\begin{aligned}
\{\mathrm{DP}<\mathrm{D}, \mathrm{DEF}>,\{\mathrm{QP}<\mathrm{Q}, 3>,\{\mathrm{NumP}<\mathrm{Num}, \mathrm{SG}> & ,\{\}\}\}\} \\
& \rightarrow \text { SEM: cachorro, livro, filho, }[\ldots]
\end{aligned}
$$

Por outro lado, a externalização dessas estruturas formadas deve ser vista como um fenômeno secundário, tal como especifica o pressuposto 5. Isso implica que todo traço formal é abstrato. Desse modo, traços formais —alocados em um Léxico-I(nterno) — somente serão associados a um expoente fonológico - alocados em um Léxico-E(xterno) - no caminho para a interface com o sistema S-M. Essa conjectura também se estende aos AC. Com isso, buscamos levar às últimas consequências a assimetria entre os sistemas C-I e S-M, apontada em Chomsky (2004, 2007, 2008, 2010a, 2013a, 2016), a saber: a visão de que o mapeamento para o sistema C-I tem precedência sobre o mapeamento para o sistema S-M. ${ }^{119}$ A sintaxe

\footnotetext{
${ }^{118}$ Partimos da assunção de que os conteúdos conceituais manipulados pela sintaxe são acategoriais, ou seja, um conteúdo conceitual somente se torna um nome, um verbo ou um adjetivo a depender da estrutura sintática em que é inserido. Evidências para a natureza acategorial dos conteúdos conceituais, comumente atrelados às raízes lexicais, podem ser encontradas nos trabalhos de Marantz (1997, 2001, 2008), Borer (2003, 2005a, 2013), Embick e Noyer (2007), Pietroski (2008, 2012), Harley (2014), entre outros.

${ }^{119}$ Argumentos em favor dessa assimetria são a ausência de ordenamento nas expressões derivadas por Merge e a necessidade de formação de cadeias de cópias, fundamentais para o sistema C-I, mas descartadas pelo sistema S-M (Cf. CHOMSKY, 1995; NUNES, 2004). Há que se mencionar também que, além dos ajustes estruturais utilizados para se derivar a distribuição superficial das entradas lexicais de uma língua —e.g., a
} 
deriva arranjos estruturais convenientes para a interpretação semântica, os quais necessitam de ajustes estruturais para se adequar à interpretação fonológica. A AI busca tornar explícita essa divisão entre as contrapartes I e E do léxico humano, já que, além de desempenharem funções gramaticais distintas, elas presumivelmente decorrem de precursores filogenéticos distintos.

Após essa breve exposição dos pressupostos gerais da AI, exploramos, nas próximas seções, seus componentes e seu funcionamento. Para tanto, na seção 4.2, descrevemos a arquitetura para a gramática concebida pela $\mathrm{AI}$ e o modo como o sistema $\mathrm{F}$ se integra à FL. Na seção 4.3, discutimos a universalidade das categorias funcionais, a fim de identificar quais são os ATR que compõem as células do sistema $\mathrm{F}$ humano. Na seção 4.4, apresentamos a estrutura elementar do molde isomórfico - i.e., da célula de $\mathrm{F}$ - a partir do qual os traços formais são derivados. Veremos como esse molde isomórfico pode dar origem à variedade de traços formais verificada translinguisticamente. Na seção 4.5, caracterizamos a emergência da porção conceitual do léxico humano sob a ótica da AI. Apontamos os mecanismos formais que associam um AC a uma instrução conceitual na interface interpretativa e, paralelamente, a uma instrução fonológica. Por fim, na seção 4.6, mostramos como a AI satisfaz os desiderata para uma sintaxe autônoma, elencados no Capítulo 2.

\subsection{A Abordagem Isomórfica e a arquitetura da gramática}

Iniciamos nossa caracterização da AI apresentando sua arquitetura da gramática. No que diz respeito a seus primitivos gramaticais, propomos, com base nos pressupostos 1 e 2 , que eles derivam de uma interface que a FL faz com o sistema F. Nesse sentido, o que Chomsky $(2000,2001,2004,2007)$ comumente rotula de "conjunto de traços F fornecido pela GU" passa a ser descrito, nesta tese, como um caractere dissociado das propriedades exclusivas ao genótipo humano; logo, dissociado da GU. Os traços formais disponíveis para a computação sintática decorrem, em nossa perspectiva, do conjunto de ATR presente no sistema $\mathrm{F}$ da espécie humana. Uma vez que $\mathrm{F}$ é compartilhado com animais não humanos, tal como são os sistemas S-M e C-I (Cf. HAUSER; CHOMSKY; FITCH, 2002; SAMUELS, 2011, 2015; YIP, 2006; BOLHUIS et al., 2014; BERWICK; CHOMSKY, 2016, entre outros), F também deve integrar a FLB, tal como apontamos no Capítulo 3.

acomodação de uma estrutura sintática ao Léxico-E disponível-, o caminho para a interface com o sistema S$M$ introduz uma série de recursos fonológicos que não estão necessariamente presentes nas entradas lexicais, tais como acento e entoação. 
Dessa forma, propomos que a FLB -i.e., o conjunto de caracteres biológicos inerentes à linguagem, compartilhados por homologia ou por analogia com animais não humanos - compõe-se de, pelo menos, três sistemas pré-adaptados. São eles:

I. Um sistema F, responsável por extrair do mundo informações sobre um conjunto predeterminado de categorias conceituais, privilegiadas para externalização;

II. Um sistema C-I, responsável pela interpretação;

III. Um sistema S-M, responsável pela externalização.

Partindo da distinção FLB/FLN, discutida no Capítulo 2, sugerimos que a emergência de um sistema combinatorial recursivo, ocorrida possivelmente na reestruturação genética que deu origem à entidade física H. sapiens, há 175.000-200.000 anos atrás (WHITE et al., 2003; MCDOUGALL; BROWN; FLEAGLE, 2005), promoveu uma reorganização do cérebro e da mente humanos, recrutando um conjunto de sistemas pré-adaptados para a linguagem (HAUSER; CHOMSKY; FITCH, 2002). Esses sistemas, notadamente, F, C-I e S-M, passaram a ser mediados por um mecanismo combinatorial, Merge, cuja expressão deriva provavelmente de uma propriedade específica ao genótipo humano, sendo, por esse motivo, relegado à FLN. Como resultado da integração entre a FLB e a FLN, as células fixadas por F, até o momento isoladas, foram então concatenadas na forma de estruturas hierarquicamente arranjadas e, subsequentemente, interpretadas semântica e fonologicamente pelos sistemas de desempenho, C-I e S-M.

Admitimos ainda, seguindo o pressuposto 3, que a FLN reduz-se à operação Merge e às interfaces com os sistemas externos, tal como preconiza a SMT. É importante salientar que essas interfaces devem ter sido estabelecidas, a priori, por uma questão de necessidade conceitual, o que, em linhas gerais, traduz-se como uma imposição de princípios do terceiro fator. Isto é, dado que a FLN representa um sistema combinatorial capaz de gerar expressões legíveis pelos sistemas externos, segue-se, por necessidade conceitual, que esses sistemas incluindo o sistema que fornece os primitivos a serem combinados- devem ter acesso à FLN. ${ }^{120}$ Assim, por hipótese, a FLN representa um sistema ótimo para satisfazer as condições de legibilidade impostas pelos sistemas com os quais dialoga (CHOMSKY, 1993, 1995, 2000,

\footnotetext{
${ }^{120}$ As considerações de necessidade conceitual determinam propriedades não específicas à linguagem. De modo geral, essas considerações buscam evidenciar que a organização interna da FLN não deriva de uma predeterminação genética específica à espécie, mas decorre de pressões impostas por leis biofísicas gerais, as quais regem o mundo natural. Uma discussão mais detalhada pode ser encontrada em Chomsky (2004, p. 105106).
} 
2004), recorrendo a uma maquinaria interna mínima capaz de derivar expressões passiveis de serem interpretadas (CHOMSKY, 2000, p. 112-113). ${ }^{121}$

Em vista disso, argumentamos que a FLN dispõe de três interfaces distintas para interagir com os sistemas externos elencados acima, nomeadamente:

I'. Traço Zero $\left(f_{0}\right)$, que faz interface com o sistema F;

II'. SEM, que faz interface com o sistema C-I;

III'. PHON, que faz interface com o sistema S-M.

No que concerne à interface entre a FLN e o sistema F, assumimos que sua articulação implementa-se de modo semelhante à Tese da Raiz Zero, proposta por Sigurđsson (2012). A interface $f_{0}$ corresponde, em linhas gerais, a uma célula interna à FLN, destituída de conteúdo, a qual será arbitrariamente preenchida pelo resultado da fixação de uma célula do sistema F. ${ }^{122}$ No momento em que a interface $f_{0}$ é associada a uma célula fixada por F, ela produz um traço formal interno à FLN, $f_{1}$, em uma dada língua L. $f_{1}$ será, então, armazenado em um Léxico-I, ou seja, em uma lista não ordenada de primitivos internos à FLN. Logo após, a FLN cria uma cópia de $f_{0}$, tornando essa interface disponível novamente. A nova cópia será preenchida por outra célula fixada por $\mathrm{F}$ e assim sucessivamente. A hipótese de que os primitivos do Léxico-I ingressam na FLN por meio de uma interface com o sistema F nos permite assegurar a simplicidade da GU pretendida pela SMT.

Tendo em vista esse conjunto de assunções, a reorganização física e mental guiada pela emergência da FLN, mais especificamente de Merge, dá origem a uma arquitetura da gramática nos moldes da representação ilustrada na Figura 7:

\footnotetext{
${ }^{121} \mathrm{O}$ termo "legibilidade" indica que as expressões formadas a partir da operação Merge devem ser legíveis pelas interfaces com as quais interage, notadamente, as interfaces com os sistemas de desempenho, C-I e S-M. Para o PM, esses sistemas têm acesso à FLN, a qual deve satisfazer certos requisitos mínimos por eles impostos, a fim de que as descrições estruturais derivadas sejam interpretadas e, eventualmente, externalizadas.

122 "Fixação" corresponde à atribuição de um valor a um determinado ATR do sistema F. Assim, uma vez que uma célula de F é fixada, ou seja, uma vez que um par ordenado $<$ ATR, VAL $>$ é estabelecido, seu resultado é inserido na FLN através de $f_{0}$. Por exemplo, a atribuição, em F, do valor 'plural' ou 'passado' a um atributo que viabiliza a depreensão dessas categorias é o que licenciará o ingresso dessa célula na FLN.
} 
Figura 7. Integração entre FLB e FLN de acordo com a AI.

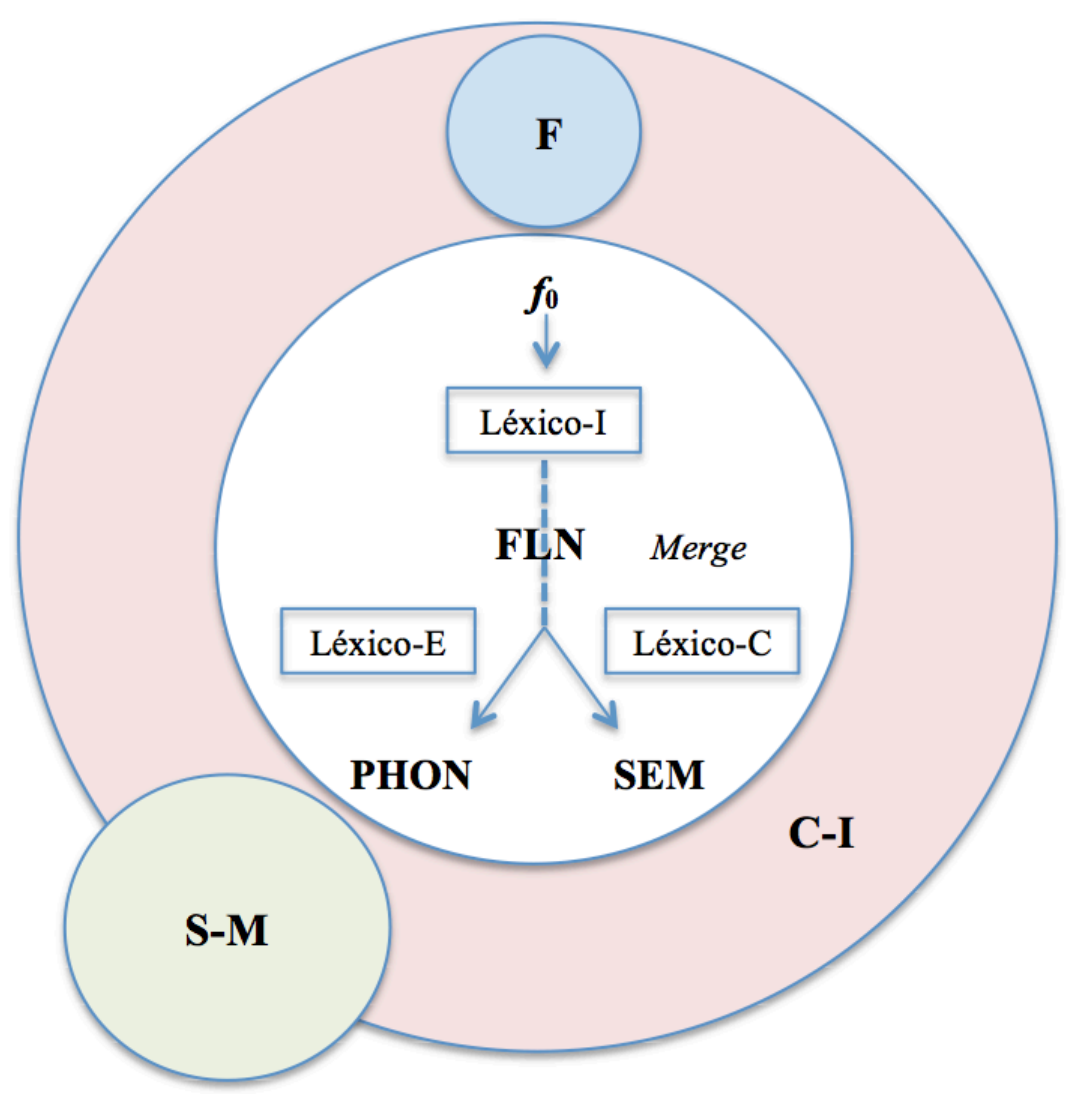

Antes de explorar as filigranas da Figura 7, é importante ressaltar que, para a AI, o repertório lexical humano não corresponde a um objeto monolítico, cuja evolução procede de um único precursor biológico. Pelo contrário, o repertório lexical humano, tal como a própria FL, decorre da junção de caracteres biológicos que evoluíram separadamente. A impressão de que as entradas lexicais provêm de um mesmo componente da gramática é meramente superficial e resultado de inclinações teóricas, como se observa em diversas abordagens lexicalistas (Cf. CHOMSKY, 1970, 1981, 1993, 2000, 2007; HALLE, 1973; ARONOFF, 1976; DI SCIULLO; WILLIAMS, 1987; LIEBER, 1992; SAG; WASOW; BENDER, 2003, entre outros). Por esse motivo, seguimos a perspectiva da MD, de que as competências que integram o repertório lexical humano estão distribuídas pela gramática na forma de três listas dissociadas, todas elas não gerativas e constituídas por informações específicas, a saber: 
- Léxico-I(nterno), que abriga o banco de primitivos linguísticos oriundos da interface $f_{0}$, ou seja, o conjunto de traços formais de uma língua $\mathrm{L}$;

- Léxico-E(xterno), que abriga as regras que associam tanto os primitivos do Léxico-I quanto os AC derivados por Merge a instruções fonológicas;

- Léxico-C(onceitual), que abriga os conteúdos conceituais extraídos da percepção, atomizados na forma de objetos linguísticos. Esses conteúdos irão ser associados aos AC derivados por Merge.

Essa divisão recupera as três listas assumidas pela MD (Cf. MARANTZ, 1995, 1997; EMBICK; NOYER, 2007; HARLEY, 2014). O Léxico-I está para a Lista 1/A, diferindo dela por ser constituído unicamente por traços formais, ao passo que o Léxico-E está para a Lista 2/B, ou seja, o "Vocabulário". Por fim, o Léxico-C está para a Lista 3/C, a "Enciclopédia", que abriga o conhecimento de mundo do falante. Quando avaliamos essas três porções do léxico humano, notamos que cada uma delas procede de habilidades vinculadas a sistemas cognitivos distintos. Enquanto o Léxico-I está intimamente associado às células fixadas pelo sistema F, o Léxico-E está atrelado a habilidades como aprendizagem vocal e à capacidade de segmentação de cadeias sonoras, as quais estão incluídas no sistema S-M; bem como a uma Teoria da Mente, tendo em conta a discussão que fizemos na subseção 3.4.1. Já a parte conceitual do repertório lexical resulta de habilidades perceptuais fornecidas pelo sistema C-I, que possibilitam a aquisição de representações conceituais não linguísticas.

Dessa maneira, podemos afirmar que a origem da competência lexical humana está diretamente atrelada à reorganização física e mental promovida por Merge. A competência lexical não deve ser analisada como um produto de modificações graduais aplicadas a um único precursor filogenético, tal como sugerem Wray (1998, 2000, 2001) e Mithen (2005, 2009), ou como um caractere inovador específico ao genótipo humano, tal como sugere Chomsky (2000, 2001, 2004, 2007). De acordo com nossa hipótese, a competência lexical humana emerge quando as habilidades que compõem os três sistemas pré-adaptados em FLB passam a ser mediadas por Merge. Essa reorganização propicia a manipulação das células fixadas por F, bem como das representações conceituais extraídas da percepção, alocadas em C-I. Em um segundo momento, esses arranjos estruturais são preenchidos com instruções fonológicas extraídas das habilidades que constituem o sistema S-M. 
Portanto, de acordo com a AI, não há uma relação de precedência entre as origens da sintaxe e do léxico humanos. A sintaxe, bem como aquilo que vimos a entender como o léxico, devem ter surgido simultaneamente. ${ }^{123}$

Recuperando a hipótese de que a linguagem humana emergiu originalmente como um sistema do pensamento, a representação da Figura 7 deve ter atingido tal configuração após a seguinte sequência de eventos: as descrições estruturais derivadas por Merge, constituídas dos primitivos fixados por F, alimentaram inicialmente apenas o sistema C-I. Algum tempo depois, o sistema S-M foi anexado à FLN. Como assinala Chomsky:

“[...] em algum momento, os modos de externalização foram estabelecidos. $\mathrm{Na}$ medida em que as condições do terceiro fator operam, a GU seria otimizada com relação à interface C-I, enquanto os mapeamentos para a interface S-M corresponderiam à 'melhor maneira possível' para se satisfazer as condições impostas pela externalização" (CHOMSKY, 2007, p. 14, tradução nossa). ${ }^{124}$

Assim sendo, posteriormente à integração dos sistemas F e C-I à Merge, o sistema S$\mathrm{M}$ foi associado à FLN, a qual vinha se desenvolvendo como uma solução ótima para as condições impostas pelas interfaces $f_{0}$ e SEM. A melhor conexão entre a FLN e o sistema S$\mathrm{M}$ foi estabelecida tardiamente. ${ }^{125}$

Conjecturamos também que o sistema C-I inclui o componente referencial instanciado por F. Essa assunção tem por objetivo vincular o conteúdo das categorias veiculadas por $\mathrm{F}$ ao conjunto de habilidades que compõem as competências conceituais da espécie, instanciadas por C-I. Com isso em mente, admitimos que as categorias pré-adaptadas, necessariamente categorizadas por um organismo - i.e., o conjunto de ATR de F-, são associadas a um

\footnotetext{
${ }^{123}$ É importante salientar que o Léxico-E e o Léxico-C contêm as chamadas "informações aprendidas" do conhecimento lexical humano, tal como rotularam Hockett (1960a, 1960b), além de Pinker e Jackendoff (2005). A arbitrariedade na associação de um conteúdo a uma instrução fonológica exige um aprendizado compartilhado entre os membros de uma comunidade, e que, portanto, devem ser aprendidos socialmente. Isso vale também para os resíduos históricos dessas associações, tais como os diferentes tipos de alomorfia, as irregularidades e defectividades dos padrões flexionais, os sincretismos e outros fenômenos morfofonológicos. Outras informações aprendidas são as idiossincrasias semânticas, verificadas em palavras derivadas (e.g., caipirinha), palavras compostas (e.g., casca grossa) e expressões idiomáticas (e.g., engolir sapos). Essas idiossincrasias devem igualmente ser aprendidas e armazenadas em nosso conhecimento de mundo.

${ }^{124}$ Trecho original: "At some stage modes of externalization were contrived. Insofar as third factor conditions operate, UG would be optimized relative to the CI interface, and the mappings to the SM interface would be the 'best possible' way of satisfying the externalization conditions".

${ }^{125}$ Evidências para a hipótese da externalização tardia são encontradas não apenas nas assimetrias observadas entre os sistemas C-I e S-M, mas também na distância temporal envolvendo as evidências genômicas que demarcam a emergência de uma competência linguística em oposição ao aparecimento dos primeiros registros arqueológicos que sinalizam a expressão de um comportamento mediado simbolicamente (Cf. HUIJBREGTS, 2017). Exploraremos essas evidências com mais detalhes no próximo capítulo.
} 
determinado valor por intermédio de C-I. Dito em outras palavras, o sistema F corresponde à porção inata, isto é, geneticamente determinada, das categorias do mundo suscetíveis a serem traduzidas em representações mentais, ou seja, em conhecimento. Enquanto F constitui-se de um conjunto de categorias inatas, os valores atribuídos a cada uma dessas categorias, embora circunscritos por um ATR, dependem da percepção para sua fixação. Tal assunção justifica a necessidade de se incluir o sistema F em C-I na representação da Figura 7. ${ }^{126}$

Tendo em mente essas considerações acerca da organização interna do conhecimento linguístico humano, podemos descrever a FL como um mosaico de propriedades, tal como sugerem Boeckx $(2012,2013 b)$ e Zuberbühler (2013). Isso se deve ao fato de que a FL é composta por diferentes componentes, análogos ou herdados de outras espécies, os quais foram rearranjados em um novo contexto. Com base no que já foi dito sobre cada um dos sistemas que a integram, resumimos suas relações filogenéticas com respeito à espécie humana na Figura 8, abaixo, inspirada nas discussões de Fujita (2017, p. 184): ${ }^{127}$

\footnotetext{
${ }^{126}$ Essa conjectura implica que parte das representações conceituais que integram o sistema C-I deriva de categorias predeterminadas geneticamente, o que corresponde, em nossos termos, aos ATR do sistema F. Por outro lado, as demais representações conceituais alocadas no sistema C-I, as quais preenchem os AC, independem dessas categorias predeterminadas para serem depreendidas. É válido lembrar que as habilidades subjacentes à sua depreensão, ou seja, à aquisição de representações conceituais não linguísticas, são também compartilhadas com animais não humanos (HAUSER, CHOMSKY; FITCH, 2002, p. 1573). Deixamos em aberto a questão do quanto essa segunda parte do sistema C-I é regulada por predeterminações inatas. É evidente que as representações que integram essa segunda parte diferem das categorias fixadas por $\mathrm{F}$, dado que essas últimas são, presumivelmente, resultado de pressões adaptativas.

${ }^{127}$ Essa caracterização da FL nos diz muito sobre o modo como ela deve ter emergido. Dado esse panorama, não há como admitir um gradualismo, como defendem autores que postulam a existência de uma protolinguagem (Cf. BICKERTON, 1990, 1995, 1998, 2000; PINKER; BLOOM, 1990; NEWMEYER, 1991, 1998; JACKENDOFF, 1999, 2002; HURFORD, 2012, entre outros), nem mesmo um total saltacionismo, em que a FL surge, em sua totalidade, de modo abrupto (Cf. CHOMSKY, 1980b). Como dissemos, a FL não é um objeto uniforme e monolítico, mas um mosaico cujas peças foram, hipoteticamente, reunidas há muito pouco tempo. A maior parte de seus componentes é homóloga ou análoga a outras espécies, e vêm evoluindo há milhões de anos, tal como é o caso dos sistemas F, C-I e S-M, enquanto outra parte, Merge e as interfaces, são provavelmente resultado de um aparecimento abrupto, pontual, possivelmente um produto da integração de suboperações mais elementares. Desse modo, não há razões para se defender que a FL resulta inerentemente de um gradualismo, ou mesmo de um saltacionismo (Cf. CLARK, 2013; BOECKX, 2013a; MIYAGAWA, 2017).
} 
Figura 8. Relações filogenéticas dos componentes da FL com a espécie humana.

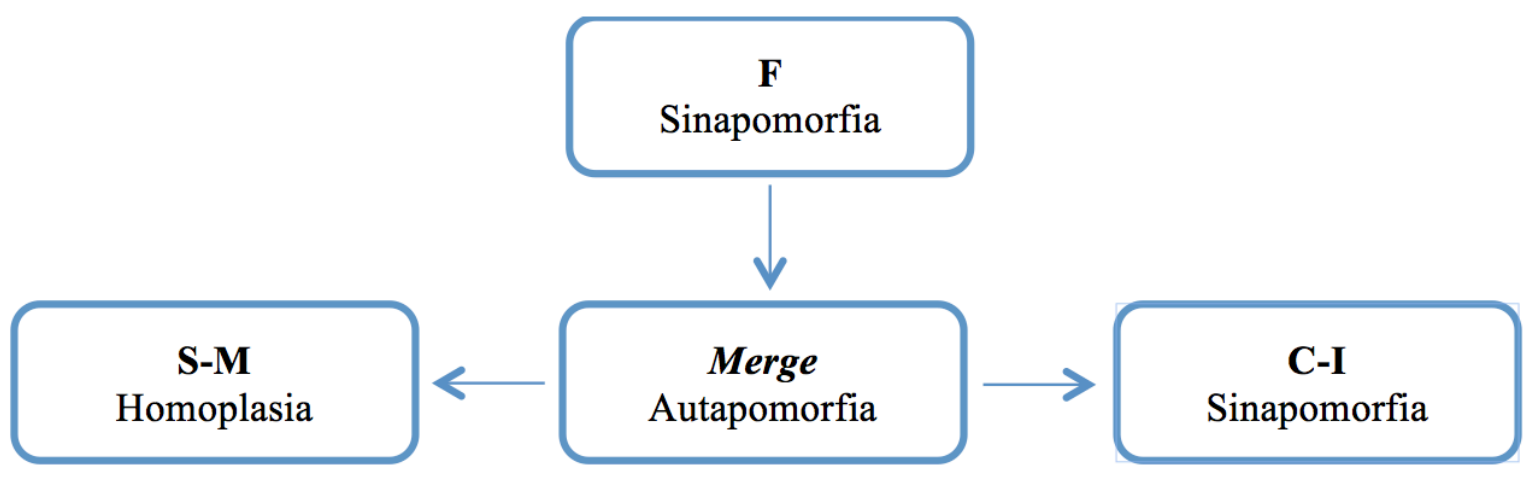

A operação Merge configura-se sugestivamente como o único componente humano da FL (HAUSER; CHOMSKY; FITCH, 2002; CHOMSKY, 2005, 2010a, 2013a, 2015, 2016, 2017; BERWICK; CHOMSKY, 2011, 2016; BOULHUIS et al., 2014, EVERAERT et al., 2015, entre outros). ${ }^{128}$ Merge constitui uma autapomorfia, ou seja, um caractere exclusivo a um único táxon, sem paralelos na natureza. ${ }^{129}$ Essa conclusão, apesar de ponderada por alguns autores (Cf. FUJITA, 2009, 2017; HORNSTEIN, 2009; BOECKX, 2009, 2011c, 2013a, 2013b, 2015; BOULHUIS; OKANOYA; SCHARFF, 2010; MIYAGAWA; BERWICK; OKANOYA, 2013; MURPHY, 2015a, 2015b, entre outros), representa um progresso nos estudos sobre a evolução da linguagem, já que, ao se reduzirem as habilidades exclusivamente humanas da competência linguística à Merge, somos capazes de assegurar que o descompasso lógico envolvendo complexidade versus tempo deixe de projetar a FL como uma anomalia do

\footnotetext{
${ }^{128}$ Embora a operação Merge não seja mencionada explicitamente em Hauser, Chomsky e Fitch (2002), ela está presente nas entrelinhas de sua argumentação, uma vez que a FLN é descrita como um mecanismo recursivo capaz de gerar estruturas sintáticas legíveis pelos sistemas C-I e S-M. É fácil notar a menção indireta à Merge em citações como "a FLN é um sistema computacional que gera representações internas e as mapeia para a interface sensório-motor através do sistema fonológico, e para a interface conceitual-intencional através do sistema semântico (formal) [...] Todas as abordagens concordam que a propriedade central da FLN é a recursividade" (FLN is a computational system that generates internal representations and maps them into the sensory-motor interface by the phonological system, and into the conceptual-intentional interface by the (formal) semantic system [...] All approaches agree that the core property of FLN is recursion) (HAUSER; CHOMSKY; FITCH, 2002, p. 1571).

${ }^{129}$ Por isso o radical grego aut, em autapomorfia, que significa "sozinho".
} 
ponto de vista evolutivo. ${ }^{130}$ Como bem aponta Boeckx (2013b, p. 7), "quanto mais atribuímos à FLB, mais a FL torna-se biologicamente viável". ${ }^{131}$

Os sistemas F e C-I, por sua vez, são uma sinapomorfia. Isto é, a semelhança desses dois sistemas com o que se observa nas habilidades conceituais de primatas não humanos decorre do fato de que ambos os taxa herdaram esses caracteres diretamente de seu ancestral comum, que devia ser dotado de F e C-I. Assim, os sistemas F e C-I devem ser vistos como caracteres homólogos, já que são presumivelmente compartilhados com o ancestral comum entre primatas não humanos e humanos. O sistema S-M, por outro lado, corresponde a uma homoplasia, ou seja, a um caractere paralelo às competências vocais observadas em pássaros canoros, decorrente de paralelismo ou de convergência evolutiva, mas não de ancestralidade. Certas habilidades do sistema S-M, em especial, aprendizagem vocal, devem ter emergido de modo independente em pássaros e em humanos, os quais compartilham um ancestral comum há aproximadamente 300 milhões de anos atrás (Cf. BENTON, 1990, p. 420; KUMAR; HEDGES, 1998, p. 917). ${ }^{132}$

Para tornar essas relações filogenéticas mais evidentes, recuperamos, na Figura 9, os diagramas arbóreos apresentados em Page e Holmes (1998, p. 21). A diferença entre cada uma dessas relações está na distribuição dos nós preenchidos em oposição aos nós vazios. Enquanto a autapomorfia apresenta um único nó isolado preenchido, a sinapomorfia apresenta dois nós preenchidos decorrentes de um nó mãe comum. Ou seja, dada nossa explicação, os

\footnotetext{
${ }^{130}$ Além disso, a operação Merge parece estar intimamente associada a outras faculdades cognitivas, tais como as habilidades combinatoriais envolvendo a música (Cf. BERWICK, 2011b; KATZ; PESETSKY, 2009) e a matemática (Cf. CHOMSKY, 2008, 2010a; TUTUSAUS, 2012). Se tais correlações forem, de fato, comprovadas, então a hipótese de Darwin (1871, p. 103), de que a emergência da competência linguística teria promovido o aparecimento de outras faculdades cognitivas, está no caminho certo. Além disso, essas correlações são altamente satisfatórias quando consideramos o problema lógico da emergência da linguagem.

${ }^{131}$ Trecho original: "[...] the more we attribute to FLB, the more biologically feasible FL becomes". Ver também Boeckx (2009, p. 46-48).

${ }^{132}$ Além das habilidades listadas por Hauser, Chomsky e Fitch (2002), resumidas no Quadro 1, Yip (2006) e Samuels $(2009,2011,2015)$ apontam outras habilidades do sistema S-M comuns a pássaros canoros, a saber: (i) agrupamento de classes naturais; (ii) agrupamento de sons em sílabas, pés e unidades mais complexas; (iii) aprendizagem de padrões e (iv) aprendizagem e produção de alternâncias com base em regras. Há ainda semelhanças que vão além dos paralelismos com a estrutura interna do canto, tal como a presença de um período crítico para aquisição do canto e da fala (Cf. DOUPE; KUHL, 1999; BOLHUIS; OKANOYA; SCHARFF, 2010), a necessidade de exposição ao canto/fala adulto para a aquisição (Cf. THORPE, 1958; MARLER, 1970), semelhanças nas estratégias empreendidas pelo infante na aquisição (Cf. LIU; GARDNER; NOTTEBOHM, 2004; O'GRADY, 2005), dependência de mecanismos neurais similares (Cf. DOUPE; KUHL, 1999; PFENNING et al., 2014), entre outras. Essa grande quantidade de paralelismos levou alguns autores a conjecturarem que há mecanismos genéticos homólogos conservados entre esses dois taxa, muito embora eles tenham divergido há pelo menos 300 milhões de anos. Bolhuis, Okanoya e Scharff (2010, p. 751), por exemplo, sugerem, no que diz respeito à aprendizagem vocal, que pássaros canoros e humanos fazem uso de regiões cerebrais análogas e homólogas e que, por esse motivo, aprendizagem vocal emerge em um cenário em que há tanto homologia quanto convergência. Isso nos indica que caracterizar o sistema S-M como uma homoplasia talvez não seja a estratégia mais adequada, embora assumamos isso por ora. Mais trabalhos serão necessários para se desvendar as relações filogenéticas que S-M apresenta com a espécie humana.
} 
sistemas F e C-I decorreriam de um ancestral comum (i.e., o nó mãe preenchido), herdados pelas espécies descendentes, primatas não humanos e humanos (i.e., os dois nós filhos preenchidos). Já a homoplasia apresenta nós preenchidos; porém, distantes em ancestralidade. Em nosso contexto, elas sugerem que pressões seletivas semelhantes estiveram presentes em taxa distantes - i.e., pássaros e humanos—, e em ambos promoveram independentemente a fixação das habilidades incluídas no sistema S-M.

Figura 9. Diagramas arbóreos representando as relações filogenéticas de autapomorfia, sinapomorfia e homoplasia. Os nós vazios representam caracteres ancestrais. Os nós preenchidos estão para as proximidades evolutivas entre um caractere derivado.

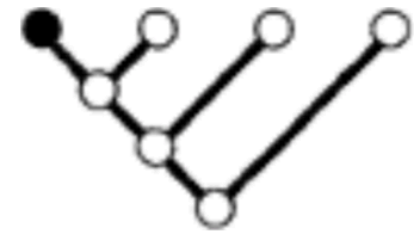

Autapomorfia

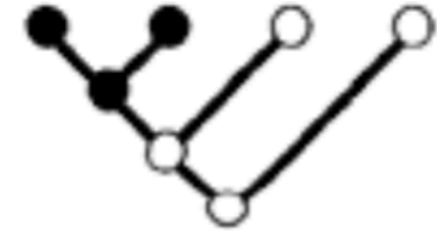

Sinapomorfia

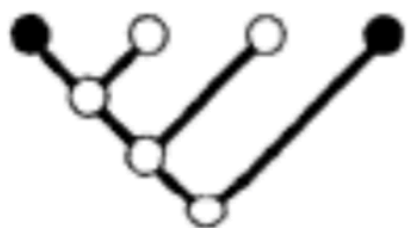

Homoplasia

Fonte: Page e Holmes (1998, p. 21).

Um último ponto acerca dos componentes da FL deve ser esclarecido: a concepção de que Merge corresponde a uma inovação evolutiva sem precedentes. Essa conjectura é alvo de inúmeros questionamentos. A razão é a seguinte: caracteres inovadores, como é o caso de Merge, normalmente resultam de mecanismos ou de sistemas já disponíveis, os quais são reciclados em um novo contexto. Embora alguns caracteres aparentem certo grau de inovação, o esperado é que eles sejam "em grande parte resultado de uma reorganização, não produto de genes inovadores”, tal como destaca West-Eberhard (2005, p. 6547). ${ }^{133}$ Ou seja, é improvável que o surgimento de um novo caractere instancie uma inovação plena (Cf. WAGNER; MÜLLER, 2002; MOCZEK, 2008; PRUD’HOMME et al., 2011). Essa expectativa conflita com a hipótese de que Merge resulta integralmente de uma mutação ocorrida exclusivamente na espécie humana, tal como sugerido por Chomsky $(2005,2010 \mathrm{~b}){ }^{134}$

\footnotetext{
${ }^{133}$ Trecho original: "[phenotypic novelty] is largely reorganizational rather than a product of innovative genes".

${ }^{134}$ É importante frisar que Chomsky recorre à ideia de uma mutação para a linguagem desde antes do PM (Cf. CHOMSKY, 1980b). Al-Mutairi (2014, p. 41) aponta que, anteriormente ao PM, Chomsky recorria à assunção de que teria havido uma "mutação arbitrária" na espécie, a qual teria ocasionado a emergência da linguagem como um todo; essa assunção é a base de sua visão saltacionista, altamente criticada em Pinker e Bloom (1990). Ela difere, consideravelmente, daquilo que o autor passou a defender após a publicação de Hauser, Chomsky e Fitch (2002).
} 
Assim, uma hipótese parcimoniosa — considerando-se o que se sabe sobre inovação fenotípica— é a de que um novo caractere emerge da reorganização de diferentes mecanismos pré-adaptados, cujos efeitos coletivos dão origem ao que parece ser uma inovação (BOECKX, 2013 b, p. 8). Seria esperado, nesse sentido, que Merge fosse da mesma forma um produto de mecanismos elementares rearranjados, os quais teriam sido exaptados de outras espécies ou de outros domínios cognitivos. Uma solução para esse impasse seria decompor a operação Merge em operações mais elementares, tal como fez Boeckx $(2006,2009)$. O autor sugere que Merge corresponde à união de outras duas suboperações, "Concatenar" e "Copiar", ambas identificáveis em outros domínios cognitivos. Em sua visão, a operação Merge não deixa de ser uma inovação evolutiva; porém, ao desmembrá-la, seu surgimento passa a se alinhar à expectativa de que inovações não emergem “do nada", já que as suboperações “Concatenar” e "Copiar" seriam ancestrais. ${ }^{135}$

No que concerne a habilidades combinatoriais, podemos afirmar, com certo grau de certeza, que os sistemas combinatoriais observados na natureza não ultrapassam a fronteira de gramáticas de estado finito, como mostram Yip (2006), Berwick et al. (2011), Heinz e Idsardi (2013), Samuels (2009, 2011, 2015) e Schlenker et al. (2016). Assim, algum fator adicional, exclusivo à espécie, deve ter propiciado a emergência de um mecanismo combinatorial com as propriedades de Merge. ${ }^{136}$ Chomsky não descarta a possibilidade de se decompor Merge em operações mais elementares (PIATTELLI-PALMARINI; URIAGEREKA; SALABURU, 2009, p. 51). Para o autor, a inovação evolutiva reduz-se a um mecanismo combinatorial irrestrito, que, como dissemos, não apresenta correlatos homólogos ou análogos nos sistemas de comunicação animal. Se sua intuição estiver correta, a autapomorfia com relação à Merge restringe-se ao ingrediente que permitiu que a espécie humana migrasse de um sistema combinatorial de estado finito a um sistema combinatorial de estado não finito. ${ }^{137}$

\footnotetext{
${ }^{135}$ Outra proposta que parte desse mesmo raciocínio é a Hipótese da Integração, sugerida nos trabalhos de Miyagawa, Berwick e Okanoya (2013), Miyagawa et al. (2014), Nóbrega e Miyagawa (2015) e Miyagawa (2017). Os autores conjecturam que os produtos de Merge resultam da integração de dois sistemas préadaptados, um sistema lexical, paralelo ao que se observa nos sistemas de alarme de primatas não humanos, do qual as entradas lexicais derivariam, e de um sistema expressivo, compartilhado com pássaros canoros, do qual habilidades combinatoriais mais rudimentares derivariam. Esses dois sistemas teriam sido incorporados unicamente na espécie humana, o que levaria à impressão de que as habilidades combinatoriais emergentes correspondem a uma novidade evolutiva. Há que se mencionar também os trabalhos de Fujita $(2009$, 2017), que argumenta que a operação Merge resulta de habilidades de encaixamento observadas em atividades motoras. Ver também Jackendoff (2007), Pulvermüller (2010), Stout (2010), Arbib (2012) e Knott (2012).

${ }^{136}$ Notadamente, um sistema combinatorial recursivo, fundamentalmente binário, cujos itens combinados encontram-se em uma relação assimétrica (i.e., um deles figura como o núcleo).

${ }^{137}$ Outros autores, como Hornstein (2009), Murphy (2015a, 2015b) e Goucha, Zaccarella e Friederici (2017), defendem que a inovação evolutiva atrelada à linguagem não está nas habilidades combinatoriais implementadas por Merge, mas em um mecanismo de rotulação, o qual asseguraria a endocentricidade das estruturas geradas, bem como sua interpretação pelos sistemas de desempenho. Hornstein (2009), por exemplo,
} 
Nesta tese, admitimos que a operação Merge corresponde a uma inovação evolutiva. Não descartamos, igualmente, a possibilidade de que essa operação tenha sido o resultado da reorganização de habilidades mais elementares. Isto é, embora Merge configure-se como uma inovação evolutiva, isso não implica que ela tenha emergido "do nada". Apesar de não entrarmos em detalhes sobre uma possível decomposição dessa operação, assumimos que ela diz respeito a um caractere exclusivo à espécie humana - i.e., uma autapormorfia - e que seu surgimento tenha redefinido consideravelmente os componentes semânticos e fonológicos cooptados para a linguagem. ${ }^{138}$ Por hipótese, a FLN/GU deve corresponder a uma operação ainda mais elementar do que aquilo que vimos apontando e seu funcionamento deve incluir outros princípios mais gerais, como sugere Chomsky (2013a, 2015); um assunto que não iremos aprofundar neste trabalho, pois ele ultrapassa o escopo de nossas questões. Essas conjecturas dependem, obviamente, de um conjunto maior de investigações interdisciplinares para serem legitimadas. ${ }^{139}$

propõe que a operação Merge deve ser decomposta nas suboperações "Concatenar" e "Rotular", sendo essa última exclusiva à espécie humana (ver também HORNSTEIN; NUNES, 2008). Apesar dessa proposta contradizer a hipótese de que rotulação é um epifenômeno, como defende Chomsky (2013a, 2015), acreditamos que elas não são totalmente excludentes. Pressões impostas pelo sistema interpretativo C-I podem ter levado à reorganização de um mecanismo combinatorial preexistente (i.e., "Concatenar"), fazendo com que suas aplicações obedecessem uma configuração binária $\{\mathrm{X}, \mathrm{XP}\}$, única à espécie. Uma sugestão preliminar para resolver esse impasse poderia levar em conta o seguinte cenário. "Concatenar" corresponderia, a princípio, a uma operação recursiva $n$-ária capaz de gerar somente estruturas planas (i.e., $\mathrm{C}(\alpha, \beta)=\alpha \beta)$. Essa operação seria compartilhada com outras espécies de animais não humanos. Os sistemas de comunicação animal que empregam "Concatenar" veiculam informações apenas através de sequências de segmentos, em que um dado elemento segue o elemento precedente sem qualquer estruturação hierárquica (Cf. YIP, 2006; GOUCHA; ZACCARELLA; FRIEDERICI, 2017). Na ausência de informações estruturais adicionais, um sistema que produz apenas sequências lineares impede a transmissão de informações mais elaboradas; fato que se justifica pela natureza holística dos conteúdos expressos por longas sequências de segmentos em animais não humanos (Cf. para pássaros, ver MARLER, 2000; BERWICK et al., 2011; para primatas não humanos, ver ARNOLD; ZUBERBÜHLER, 2006a, 2006b, 2008, 2012, 2013; SCHLENKER et al., 2016). O sistema C-I, visando extrair um conjunto maior de informações dessas sequências de segmentos, teria imposto combinações de constituintes dois a dois, promovendo o caráter binário de Merge, tal como descrito em (33a). Com essas configurações binárias estabelecidas, um sistema de busca mínima, nos moldes de Chomsky (2013a, 2015), poderia então determinar o núcleo de um objeto derivado, ampliando a expressividade do novo sistema combinatorial. A operação "Rotular" não seria uma inovação evolutiva, como propõem os autores acima, mas um epifenômeno decorrente de princípios do terceiro fator. Dado que Merge também é capaz de mover constituintes, a operação "Copiar" seria um bônus (HORNSTEIN, 2017, p. 78). Isso asseguraria a natureza combinatorial irrestrita dessa nova operação e, paralelamente, evitaria a assunção de uma operação "Copiar" independente, contra Boeckx (2006, 2009). De acordo com essa nossa breve sugestão, apresentada apenas como um projeto de solução alternativa, não haveria uma FLN. A FLB incluiria a operação "Concatenar", sendo a inovação evolutiva os efeitos coletivos desses sistemas reorganizados e a binariedade imposta por C-I a "Concatenar".

${ }^{138}$ Para a fonologia, ver Yip (2006), Samuels (2009, 2011, 2015); para a semântica, ver Uriagereka (2008), Hinzen (2007, 2011), Searle (2009), Pietroski (2011).

${ }^{139}$ Se for possível demostrar que a operação Merge é um produto da junção de caracteres exaptados e de princípios mais gerais da natureza, então, não haveria nada exclusivamente humano para a linguagem, como já destacamos anteriormente. A FL corresponderia apenas a um conglomerado de caracteres cooptados. Dito em outras palavras, se certos aspectos das habilidades combinatoriais forem, de fato, compartilhados com outras espécies e/ou domínios cognitivos, tal como sugerem Boeckx (2006, 2009) e Miyagawa, Berwick e Okanoya (2013), e se rotulação for realmente um epifenômeno de princípios do terceiro fator, então devemos assumir 
No que segue, descrevemos as bases de nossa proposta para a emergência do léxico e de sua articulação com a sintaxe. Dada a centralidade da operação Merge na reorganização dos sistemas pré-adaptados para a linguagem, mostramos como a assunção desse mecanismo combinatorial é capaz de explicar não apenas as propriedades combinatoriais da gramática, bem como as circunstâncias que levaram ao surgimento do repertório lexical humano. Assim, buscamos reconstruir a teoria sintática a partir de Merge; uma tarefa central para o PM, como frisa Jackendoff (2011, p. 591). Para tanto, exploramos inicialmente as evidências disponíveis para se admitirem categorias universais subjacentes ao repertório de traços formais da linguagem humana. Essa investigação é fundamental para se ratificar a validade de um sistema F na espécie e, paralelamente, para se identificar quais são os ATR que constituem esse sistema F. Será esse o tópico que desenvolveremos na próxima seção.

\subsection{A base universal das categorias funcionais}

Ao investigar as categorias funcionais empregadas pelas línguas naturais, percebemos uma contradição em sua distribuição. Por um lado, encontramos evidências de que o conjunto de categorias funcionais é universal, dada a regularidade dos domínios funcionais observados translinguisticamente (e.g., a sequência C-T- $v$-V). Por outro, notamos que os inventários de categorias funcionais das línguas são variados e podem ser constituídos por categorias cujos conteúdos diferem consideravelmente. ${ }^{140}$ Por exemplo, o mandarim e um grande número de línguas austronésias fazem uso de classificadores numerais (CL), ilustrados com os dados em (36), uma categoria funcional que está ausente nas línguas indo-europeias (AIKHENVALD, 2000, p. 121). Já as línguas indo-europeias dispõem de uma categoria funcional tempo, a qual está ausente em siksiká (WILTSCHKO, 2014, p. 12). ${ }^{141}$ No exemplo em (37), a mesma forma verbal pode indicar tanto um evento ocorrido no presente quanto um evento ocorrido no passado.

que não há nenhum caractere fornecido exclusivamente pelo genótipo humano. A sintaxe, bem como o léxico, decorreriam de sistemas e de operações já disponíveis na natureza. Embora acreditemos que essa área de investigação esteja caminhando para uma conclusão como essa, destacamos que ainda é muito cedo para se afirmar categoricamente que não há nada exclusivamente humano para a linguagem.

${ }^{140}$ De modo geral, essas categorias são descritas pela literatura como "gramaticais", já que incluem as categorias lexicais: nome, verbo e adjetivo. Uma vez que, nesta tese, admitimos que o conjunto de categorias gramaticais, incluindo os núcleos nominalizadores, verbalizadores e adjetivizadores, correspondem a nós funcionais, iremos tratá-las como categorias "funcionais", a fim de evitar qualquer conflito de nomenclatura mais adiante.

${ }^{141}$ Do inglês, Blackfoot. 
(36) Mandarim (WILTSCHKO, 2014, p. 13)
um CL gato
'um gato'
a. yi4 zhil maol
b. sanl zhil maol
três CL gato
'três gatos'

(37) Siksiká (LOUIE, 2008 apud WILTSCHKO, 2014, p. 13) ${ }^{142}$
a. Anna
Mai'stoo
isttso'kiniwa
ann-wa
Mai'stoo-wa isttso'kini-wa
DEM-PROX
Corvo-PROX
com fome.AI-PROX
'Mai'stoo está com fome' ou 'Mai'stoo estava com fome'
b. Anna Mai'stoo áíhpiyiwa.
ann-wa Mai'stoo-wa á-ihpiyi-wa
DEM-PROX Corvo-PROX IMPF-dançar.AI-PROX
'Mai'stoo está dançando' ou 'Mai'stoo estava dançando'

Esse descompasso entre a distribuição sistemática das categorias funcionais e a ampla variedade dos conteúdos por elas expressos nos coloca duas questões cruciais. Primeiro, como caracterizar a natureza das categorias funcionais? Ou seja, de que modo sua distribuição e sua variedade podem ser definidas de acordo com a AI? E, em segundo lugar, em que sentido podemos dizer que as categorias funcionais correspondem a uma propriedade universal, determinada pela competência linguística humana, e, assim, motivar a presença de um sistema F na espécie? Encontramos, na literatura, três hipóteses distintas para explicar a disparidade entre a distribuição e a variedade das categorias funcionais das línguas naturais. Nas próximas três subseções, exploramos cada uma dessas hipóteses em separado. Iremos, no fim, nos filiar à última hipótese, a "Hipótese da Coluna Universal", para responder as duas questões acima. Será a partir dessa última hipótese que extrairemos as bases dos ATR que compõem o sistema F humano.

\footnotetext{
${ }^{142}$ LOUIE, M. Blackfoot's non-affirmative endings: Topical NPIs with existential wide-scope. Manuscrito. University of British Columbia, Vancouver, 2008.
} 


\subsubsection{Hipótese da ausência de uma base universal}

A primeira hipótese defende a inexistência de categorias funcionais universais (Cf. JOOS, 1957; DRYER, 1997; HASPELMATH, 2007). Em outras palavras, "as línguas podem diferir umas das outras sem limites e de modos imprevisíveis" (JOOS, 1957, p. 96). ${ }^{143}$ Os proponentes dessa hipótese — majoritariamente tipólogos e funcionalistas - assumem que o repertório de categorias funcionais é potencialmente infinito e que, ao cerceá-lo, estaríamos impedindo a identificação de novas categorias. De acordo com essa perspectiva, a conjectura de que há classes de palavras e relações gramaticais comuns translinguisticamente não passa de uma invenção (DRYER, 1997, p. 117). Tal posicionamento teórico retira da GU qualquer influência que ela possa apresentar na determinação do léxico humano (CROFT, 2001, p. 34). Observem que essa primeira hipótese privilegia a variedade de conteúdos veiculados pelas categorias funcionais e, coincidentemente, deixa de considerar como fator relevante os efeitos regulares de ordenamento que essas categorias apresentam.

Wiltschko (2014, p. 20-21), em contrapartida, mostra que as línguas naturais agrupam suas categorias funcionais de modo sistemático, e que, muito embora essas categorias variem de uma língua para outra, elas estão distribuídas em domínios sintáticos comuns, universais. Inúmeras línguas reiteram a existência de um grupo restrito de domínios sintáticos, os quais são normalmente identificados através de categorias funcionais específicas. Nas línguas indoeuropeias, por exemplo, o sintagma verbal circunscreve o ambiente sintático em que os papéis semânticos dos atores de um evento (i.e., os papéis temáticos) são determinados. Já o domínio que abriga marcas aspectuais e temporais corresponde ao ambiente sintático em que papéis gramaticais, como sujeito e objeto, são definidos. Por sua vez, o domínio sentencial mais periférico, responsável por tipificar uma sentença, diz respeito ao ambiente sintático em que papéis discursivos, como tópico e foco, são atribuídos. É importante destacar que esses domínios sintáticos não são meras estipulações intrateóricas; pelo contrário, eles encontram motivações de diversas ordens, a saber: eles são responsáveis por restringir a organização hierárquica das categorias funcionais de uma língua (i.e., seu escopo) e, paralelamente, eles são responsáveis por determinar o ordenamento linear que essas categorias apresentam. ${ }^{144}$

\footnotetext{
${ }^{143}$ Trecho original: "[...] languages could differ from each other without limit and in unpredictable ways".

${ }^{144}$ Evidências adicionais para a assunção desses domínios sintáticos podem ser encontradas na distribuição dos advérbios pela sentença. Alguns advérbios modificam apenas aspectos do domínio verbal (e.g., advérbios orientados para o evento, como realmente e infelizmente), enquanto outros advérbios modificam somente aspectos da área em que os papéis gramaticais são determinados (e.g., advérbios orientados para o sujeito, como tristemente e calmamente). Há ainda advérbios que modificam a área em que papéis discursivos são
} 
Notamos, por exemplo, que as categorias funcionais que interagem com o domínio verbal são superficializadas mais próximas da raiz verbal do que as categorias funcionais que interagem com o domínio dos papéis gramaticais, tal como a categoria tempo. Já as categorias que interagem com o domínio discursivo são realizadas geralmente em uma posição mais distante da raiz verbal. ${ }^{145}$ Para ilustrar essa regularidade distribucional, Wiltschko (2014, p. 21-22) nos oferece o seguinte contraste. A autora compara a ordem linear de uma sentença do inglês com a ordem linear de uma sentença em siksiká. Na sentença em inglês, reproduzida em (38a), o constituinte-wh (i.e., what 'o que'), associado a um tipo especial de foco, ocorre na periferia esquerda da sentença. Esse constituinte é seguido por um auxiliar verbal, responsável por realizar a informação de tempo passado (i.e., did), que, por sua vez, antecede o sujeito oracional (i.e., you '2P.SG') e o verbo (i.e., see 'ver'). A sequência de categorias funcionais correspondente ao ordenamento linear da sentença em (38a) está representada em $(38 b)$.

(38) Inglês (WILTSCHKO, 2014, p. 21)
a. What did you see?
WH AUX.PASS 2P.SG ver
b. foco $>$ tempo $>$ sujeito $>$ verbo

Já na língua siksiká, as categorias funcionais que instanciam os domínios sintáticos elencados acima são realizadas por meio de morfemas sufixais. Apesar de sua ordem linear diferir da ordem observada na sentença em inglês, a distribuição desses domínios permanece a mesma. O sufixo $-o$, em (39a), corresponde a um morfema que indica a transitividade verbal —no caso, uma marca transitiva —, e a animacidade de seus argumentos — no caso, animado. $-o$, portanto, interage com o domínio do evento e se realiza próximo à raiz verbal yooht 'ouvir'. Em seguida, temos a categoria funcional "direto", responsável por determinar os papéis gramaticais dos argumentos verbais. No exemplo em (39a), ela indica que o pronome nit '1P.SG' deve ser interpretado como o sujeito da sentença; logo, deve interagir com o domínio gramatical. ${ }^{146}$ Por fim, o morfema -wa realiza a categoria funcional "proximidade", a

introduzidos (e.g., advérbios voltados para o falante, como francamente) (Cf. JACKENDOFF, 1977; CINQUE, 1999; ERNST, 2002).

${ }^{145}$ Essa afirmação, recupera, em certo sentido, o "Princípio do Espelho" (BAKER, 1985), o qual assinala que as “derivações morfológicas devem refletir diretamente as derivações sintáticas (e vice-versa)" (1985, p. 375) [Trecho original: "morphological derivations must directly reflect syntactic derivations (and vice-versa)"].

${ }^{146}$ Como mostra Wiltschko (2014, p. 17), o siksiká dispõe de um sistema de marcação de direcionamento, direto/inverso. Em uma sentença como Nitsinóáwa (nit-ino-aa-wa) lit. 1-ver-TA-DIR-PROX 'Eu vi ele/ela', 
qual está intimamente associada ao domínio discursivo (Cf. BLISS, 2005, 2013 apud WILTSCHKO, 2014, p. 21). ${ }^{147 / 148 / 149}$ Em (39b), apresentamos a distribuição linear dessas categorias.

(39) Siksiká (BLISS, 2013, p. 33 apud WILTSCHKO, 2014, p. 22)

a. Nitsóóhtowawa

nit-yooht-o-a-wa

1P.SG-ouvir-TA-DIR-PROX

'Eu ouvi ele/a'.

b. [...] verbo $<$ transitividade $<$ direcionamento $<$ proximidade

Não há dúvidas de que o repertório de categorias funcionais empregado pelo inglês e pelo siksiká difere amplamente. No entanto, os domínios sintáticos aos quais suas categorias funcionais estão associadas não se manifestam de maneira aleatória. Podemos perceber que as categorias funcionais atreladas ao domínio do evento (viz., o verbo no inglês e o marcador transitivo-animado em siksiká) são introduzidas antes das categorias funcionais envolvidas com o domínio gramatical (viz., tempo no inglês e o marcador direto em siksiká), que, por sua vez, antecedem as categorias funcionais atreladas ao domínio discursivo (viz., o núcleo que acomoda o constituinte- $w h$ em inglês e proximidade em siksiká). Tal correspondência na organização linear dessas categorias funcionais nos indica que os domínios sintáticos que as abrigam são muito possivelmente universais, apesar de haver uma variação considerável no conteúdo que elas veiculam.

Assim, embora o inglês e a língua siksiká divirjam significativamente no que concerne ao conteúdo de suas categorias funcionais e ao seu tipo morfológico, o arranjo linear de suas categorias funcionais apresenta os mesmos efeitos de ordenamento, seguindo um padrão

paralela a sentença em (39a), não é evidente que o pronome nit- corresponda ao sujeito oracional, o que, nas línguas indo-europeias, é determinado através das marcas de concordância no verbo. Assim, o que o morfema direto faz é remover essa ambiguidade, apontando que o pronome nit- tem o papel gramatical de sujeito. Já a marca inverso, presente na sentença Nitsinóóka (nit-ino-ok-wa) lit. 1-ver.TA-INV-PROX 'Ela/ele me viu', indica que esse mesmo pronome nit- deve ser interpretado como o objeto sentencial.

${ }^{147}$ BLISS, H. A. Formalizing point-of-view: The role of sentience in Blackfoot's direct/inverse system. 2005. Dissertação (Mestrado em Linguística) - University of Calgary, Alberta, Canadá, 2005.

${ }^{148}$ BLISS, H. A. The Blackfoot configurationality conspiracy: Parallels and differences in clausal and nominal structure. 2013. Tese (Doutorado em Linguística) - University of British Columbia, Vancouver, 2013.

${ }^{149}$ Marcas de proximidade apontam a distância de um referente com relação ao falante. Por exemplo, em squamish (ou skwxwu7mesh), todo determinante deve ser marcado com relação à localização do referente, como aponta Wiltschko (2014, p. 18). Na sentença Chen tákw-an ti stákw lit. 1SG.S beber-TR DET água 'Eu bebi água', a marca de proximidade $t i$ indica que a água estava próxima ao falante (mas não próxima ao ouvinte, ou longe do falante e do ouvinte). 
universal. Esse padrão está caracterizado em (40), retirado de uma representação elaborada por Wiltschko (2014, p. 14). A letra $c$ está para as categorias funcionais específicas de cada língua. Essa regularidade translinguística dos efeitos de ordenamento, reiterada por autores de diferentes filiações teóricas (Cf. CINQUE, 2013), desafia a conjectura de que não existem propriedades universais envolvendo as categorias funcionais. Contudo, o padrão descrito em (40) é inteiramente desconsiderado pela hipótese destacada nesta subseção, que o vê apenas como uma simples casualidade.

(40) Efeitos de ordenamento universal das categorias funcionais $c:$ DISCURSIVO $>c$ : GRAMATICAL $>c$ : EVENTIVO $>c$ : RAIZ VERBAL

Além dos efeitos de ordenamento retratados em (40), outras objeções são feitas com relação a essa primeira hipótese. Uma delas é fornecida por dados de aquisição. Crianças são sensíveis à distribuição das categorias funcionais desde muito cedo, adquirindo-as a partir dos três primeiros meses de idade (LABELLE, 2005, p. 436). Uma terceira objeção, colocada por Wiltschko (2014, p. 22), é a existência de um paralelismo funcional e distribucional entre as categorias do domínio verbal, em (40), e as categorias do domínio nominal (BRAME, 1981; ABNEY, 1987; SZABOLCSI, 1994). Esse paralelismo serve como mais um indicativo de que deve haver um arranjo estrutural universal para as categorias funcionais, categorialmente neutro, responsável por determinar as funções sintáticas que as categorias verbais e nominais desempenham. Se partirmos da premissa de que esses domínios sintáticos não são universais, como assume a primeira hipótese, então o paralelismo presente entre os arranjos funcionais verbais e nominais demanda uma explicação mais elaborada. Na realidade, para essa primeira hipótese, tal paralelismo inexiste.

\subsubsection{Hipótese da Base Universal}

A segunda hipótese que busca esclarecer o descompasso descrito no início desta seção é diametralmente oposta à primeira. Ela foi formulada ainda nos primeiros anos da Gramática Gerativa (GG), durante o modelo da Teoria Padrão (CHOMSKY, 1965; BACH, 1968; ROSS, 
1970; LAKOFF, 1970). Essa hipótese foi denominada por Ross (1970, p. 260) de "Hipótese da Base Universal" (HBU) e está definida em (41): ${ }^{150}$

(41) Hipótese da Base Universal (ROSS, 1970, p. 260, tradução nossa)

“A estrutura profunda de todas as línguas é idêntica, e tal semelhança limita-se ao nível de ordenamento dos constituintes imediatamente dominados pelo mesmo nó". 151

O que Ross sugere com a hipótese em (41) é o seguinte: o suposto componente de base, que, então, abrigava as regras estruturais e as regras lexicais da gramática, deveria ser universal, comum a todas as línguas. Por outro lado, a variação observada entre as línguas deveria ser analisada como uma questão de superfície, ou seja, do modo como essas regras estruturais e suas entradas lexicais eram ordenadas linearmente. Muito embora o componente de base tenha sido descartado no início da década de 70 (Cf. CHOMSKY, 1970; SCALISE, 1984), a GG manteve a assunção de que há uma base universal para o arranjo estrutural e para a variedade de categorias funcionais observada entre as línguas. No PM, por exemplo, essa base universal diz respeito ao conjunto de traços formais fornecidos pela GU, a partir do qual uma dada língua L extrai um subconjunto, como descreve Chomsky nos seguintes trechos:

“A GU disponibiliza um conjunto $F$ de traços (propriedades linguísticas) e de operações $\mathrm{C}_{\mathrm{HL}}$ (o procedimento computacional para a linguagem humana), as quais acessam F para gerar expressões" (CHOMSKY, 2000, p. 100, tradução nossa). ${ }^{152}$

“A FL especifica os traços F disponíveis para fixar qualquer língua particular L [...] Adotamos a assunção convencional de que L faz uma única seleção [FL] de F. Esses serão os traços que entrarão em L; os demais podem ser desconsiderados no uso de L" (CHOMSKY, 2001, p. 10, tradução nossa). ${ }^{153}$

\footnotetext{
${ }^{150} \mathrm{O}$ nome dado à hipótese faz alusão ao componente de base, assumido pela Teoria Padrão (Cf. CHOMSKY, 1965). Esse componente, também chamado de componente categorial, continha regras estruturais, ou seja, regras capazes de gerar uma descrição estrutural (e.g., NP $\rightarrow$ Det (A) N), e regras lexicais, que apontavam os contextos de inserção das entradas lexicais às descrições estruturais geradas (e.g., Det $\rightarrow a$; $\mathrm{A} \rightarrow$ bela; $\mathrm{N} \rightarrow$ atriz).

${ }^{151}$ Trecho original: "The Universal Base Hypothesis: The deep structures of all languages are identical, up to the ordering of constituents immediately dominated by the same node".

152 Trecho original: "UG makes available a set F of features (linguistic properties) and operations CHL (the computational procedure for human language) that access $\mathrm{F}$ to generate expressions".

${ }^{153}$ Trecho original: "“FL specifies the features F that are available to fix each particular language L [...] We adopt the conventional assumption that L makes a one-time selection [FL] from F. These are the features that enter into L; others can be disregarded in use of L"
} 


\begin{abstract}
" $\mathrm{S}_{0}$ determina o conjunto $\{\mathrm{F}\}$ de propriedades ("traços") disponíveis para as línguas. Cada $L$ faz uma única seleção de um subconjunto $[F]$ de $\{F\}$ e uma reunião única de elementos de $[\mathrm{F}]$ como seu léxico LEX, o qual podemos considerar como uma clássica "lista de exceções", colocando de lado outras questões (CHOMSKY, 2004, p. 107 , tradução nossa). ${ }^{154}$
\end{abstract}

Assunções semelhantes são observadas em diferentes abordagens gerativistas.

A MD, por exemplo, admite que os itens funcionais armazenados em sua Lista 1/A correspondem a categorias universais (MARANTZ, 1997, p. 203). O programa cartográfico e a nanossintaxe, por sua vez, postulam que toda categoria funcional encontrada em uma dada língua deve igualmente ocorrer nas demais. Assim, as projeções funcionais de uma língua particular constituem uma sequência funcional comum a todas as línguas (CINQUE; RIZZI, 2008, p. 45). ${ }^{155}$ É possível notar, através dessas observações, que as abordagens gerativistas, de modo geral, compartilham o pressuposto de que as categorias funcionais são universais e predeterminadas pela GU. Em virtude da assunção de que a GU dispõe do conjunto de todas as categorias funcionais passíveis de ocorrer nas línguas naturais, o que cada língua particular faz é extrair um subconjunto de categorias funcionais dessa lista universal e, então, utilizá-lo para formação de descrições estruturais.

Para ilustrar o pressuposto partilhado pelas abordagens gerativistas, Wiltschko (2014, p. 11) representa a HBU através dos conjuntos de categorias funcionais listados em (42). No exemplo, $\mathrm{C}_{\mathrm{GU}}$ diz respeito ao conjunto universal de categorias funcionais fornecidas pela $\mathrm{GU}$, enquanto $\mathrm{C}_{\mathrm{Lg}}$ diz respeito ao subconjunto de categorias funcionais selecionado por uma língua específica.

$$
\begin{aligned}
\text { a. } \mathrm{C}_{\mathrm{GU}} & =\left\{c_{1}, c_{2}, c_{3}, \ldots c_{n+1}\right\} \\
\text { b. } \mathrm{C}_{\mathrm{Lg} 1} & =\left\{c_{1}, c_{2}, c_{3}, \ldots c_{n+1}\right\} \\
\mathrm{C}_{\mathrm{Lg} 2} & =\left\{c_{1}, c_{4}, c_{5}, \ldots c_{n+1}\right\} \\
\ldots &
\end{aligned}
$$

\footnotetext{
${ }^{154}$ Trecho original: "S $\mathrm{S}_{0}$ determines the set $\{\mathrm{F}\}$ of properties ("features") available for languages. Each $\mathrm{L}$ makes a one-time selection of a subset $[F]$ of $\{F\}$ and a one-time assembly of elements of [F] as its lexicon LEX, which we can take to be a classical "list of exceptions," putting aside further issues.

${ }^{155}$ A nanossintaxe toma por base a cartografia, mas desmembra as hierarquias funcionais postuladas por esse programa em primitivos ainda menores, o que motiva o prefixo "nano" em seu nome. Essas categorias, de acordo com o modelo, também ocorrem abaixo do nível da palavra. Para a nanossintaxe, todo traço formal representa um núcleo independente em uma sequência funcional (Cf. STARKE, 2009); uma assunção que partilhamos nesta tese.
} 
Há, porém, três grandes problemas para a HBU, identificados pela autora. O primeiro deles destaca o fato de que as categorias funcionais fornecidas pela GU não são atestadas universalmente. Como vimos em (37), a língua siksiká não possui tempo como uma categoria morfossintática e, da mesma forma, as línguas indo-europeias não possuem um marcador “direto/indireto". Essa situação, no entanto, é de certo modo prevista pela HBU, uma vez que seus autores partem do princípio de que as línguas naturais selecionam, como propõe o PM, ou realizam morfologicamente, no caso do programa cartográfico, apenas um subconjunto das categorias universais, tal como representado em (42). Já os outros dois problemas apontados por Wiltschko são mais preocupantes e decorrem de duas previsões feitas pela HBU, a saber: (i) a previsão de que as categorias funcionais de um mesmo tipo exibem um comportamento universal, e (ii) a previsão de que qualquer categoria funcional específica de uma língua deve fazer parte de um inventário universal.

Iniciemos pela previsão (i). Ao comparar a distribuição das marcas de tempo passado em inglês e em halkomelem, Wiltschko (2014, p. 15-16) observa que, enquanto a categoria tempo é marcada obrigatoriamente no inglês, tal como se verifica em (43), sua marcação é opcional em halkomelem, (44). ${ }^{156}$ Os verbos em halkomelem podem permanecer sem qualquer marcação de tempo e sua interpretação será ou de tempo presente ou de tempo passado, como pode ser percebido no contraste entre as sentenças em (44). A privação da marca de passado -lh, em (44b), torna a sentença ambígua. Em ambas as línguas, os morfemas de tempo passado veiculam o mesmo conteúdo; entretanto, eles apresentam um comportamento formal distinto. Essa ausência de sistematicidade em seu comportamento põe em dúvida o fato de estarmos, realmente, lidando com uma mesma categoria funcional, oriunda de um banco de categorias universais.

(43) Inglês (adaptado de WILTSCHKO, 2014, p. 98)
a. Yoshi play-ed ball (yesterday)
Yoshi jogar-PASs bola ontem
'Yoshi jogou bola (ontem)'.
b. *Yoshi play ball (yesterday)
Yoshi jogar bola ontem
Leitura pretendida: 'Yoshi jogou bola (ontem)'.

\footnotetext{
${ }^{156}$ Percebam que mesmo a presença de um advérbio de tempo em (43), yesterday 'ontem', não é suficiente para assegurar a ausência de uma marca de tempo no núcleo verbal, o que se verifica na agramaticalidade da sentença em (43b).
} 
(44) Halkomelem (RITTER; WILTSCHKO, 2014, p. 1332)
a. $i-l h$
qw'eyilex tú-tl'ó
AUX-PASS dançar DET-PRN
'Ele estava dançando'.
b. $\quad i \quad q w$ 'eyílex tú-tl'ó
AUX dançar DET-PRN
'Ele está/estava dançando'.

Já a previsão (ii) é desafiada pela existência de um conjunto de categorias funcionais raramente atestadas. A língua squamish nos fornece um bom exemplo. Nessa língua, verbos transitivos são marcados por um morfema de "controle" que expressa, simultaneamente, tanto informações concernentes à transitividade quanto informações concernentes às competências do agente que desempenha a ação, ou seja, se ele/a está ou não no controle da ação descrita. $O$ marcador - at indica uma ação deliberada, tal como ilustrado no exemplo em (45a), ao passo que o marcador -nexw aponta que o evento não está sob o controle do agente, ou seja, é um ato acidental, como mostra a sentença em (45b). Outros exemplos de categorias funcionais altamente específicas são as marcas "direto/indireto" e "proximidade" discutidas no exemplo (39).

(45) Squamish (JACOBS, 2011, p. 1 apud WILTSCHKO, 2014, p. 18) $)^{157}$
a. Chen kw'lh-at ta tiy
1SG.S colocar-TRANS DET chá
'Eu coloquei o chá (deliberadamente)'.
b. Chen kw'élh-nexw ta tiy
1SG.S espirrar-LC.TRANS DET chá
'Eu espirrei o chá (acidentalmente)'.

Assumir que categorias funcionais tão específicas — claramente ausentes na grande maioria das línguas naturais - são determinadas pela GU é demasiadamente contra-intuitivo. Além disso, devemos considerar com atenção o fato de que certas categorias funcionais, embora distintas em conteúdo, desempenham funções sintáticas paralelas, tal como é o caso

\footnotetext{
${ }^{157}$ JACOBS, P. W. Control in Skwxwu7mesh. Manuscrito, University of British Columbia, Vancouver, 2011.
} 
das categorias funcionais tempo e direto, discutidas com base nas sentenças do inglês e do siksiká, em (38) e (39). Essas duas categorias estão envolvidas na determinação de papéis gramaticais. Sua aparente complementaridade nos sugere que deve haver categorias mais abstratas, a partir das quais as categorias funcionais específicas de uma determinada língua são derivadas. Essa complementaridade também contesta a necessidade de se marcar previamente categorias funcionais raras como parte do conjunto de informações universais predeterminadas pelo genótipo humano.

\subsubsection{Hipótese da Coluna Universal}

Tendo em vista a incapacidade dessas duas hipóteses de explicar a contradição acerca da distribuição regular e da variabilidade de conteúdo das categorias funcionais, Wiltschko (2014, 2015), avançando os trabalhos de Ritter e Wiltschko $(2009,2014)$, propõe uma solução alternativa, a que ela dá o nome de "Hipótese da Coluna Universal" (HCU). A autora destaca que um dos principais equívocos das duas hipóteses exploradas acima é o seguinte: ambas partem da premissa de que o conjunto de categorias universais equivale diretamente às categorias funcionais verificadas translinguisticamente. A inovação trazida pela HCU é reconhecer que o conjunto de categorias universais é, na realidade, fundamentalmente distinto do conjunto de categorias funcionais específicas de cada língua. Partindo dessa assunção, Wiltschko (2014, p. 24) estabelece dois pressupostos gerais para guiar a construção da HCU, notadamente:

(46) Pressupostos gerais da HCU (WILTSCHKO, 2014, p. 24, tradução nossa)

a. As categorias funcionais específicas de uma língua (c) são construídas a partir da associação entre um conjunto restrito de categorias universais $\kappa$ e uma Unidade da Linguagem (UdL), a qual é específica das línguas;

b. O conjunto de categorias universais $\kappa$ é hierarquicamente organizado, sendo que cada camada de $\kappa$ é definida por uma única função gramatical. ${ }^{158}$

Em linhas gerais, a HCU postula que as categorias funcionais observadas nas línguas naturais são derivadas durante o desenvolvimento de um indivíduo, não predeterminadas pela

\footnotetext{
${ }^{158}$ Trecho original: “(i) Language-specific categories (c) are constructed from a small set of universal categories $\kappa$ and language-specific UoLs [Units of Language]; (ii) the set of universal categories $\kappa$ is hierarchically organized where each layer of $\kappa$ is defined by a unique function".
} 
GU, como sugere a HBU. ${ }^{159}$ Tal conjectura está retratada no pressuposto em (46a). O que a GU fornece, de acordo com a HCU, é somente um conjunto reduzido de categorias universais $\kappa$, a partir das quais categorias funcionais específicas são criadas. Tal assunção está atrelada à "Hipótese do Parâmetro da Concretização", sugerido anteriormente por Ritter e Wiltschko (2009, p. 156), a qual sugere que o conteúdo veiculado por uma dada categoria funcional está sujeito à variação paramétrica. Essa hipótese está definida em (47):

(47) Hipótese do Parâmetro da Concretização (RITTER; WILTSCHKO, 2009, p. 156, tradução nossa)

“O conteúdo substantivo de uma determinada categoria funcional está sujeito à variação paramétrica, limitado apenas pela função universalmente determinada dessa categoria". 160

Sendo assim, para a HCU, o conjunto das categorias universais fornecidas pela GU, $\mathrm{C}_{\mathrm{GU}}$, é essencialmente distinto do conjunto de categorias funcionais presentes em uma dada língua particular, $\mathrm{C}_{\mathrm{Lg}}$. Enquanto o primeiro conjunto corresponde a um número limitado de primitivos universais, o segundo conjunto é significativamente maior. Em (48), elencamos as categorias universais $\kappa$, determinadas pela GU, de acordo com a HCU. E, no exemplo (49), apresentamos a coluna estrutural universal formada pelo conjunto de categorias $\kappa$, assinalada no pressuposto em (46b), a qual é responsável por dar nome à hipótese.

(48) Conjunto de categorias universais $\kappa$

$\mathrm{C}_{\mathrm{GU}}=\kappa$ :vinculação discursiva $>\kappa$ :ancoragem $>\kappa$ :ponto de vista $>\kappa$ :classificação

\footnotetext{
${ }^{159}$ Uma hipótese paralela vem sendo desenvolvida por Biberauer (2016).

${ }^{160}$ Trecho original: "Parametric Substantiation Hypothesis: The substantive content of a given functional category is subject to parametric variation, constrained only by the universally determined core function of that category".
} 
(49) Coluna universal

$\kappa$ :vinculação discursiva

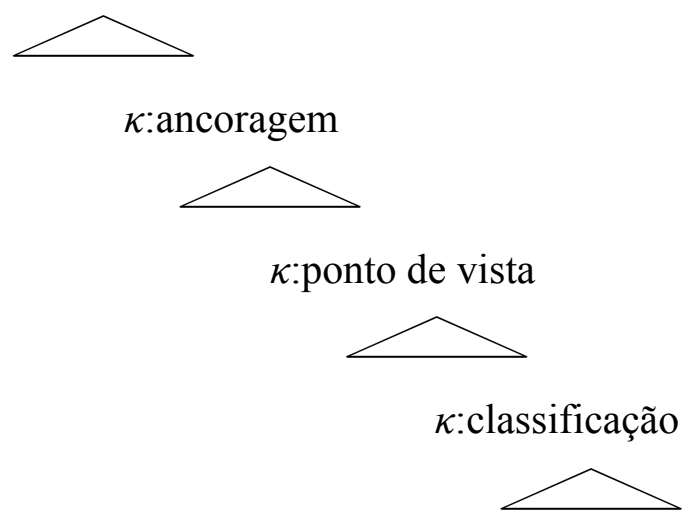

As categorias universais em (48) expressam somente funções gramaticais. Por essa razão, elas são consideradas categorialmente neutras, ou seja, elas não fazem uma distinção prévia acerca das categorias funcionais atreladas a verbos e nomes. O mesmo arranjo em (49) serve como base para a construção de categorias funcionais associadas tanto ao domínio verbal quanto ao domínio nominal. Nesse sentido, as funções representadas pelas categorias $\kappa$ listadas em (48) são universais e transcategoriais. Para a HCU, as línguas variam somente no modo como elas constroem categorias funcionais responsáveis por desempenhar as funções gramaticais predeterminadas pelas categorias $\kappa$. É válido destacar que o arranjo estrutural em (49) está associado diretamente aos domínios sintáticos discutidos na subseção 4.3.1, os quais foram representados previamente no esquema em (40). No que concerne ao domínio verbal, esse arranjo de categorias universais recupera integralmente a coluna estrutural defendida pela GG, a saber, a composição C-T-(Asp)-v/V.

As funções expressas pelas categorias em (48) podem ser descritas do seguinte modo. A categoria mais baixa, $\kappa$ :classificação, tem a função de determinar se a estrutura sintática a ser derivada irá dar origem a um evento ou a um indivíduo. Em outras palavras, essa categoria "classifica" uma raiz lexical como verbo ou nome. $\kappa$ :classificação serve, portanto, como base para a formação dos núcleos categorizadores, $v$ e $n$. A segunda categoria, $\kappa$ :ponto de vista, introduz uma perspectiva acerca do evento ou do indivíduo. No domínio verbal, por exemplo, $\kappa$ :ponto de vista é normalmente realizada por uma categoria aspectual, que adiciona um tempo de referência ao evento. Esse tempo de referência agrega um ponto de vista com relação ao evento descrito pelo verbo. ${ }^{161}$ Já no domínio nominal, essa mesma categoria promove a

${ }^{161}$ Como assinala Wiltschko (2014, p. 250), na maioria das línguas indo-europeias, a categoria "ponto de vista" apresenta um conteúdo temporal. Tanto a categoria tempo quanto a categoria aspecto expressam uma informação com relação ao tempo. No entanto, tempo é uma categoria dêitica, cuja função é localizar o tempo 
formação dos traços $\varphi$, tais como gênero e número. A terceira categoria, $\kappa$ :ancoragem, insere o evento ou o indivíduo no espaço e/ou no tempo de enunciação. No domínio verbal, ela é instanciada comumente pela categoria tempo, enquanto no domínio nominal ela é realizada por um núcleo determinante, instanciado por um artigo definido ou por um demonstrativo. ${ }^{162}$ Por fim, a categoria $\kappa$ :vinculação estabelece uma relação entre a proposição ou o referente e o discurso em andamento. A autora atrela essa categoria universal ao núcleo complementizador $\mathrm{C}$, no domínio verbal, e a um núcleo de Caso, $\mathrm{K}$, no domínio nominal.

Em (50), fornecemos um apanhado das categorias funcionais mais representativas das categorias universais elencadas em (48), seguindo as observações de Wiltschko. E, em (51), apresentamos um resumo das funções gramaticais expressas por cada uma dessas categorias.

(50) Vinculação discursiva $>$ Ancoragem $>$ Ponto de vista $>$ Classificação

$$
\mathrm{CP} / \mathrm{KP} \quad \mathrm{IP} / \mathrm{DP} \quad \mathrm{AspP} / \varphi \mathrm{P} \quad \nu \mathrm{P} / n \mathrm{P}
$$

(51) Funções das categorias universais $\kappa$

a. CLASSIFICAÇÃO: Introduz e classifica uma raiz lexical como um evento (i.e., verbo) ou como um indivíduo (i.e., nome);

b. PONTO DE VISTA: Adiciona um ponto de vista com relação ao evento ou ao indivíduo;

c. ANCORAGEM: Ancora o evento ou o indivíduo ao enunciado, resultando em uma ancoragem dêitica ou anafórica;

d. VINCULAÇÃo DISCURSIVA: Vincula o evento ou o indivíduo ao discurso.

Como destacamos algumas vezes, é a partir das categorias universais que categorias funcionais específicas serão formadas. Wiltschko (2014, p. 34-36) assume que toda categoria funcional específica de uma língua consiste, por um lado, de (i) uma UdL, e, por outro, de (ii) uma categoria universal $\kappa$. Uma UdL corresponde a uma associação entre uma unidade fonológica $(\pi)$ e uma unidade semântica $(\Sigma)$, ambas determinadas por uma língua particular.

do evento com relação ao tempo de fala ou do enunciado (i.e., se o evento reportado ocorreu antes do momento de fala — no passado - ou simultaneamente ao tempo de fala — no presente). Já a categoria aspecto tem o propósito de fornecer uma perspectiva temporal acerca do evento. Ela localiza o evento com respeito a um tempo de referência, o que Wiltschko rotula de "ponto de vista", recuperando a discussão de Smith (1991). O tempo de referência pode estar fixado durante a ocorrência do evento - i.e., o que comumente chamamos de imperfectivo - ou após a ocorrência do evento-i.e., o que comumente chamamos de perfectivo.

${ }^{162}$ Por exemplo, a função da categoria "ancoragem" no domínio verbal é a de estabelecer uma relação entre o enunciado e o evento descrito por um verbo; assim, a categoria funcional TEMPO "ancora" o evento relatado à situação de enunciação. 
Grosso modo, uma UdL representa a visão canônica de morfema e, nesse sentido, pode ser realizada de diferentes modos, seja como uma forma presa ou como uma forma livre. Assim, seguindo as diretrizes colocadas pelo pressuposto (46a), uma categoria funcional $c$ será criada quando uma categoria universal $\kappa$ for vinculada a um par $\{\pi, \Sigma\}$. Essa assunção está descrita na fórmula em (52).

(52) Formação de uma categoria funcional $c$ específica de uma língua

$$
c=<\kappa+\{\pi, \Sigma\}>
$$

Em (53), representamos a distinção entre o conjunto de categorias universais, $\mathrm{C}_{\mathrm{GU}}$, e o conjunto de categorias funcionais de uma língua, $\mathrm{C}_{\mathrm{Lg}}$, de acordo com a HCU. Observem que, ao contrário da $\mathrm{HBU}$, as categorias funcionais de uma língua não constituem um subconjunto das categorias universais predeterminadas, diferentemente do que vimos nas representações em (42).

(53) a. $\mathrm{C}_{\mathrm{GU}}:\left\{\kappa_{1}, \kappa_{2}, \kappa_{3}, \kappa_{4}\right\}$

b. $\mathrm{C}_{\mathrm{Lg}}:\left\{c_{1}:<\kappa, \mathrm{UdL}>_{1}, c_{2}:<\kappa, \mathrm{UdL}>_{2}, c_{3}:<\kappa, \mathrm{UdL}>_{3} \ldots c_{n+1}:<\kappa, \mathrm{UdL}>\right\}$

Para ilustrar o modo como uma categoria funcional específica de uma língua é criada, tomemos como exemplo a construção da categoria TEMPO. Vimos que TEMPO é uma categoria funcional responsável por estabelecer uma relação entre o enunciado e o evento descrito por um verbo, atrelando o evento relatado pelo núcleo verbal à situação de enunciação. Essa categoria funcional relaciona-se à categoria universal $\kappa$ :ancoragem. Em uma língua como o inglês, a categoria funcional TEMPO é construída a partir do pareamento entre a categoria universal $\kappa$ :ancoragem e uma UdL, ou seja, um par de (i) sequências fonológicas, como $/{ }_{\pi} S /$ e $/_{\pi} e d /$, e de (ii) conteúdos semânticos, como 'presente' e 'passado'. Esse pareamento dá origem aos traços formais listados em (54):

(54) Inglês
a. $c$ :TEMPO $<\kappa$ :ANCORAGEM, $\{\pi: \mathrm{s}, \Sigma$ :presente $\}>$
b. $c$ :TEMPO $<\kappa$ :ANCORAGEM, $\{\pi: \mathrm{s}, \Sigma$ :passado $\}>$

A diferença entre a categoria funcional TEMPO e a categoria universal $\kappa$ :ancoragem reside no fato de que TEMPO representa apenas uma das opções que as línguas naturais têm 
para expressar essa categoria universal. Como vimos no exemplo (44), o halkomelem não usa suas marcas de tempo para "ancorar" o evento no tempo em relação ao enunciado. Wiltschko (2014, p. 125-130) mostra que, embora o halkomelem disponha de uma categoria TEMPO, essa língua emprega a categoria $c$ :LOCALIZAÇÃO para realizar $\kappa$ :ancoragem. Percebam que, pela lógica da HCU, somos naturalmente levados a fazer a seguinte questão: "dada a ausência de uma categoria funcional TEMPO, qual outra categoria funcional uma língua particular poderia empregar para expressar $\kappa$ :ancoragem?" Ou seja, a premissa de que a categoria funcional TEMPO não é primitiva, mas construída com base em uma categoria universal $\kappa$ :ancoragem, nos estimula a procurar outra categoria funcional capaz de servir à mesma função e, então, ser associada a uma mesma categoria universal $\kappa$.

Wiltschko (2014, p. 118) nota que, não apenas o halkomelem faz uso de uma categoria funcional distinta no contexto de $\kappa$ :ancoragem, mas também a língua siksiká, cuja categoria $\kappa$ :ancoragem é realizada por $c$ :PESSOA, e o alemão da Áustria setentrional, que faz uso da categoria $c$ :REALIS. ${ }^{163}$ Em vista disso, tornam-se evidente as razões pelas quais TEMPO parece estar ausente em um conjunto diversificado de línguas. No caso do halkomelem, por exemplo, há evidências de que a categoria $\kappa$ :ancoragem é um domínio ativo na coluna em (49). Esse domínio sintático, como já dissemos, diz respeito ao ambiente estrutural em que o papel de sujeito gramatical é atribuído e, ao mesmo tempo, o ambiente em que o evento reportado é atrelado ao enunciado. Ritter e Wiltschko $(2005,2009)$ mostram que os auxiliares locativos proximal $i$ 'estar aqui' e distal li 'estar lá' expressam o mesmo tipo de contraste comumente estabelecido pela categoria TEMPO, cuja função é ancorar o evento ao enunciado. Exemplos do emprego desses auxiliares locativos estão apresentados em (55).

\footnotetext{
${ }^{163}$ E válido apontar que as marcas de pessoa em siksiká apresentam propriedades distintas das marcas de pessoa nas línguas indo-europeias. Enquanto nas línguas indo-europeias, a categoria PESSOA está circunscrita a marcas de concordância e a pronomes; em siksiká, elas apresentam uma função expandida. Essa língua faz uma distinção entre "pessoas locais" (1 e 2P) e "pessoas não locais" (3P). "Pessoas locais" sinalizam que o participante de um evento é idêntico ao participante do enunciado, semelhantemente à função de tempo presente, que, nas línguas indo-europeias, determina que o tempo do evento coincide com o tempo da fala (e.g., nit-a-yiitsittsimaa-hp-innan lit.1-IMPF-fatiar.carne.AI-LOC-1PL 'Nós (excl.) estamos fatiando carne'). Já "pessoas não locais" sinalizam que o participante do evento difere do participante do enunciado, da mesma forma que o tempo passado nas línguas indo-europeias, o qual indica que o tempo do evento é distinto do tempo de fala (e.g., a-yiitsittsimaa- $\varnothing$-yi-aawa lit. IMPF-fatiar.carne.AI-NONLOC-3PL-3PL.PRN 'Eles estão fatiando carne') (Cf. WILTSCHKO, 2014, p. 120-121). Embora a categoria TEMPO esteja ausente nessa língua, a categoria PESSOA parece estar servindo como a categoria funcional que desempenha suas funções de ancoragem.
} 
(55) Halkomelem (RITTER; WILTSCHKO, 2009, p. 151)
a. $i$
qw'eyílex tú-tl'ò
AUX-AQUI dançar DET-3PRN
'Ele estava dançando (aqui)'.
b. lí qw'eyílex tú-tl'ò
AUX-LÁ dançar DET-3PRN
'Ele estava dançando (lá)'.

Os auxiliares locativos $i$ e li são obrigatórios em sentenças independentes indicativas e em sentenças subjuntivas, o que nos sinaliza seu uso como uma categoria regular. ${ }^{164}$ Diversas evidências sustentam a assunção de que esses auxiliares locativos representam o equivalente formal e funcional da categoria TEMPO. A primeira delas é sua posição linear. Os auxiliares locativos em halkomelem devem obrigatoriamente preceder o complexo verbal, o qual inclui uma marca de transitividade e marcas de concordância com o objeto. Isso pode ser visto na disposição das categorias funcionais do domínio verbal retratadas no esquema genérico em (56), retirado de Wiltschko (2014, p. 126). O complexo verbal está delimitado por colchetes.

\section{(56) $\mathbf{A U X}=$ SUBJ.CL [vRadical Raiz-TRANS-OBJ-ERG]}

A marca de transitividade codifica tanto informações sobre a transitividade verbal quanto informações aspectuais, realizadas por uma marca de controle. ${ }^{165}$ A categoria TRANS, dessa forma, deve ser responsável pela instanciação dos núcleos $v$ e Asp, que, como vimos, associam-se às categorias universais $\kappa$ :classificação e $\kappa$ :ponto de vista, respectivamente. Isso nos revela que os auxiliares locativos devem estar alocados em uma posição estrutural acima desses dois domínios sintáticos, no ambiente estrutural correspondente à $\kappa$ :ancoragem. Uma segunda evidência para essa assunção é o fato de que esses auxiliares locativos são realizados em uma posição estrutural mais baixa do que a das categorias funcionais associadas à $\kappa$ :vinculação discursiva, ou seja, a complementizadores, abrigados pelo núcleo funcional C.

\footnotetext{
${ }^{164}$ Vimos, no exemplo (44), que a ausência de regularidade na distribuição das marcas de tempo em halkomelem e a ambiguidade gerada nas sentenças em que essas marcas estão ausentes nos sinalizam que a categoria TEMPO não opera de modo semelhante às línguas em que TEMPO é uma categoria regular, obrigatória, como é o caso das línguas indo-europeias. Wiltschko (2014, p. 103-106) mostra que, embora TEMPO seja uma categoria funcional do halkomelem, essa categoria não está associada ao domínio sintático representado por $\kappa$ :ancoragem. Para a autora, a categoria TEMPO em halkomelem funciona como um modificador. Ver também Ritter e Wiltschko $(2005,2009,2014)$ para mais argumentos em favor dessa assunção.

${ }^{165}$ A categoria CONTROLE descreve as competências do agente que desempenha a ação, ou seja, se ele/a está ou não no controle da ação, tal como vimos no exemplo (45).
} 
Nos exemplos (57) e (58), é possível verificar que o complementizador we 'se' deve preceder os auxiliares.

(57) Halkomelem (GALLOWAY, 2009, p. 886 apud WILTSCHKO, 2014, p. 127) ${ }^{166}$

$$
\begin{array}{llll}
\text { we lí-s } & \text { thét } t a & \text { sqwálewel }[\ldots] \\
\text { COMP } & \text { AUX-2S dizer DET.2SG } & \text { pensamento }
\end{array}
$$

'se você pensa que $[\ldots]$ "..

lit.: 'se sua mente diz que $[\ldots]$ "..

(58) Halkomelem (WILTSCHKO, 2006, p. 291 apud WILTSCHKO, 2014, p. 127) ${ }^{167}$

$$
\begin{array}{lllll}
\text { xélh cha te-l sqwálewel }[. . .] \text { we li-s } & \text { thémexw } \\
\text { triste FUT DET-1SG.POSS pensamento COMP AUX-3S chover }
\end{array}
$$

'Ficarei triste (lit.: 'meus pensamento se entristecerão) se chover'.

Os exemplos em (57) e em (58) nos fornecem ainda uma evidência adicional para se associar a categoria LOCATIVO à $\kappa$ :ancoragem. Eles nos mostram que os auxiliares locativos estão alocados no domínio sintático em que o papel gramatical de sujeito é determinado. Mais especificamente, as sentenças condicionais do halkomelem, como aquelas em (57) e (58), desencadeiam uma forma de concordância subjuntiva com o auxiliar locativo, observada nas marcas morfológicas de pessoa afixadas a esses auxiliares. ${ }^{168}$ A função dessas marcas é a de indexar o sujeito sentencial ao auxiliar. Essa função estabelece, de acordo com a autora, um paralelo com o funcionamento da categoria funcional TEMPO, indicando que LOCATIVO deve estar realizando a categoria $\kappa$ :ancoragem nessa língua.

Uma quarta evidência é a impossibilidade de se empregarem esses auxiliares locativos em sentenças imperativas, as quais são, nas línguas indo-europeias, normalmente não finitas. Em (59b), por exemplo, a inserção do auxiliar locativo distal torna a sentença agramatical.

\footnotetext{
${ }^{166}$ GALLOWAY, B. D. Dictionary of Upriver Halkomelem. Berkeley, CA: University of California Press, 2009.

${ }^{167}$ WILTSCHKO, M. On ergative agreement and anti-agreement. In Halkomelem Salish. In BISCHOFF, S.; BUTlER, L.; NORQUEST, P.; SIDDIQI, D. (orgs.) Studies in Salishan: MIT Working Papers on Endangered and Less Familiar Languages, vol. 7, 2006, p. 241-273.

${ }^{168}$ Em (58), a marca de 3 SG concorda com um expletivo, semelhante à it rains 'chove'.
} 
(59) Halkomelem (RITTER; WILTSCHKO, 2009, p. 171)

a. qw'eyilex-lha!

dançar-IMP

'Dance!'

b. *lí qw'eyiléx-lha!

AUX dançar-IMP

'Dance!'

Verificamos, com esse conjunto de dados, que os auxiliares locativos em halkomelem apresentam a mesma função que as marcas de tempo no inglês, ou seja, a de ancoragem. Esses auxiliares ordenam a situação descrita pelo evento em relação à situação do enunciado ao apontar que a localização do evento é ou não é a mesma localização do enunciado. Com base nessas observações, podemos afirmar que, na língua halkomelem, a categoria universal $\kappa$ :ancoragem, ao ser associada às sequências fonológicas $/ \pi \mathrm{i} / \mathrm{e} / \pi \mathrm{l}$ / e aos conteúdo semânticos 'proximal' e 'distal', dão origem à categoria funcional LOCALIZAÇÃo e aos traços formais elencados em (60):

(60) Halkomelem
a. $c$ :LOCALIZAÇÃO < <:ANCORAGEM, $\{\pi: 1, \Sigma:$ proximal $\}>$
b. $\quad c:$ LOCALIZAÇÃO < $\kappa:$ ANCORAGEM, $\{\pi:$ lí, $\Sigma: \operatorname{distal}\}>$

Em resumo, a HCU parte da assunção de que a estrutura universal em (49) expressa as necessidades básicas subjacentes à construção das hierarquias funcionais das línguas naturais. Entretanto, cada língua é responsável por formar suas próprias categorias funcionais. Dessa forma, a tese colocada pela HCU pode ser sintetizada do seguinte modo: ao se abstraírem as categorias funcionais de uma língua particular, o que resta é somente uma coluna universal, com domínios associados a funções regulares, cuja manifestação se dá por meio de categorias funcionais específicas. Ao recorrermos às categorias universais $\kappa$, somos capazes de estabelecer uma mediação entre o que há de universal envolvendo as categorias funcionais da linguagem humana e o que há de variável, diferentemente do que fazem a primeira hipótese e a HBU. É com base na tese lançada pela HCU que argumentamos em favor de propriedades universais subjacentes às categorias funcionais. Será através das categorias universais representadas por $\kappa$ que postularemos o conjunto de ATR disponível no sistema F da espécie, como veremos na próxima seção. 


\subsection{O molde isomórfico do léxico funcional humano}

Argumentamos, no Capítulo 3, que o sistema F compreende um conjunto restrito de células, constituídas por uma estrutura interna rígida, as quais são descritas em termos de um par ordenado $<$ ATR, VAL $>$. O membro ATR desse par ordenado diz respeito a uma categoria pré-adaptada que uma dada espécie está predisposta a categorizar. Por esse motivo, os ATR disponíveis em $\mathrm{F}$ devem ser entendidos como categorias geneticamente predeterminadas. Já o membro VAL desse par ordenado corresponde a qualquer elemento acessível à percepção, capaz de satisfazer as especificações impostas por um ATR. VAL - i.e., aquilo que pode ser categorizado - pertence ao conjunto delimitado por um ATR e é estabelecido por meio da experiência de um indivíduo. Vimos que, para um macaco-vervet, VOAR instancia um dos ATR das células de seu sistema F. Assim, todo elemento no mundo capaz de satisfazer esse ATR —i.e., todo elemento passível de ser incluído no conjunto delimitado por VOARpoderá ser categorizado e, então, servir como um de seus VAL (e.g., uma folha caindo, uma espécie aviária, etc.).

Por conveniência, recuperamos, em (61), nossa definição para as células que integram o sistema F.

(61) Célula em F

a. Uma célula $\mathrm{C}$ em F é um par ordenado $<\mathrm{ATR}$, VAL $>$ que satisfaz:

(i) ATR pertence ao conjunto finito A das categorias referenciais determinadas pela dotação biológica de uma espécie;

(ii) VAL corresponde a um elemento de ATR (i.e., VAL pertence a ATR).

b. Assim, dado que A é o conjunto das categorias referenciais, então o conjunto de todas as células $\mathrm{C}$ em $\mathrm{F}$ de um organismo $\mathrm{O}$ é dado por $\{<\mathrm{ATR}, \mathrm{VAL}>=\mathrm{ATR} \in$ A e VAL $\in$ ATR $\}$.

c. Denotamos uma célula arbitrária $\mathrm{C}$ por $<$ ATR, VAL $>$ (i.e., $\mathrm{C}=<\mathrm{ATR}, \mathrm{VAL}>$ ) e o conjunto das células $\mathrm{C}$ de $\mathrm{F}$ de um organismo $\mathrm{O}$ por $=\{<\mathrm{ATR}, \mathrm{VAL}>\mid \mathrm{ATR} \in$ A e VAL $\in$ ATR $\}$.

A universalidade das categorias $\kappa$, juntamente com a natureza fixa, unidirecional, dos traços formais — cujo mapeamento é paralelo ao das categorias referenciais manifestadas no 
comportamento vocal primata- ${ }^{169}$ nos sugerem que as categorias $\kappa$ podem instanciar os ATR do sistema F humano. Como destacamos algumas vezes, ATR são específicos de uma espécie e resultam de pressões adaptativas, as quais tornam seus membros sensíveis a experienciar, categorizar e eventualmente externalizar um grupo particular de categorias do mundo. Sendo assim, é teoricamente esperado que o conjunto de ATR de primatas não humanos — composto por categorias que expressam classes de predadores, alimentos, urgência e relações sociais - divirja do conjunto de ATR dos humanos modernos. Diferentes pressões adaptativas aplicadas às espécies hominínias que antecederam o surgimento do $H$. sapiens podem ter levado a uma reorganização desses ATR, resultando no inventário atual. Essa reorganização apresenta como causa hipotética as alterações ambientais ocorridas desde a cisão entre primatas não humanos e humanos, bem como as mudanças nos estilos de vida de espécies hominínias ancestrais. ${ }^{170}$

Desse modo, levando em consideração a estabilidade translinguística dos domínios e das funções definidas pelas categorias universais $\kappa$, assumimos que elas correspondem aos ATR do sistema F humano. É importante salientar que, contrariamente à HCU e à HBU, não propomos que as categorias $\kappa$ representam uma inovação evolutiva determinada pelo genótipo da espécie; i.e., pela GU. Uma assunção como essa nos afastaria dos critérios de adequação evolutiva, uma vez que ela sobrecarrega o papel da GU no desenvolvimento da linguagem. Em vez disso, argumentamos que as categorias $\kappa$ instanciam um conjunto predeterminado de categorias referenciais, ancoradas em um sistema referencial F, cujas bases cognitivas são anteriores à emergência da FL. F vem evoluindo presumivelmente há milhões de anos, dado que seus mecanismos podem ser observados em taxa que precederam o surgimento da ordem primata, tais como em roedores e em aves (Cf. WHEELER; FISCHER, 2012; TOWNSEND; MANSER, 2013).

Outra distinção importante a ser destacada é que, opostamente à HCU, não admitimos que as categorias $\kappa$ representam somente funções atribuídas a domínios sintáticos específicos.

\footnotetext{
${ }^{169}$ Cf. seção 3.3 do Capítulo 3.

${ }^{170}$ Por exemplo, após o surgimento dos primeiros membros do gênero Homo, há aproximadamente 2-2.5 milhões de anos atrás, há inúmeras evidências fósseis e arqueológicas de que esses indivíduos deixaram de ter uma vida exclusiva ao interior das florestas e passaram a explorar as savanas africanas, chegando a sair do continente africano (Cf. TATTERSALL, 2008, 2012, 2016a). O Homo erectus, por exemplo, é encontrado em diversas regiões da Ásia. Descobertas recentes sugerem que o H. erectus pode ter emergido, na realidade, no continente asiático, uma vez que há evidências fósseis de que as migrações de espécies hominínias para fora da África iniciaram-se anteriormente há 1.86 milhão de anos (Cf. ZHU et al., 2018). O Homo heidelbergensis, a primeira espécie hominínia cosmopolita, tem fósseis distribuídos pela Europa, pela Ásia e pela África, com exemplares datando de pelos menos 500 mil anos atrás (Cf. TATTERSALL, 2008, p. 105). Essas mudanças nos estilos de vida, em decorrência das migrações para ambientes diversos — bem como as alterações climáticas e ambientais que se sucederam—, devem ter influenciado fortemente a determinação de novos ATR no sistema $\mathrm{F}$ humano.
} 
Como apontamos, elas correspondem a um grupo de categorias referenciais pré-adaptadas, cujo papel primário é orientar as competências perceptuais da espécie e, com isso, possibilitar a fixação dos conteúdos a serem referidos. Suas funções gramaticais atuais e os domínios sintáticos que elas delimitam podem ser um efeito colateral da própria exaptação do sistema $\mathrm{F}$ e de uma pressão imposta pelo sistema C-I, uma vez que as células fixadas por F passaram a ser agrupadas em arranjos estruturais. Assim sendo, as categorias universais $\kappa$ são, de acordo com a AI, constituídas por um conteúdo mínimo, que, em um primeiro momento, apresenta a função de direcionar a percepção de um indivíduo, tornando-o sensível a experienciar certas situações do mundo. A categoria "classificação", por exemplo, permite que um indivíduo seja capaz de distinguir objetos de eventos. Já a categoria "ancoragem" permite que ele/a seja capaz de depreender categorias dêiticas e anafóricas, e, dessa forma, determinar a localização espacial ou temporal de um objeto ou de um evento.

Em resumo, o que o sistema $\mathrm{F}$ fornece à espécie humana é um conjunto restrito de categorias genéricas. Já o modo como essas categorias serão fixadas —ou melhor, associadas a um dado VAL — dependerá da experiência particular do indivíduo. ${ }^{171}$

Com esse panorama em mente, propomos que o sistema $\mathrm{F}$ humano compreende o conjunto de células elencado em (62). Reparem que os membros correspondentes aos ATR nas células em (62) são realizados pelas quatro categorias universais $\kappa$ postuladas pela HCU. $x$, por sua vez, equivale ao VAL a ser determinado através da experiência. Vale ressaltar que o rótulo "isomórfico" que dá nome à $\mathrm{AI}$ faz referência à estrutura rígida descrita pela célula em (61), a qual serve como um molde para a formação das células do sistema $\mathrm{F}$ humano, em (62). Defendemos que é a partir desse molde isomórfico universal que a multiplicidade de traços formais verificada nas línguas naturais é formada. Esse argumento ficará evidente mais adiante.

(62) Conjunto de células que integram o sistema $F$ da espécie humana
a. <CLASSIFICAÇÃO, $x>$
b. $<$ PONTO DE VISTA, $x>$
c. $<$ ANCORAGEM, $x>$
d. $<$ VINCULAÇÃO, $x>$

\footnotetext{
${ }^{171}$ Há, obviamente, uma assimetria nos contextos de fixação de uma célula em F, quando consideramos a filogenia e a ontogenia da linguagem. Nesse segundo contexto, a presença de uma língua já estabelecida servindo como input no processo de aquisição induz uma criança a considerar exclusivamente uma das opções possíveis para fixar os $\mathrm{ATR} / \kappa$ de seu sistema $\mathrm{F}$. Em vista disso, se a criança é exposta a uma língua indoeuropeia, é esperado que a categoria "ancoragem" seja fixada por informações concernentes a TEMPO, mas não à LOCALIDADE, como é o caso do halkomelem.
} 
Adicionalmente, seguindo a tese elementar da $\mathrm{HCU}$, assumimos que a diversidade de categorias funcionais específicas das línguas é derivada, opostamente à assunção de que elas são predeterminadas pelo genótipo humano, tal como propõe a HBU. Cada língua particular irá estabelecer seu conjunto de categorias funcionais, construindo-as a partir da fixação das células em (62). No que concerne à AI, argumentamos que a formação de uma categoria funcional específica - e, por conseguinte, a formação de um traço formal - ocorre em duas etapas, a saber: (i) uma etapa externa à FLN e (ii) uma etapa interna à FLN. A primeira etapa compreende a fixação de uma das células em (62), ou seja, a associação de um VAL a um ATR. Já a segunda etapa representa o momento em que uma célula fixada é atrelada a uma categorial funcional $c$ e a um domínio funcional particular, nominal ou verbal, internamente à FLN, através da interface $f_{0}$. Exploramos essas duas etapas em detalhes a seguir.

\subsubsection{Etapas de formação de uma categoria funcional}

Vimos que, para a HCU, a formação de uma categoria funcional $c$ ocorre através da combinação entre uma categoria universal $\kappa$ e uma UdL, tal como retratado na fórmula em (52), reproduzida em (63).

(63) Formação de uma categoria funcional $c$, específica de uma língua (HCU)

$$
c=<\kappa+\{\pi, \Sigma\}>
$$

A formação de uma categoria funcional nos termos propostos em (63) é, entretanto, incoerente com o pressuposto 5. Como indicamos na introdução deste capítulo, a associação entre um primitivo formal e uma instrução fonológica diz respeito a um fenômeno secundário; uma assunção que se alinha à hipótese de que a linguagem humana emergiu como um sistema do pensamento (CHOMSKY, 2015, 2016; BERWICK; CHOMSKY, 2016; HUIJBREGTS, 2017). Sendo assim, para a AI, uma UdL deve conter apenas $\Sigma$, uma vez que sua contraparte $\pi$ não é intrínseca ao primitivo formado. A contraparte $\pi$ será vinculada a $\Sigma$ tardiamente, tanto em termos evolutivos quanto em termos formais. Dadas essas premissas, a formação de uma categorial funcional $c$ deve partir da fórmula em (64). Percebam que a representação em (64) dialoga diretamente com as células em (62). $\Sigma$ representa VAL, enquanto $\kappa$ representa os ATR da espécie humana. A associação de um $\Sigma$ (ou VAL) a um $\kappa$ (ou ATR) ocorre, por hipótese, 
externamente à FLN. Essa integração $<\kappa+\Sigma>$ define a primeira etapa de formação de uma categoria funcional. ${ }^{172}$

(64) Formação de uma categoria funcional $c$, específica de uma língua (AI)

$$
c=<\kappa+\Sigma>
$$

Tendo em vista essas considerações, admitimos que, assim que uma célula do sistema F é fixada, ou seja, assim que um $\Sigma$ é associado a um $\kappa$, dadas as instruções estipuladas em (61), a célula fixada está apta a ser inserida na FLN. Seguindo as diretrizes apresentadas no início deste capítulo, uma célula fixada em $\mathrm{F}$ ingressa na FLN por intermédio da interface $f_{0}$. Será apenas internamente à FLN que sua categoria funcional $c$ será estabelecida, tal como ilustrado em (65). Em (65a), caracterizamos a primeira etapa de formação de uma categoria funcional $c$, como descrito em (64). Nessa etapa, uma célula do sistema F humano é fixada: a categoria $\kappa$ :ancoragem é associada a um valor, $\Sigma$ :passado. Logo após, a célula fixada em $\mathrm{F}$ ingressa na FLN por intermédio de $f_{0}$. Internamente à FLN, uma determinação categorial $c-$ no caso, $c$ :TEMPO - é associada à célula fixada, dando origem a um traço formal, tal como representado no exemplo (65b). Esse rótulo $c$ é específico à $\mathrm{L}_{1}$.

(65) a. Em F: < $<$ :ANCORAGEM, $\Sigma$ :passado $>$

A célula, em (65a), torna-se um traço formal, em (65a'), internamente à língua $\mathrm{L}_{1}$ : a'. Em L $\mathrm{L}_{1}$ : c:TEMPO < $\kappa$ :ANCORAGEM, $\Sigma$ :passado $>$

Um rótulo $c$ pode ser analisado como uma generalização estabelecida internamente a uma língua $\mathrm{L}$, acerca de um grupo de células fixadas por uma mesma categoria $\kappa$. Desse modo, a categoria especifica $c$ não precisa, a princípio, ser formalizada em termos de uma informação adicional inserida pela FLN às células que ingressam no Léxico-I. Sua determinação é, em certo sentido, epifenomenal e leva em conta as relações de conteúdo presentes entre os $\Sigma$ que servem como valores para uma categoria $\kappa$. Se uma língua L gera duas categorias $c$ a partir de uma mesma categorial universal $\kappa$, então, de acordo com essa conjectura, cada categoria $c$ será identificada a partir das generalizações aplicadas sobre um conjunto particular de $\Sigma$. Por exemplo, a categoria $\kappa$ :ponto de vista serve, para Wiltschko

\footnotetext{
${ }^{172}$ Optamos por seguir a notação sugerida pela $\mathrm{HCU}$, ou seja, $c, \kappa, \Sigma, \pi$, a fim de que a representação dos traços formais, mais adiante, fique visualmente mais acessível. É importante destacar que, embora a notação empregada seja semelhante, cada um desses caracteres deriva de motivações distintas daquelas assumidas pela HCU, como descrevemos nesta seção.
} 
(2014), como base para a formação dos traços $\varphi$ nas línguas indo-europeias. Cada categoria $c$ desse conjunto de traços decorrerá de uma generalização aplicada sobre os $\Sigma$ de $\kappa$ (e.g., se $\Sigma$ : 1P, 2P, 3P, então $c$ :PESSOA; se $\Sigma:$ SG, PL, etc., então $c$ :NÚMERO).

Postulamos adicionalmente que, ao ingressar na FLN, uma célula também é atrelada a uma perspectiva interpretativa, que, grosso modo, pode ser traduzida em termos dos domínios categoriais nominais e verbais. Lembrem-se que, para a HCU, as categorias universais $\kappa$, bem como as hierarquias funcionais que elas formam, são acategoriais. Assim, para explicar o fato de que os traços formais se distribuem em hierarquias funcionais distintas, propomos que a segunda etapa de formação de uma categoria funcional não apenas determina a categoria $c$ que uma célula irá apresentar, como também atribui a essa célula a capacidade de impor uma perspectiva interpretativa ao elemento em seu complemento estrutural. Essa proposta parte de discussões feitas em Panagiotidis (2015). O autor defende que nomes e verbos codificam um tipo particular de conceptualização, a que ele chama de "perspectiva interpretativa". Isto é, as informações categoriais nominais e verbais estabelecem diferentes perspectivas acerca de um mesmo conteúdo conceitual; uma assunção semelhante à de Langacker (1987).

Panagiotidis (2015, p. 82) argumenta que nomes e verbos são diferenciados a partir da perspectiva interpretativa que eles impõem. O autor, então, sugere que um núcleo categorial $n$ contém um traço $[\mathrm{N}]$ responsável por atribuir a seu complemento — comumente uma raiz-a perspectiva "substância"; do inglês, sortal. Na filosofia, sortal é um conceito que apresenta identidade, existência contínua (i.e., integridade estável no tempo) e é capaz de servir como resposta a perguntas do tipo “O que é isso?”. Por outro lado, um núcleo verbal $v$ contém um traço [V] responsável por impor ao conteúdo em seu complemento a perspectiva "extensível no tempo" (2015, p. 86). Essa caracterização da interpretação verbal descende da teoria de protótipos, proposta por Guivón (1984), que se vale do critério da estabilidade temporal para determinar as distinções entre as categorias lexicais. A categorial verbal, para essa teoria, é a menos estável temporalmente e sua instabilidade representa sua característica definidora.

Esse critério da estabilidade temporal serve como um parâmetro para a distinção entre as categorias nominais e verbais em diferentes tradições linguísticas. Na GG, por exemplo, Uriagereka (1999, p. 50-58) propõe que nomes e verbos instanciam espaços matemáticos de dimensões variadas. Nomes, em sua perspectiva, são espaços permanentes, estáveis, ao passo que os verbos são espaços mutáveis, instáveis. Acquaviva (2009b, p. 2) também assinala a ausência de uma extensão temporal em nomes, destacando que "o significado verbal [...] é construído a partir de uma dimensão temporal. [Já] o significado nominal, opostamente, não 
inclui uma dimensão temporal". ${ }^{173}$ É com base nessa distinção que Panagiotidis (2015) busca codificar as diferentes perspectivas interpretativas atribuídas a um conceito, ressaltando que essas perspectivas não são intrínsecas ao conceito per se, mas determinadas internamente à FLN. Ou seja, os traços [N] e [V] modelam o modo como manipulamos e interpretamos um mesmo conteúdo conceitual.

Em resumo, para Panagiotidis (2015, p. 84):

(66) Perspectivas interpretativas atribuídas pelas categorias nominal e verbal

a. Um traço $[\mathrm{N}]$ impõe uma perspectiva "substância" ao complemento do núcleo categorizador em LF;

b. Um traço [V] impõe uma perspectiva "extensível no tempo" ao complemento do núcleo categorizador em LF.

A adoção dessas perspectivas interpretativas nos permite explicar as assimetrias entre a chamada categorização conceitual e a categorização linguística dos conteúdos conceituais. ${ }^{174}$ Por exemplo, todos os objetos físicos são categorizados como nomes translinguisticamente (e.g., pedra, livro, mesa); porém, nem todos os nomes denotam objetos físicos (e.g., teoria, axioma, casamento). Essa assimetria não impede, todavia, que os conceitos pedra e teoria sejam manipulados da mesma maneira pela FLN. Isso nos indica que [N] e [V] circunscrevem um conceito a uma perspectiva específica, fazendo com que conceitos de ordens distintas como "[...] pedra e teoria sejam tratados igualmente pela gramática, muito embora [eles] não compartilhem propriedades comuns" (PANAGIOTIDIS, 2015, p. 84). Nesta tese, partilhamos a hipótese de que as categorias [N] e [V] impõem uma perspectiva particular aos conteúdos conceituais extraídos da categorização. No entanto, formalizamos essa hipótese de um modo diferente da caracterização em (66).

Em nossa proposta, toda célula que ingressa na FLN por meio de $f_{0}$ deve ser atribuída a um domínio interpretativo $\delta$ correspondente às perspectivas interpretativas "substância" e “extensível no tempo". Diferentemente de Panagiotidis (2015), não assumimos que [N] e [V] sejam traços formais, nem uma propriedade exclusiva dos núcleos categoriais $n$ e $v$. O que

\footnotetext{
${ }^{173}$ Trecho original: "verbal meaning is based on event structure [...], it has a temporal dimension built in. Nominal meaning, by contrast, does not have a temporal dimension built in".

${ }^{174}$ De certa maneira, essa distinção feita por Panagiotidis $(2015$, p. 84) remonta à oposição entre "conhecimento conceitual" e "conhecimento lexical", os quais são vistos como competências dissociadas e alocadas em diferentes regiões do cérebro (Cf. HUMPHREYS; FORDE, 2001; DAMASIO et al., 2004; JACKENDOFF; PINKER, 2005; VIGLIOCCO; KITA, 2006). Essa cisão entre conceitos e entradas lexicais endossa a assunção de que as competências conceituais para a linguagem humana estavam disponíveis anteriormente à emergência da FL (Cf. HAUSER; CHOMSKY; FITCH, 2002; HURFORD, 2007; TALLERMAN, 2009, entre outros).
} 
sugerimos é que essas duas perspectivas, denotadas por conveniência pelas notações [N] e [V], correspondem a distinções que a FLN, necessariamente, estabelece acerca dos conteúdos fixados pelo sistema F. Por essa razão, elas estão marcadas em todo traço formal presente no Léxico-I. ${ }^{175}$ Buscamos, por meio dessa conjectura, não apenas assegurar a interpretação de um AC na interface SEM, como permitir que essa interface seja capaz de identificar quais traços formais podem participar de uma mesma hierarquia funcional. De acordo com a AI, portanto, o domínio $\delta$ apresenta duas funções internamente à FLN, a saber:

(67) Funções dos domínios interpretativos $\delta$ internamente à FLN

a. Função interpretativa: Impor pós-sintaticamente uma perspectiva interpretativa ao conteúdo conceitual inserido em um AC;

b. Função estrutural: Identificar traços formais que participam de uma mesma hierarquia funcional, promovendo, assim, a formação de uma projeção estendida.

A função interpretativa, em (67a), recupera a proposta de Panagiotidis (2015), descrita em (66). Nesse contexto, o domínio $\delta$ tem, primeiramente, a função de delimitar um AC no complemento de uma hierarquia funcional, dado que os AC correspondem a conjuntos vazios. Paralelamente, o domínio $\delta$ determina a perspectiva interpretativa a que o conteúdo conceitual inserido nesse AC deverá se acomodar. ${ }^{176}$ Já a função estrutural, em (67b), define quais são as categorias funcionais que podem ser associadas à perspectiva "substância" e à perspectiva “extensível no tempo". Essa divisão possibilita que as categorias funcionais derivadas sejam

\footnotetext{
${ }^{175}$ Não nos é clara, até o momento, a razão pela qual as línguas distribuem seus conteúdos conceituais entre "substâncias" e situações "extensíveis no tempo", e nem por que essas perspectivas interpretativas deveriam se circunscrever a uma única categoria funcional, uma vez que elas parecem ser determinadas pela sequência funcional a que um conteúdo conceitual é associado (Cf. BORER, 2013). Por essa razão, assumimos que o domínio $\delta$ é uma propriedade uniforme entre os traços formais e que será a cadeia funcional que eles formam que irá, pós-sintaticamente, impor uma perspectiva interpretativa a um conceito. Alguns autores, por exemplo, sugerem que a categoria "substância"/sortal é um primitivo cognitivo inato (Cf. CAREY, 1997; HAUSER; CAREY, 1998). Esse primitivo nos permitiria, a princípio, individualizar e identificar objetos, demarcando onde um objeto termina e onde outro objeto se inicia, bem como quais seriam suas propriedades físicas. Há indícios de que primatas não humanos também teriam uma habilidade paralela, já que são capazes de perceber a ausência e a presença de um determinado objeto nas imediações (Cf. HAUSER; MCNEILAGE; WARE, 1996; HAUSER; CAREY, 2003). Essa conclusão nos é oferecida pelos trabalhos que avaliaram as habilidades aritméticas de primatas não humanos. O fato de sortal ser uma possível categoria primitiva não nos esclarece, ainda, por que ela foi privilegiada pela espécie humana.

${ }^{176}$ Essa formalização assegura ainda que a ausência de gramaticalização de uma categoria $\kappa$ não impeça que um AC fique sem interpretação na interface SEM. Um traço formal como [T:passado] é capaz de determinar que o conteúdo conceitual inserido em um AC seja interpretado como algo "extensível no tempo". Além disso, tal apontamento nos mostra que propostas que descartam os núcleos categoriais $n$ e $v$ não são incompatíveis com as considerações feitas pela AI, como é o caso de Harley e Noyer (1999), Alexiadou (2001), Borer (2003, 2005a, 2005b, 2013) e de Belder (2011). Para esses autores, outros núcleos funcionais como T e D seriam igualmente capazes de determinar a interpretação de um conteúdo conceitual; o que, para a AI, é uma consequência da presença de um $\delta$ em todo traço formal.
} 
agrupadas em um mesmo arranjo estrutural, dando origem a uma projeção estendida. Assim, para a AI, uma sequência funcional como C-T-Asp-v implica que cada um de seus traços formais foi marcado com um $\delta=[\mathrm{V}]$ quando ingressou na FLN.

É válido destacar que o domínio $\delta$ não tem o papel de determinar o ordenamento das categorias funcionais internamente a uma projeção estendida. A princípio, diferentes arranjos estruturais podem ser formados fazendo uso de um mesmo conjunto de traços formais em que $\delta$ equivale a $[\mathrm{V}]$, já que todos esses traços se associam à mesma perspectiva interpretativa (e.g., v-C-T-Asp; Asp-C-v-T). Para resolver esse impasse, hipotetizamos que o ordenamento das categorias funcionais internamente a uma projeção funcional, e os arranjos sistemáticos que essas categorias formam translinguisticamente, decorrem de uma imposição feita pelo sistema C-I, tal como sugerem Fortuny (2008) e Boeckx (2008, 2015). Assim sendo, a FLN pode derivar, por hipótese, diversos agrupamentos de traços formais; porém, o sistema C-I, ao ter acesso às estruturas formadas, irá interpretar como uma projeção estendida apenas aquelas cujos traços formais apresentam um mesmo domínio $\delta$, e cuja disposição das categorias $\kappa$ segue o ordenamento retratado em (68). Observem que o ordenamento em (68) parece ser cumulativo em termos interpretativos. ${ }^{177}$

(68) $\kappa$ :vinculação discursiva $>\kappa$ :ancoragem $>\kappa$ :ponto de vista $>\kappa$ :classificação

Em síntese, as duas etapas para a formação de uma categoria funcional específica, e, por conseguinte, para a formação de um traço formal, podem ser descritas como em (69). A primeira etapa, em (69a), é determinada internamente ao sistema F e, portanto, processa-se externamente à FLN. Já a segunda etapa, em (69b), ocorre internamente à FLN. Como parte final desse processo, o traço formal derivado, ilustrado na representação em (69b), será, então, inserido no Léxico-I da língua $\mathrm{L}_{1}$.

(69) Formação de uma categoria funcional $c$ específica de uma língua
a. Etapa \#1/Externa à FLN: $<\kappa, \Sigma>$
b. Etapa \#2/Interna à FLN: $<\kappa, \Sigma>+c+\delta$

Como produto desse conjunto de assunções, admitimos que um primitivo do Léxico-I humano, isto é, um traço formal, pode ser definido de acordo com as especificações em (70).

\footnotetext{
${ }^{177}$ Por exemplo, é preciso que se tenha primeiramente um evento antes de atribuir a esse evento um ponto de vista, e, então, ancorá-lo a um enunciado, para, no fỉm, estabelecer uma proposição.
} 
Nessa caracterização, alteramos a notação que descreve um traço formal, a fim de facilitar seu emprego nas representações arbóreas. A notação em (70), no entanto, não altera em nada as expectativas funcionais acerca desse primitivo. É válido destacar ainda que inserimos uma perspectiva interpretativa $[\mathrm{A}]$ à descrição em (70). Estamos cientes de que há dúvidas quanto à plausibilidade de se assumir que $[\mathrm{A}]$ instancia uma perspectiva interpretativa primitiva $(\mathrm{Cf}$. MORENO; PANAGIOTIDIS, 2018). Essa inserção provisória de [A] nos auxilia, pelo menos, a identificar os grupos de categorias funcionais que não atribuem perspectivas [N] e [V].

(70) Traço formal

Um traço formal no Léxico-I de uma língua L constitui-se de

$<\kappa, \Sigma>c_{[\delta]}$

Em que:

a. $\kappa$ corresponde às categorias universais, a partir das quais derivamos as categorias funcionais específicas de L (i.e., o conjunto de $\kappa /$ ATR da espécie humana);

b. $\Sigma$ corresponde aos elementos circunscritos por cada $\kappa /$ ATR da espécie humana;

c. $c$ corresponde à categoria funcional específica formada a partir do pareamento entre $\kappa$ e $\Sigma$, determinada internamente à FLN;

d. $\delta$ corresponde à perspectiva interpretativa que cada traço formal atribui ao seu complemento nas interfaces com os sistemas interpretativos, a saber:

d'. Se $\delta=[N]$, então seu complemento deve ser interpretado como uma substância; d'. Se $\delta=[V]$, então seu complemento deve ser interpretado como algo extensível no tempo;

d"', Se $\delta=[\mathrm{A}]$, então seu complemento deve ser interpretado como uma propriedade.

Como estabelecido pelo pressuposto 4, destacado no início deste capítulo, o Léxico-I é composto apenas por uma única classe de primitivos: traços formais. Esses primitivos, como vimos, são construídos a partir do molde isomórfico universal descrito em (70), cuja estrutura interna deriva das células fixadas pelo sistema F, externamente à FLN. Contudo, a descrição em (70) representa a estrutura canônica dos traços formais. Outros tipos de traços formais são verificados nas línguas naturais. Na próxima subseção, mostramos de que modo variações na 
organização desse molde isomórfico pode dar origem à variedade de traços formais observada intra- e translinguisticamente.

\subsubsection{A instalação da multiplicidade de traços formais}

Propomos que a multiplicidade de traços formais verificada em uma língua particular, bem como a variedade de traços formais observada entre as línguas naturais, é um reflexo da presença de três pontos de variação no molde isomórfico em (70). São eles:

V Variação em $\Sigma$; i.e., variação de conteúdo;

$>$ Variação em $\delta$; i.e., variação de domínio;

$>$ Variação em $c$; i.e., variação na determinação ou não de uma categoria funcional.

No que diz respeito à variação em $\Sigma$, um traço formal pode variar na atribuição de um $\Sigma$ a uma categoria universal $\kappa$ - e.g., se $\kappa$ :ancoragem é fixado como passado ou distal—, e no número de discriminações de $\Sigma$ feitas a uma mesma categoria universal $\kappa .{ }^{178}$ Essa variação é o que dá origem às diferentes categorias funcionais verificadas translinguisticamente, tal como defendido pela HCU. No entanto, embora haja variação em $\Sigma$, é importante destacar que essa variação não é livre. Os conjuntos definidos pelas categorias $\kappa$ delimitam os tipos de conteúdo passíveis de serem categorizados por uma dada espécie, como especificamos na definição das células de F, em (61). No caso da linguagem humana, essa conjectura se justifica pelo fato de que inúmeras noções semânticas e cognitivas não são expressas gramaticalmente, tal como ressaltam Talmy (1985), Cinque e Rizzi (2010), Cinque (2013), Rizzi e Cinque (2016), entre outros autores.

Talmy (1985, p. 134), por exemplo, assinala que:

"Há inúmeras características dos participantes de um evento que não estão marcadas em nenhum lugar do complexo verbal, mesmo que essas características pareçam tão razoáveis (à primeira vista) quanto as qualidades marcadas. Dessa forma, embora a numerosidade e a distribuição de um argumento possam ser marcadas, não haverá

\footnotetext{
${ }^{178}$ Por exemplo, a variação intra- e translinguística nos valores atribuídos à categoria funcional NÚMERO (e.g., singular, plural, dual, paucal, etc.) e à categoria funcional DEMONSTRATIVO (e.g., proximal, medial, distal, etc.). Deixamos em aberto, no entanto, a questão do quanto um valor $\Sigma$ pode ser decomposto semanticamente em conteúdos mais elementares, como sugerem os estudos em morfossemântica. Harbour (2013), por exemplo, propõe que os valores atribuídos à categoria NÚMERO são construídos a partir das informações \pm atômico e \pm mínimo, cujas combinações dão origem a traços formais como [-atômico, -mínimo] = plural, [-atômico, + mínimo] $=$ dual, etc.
} 
marcas funcionais para sua cor ou se ele tem um arranjo simétrico, muito embora essas mesmas qualidades sejam importantes em outros sistemas cognitivos, tal como para a percepção visual” (TALMY, 1985, p. 134, tradução nossa). ${ }^{179}$

Em outras palavras, não é plausível admitir que "qualquer propriedade ou distinção semântica imaginável possa ser gramaticalizada, expressa através de um elemento funcional" (CINQUE; RIZZI, 2010, p. 78). ${ }^{180}$ Para a AI, como dissemos, esse impedimento é resultado de imposições feitas pelas categorias $\kappa$. Essas categorias permitem que uma língua seja capaz de gramaticalizar distinções relativas ao tempo e às atitudes do falante com relação à verdade de uma proposição, mas não categorias funcionais que expressam "medo", "fome", "perigo", “preocupação", etc., tal como frisa Cinque (2013, p. 51). Esse mesmo raciocínio está presente na caracterização das categorias referenciais de primatas não humanos, discutidas no Capítulo 3. Lembrem-se que as imposições feitas por essas categorias predeterminadas geneticamente são o que torna uma espécie sensível a categorizar e a externalizar certas situações do mundo.

Dadas essas características da variação em $\Sigma$, ilustramos, em (71), o modo como ela se estabelece internamente à AI. Recuperamos, para tanto, a discussão envolvendo a fixação da categoria universal $\kappa$ :ancoragem no inglês e no halkomelem, vistas na subseção 4.3.3. Observem que, nas representações em (71), o valor de $\Sigma$ atribuído a uma célula em F é o que determina a natureza da categoria funcional $c$ formada em uma língua particular L. Tanto o $\Sigma$ selecionado para fixar $\kappa$ :ancoragem quanto a categoria $c$ formada internamente à FLN estão destacadas em negrito nos exemplos abaixo. Em (71c) e em (72c), reproduzimos o traço formal resultante dessa variação em $\Sigma$.

(71) Inglês
a. Etapa $\# 1$, em F: $<\kappa$ :ANCORAGEM, $\Sigma$ :passado $>$
b. Etapa \#2, na FLN: $\mathrm{L}_{\mathrm{I}}$ : c:TEMPO $<\kappa$ :ANCORAGEM, $\Sigma$ :passado $>_{[\mathrm{V}]}$
c. Traço formal: $<\mathrm{PASS}>\mathrm{T}_{[\mathrm{V}]}$

\footnotetext{
${ }^{179}$ Trecho original: "There are many characteristics of an event's participants that are not marked anywhere in the verb complex, even though they seem as reasonable (from an a priori perspective) as the qualities that are marked. Thus, while an argument's numerosity and distribution can be marked, there will be no marking for its color or whether it has a symmetrical arrangement, even though these very qualities are important in other cognitive systems, such as visual perception."

${ }^{180}$ Trecho original: "[Clearly, it is not the case that] any imaginable semantic property or distinction can be grammaticalized, expressed by a functional element".
} 
(72) Halkomelem
a. Etapa \#1, em F: < $\kappa$ :ANCORAGEM, $\Sigma$ :distal $>$
b. Etapa \#2, na FLN: $\mathrm{L}_{2}$ : c:LOCALIZAÇão $<\kappa$ :ANCORAGEM, $\Sigma$ :passado ${ }_{[\text {[V] }}$
c. Traço formal: $<$ DISTAL $>\mathrm{LOC}_{[\mathrm{V}]}$

A variação em $\delta$, por sua vez, relaciona-se à perspectiva interpretativa que uma determinada sequência funcional impõe a um $\mathrm{AC}$ em seu complemento. Esse tipo de variação é o que promove, de acordo com a AI, a identificação de diferentes projeções estendidas, sejam elas nominais ou verbais. Reparem que, em nossa formalização, as projeções estendidas não estão pré-formadas no léxico e tampouco são predeterminadas pela GU. Na verdade, elas são derivadas através da operação Merge e validadas pelo sistema C-I. Como argumentamos na última subseção, a formação de uma projeção estendida parte de uma equivalência nos valores do domínio $\delta$ de traços formais concatenados em uma disposição imediatamente local. Nessa sequência funcional, não deve haver outros traços formais intervenientes, cujo domínio $\delta$ difere daquele dos demais traços que compõem a projeção.

Para ilustrar os arranjos formados a partir dessas projeções funcionais, descrevemos, no que segue, as projeções estendidas do domínio verbal e do domínio nominal nas línguas indo-europeias. Assumimos que, nessas línguas, os traços formais marcados com $\delta=[\mathrm{V}]$ são associados às categorias $\kappa$ cujos valores são C, T, Asp e $v$, tal como sugerido em Wiltschko (2014, p. 78). A projeção estendida formada através do agrupamento dessas categorias $c$, por intermédio de Merge, está representada em (73):

(73) Projeção estendida associada a $\delta=[\mathrm{V}]$

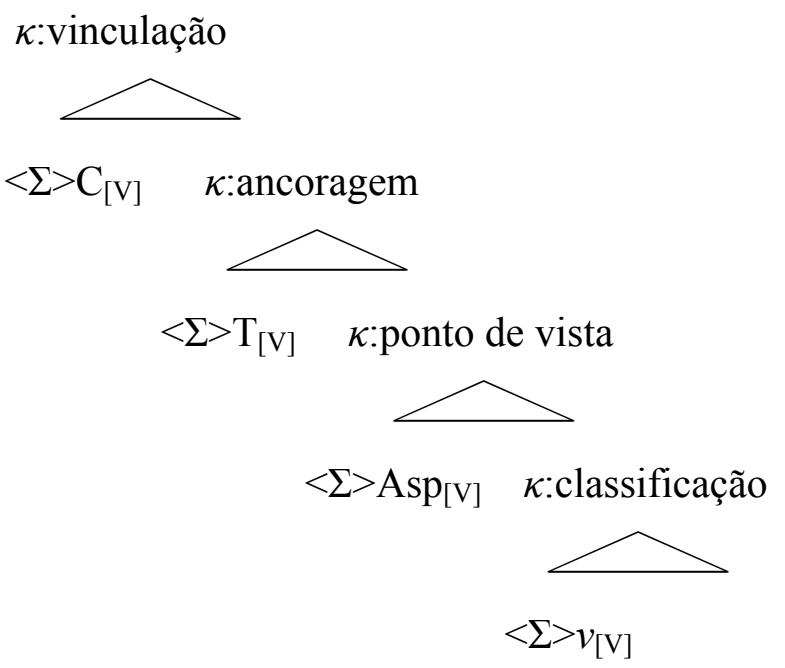


Para compor a projeção estendida associada ao domínio $\delta=[\mathrm{N}]$, partimos de assunções feitas por Borer (2005a), Wiltschko (2014), Hachem (2015) e Klochmann (2017). Em linhas gerais, propomos que as categorias $\kappa$, no domínio nominal, derivam categorias funcionais que (i) classificam objetos, (ii) distinguem quantidades, (iii) determinam a localização espacial de um objeto e (iv) vinculam essas informações a um enunciado. Como vimos na subseção 4.3.3, Wiltschko (2014, p. 75-69) aponta que as categorias $c$ no domínio nominal das línguas indoeuropeias são: $\mathrm{K}, \mathrm{D}, \varphi$ e $n$. Partimos dessa proposta inicial, aplicando a ela modificações pontuais, com base em revisões feitas pelos autores mencionados neste parágrafo.

Hachem (2015, p. 57), por exemplo, nota que a distribuição de Wiltschko não é capaz de explicar a formação de quantificadores, tais como muitos, poucos e alguns. Para preencher essa lacuna, a autora postula que, além das quatro categorias universais $\kappa$ vislumbradas pela HCU, deve existir uma categoria adicional: $\kappa$ :quantidade. "Quantidade" seria responsável pela formação dos quantificadores, dos números cardinais e de artigos indefinidos. A adição dessa nova categoria universal ao quadro de ATR humanos não é improvável, especialmente de um ponto de vista evolutivo. Experimentos com diversas espécies de animais não humanos nos indicam que habilidades para depreensão de cardinalidade/numerosidade são ancestrais (Cf. SPELKE, 2000, 2003; CAREY, 2009); em particular, a depreensão de quantias que variam entre os números 1 e 4 (Cf. HAUSER; MACNEILAGE; WARE, 1996; HAUSER; CAREY; HAUSER, 2000; HAUSER; CAREY, 2003; SPELKE, 2003; CAREY, 2009, entre outros). Em vista disso, nos parece plausível que a categoria $\kappa$ :quantidade tenha sido selecionada, em um dado momento, para compor o conjunto de ATR humanos, mostrando-se adaptativamente mais relevante do que as categorias então disponíveis.

Assumimos ainda com Hachem (2015, p. 137) que a relação entre os determinantes e informações concernentes à dêixis não é intrínseca, como propôs Wiltschko, mas decorre de localidade estrutural. Determinantes e itens formais que expressam dêixis são, nesse sentido, derivados a partir de categorias universais distintas. Hachem argumenta que um determinante não tem a função de ancorar o referente ao enunciado, mas de vinculá-lo ao discurso. Sendo assim, um núcleo D não seria uma categoria funcional derivada a partir de $\kappa$ :ancoragem, mas de $\kappa$ :vinculação. Sua função é apenas a de determinar que o sintagma nominal apresenta uma referência definida (Cf. BORER, 1989, 1999; SILONI, 1997). Dessa forma, as informações dêiticas veiculadas por um DP circunscrevem-se aos demonstrativos, cuja função prototípica é a de estabelecer distinções entre localidades, sejam elas proximais (e.g., este/a, esse/a), distais (e.g., aquele/a), ou mesmo mediais. Dadas essas conjecturas, demonstrativos devem ser vistos como os núcleos responsáveis por "ancorar" espacialmente o referente denotado por um NP e 
correspondem à categoria funcional $c$ derivada com base em $\kappa$ :ancoragem. Determinantes, por outro lado, são um produto de $\kappa$ :vinculação, responsáveis por expressar definitude e conectar o referente ao contexto. ${ }^{181}$

A terceira revisão que fazemos com relação à proposta inicial de Wiltschko (2014) diz respeito à natureza da categoria universal $\kappa$ :ponto de vista. A autora sugere que essa categoria dá origem aos chamados traços $\varphi$. Nesta tese, propomos uma dissociação no estabelecimento desses traços, especialmente daqueles que expressam $c$ :NÚMERO e $c$ :GÊNERO. Argumentamos que os valores atrelados à $c$ :GÊNERO, bem como às demais formas gramaticais empregadas para a classificação dos nomes - e.g., as classes nominais das línguas bantas, bem como das línguas papuas-, são determinados através de $\kappa$ :classificação. Gênero e classes nominais apresentam uma distribuição formal semelhante, notadamente: (i) são categorias funcionais regulares nos sintagmas de que participam; (ii) são categorias obrigatórias, ou seja, todo nome em uma língua com sistemas de classificação deve ser atribuído a um gênero ou a uma classe; e ambas (iii) apresentam relações de dependência para fora do sintagma nominal (Cf. DIXON, 1982, 1986; AIKHENVALD, 2000; GRINEVALD, 2002). ${ }^{182}$ É válido destacar ainda que marcas de gênero e de classes nominais se manifestam em uma posição estrutural próxima da raiz, sendo realizadas anteriormente à inserção das marcações de número (Cf. CRYSMA; MARTEN; SYBESMA, 2011).

Nesta tese, tomamos ao pé da letra a ideia de que a categoria $\kappa$ :classificação distribui

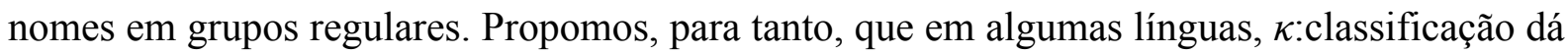
origem a dois grupos de categorias funcionais. Por uma lado, $\kappa$ :classificação possibilita a

\footnotetext{
${ }^{181}$ A categoria KP, que para Wiltschko (2014) associa-se à $\kappa$ :vinculação, é motivo de extensa discussão, uma vez que caso morfológico, explorado nas discussões da autora, pode corresponder a um fenômeno póssintático. Se assim for, marcas de caso não devem ser entendidas como uma informação fundamental para o licenciamento de um DP (Cf. MARANTZ, 2000; MCFADDEN, 2004, 2009; SIGURĐSSON, 2006, 2009; BOBALJIK, 2008, entre outros). Ainda, de acordo com essa última perspectiva, caso estrutural, bem como caso inerente/lexical, são realizados no ramo de PF a partir da descrição estrutural definida previamente pela sintaxe. Por exemplo, Marantz (2000) e McFadden $(2004,2006)$ assumem que o componente morfológico no ramo de PF pode verificar se um DP, em um dado domínio de fase, é c-comandado por outro DP em uma posição superior ou não. Com base nessas informações, o DP que sofreu Spell-Out será realizado com morfologia nominativa ou com morfologia acusativa a depender de sua configuração estrutural; uma abordagem puramente relacional. Outros autores, como Miyagawa, Wu e Koizumi (2018), argumentam que a marcação de caso é epifenomenal e decorre de efeitos de rotulação da estrutura sintática. Assim sendo, se caso for, fundamentalmente, uma categoria configuracional, como sugerem essas duas linhas de pensamento, então não haveria motivos para discriminá-los pré-sintaticamente na forma de traços formais derivados por F. É por essa razão que removemos $\mathrm{K}$ dos produtos derivados pelo sistema $\mathrm{F}$ e os alocamos, por ora, como resultado de marcações morfológicas pós-sintáticas.

${ }^{182}$ Por exemplo, o árabe e o hebraico apresentam concordância em gênero nas relações sujeito-verbo (e.g., no árabe, Pakal-at l-banaat l-taSaam lit. comer-FEM a-menina-FEM-PL a-comida 'A menina comeu a comida'; SHLONSKY, 1989, p. 4), da mesma que as línguas bantas (e.g., batoto ba-mingi b-a iki ki-pande ba-li-kwaka-po lit. CL2.crianças CL2.muitas 2-CON DEM.CL7 CL7-peça CL2-PASS-estar-ASP-LOC 'Muitas crianças desta área estavam lá'; KABUYA, 1999, p. 94).
} 
formação do núcleo $n$, como determina Wiltschko (2014). Por outro, essa categoria universal permite a formação de um nível adicional para a classificação dos nomes, o qual se manifesta através das categorias funcionais $c$ :GÊNERO e $c$ :CLASSES NOMINAIS. Assim, enquanto $n$ distingue objetos de eventos, $c$ :GÊNERO e $c$ :CLASSES NOMINAIS distribuem esses objetos em grupos ainda mais específicos. No caso das línguas indo-europeias, nomes são comumente distinguidos entre 'masculino', ‘feminino' e 'neutro'. Já nas línguas bantas, nomes podem ser divididos em 'pessoa', 'animal', 'objeto redondo', entre outras formas de classificação, como é o caso do suaíli (Cf. CRYSMA; MARTEN; SYBESMA, 2011, p. 254). As línguas que não fazem distinções em gênero ou em classes nominais, como o inglês e o japonês, não devem criar essa segunda camada de $\kappa$ :classificação. ${ }^{183}$

Já a categoria $\kappa$ :ponto de vista está atrelada, em nossa perspectiva, a $c$ :NÚMERO, bem como aos classificadores numerais. Sua função é atribuir um ponto de vista a um determinado objeto, definindo-o como massivo, como contável ou como um coletivo. Seguindo a proposta de Borer (2005a), assumimos que todo núcleo $n$, isoladamente, é interpretado como um nome massivo. Para que um nome se torne contável, é preciso que ele seja, primeiramente, dividido em partes. A autora argumenta que a função de dividir um nome em partes contáveis está a cargo dos morfemas de número e dos classificadores numerais; como é o caso do mandarim e do japonês. Essas categorias funcionais $c$ são "divisores" que, uma vez associados a um $n$, permitem que o nome em questão seja quantificado. Com base nessas premissas, assumimos que, no domínio nominal, $\kappa$ :ponto de vista possibilita a formação de categorias funcionais capazes de dividir um nome em partes menores, e, com isso, permitir que esse nome seja quantificado pelas categorias funcionais formadas a partir de $\kappa$ :quantificação. ${ }^{184}$

\footnotetext{
${ }^{183}$ Marcas de gênero são encontradas apenas em pronomes nessas línguas. Assim, tendo em vista sua distribuição restrita, sugerimos que essas categorias devem ter sido fixadas através de modificadores, os quais serão descritos mais adiante. Essa assunção é uma extensão do que Wiltschko (2014) propôs para a categoria TEMPO na língua halkomelem.

${ }^{184}$ Lieber (2012, p. 2015-2107) argumenta que a categoria número, nos nomes, e a categoria aspecto, nos verbos, devem ser tratadas como uma mesma categoria semântica. A correlação sugerida pela autora nos permite equiparar funcionalmente a categoria universal $\kappa$ :ponto de vista no domínio nominal e no domínio verbal, endossando a hipótese de que número é um produto da fixação de $\kappa$ :ponto de vista. Mais especificamente, de acordo com Lieber, diferentes tipos de marcas aspectuais podem expressar que as ações ou os estados descritos por um verbo são compostos por uma ou mais partes, ou que que eles são internamente indistintos. Marcas morfológicas que designam ações repetidas, como é o caso do prefixo re- no português, podem ser vistas como um correspondente das marcas morfológicas que formam nomes plurais e contáveis. Isso se deve ao fato de que essas marcas designam eventos distintos, mas idênticos àquele de sua base. Afixos semelfactivos, isto é, afixos que denotam uma ação verbal singular, pontual, estariam correlacionados ao número singular dos nomes contáveis, tendo em vista que semelfactivos denotam eventos unitários delimitados temporalmente, da mesma forma que o singular designa entidades unitárias, delimitadas espacialmente. Já marcas aspectuais distributivas estariam correlacionadas aos nomes coletivos. Para a autora, o fato de que as marcas distributivas identificam uma série de eventos idênticos que juntos formam um único evento, sugere que elas seriam paralelas aos nomes coletivos (e.g., manada), que consistem de múltiplas entidades idênticas concebidas como um todo. Por
} 
Em resumo, a projeção estendida de um $\delta=[\mathrm{N}]$ nas línguas indo-europeias contém a seguinte hierarquia de núcleos funcionais. $n$ está para o núcleo categorial nominal, enquanto Gen corresponde à $c$ :GÊNERO. Nesse domínio sintático, os nomes são distribuídos em classes específicas. Num, por sua vez, corresponde à categoria funcional $c$ :NÚMERO. Nesse domínio, determinamos se um nome é interpretado como massivo, contável ou como coletivo. Já Q está para o domínio sintático em que os quantificadores estão acomodados, incluindo também os numerais e os artigos indefinidos. O núcleo Dem abriga os demonstrativos, o domínio em que a dêixis é estabelecida. Finalmente, o núcleo funcional D hospeda determinantes, o domínio sintático da vinculação com o discurso.

(74) Projeção estendida associada a $\delta=[\mathrm{N}]$

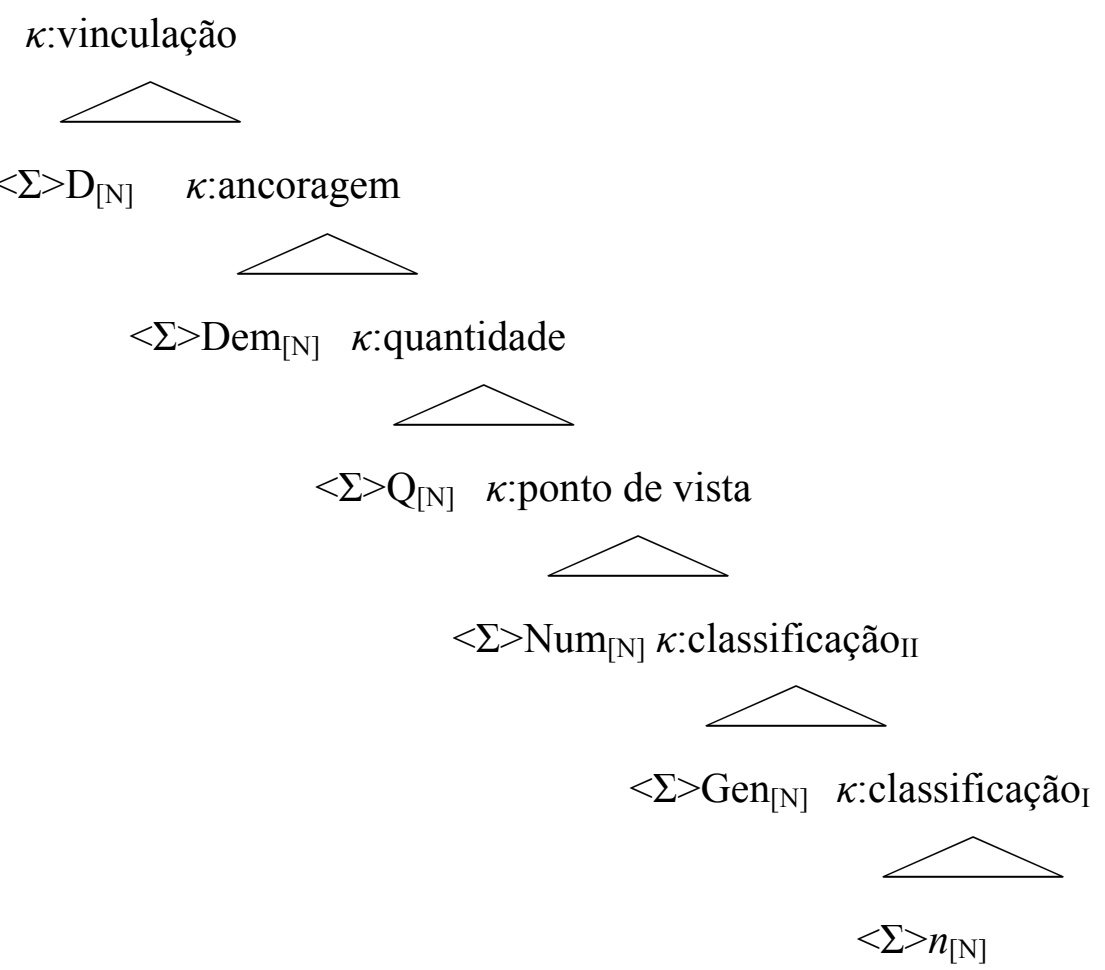

Há ainda um segundo tipo de variação em $\delta$ que nos permite explicar a formação de núcleos categoriais capazes de alterar a categoria lexical de seu complemento, se nominal ou se verbal, sem muitas vezes promover uma alteração semântica além daquela requerida pela alteração categorial (Cf. BEARD, 1995; ADAMS, 2001). Esses núcleos são realizados pelos chamados "afixos transposicionais", tais como os nominalizadores verbais -dor, -tor, -sor (e.g., jogador, inspetor, agressor), -ante, -ente, -inte (e.g., estudante, combatente, ouvinte), mantém inalterada por um período de tempo, sem qualquer diferenciação interna de suas partes. 
ção (e.g., nomeação), -mento (e.g., acolhimento), -ório (e.g., velório), e os verbalizadores nominais, como os sufixos -ej- (e.g., velejar), -iz- (e.g., cristalizar), -ear (e.g., cabecear), -isc(e.g., chuviscar), entre vários outros (Cf. ROCHA, 1999; BASÍLIO, 2004). Conjecturamos que a variação no modo como o domínio $\delta$ é atribuído a um traço formal abre a possibilidade de se derivarem traços "transpositores", cujo papel é alterar, "transpor", a natureza da projeção funcional que está sendo derivada. Sua formalização parte da ideia de C-funtores proposta em Borer $(2013,2014 b)$, muito embora as partes que integram esses "transpositores" decorram de motivações distintas.

Borer $(2013,2014 b)$ propõe a ideia de C-funtor com o intuito de eliminar o número de morfemas zeros empregados na morfologia derivacional. A autora diverge de modelos como a MD, que faz uso de núcleos categoriais zeros indiscriminadamente. Apesar de nosso interesse não estar voltado para questões envolvendo a expoência dos morfemas, julgamos que sua proposta abarca uma série de propriedades da morfologia derivacional que são ignoradas pela MD. Uma delas é o fato de que há morfemas derivacionais capazes de alterar a categoria lexical de sua base e que, ao mesmo tempo, apresentam exigências específicas acerca do tipo de base que tomam. Por exemplo, -mento forma nomes somente a partir de bases verbais, da mesma forma que -dade forma nomes somente a partir de bases adjetivais. Os categorizadores postulados pela MD não conseguem prever essas distinções, uma vez que apenas discriminam nomes $(n)$ de verbos $(v)$. A ausência de informações adicionais nesses núcleos categorizadores impede que a MD explique a distribuição e a variedade de conteúdos atrelados aos morfemas derivacionais.

Para ilustrar as limitações da MD no que concerne à morfologia derivacional, Nóbrega (2015a, p. 46) contrasta dois nominalizadores adjetivais com distribuições distintas. O autor mostra que -able seleciona apenas núcleos verbais para formar adjetivos (e.g., forget(t)-able 'esquecível'), ao passo que -ful seleciona tanto núcleos verbais quanto núcleos nominais (e.g., $v \rightarrow a$ : forget-ful 'esquecido'; $n \rightarrow a$ : peace-ful 'pacífico'). Para a MD, tanto o adjetivo forgettable quanto o adjetivo forgetful apresentam o mesmo padrão de estrutura sintática (viz., $[a[v \sqrt{ }$ FORGET $])$, em que -able e -ful são expoentes fonológicos do núcleo categorial $a$. Não há nada além dessa informação categorial $a$ para regular quando o componente morfológico deve selecionar-able e quando ele deve selecionar -ful como expoente de $a$. A ausência de informações estruturais adicionais torna a formação dos nomes forgettable e forgetful um caso de variação livre. Há que se observar ainda que a MD não diz nada a respeito da diferença de conteúdo presente entre esses dois nominalizadores adjetivais. 
O segundo problema apontado por Borer $(2013,2014 b)$ é exatamente esse: a ausência de discriminações acerca dos conteúdos expressos pelos morfemas derivacionais. Para a MD, os sufixos -dor, -tor, -sor, -ante, -ente, -inte, -ção, -mento, -ório e os demais nominalizadores do português representam expoentes fonológicos de um mesmo $n$. Não há nada nesse traço formal que indique diferenças de conteúdo, por exemplo, o fato de que o sufixo -ório forma nomes que indicam locais (e.g., lava(t)ório), enquanto o sufixo -tor forma instrumentos (e.g., interruptor). É com base nessas considerações, que Borer postula os $\mathrm{C}$-funtores, cuja estrutura elementar é: $\mathrm{C}_{\mathrm{V}[\mathrm{N}]}, \mathrm{C}_{\mathrm{N}[\mathrm{V}]}$, etc. $\mathrm{C}$ indica a semântica do morfema, enquanto as especificações categorias subscritas indicam a categoria que rotula a estrutura formada e o tipo de categoria que o funtor toma como complemento. No caso de $\mathrm{C}_{\mathrm{V}[\mathrm{N}]}$, temos um verbalizador nominal. $\mathrm{A}$ estrutura de um traço "transposicional", como sugere a AI, é semelhante à de um C-funtor. C está para $\Sigma$, enquanto a categoria que rotula está para $c$. Por fim, a categoria que serve para indicar a natureza do complemento está para o domínio $\delta$.

De acordo com a AI, os núcleos transpositores comportam-se do seguinte modo. No caso dos nominalizadores verbais, um núcleo categorial $n$ é associado a $\delta=[\mathrm{V}]$, em vez de ser atribuído a $\delta=[\mathrm{N}]$. Como resultado, esse núcleo categorial pode ser incluído em uma estrutura sintática cuja projeção vem se desenvolvendo na forma de um domínio verbal. Assim, a equivalência de domínios $\delta$ assegura que o sistema C-I não descarte esse arranjo de traços. Ao mesmo tempo, a categoria $n$, responsável por determinar o rótulo do OS resultante, permite que traços formais $\operatorname{com} \delta=[\mathrm{N}]$ possam ser combinados à estrutura, dando início a formação de uma projeção nominal a partir daquela porção da estrutura sintática. É dessa maneira que a natureza categorial da estrutura sintática é "transposta".

Em (75), ilustramos essa alteração categorial através da representação da estrutura genérica de um tipo de nominalização verbal. Exemplos correspondes à estrutura genérica em (75) seriam as nominalizações em -mento, como movimento, ferimento, sofrimento. ${ }^{185}$ Outros núcleos da projeção estendida de um domínio verbal poderiam estar incluídos acima do traço categorial verbal, regulando diferenças de leitura das nominalizações e de quais formas afixais poderiam servir como expoentes do traço transpositor $<\Sigma>n_{[\mathrm{V}]}$ (e.g., como se espera da distinção entre os afixos -mento e -ção, Cf. OLIVEIRA, 2007; FREITAS, 2014). Esse mesmo

\footnotetext{
${ }^{185}$ Obviamente, a estrutura em (75) não contempla os casos em que -mento nominaliza uma raiz, em dados como fragmento, argumento, cimento, aumento. Como destaca Freitas (2015, p. 15), uma evidência para a ausência de uma camada verbal nessas palavras é a ausência de uma vogal temática, comum às nominalizações deverbais, como se observa em mov-i-mento, sofrimento, (em que a vogal temática /e/ é alteada para /i/), fer-imento, etc.
} 
papel dos traços transpositores está envolvido na formação de verbos denominais, de nomes deadjetivais, e das demais formas de transposição categorial da estrutura sintática. ${ }^{186}$

(75) O papel do traço transpositor

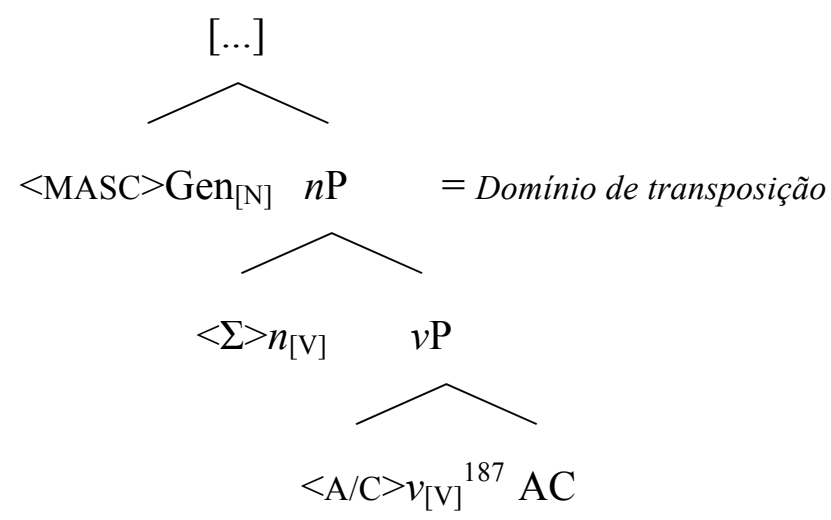

Um terceiro e último tipo de variação no molde isomórfico está relacionado à variação em $c$, ou seja, se uma categoria específica é atribuída ou não a uma célula fixada por F. Vimos que o rótulo $c$ pode ser o resultado de uma generalização feita pela FLN acerca de um grupo de $\Sigma$ associados a uma mesma categoria $\kappa$. Há, no entanto, um conjunto de morfemas que não formam essas classes naturais, sendo instâncias únicas de um mesmo conteúdo. Associamos a esse tipo de traços formais o que chamamos de "modificadores". Esses traços modificadores agregam um conteúdo à estrutura sintática, sem interferir em sua natureza categorial. A esses traços associamos os chamados afixos não transposicionais, ou seja, morfemas derivacionais que não alteram a categoria da base às quais se concatenam. Exemplos são os prefixos $b i-, e x-$ , des-, i(n)-, intra-, pré-, pós, sub-, anti-, mini-, micro-, etc., e os sufixos -(z)inh, -(z)ão, -aç-, eir, -elh-, -ic-, etc.

\footnotetext{
${ }^{186}$ A formação de nomes deadjetivais merece um comentário separado. Nominalizações deadjetivais são restritas, ocorrendo somente com os adjetivos que podem aparecer em uma posição predicativa, tal como verifica Roy (2010). Assim, os adjetivos que podem servir de base para nominalizações devem apresentar necessariamente um uso predicativo, isto é, devem ocorrer em posição predicativa, como em construções copulares (e.g., esse menino está doente). Os adjetivos que apenas apresentam um uso atributivo, como modificador nominal (e.g., o último jogador), não estão disponíveis para nominalização. Exemplos desse contraste estrutural são: (i) o pobre menino, o menino é pobre, a pobreza do menino; (ii) uma escolha possível, essa escolha é possivel, a possibilidade da escolha; (iii) um inimigo possivel, *esse inimigo é possivel, *a possibilidade do inimigo, (iv) o último presidente, ${ }^{*}$ o presidente é último, *a ultimidade do presidente. Isso nos sugere que um traço $\left\langle\Sigma>n_{[\mathrm{A}]}\right.$ deve ter como seu complemento uma projeção predicativa que abriga um adjetivo. $\mathrm{O}$ sujeito desse adjetivo pode, eventualmente, ser realizado após a nominalização, como se verifica nos contrastes apontados. Ver Roy (2010, p. 149-152) para uma distribuição das classes de nomes formadas a partir de adjetivos.

${ }^{187} \mathrm{~A} / \mathrm{C}$ remete a agente/causa, isto é, à possibilidade de se interpretar um DP que venha a servir como um o argumento externo do núcleo que abriga o traço $\left\langle\mathrm{A} / \mathrm{C}>v_{[\mathrm{V}]}\right.$ como um agente/causa. Tal assunção será melhor explicada na seção 4.6.
} 
Observem que esses afixos apresentam um conteúdo semântico particular, que não se agrupa em supercategorias, como é o caso dos traços formais destacados na variação em $\Sigma$. Os modificadores, de modo geral, não compartilham uma propriedade semântica comum e, paralelamente, não são mutuamente exclusivos. Essas duas propriedades são verificadas, em oposição, na distribuição da categoria funcional $c$ :TEMPO, cujos valores 'presente' e 'passado' estabelecem uma relação entre o tempo do evento e o tempo de fala - logo, apresentam uma propriedade semântica comum —, e não coocorrem em um mesmo verbo — são mutuamente exclusivos. ${ }^{188}$ Outra característica desses morfemas é o seu conteúdo, que, muitas vezes, está atrelado a um significado comumente expresso pelas raízes. Por exemplo, o sufixo -eir agrega o significado 'árvore/ramo de' a nomes, como em mamoeiro, pereira, roseira. Na língua big nambas, há um morfema derivacional -et que insere o conteúdo 'sagrado', como em dui-et 'homem sagrado', navanel-et 'estrada sagrada' (Cf. FOX, 1979, apud HASPELMATH; SIMS 2010, p. 86). ${ }^{189}$

Um segundo grupo de morfemas cujo comportamento assemelha-se ao dos morfemas não transposicionais é o dos classificadores nominais. Esses classificadores diferem tanto das classes nominais, que atrelamos à categoria gênero, quanto dos classificadores numerais, que atrelamos à categoria número. Os classificadores nominais são morfemas que qualificam um nome ao tornar saliente uma de suas propriedades inerentes. Dixon $(1982,1986)$, Aikhenvald (2000) e Grinevald (2002) apontam que os classificadores nominais não são obrigatórios e não desencadeiam concordância interna e externamente ao sintagma nominal. Além disso, línguas com sistemas de classificação nominal podem ter um mesmo nome ocorrendo com diferentes classificadores. Por exemplo, na língua minangkabau, o nome limau 'limão' pode ser concatenado tanto ao classificador batang 'árvore', a fim de caracterizar o limoeiro, batang limau — semelhantemente ao sufixo -eir- do português—, quanto ao classificador buah 'fruta', a fim de caracterizar a fruta, como em buah limau 'limão' (MARNITA, 1996, apud AIKHENVALD, 2000, p. 84). ${ }^{190}$

Uma propriedade adicional é o fato de que eles não são mutuamente exclusivos. Isso se verifica nos sintagmas nominais da língua yidiny. O classificador nominal bama 'pessoa'

\footnotetext{
${ }^{188}$ Alguns traços modificadores podem, a princípio, ser agrupados em uma mesma classe, como é o caso dos morfemas avaliativos -(z)inh, -(z)ão, -aç-, -elh-, -in-. Porém, o fato de eles não serem mutuamente exclusivos impede que eles formem uma categoria $c$. Esse seu agrupamento é, portanto, meramente descritivo. Exemplos da ausência de exclusividade estão presentes em boneq-inh-a-(z)inha, chup-ão-(z)inho, pequen-ino-(z)inho, etc.

${ }^{189}$ FOX, G. J. Big Nambas grammar. Canberra: Australian National University, 1979.

${ }^{190}$ MARNITA, R. Classifiers in minangkabau. 1996. Tese (Doutorado em Linguística) - Australian National University, 1996.
} 
pode coocorrer com os classificadores nominais waruja 'homem' e bunya 'mulher', tal como se verifica no exemplo (76):

(76) Yidiny (DIXON, 1977, p. 484 apud AIKHENVALD, 2000, p. 83)

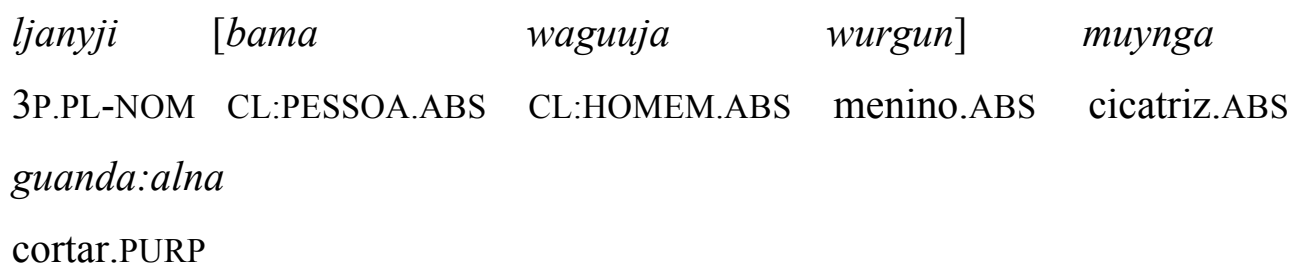

'Nós devemos fazer as marcas tribais [no] menino'

Para abarcar as propriedades desse grupo de traços modificadores, propomos que eles carecem da determinação de uma categoria específica $c$. Esses traços formais apresentam apenas um valor $\Sigma$ e um domínio $\delta$. A ausência de uma categoria $c$ nos sugere que eles não derivam da fixação de uma categoria universal $\kappa$. Muito provavelmente, eles representam o resultado de um processo de gramaticalização do conteúdo atrelado a um AC. Assim, levando em consideração que o sistema $\mathrm{F}$ é incluído pelo sistema C-I, como destacamos na seção 4.2, admitimos que certos conteúdos conceituais de C-I são processados por meio de $\mathrm{F}$ e, então, inseridos na FLN através da interface $f_{0}$. Dado que somente o valor $\Sigma$ ingressa na FLN sem estar associado a uma categoria $\kappa$, o que temos é um $\Sigma$ isolado sendo atribuído a um domínio $\delta$. Como resultado, o traço formal derivado apenas agrega um conteúdo semântico à estrutura, sem influenciar nas questões de rotulação. Uma vez que um rótulo categorial $c$ está ausente, o rótulo $c$ de seu complemento é percolado e, então, passa a rotular o OS formado. ${ }^{191}$

Em (77), abaixo, ilustramos a concatenação de um modificador na estrutura sintática. Reparem que sua concatenação segue a ideia de um adjunto. Adjuntos não têm participação efetiva na computação sintática, como salientam Iruntzun e Gallego (2007), pois não formam exigências imprescindíveis para a boa formação da sentença —neste caso, das palavras-, entre outras propriedades. Os adjuntos simplesmente estão "lá". Na estrutura abaixo, notamos que a ausência de um rótulo categorial no traço modificador faz com que o rótulo categorial de seu complemento seja o responsável por rotular o OS resultante, como destacamos em negrito. Morfemas derivacionais que podem servir como expoentes para o traço $<\Sigma>_{[\mathrm{N}]}$, em (77), são anti, como em antirugas, micro-, como em microavião, e bi-, como em bimotor, etc.

\footnotetext{
${ }^{191}$ No que concerne à ontogenia da linguagem, supomos que a criança postula esses traços formais, isto é, ao perceber que um determinado conjunto de conteúdos conceituais são realizados de modo fixo, sem dar margem à polissemia, elas então os fixam através do sistema F. Eles não são determinados pelos ATR de suas células, mas apenas ingressam por meio de F na FLN.
} 
(77) O papel dos traços modificadores

$[\ldots]$

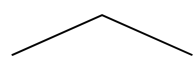

$<\mathrm{MASC} / \mathrm{FEM}>\mathrm{Gen}_{[\mathrm{N}]} \quad \boldsymbol{n P}$

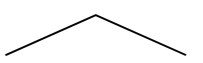

$<\Sigma>_{[\mathrm{N}]} \quad \boldsymbol{n P}$

${ }_{\pi}$ antil, $/{ }_{\pi}$ microl, $/{ }_{\pi} b i / \longrightarrow$

$<\mathrm{SUBS}>\boldsymbol{n}_{[\mathrm{N}]} \mathrm{AC}$

$\mathrm{SEM} \rightarrow$ ruga, avião, motor

Devemos ressaltar que, o fato de um conteúdo conceitual ter sido fixado por meio de F, implica que esse conteúdo não está sujeito à polissemia. Como discutimos no Capítulo 3, somente as raízes lexicais — no nosso caso, os AC - apresentam a possibilidade de recuperar diferentes conteúdos, ou seja, somente as raízes/AC são polissêmicos. Um traço formal deve apresentar uma relação unidirecional com o conteúdo que veicula. Nesse sentido, é esperado que a contribuição semântica dos traços modificadores seja computada composicionalmente e possa ser depreendida na extensão do nome derivado. Essa oposição distingue o que vem a ser um classificador nominal e um morfema derivacional, do que vem a ser uma raiz ou um AC. Exemplos para corroborar a contribuição semântica composicional desses morfemas podem ser notados na língua murrinhpatha. Walsh (1997, p. 275) lista as alterações de significado decorrentes da alternância de classificadores nominais concatenados ao nome kamarl 'olho': 
(78) Murrinhpatha (WALSH, 1997, p. 275)
a. nanthi
kamarl
CL:GENÉRICO olho
'olho/face'
b. kura kamarl
CL:AQUÁTICO olho
'charco (do inglês water-hole)
c. kardu kamarl
CL:HUMANO olho
'amado/a, namorado/a'
d. $m i \quad$ kamarl
CL:VEGETAL olho
'semente'

Embora o significado dos nomes em (78) seja não composicional, todos eles agregam o conteúdo denotado pelo classificador. Em (78a), o caráter genérico do categorizador nanthi permite a recuperação integral do referente associado ao nome. Em (78b), o classificador aquático kura insere um conteúdo relativo à água, ao nome kura kamarl 'charco' (i.e., poça de água parada, suja e rasa). Em (78c), o classificador nominal humano kardu contribui para a formação de um nome que remete a um indivíduo humano, kardu kamarl 'namorado/a'. Por fim, em (78d), o classificador nominal vegetal $m i$ leva à formação de um nome que remete a um vegetal, mi kamarl 'semente'. Dessa maneira, apesar dos nomes em (78) apresentarem um conteúdo idiossincrático, sua idiossincrasia deve estar a cargo da raiz/AC, e não dos traços modificadores que realizam os classificadores nominais, visto que seu conteúdo está presente na semântica lexical do nome derivado.

Por fim, podemos afirmar que a AI prevê, pelo menos, a existência de três classes de morfemas internamente à FLN, um deles derivado através de Merge, os AC, e os outros dois derivados através de modificações aplicadas às células fixadas pelo sistema $\mathrm{F}$. Tal taxonomia de morfemas está descrita no Quadro 4, abaixo. A variedade funcional do Quadro 4 é obtida durante a aquisição da linguagem, sendo regulada pelo modo como a criança deriva os traços formais a partir dos inputs que recebe do ambiente (Cf. BIBERAUER, 2016). A determinação de quais conteúdos conceituais em C-I podem ser fixados na forma de traços modificadores é, por hipótese, determinada apenas na aquisição, a depender da natureza do input, uma vez que a formação desses traços não é regulada por uma categoria universal $\kappa$. 
Quadro 4. Taxonomia dos morfemas estipulados pela AI.

\begin{tabular}{c|c|c}
\hline Morfemas & Correspondentes & Classes funcionais \\
\hline\{\}$=\varnothing$ & $\mathrm{AC}$ & $\mathrm{AC}(=$ Raízes) \\
\hline$<\Sigma>_{c[\delta]}$ & Traços formais & Morfemas flexionais \\
& Traços transposicionais & Quantificadores \\
& & Complementizadores \\
& & Pronomes \\
& & Conectivos \\
& & Morfemas derivacionais \\
\hline$<\Sigma>_{[\delta]}$ & Traços modificadores & Morfemas derivacionais \\
& & não transposicionais \\
& & Classificadores nominais \\
\hline
\end{tabular}

Na seção seguinte, exploramos o modo como os AC são estabelecidos pela operação Merge e de que forma eles são associados a um conteúdo conceitual em LF e a uma instrução fonológica no ramo de PF.

\subsection{A emergência do léxico conceitual humano}

Argumentamos, no início deste capítulo, que as raízes lexicais são, de acordo com a AI, definidas estruturalmente. A assunção elementar subjacente a essa proposta é a de que as raízes não constituem um primitivo da gramática. Elas seriam, na verdade, derivadas através de Merge. Vimos, no Capítulo 3, que a natureza altamente polissêmica das raízes nos leva a caracterizá-las como um objeto semanticamente vazio, tendo em vista que elas representam uma potencialidade de significados (Cf. MARANTZ, 1995; BORER, 2013; HARLEY, 2014, entre outros autores). Uma vez que as raízes não têm um significado predeterminado, não vemos razão para admitir que elas constituem um primitivo autônomo. A própria operação Merge é, em princípio, capaz de gerar um OS contendo essas propriedades. Dado que todo conjunto pode servir como input para as aplicações de Merge, então um conjunto vazio deve ser igualmente visto como um OS disponível para participar dessas aplicações.

É com essa conjectura em mente, que sugerimos a ideia de um AC, definido em (32), e recuperado, por conveniência, em (79): 


\section{(79) Átomo conceitual}

Átomo conceitual (AC) é um conjunto vazio resultante da primeira aplicação da operação Merge. Esse conjunto corresponde a um nó terminal da estrutura sintática, a ser preenchido por um conteúdo conceitual pós-sintaticamente.

Em linhas gerais, o que a AI tenta abarcar é a assunção de que há, pelo menos, dois tipos de significados a serem contemplados por uma hipótese sobre a gramática. Temos, por um lado, um significado propriamente linguístico, derivado pela FLN através da concatenação de traços formais em arranjos estruturais organizados hierarquicamente. $\mathrm{O}$ que um $\mathrm{AC}$ delimita, por sua vez, é um domínio da estrutura sintática dedicado à inserção de outro tipo de significado, que chamamos de significado enciclopédico. Esse significado enciclopédico "não apresenta nenhuma propriedade formal e é equivalente, $[\ldots]$ a um 'material' que é despejado no molde estrutural a ser atribuído a propriedades gramaticais" (BORER, 2005a, p. 108). ${ }^{192}$ A nosso ver, toda hipótese sobre a emergência da competência linguística deve fornecer uma explicação sobre o modo como esses significados são gerados e associados internamente à FLN.

Para a AI, a relação entre esses dois tipos de significado é estabelecida do seguinte modo: a linguagem do pensamento, que resulta da emergência da operação Merge, consiste de uma habilidade para organizar informações formais em arranjos estruturais semanticamente rígidos, os quais dão origem a um significado linguístico. Esse significado linguístico, gerado internamente à FLN, pode ser vinculado a um significado enciclopédico através de um AC, um nó da estrutura sintática vazio de conteúdo, disponível para ser preenchido por um dado conteúdo enciclopédico no caminho para a interface SEM. Teoricamente, uma vasta quantidade de significados enciclopédicos pode ser atrelada a um mesmo arranjo estrutural derivado por Merge (MARANTZ, 1995; BORER, 2003, 2005a, 2013). ${ }^{193}$

\footnotetext{
192 Trecho original: "[...] does not have any formal properties, and is, in this sense, tantamount to [raw material], 'stuff' which is poured into the structural mould to be assigned grammatical properties."

${ }^{193}$ Por exemplo, o conteúdo como GATO apresenta, em termos gerativos, o mesmo potencial de se tornar um nome, um verbo ou mesmo um adjetivo. A depender da categoria sintática da estrutura a que esse conteúdo for associado, seu significado irá variar. Marantz (2001) destaca que: "A interação entre a semântica de uma raiz e a semântica dos núcleos categorizadores que formam nomes, verbos e adjetivos determinará quão boa será uma combinação entre uma raiz e um núcleo [categorizador]. Assim, enquanto GATO, como nome, é bom, da mesma forma que é bom GATO, como um adjetivo ("catty"), GATO como verbo não tem um significado/um uso óbvio, embora possa receber um significado contextualmente (e.g., Imitando seu felino de estimação, miando e se coçando, Fred "gat(e)ou" pela casa por horas) [Trecho original: "The interaction of root semantics and the semantics of the heads that create nouns, verbs and adjectives determines how good a combination of a root and such a head will be. So, while "cat" as a noun is fine, as is "cat" as an adjective ("catty"), "cat" as a
} 
Mais especificamente, argumentamos que a competência linguística humana surge quando as informações semanticamente fixas das células determinadas pelo sistema $\mathrm{F}$ passam a ser organizadas na forma de uma estrutura sintática. Essa habilidade é, a princípio, o que levou ao surgimento de uma linguagem do pensamento. As células do sistema F estavam, até então, isoladas. Assim que um pensamento organizado foi fixado, como uma consequência direta de Merge, a criação de um conjunto vazio na base dos arranjos derivados possibilitou - em nosso entendimento - que os conceitos não linguísticos em C-I passassem a ser manipulados e associados às estruturas semanticamente rígidas derivadas pela FLN. Em outras palavras, um AC funciona figurativamente como uma membrana permeável entre a FLN e a cognição. O aparecimento de um dispositivo mental fundamentalmente vazio foi o que presumivelmente promoveu uma expansão vocabular na espécie e consequentemente levou a uma ampliação, sem precedentes, de suas competências expressivas.

Como visto na seção 3.4, primatas não humanos apresentam habilidades perceptuais sofisticadas, sendo supostamente capazes de associar sons a conteúdos de maneira ilimitada. Porém, esses animais aparentemente não são capazes de manipular os conteúdos extraídos da percepção. Cheney e Seyfarth $(2005$, p. 149) apontam que "primatas não humanos dominam muitos conceitos para os quais eles não têm nenhuma palavra". Parece-nos, nesse sentido, que os conceitos depreendidos por primatas não humanos estão retidos em seu sistema C-I. Se é o caso que o sistema C-I humano decorre do sistema C-I primata, então podemos admitir que o estabelecimento de um elemento vazio internamente à FLN proporcionou um enorme salto cognitivo na espécie humana, pois teria sido através desse elemento vazio que os conteúdos conceituais retidos em C-I puderam passar a ser manipulados e subsequentemente associados aos significados linguísticos das estruturas derivadas pela FLN.

verb has no obvious meaning/use, although it can be given fine meanings contextually ("Meowing and scratching in imitation of his pet feline, Fred catted around the house for hours"). De acordo com essa perspectiva, não há contextos de agramaticalidade envolvendo a inserção do conteúdo GATO nesses três ambientes estruturais distintos, mas de coerção conceitual/estrutural. As estruturas podem ser bem formadas do ponto de vista sintático; porém, o conteúdo enciclopédico a elas associado pode levar à criação de significados anômalos. Como bem pontua Borer (2005a, p. 8), "o resultado da coerção é sintaticamente bem formado, e tipicamente interpretável, muito embora seja anormal em outros aspectos [Trecho original: "The output of coercion is syntactically well-formed, and typically interpretable, although it maybe anomalous in other respects"]. Borer (2005a, p. 8) ilustra essa liberdade de associação entre o significado linguístico da estrutura e significados enciclopédicos com o sintagma nominal. Nomes considerados comuns podem ser transformados em nomes próprios, e vice-versa. Da mesma forma, nomes ditos "lexicalmente" massivos podem se tornar contáveis de um ponto de vista sintático e contáveis podem ser massificados (e.g., Cat came lit. O Gato veio (interpretado como nome próprio); The three Kims I met yesterday were at all tall lit. As três Kims que eu encontrei ontem não eram altas (interpretado como um nome comum); This is too little carpet for so much money lit. Tem muito pouco carpete pra tanto dinheiro; There are three wines in the cellar lit. Tem três vinhos na adega). 
Ao derivar um modo de associar significados linguísticos aos conceitos alocados em C-I, a espécie humana passou a operar por meio de um algoritmo mental diferenciado. Desde então, ela não apenas vincula os significados linguísticos aos significados enciclopédicos que constituem seu conhecimento de mundo-, como também gera novos conceitos a partir das habilidades combinatoriais da operação Merge (e.g., através da formação de palavras, da atribuição de significados polissêmicos e/ou idiossincráticos a um mesmo AC, etc.). Essa distinção entre significado linguístico versus conhecimento enciclopédico é uma característica de modelos gramaticais que descrevem a FLN como um sistema ontologicamente produtivo, tal como assinala Hinzen (2009, p. 37). Isto é, a FLN, de acordo com essa perspectiva, deriva e adiciona novos conceitos ou estruturas ao domínio conceitual da mente, em vez de somente codificar conceitos já existentes e transformá-los em objetos linguísticos.

A assunção de que as raízes constituem um placeholder - i.e., um espaço da estrutura sintática dedicado à inserção de um conteúdo enciclopédico - foi sugerida, pela primeira vez, por Marantz (1995). Para o autor, o sistema computacional da FLN é alheio aos significados enciclopédicos. Esses significados não apresentam nenhum papel internamente à sintaxe e, portanto, não devem estar presentes pré-sintaticamente. Em suas palavras:

\footnotetext{
“A diferença entre 'cachorro' e 'gato' é uma questão de conhecimento enciclopédico e esse conhecimento é usado na interpretação semântica de LF, mas não nas computações gramaticais feitas sobre LF ou envolvendo LF. Um nó em LF pode ser tal que, em PF, 'cachorro' ou 'gato' podem ser igualmente inseridos” (MARANTZ, 1995, p. 3, tradução nossa). ${ }^{194}$
}

Nesta tese, seguimos a intuição de Marantz (1995). Porém, o estabelecimento de um $\mathrm{AC}$ — que instancia um tipo de placeholder — segue a descrição em (80b), de nossa definição para a operação Merge apresentada previamente no exemplo (33):

(80) Merge

a. Dados dois OS $\alpha$ e $\beta$, forme um conjunto $\{\alpha, \beta\}$.

$$
\mathrm{M}(\alpha, \beta)=\{\alpha, \beta\}
$$

b. Na ausência de um OS servindo como input, forme um conjunto vazio.

$$
\mathrm{M} \rightarrow\{\}=\varnothing \text {. }
$$

\footnotetext{
194 Trecho original: "The difference between "dog" and "cat" is a matter of Encyclopedic knowledge and that such knowledge is used in semantic interpretation of LF, but not in grammatical computations over LF or involving LF. A node at LF might be such that at PF, either "dog" or "cat" might have equally well been inserted".
} 
O estabelecimento de um AC ocorre do seguinte modo. Assumindo que a formação de um OS pode se iniciar sem que o Léxico-I seja, necessariamente, acessado, sugerimos que a primeira aplicação de Merge delimita o próprio espaço computacional, que, em seguida, é concatenado a um traço formal extraído do Léxico-I. Essa assunção parte de discussões feitas em de Belder e van Craenenbroeck (2015). Esse espaço computacional delimitado por Merge constitui um conjunto vazio. Após a concatenação desse primeiro traço formal, o conjunto vazio em seu complemento - i.e., um AC - é demarcado por uma perspectiva interpretativa, determinada pelo domínio $\delta$ do traço. Essa demarcação está descrita no exemplo (81). É dessa maneira que asseguramos que o conteúdo conceitual/enciclopédico a ser inserido em um AC, no caminho para o sistema C-I, será interpretado como uma "substância" ou como algo “extensível no tempo". 195

(81) a.

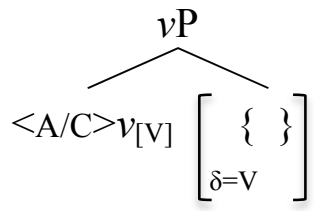

b.

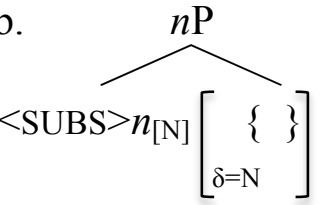

A ideia de que um traço formal atribui ao seu complemento um domínio interpretativo é construída, formalmente, a partir da hipótese do "espaço do complemento categorial", do inglês categorial complement space (CCS), sugerida por Borer (2013, 2014b). De acordo com a autora, uma projeção estendida, seja verbal ou nominal, ou mesmo um C-funtor, como descrito acima, têm o poder de dividir o espaço sintático, fazendo com que o conteúdo conceitual presente em seu complemento seja lido como um verbo ou como um nome. Para ilustrar essa sua proposta, a autora estabelece uma comparação com as representações gestálticas do exemplo (82). Essa comparação pode ser reescrita do seguinte modo: o espaço em branco delineado pelos traços das duas figuras em (82) não apresentam propriedades além daquelas definidas pelas próprias marcas em preto. Em (82a), o espaço interno formado não é em si um "triângulo", embora um objeto que tenha as propriedades de "triângulo" possa ser encaixado nessa posição. O mesmo pode ser dito com relação ao "círculo" representado no exemplo (82b). Reparem, ainda, que um "círculo" não pode ser encaixado no espaço delimitado em (82a), da mesma forma que um "triângulo" não pode ser encaixado em (82b).

\footnotetext{
${ }^{195}$ Essa caracterização de um AC implica que há contextos em que uma estrutura sintática é derivada sem um AC, o que é empiricamente atestado. Panagiotidis (2015, p. 94) destaca que quando raízes — no nosso caso, um $\mathrm{AC}$ - não são manipuladas pela FLN, obtemos expressões como this is her 'Isso é ela', I got that 'Eu entendi', It's here 'é aqui'. Ver também Emonds (1985).
} 


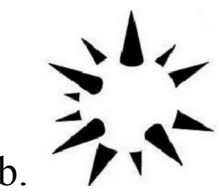

Em outras palavras, quando um conteúdo conceitual é inserido no espaço delimitado por $[\mathrm{N}]$, ele passa a ser percebido como algo equivalente a uma "substância", e se vincula às propriedades que derivam da interpretação "substância". O conceito não é uma substância, tal como o espaço interno às linhas em (82a) e em (82b) não são um "triângulo" e um "círculo". O conceito inserido no domínio $[\mathrm{N}]$ equivale a uma "substância" enquanto estiver incluído no domínio delimitado pelo traço formal que o toma como complemento. Essa intuição, compartilhada de Borer $(2013,2014 b)$, descreve o papel que o domínio $\delta$ desempenha quando um determinado AC é associado a um conteúdo conceitual pós-sintaticamente. Assim sendo, argumentamos que a perspectiva interpretativa definida por $\delta$ torna um conteúdo conceitual equivalente a uma "substância" ou a "algo extensível no tempo", como descreve Panagiotidis (2015), e, ao mesmo tempo, impede que esse conteúdo conceitual seja interpretado de forma distinta daquela determinada pelo valor de $\delta$.

De um ponto de vista filogenético, conjecturamos que as estruturas formadas pela FLN foram inicialmente atreladas a qualquer conteúdo conceitual disponível em C-I, de modo indiscriminado, tendo em vista que esses conteúdos não estavam relacionados a uma forma fonológica. No momento em que o sistema S-M foi associado à FLN, surgiu, então, a necessidade de se assegurar que aquilo que era interpretado por C-I recebia, no ramo de PF, uma instrução fonológica adequada. Ou seja, era preciso garantir que, se o sistema C-I interpretasse um AC como 'cachorro', $\mathrm{PF}$ não poderia vincular esse mesmo $\mathrm{AC}$ a uma instrução fonológica como / gato/. Em princípio, isso seria possível, uma vez que um AC, por si só, não contém informações prévias capazes de individualizá-lo. Portanto, todo AC, internamente à sintaxe, é idêntico. Em vista disso, assumimos que, em decorrência da associação entre S-M e a FLN, os AC passaram a ser individualizados sintaticamente. Especificamente, a FLN passou a indexar os domínios interpretativos que incluem um AC. Como resultado, no momento do Spell-Out sintático, um índice passou a ser atribuído a um AC, garantindo que o conteúdo inserido em LF fosse associado a uma instrução fonológica adequada em PF.

Em (83), definimos esse mecanismo de indexação tardia: 
(83) Indexação tardia

No momento do Spell-Out sintático, atribua um índice alfanumérico a um AC circunscrito por um domínio $\delta$.

A hipótese da indexação tardia resulta da associação entre as propostas de Harley (2014) e de Boeckx (2015). Harley propõe que as raízes são individualizadas por meio de um índice, com base nas discussões de Acquaviva (2009a) e Pfau (2009). A autora mostra, através de diferentes fatos empíricos, que não é razoável admitir que as raízes apresentam uma forma fonológica prévia, tendo em vista que elas estão sujeitas a alomorfias de diversas ordens — contra Borer (2013, 2014b)—, e que as raízes tampouco contêm um conteúdo prévio, dado o seu caráter polissêmico — contra Arad (2003, 2005). ${ }^{196}$ Harley (2014, p. 242247) sugere, em contrapartida, que as raízes são individualizadas sintaticamente através de índices abstratos representados por caracteres alfanuméricos (e.g., $\left.\sqrt{ }_{77}\right)$. Esses índices são associados às raízes na computação sintática e, pós-sintaticamente, eles estabelecem uma ligação entre um conjunto de instruções de Spell-Out em PF e um conjunto de instruções interpretativas em LF.

Exemplos do modo como essas instruções estão agrupadas podem ser vistos em (84), a partir da raiz throw, do inglês:

(84) Instruções de interface para interpretação de uma raiz (HARLEY, 2014, p. 244) a. Instruções em PF (Lista 2)

b. Instruções em LF (Lista 3)

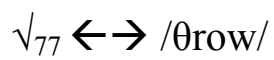

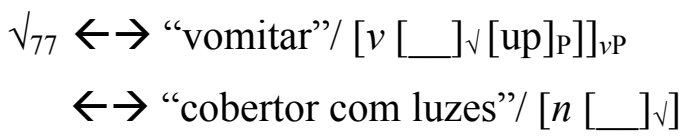

A fatoração dessas informações associadas às raízes pela arquitetura da gramática faz com que cada ramo da FL opere, exclusivamente, com as informações que the cabem, evitando assim que a sintaxe tenha acesso a traços fonológicos e a conteúdos enciclopédicos, os quais não são empregados por suas operações. Uma vez que as raízes apresentam apenas uma identidade sintática, sua interpretação fonológica e semântica irá ocorrer somente após o Spell-Out. É importante ressaltar que a interpretação de uma raiz depende de um contexto

\footnotetext{
${ }^{196}$ Cf. subseção 3.3.2, do Capítulo 3.
} 
sintático especificado nas instruções em PF e em LF, como aqueles em (84). Boeckx (2015, p. 29) segue a hipótese inicial de Harley (2014). No entanto, o autor sugere — apesar de não explorar sua sugestão- que os índices alfanuméricos possam ser atribuídos no momento do Spell-Out sintático, logo antes da estrutura ser enviada para as interfaces interpretativas. Essas duas propostas dialogam diretamente com o que pretende a AI.

Acreditamos que a sugestão de Boeckx (2015) seja a maneira mais adequada para se capturar a intuição de Harley (2014). Isso se deve ao fato de que a postulação de um índice alfanumérico somente se faz necessária após a anexação de S-M à FLN, que, por conjectura, ocorreu tardiamente (Cf. CHOMSKY, 2004, 2007, 2008, 2010a, 2013a, 2016; BERWICK; CHOMSKY, 2016; HUIJBREGTS, 2017, entre outros). Em princípio, nada determina que a atribuição de um índice a um AC deva ocorrer, indispensavelmente, antes da manipulação sintática. As razões são as seguintes: primeiro, um AC é derivado sintaticamente; segundo, um conteúdo enciclopédico somente lhe será aferido no caminho para o sistema C-I. Qualquer discussão que envolva a indução de uma escolha deliberada de conteúdos conceituais a compor a estrutura, ou seja, que tenha por objetivo explicar as intenções do falante, está fora do escopo de um modelo de competência, como é o nosso caso. Essa discussão será relevante em um modelo de produção (Cf. PFAU, 2009). Tendo em vista que uma estrutura derivada por Merge pode ser associada, teoricamente, a qualquer conteúdo em C-I, a designação de um índice alfanumérico ocorre unicamente no momento em que a estrutura sintática é enviada para as interfaces.

Assumimos, em resumo, que os índices são invisíveis para a sintaxe e operam como instruções para os sistemas externos, C-I e S-M, os quais buscam o conceito relevante e a matriz fonológica adequada para um $\mathrm{AC}$ na memória de longo prazo. Assumimos também que a indexação contribui para a expansão do inventário lexical humano. Possivelmente, a indexação - i.e., a relação de uma forma a um conteúdo - foi o que impulsionou a criação de um Léxico-C. Ao se atrelar um conteúdo conceitual a uma forma, o conhecimento de mundo do falante começa a ser formado e, em certo sentido, forma e conteúdo estão em uma relação de dependência. Isso se deve ao fato de que as línguas diferem em termos de quais conceitos elas lexicalizam (Cf. BORER, 2005a, p. 12). Assim, devemos esperar que a formação de um Léxico-C depende de informações estabelecidas socialmente e que, por esse motivo, devem também passar pelo crivo de um sistema compartilhado de formas, sejam elas sinais ou sons. O mesmo é esperado com relação à fixação de conteúdos idiossincráticos, tais como aqueles verificados em palavras derivadas (e.g., quentão), em palavras compostas (e.g., caixa-preta) e em expressões idiomáticas (e.g., chutar o balde). 
Seguindo Harley (2014), admitimos que o Léxico-C de uma língua L corresponde ao conjunto de instruções de LF de todos os índices estabelecidos. Essas instruções representam os conteúdos conceituais lexicalizados por L. O índice, por sua vez, delimita um subconjunto desses conteúdos lexicalizados, a que chamados de instruções de LF. Cada instrução de LF está marcada com um contexto sintático indicando seu local de inserção, o qual é estabelecido socialmente através da experiência. Esse contexto determina qual dentre as instruções associadas a um mesmo índice será responsável por preencher um AC. Em (85), recuperamos as instruções atreladas a um $\mathrm{AC}$ hipotético, $\mathrm{AC}_{243}$, apresentadas previamente em (27).

(85) Instruções conceituais atreladas ao $\mathrm{AC}_{243}$ (/sãm.ba/)

$$
\begin{array}{rlr}
\mathrm{AC}_{243} & \leftarrow \text { "samba" } \\
& \leftarrow \rightarrow \text { "ser preso"/ }\left[v[\ldots]_{\mathrm{AC}}\right] & (\text { e.g., } x \text { sambou }) \\
& \leftarrow \rightarrow \text { "folgado"/ }\left[\left[v\left[[\text { estar }] \mathrm{v}\left[\mathrm{v}[\ldots]_{\mathrm{AC}}\right]\right]_{\mathrm{vP}}\right.\right. & (\text { e.g., } x \text { está sambando }) \\
& \leftarrow \rightarrow \text { "problema"/ }\left[v\left[[\text { dar }] \mathrm{v}\left[\mathrm{n}[\ldots]_{\mathrm{AC}}\right]\right]_{\mathrm{vP}}\right. & \\
& \leftarrow \rightarrow \text { "cueca"/ }[[n[\ldots] \mathrm{AC}][\text { canção }]]_{\mathrm{nP}}
\end{array}
$$

O Léxico-E, por sua vez, congrega o conjunto de instruções de PF de todos os índices estabelecidos em uma língua L. Suas instruções apresentam a mesma forma das instruções em (85), como vimos no exemplo (84). A multiplicidade de instruções de PF é responsável por determinar casos de alomorfia contextual, como o famoso caso da morfologia irregular de passado no inglês. Essa alomorfia é sensível a um traço de passado em T. Um conteúdo como TEACH 'ensinar', por exemplo, deve ser realizado como /to/ no ambiente do AC vinculado a TEACH, e o traço de passado deve ser realizado como / $t /$ nesse mesmo ambiente, tal como descrito na instrução em (86). É importante destacar que os expoentes fonológicos dos traços formais também são determinados por instruções em PF, como estabelece o pressuposto 5, tal como é o caso do traço de tempo passado no inglês, cujas instruções estão listadas em (87): ${ }^{197}$

(86) Instruções fonológicas atreladas à raiz $\mathrm{AC}_{32}(\mathrm{TEACH})$

$$
\begin{aligned}
\mathrm{AC}_{32} & \left.\leftarrow / /_{\pi} \mathrm{t} \mathrm{J} / /\left[<\mathrm{PASS}_{\mathrm{T}[\mathrm{V}]}[\mathrm{v}[\ldots]]_{\mathrm{AC}}\right]\right] \\
& \leftarrow \rightarrow / \pi \mathrm{ti}: \mathrm{t} / / \text { elsewhere }
\end{aligned}
$$

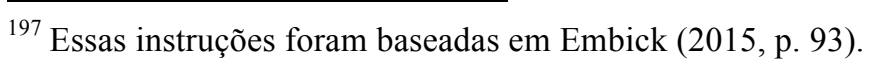


(87) Instruções fonológicas atreladas ao traço $<$ PASS $>_{\mathrm{T}[\mathrm{V}]}$

$$
\begin{aligned}
<\mathrm{PASS}_{\mathrm{T}[\mathrm{V}]} & \leftarrow \rightarrow /_{\pi} \mathrm{t} / /\left\{\mathrm{AC}_{32} \text { 'TEACH', } \mathrm{AC}_{265} \text { 'BEND', } \mathrm{AC}_{68} \text { 'LEAVE', etc. }\right\} \\
& \leftarrow \rightarrow /_{\pi} \varnothing / /\left\{\mathrm{AC}_{58} \text { 'PUT', } \mathrm{AC}_{123} \text { 'QUIT', } \mathrm{AC}_{34} \text { 'HIT', etc. }\right\} \\
& \leftarrow \rightarrow /_{\pi} \mathrm{ed} / / \text { elsewhere }
\end{aligned}
$$

Por fim, apontamos uma última particularidade acerca dos mapeamentos referenciais da linguagem humana, associada aos conteúdos descritos pelas instruções de LF. Chomsky (2010a, 2015, 2016) assinala que há uma assimetria entre os símbolos internos à FLN, correspondentes às "palavras", e os sistemas representacionais de animais não humanos. O autor aponta que, enquanto as "palavras" não apresentam uma relação com uma entidade concreta no mundo - i.e., uma "palavra" ou uma representação conceitual não denotam um indivíduo ou evento independentes da mente humana-, os sistemas representacionais de animais não humanos se fundamentam em uma correspondência referencialista, em que há uma relação de um-para-um entre os processos de sua mente/cérebro e "um aspecto do ambiente para o qual esses processos adaptam o comportamento do animal" (GALLISTEL, 1990 apud CHOMSKY, 2010a, p. 59), ${ }^{198 / 199}$ uma assunção que foi compartilhada no Capítulo 3.

Chomsky argumenta que a linguagem humana não apresenta essas correspondências referencialistas, pois não há uma relação direta entre um símbolo interno à FL e uma entidade concreta, independente da mente, no mundo. Em suas palavras, "o que nós tomamos como sendo um rio, uma pessoa, ou água acaba sendo identificado como um construto físico de algum tipo" (2010a, p. 46). Nesse sentido, os símbolos conceituais internos à FL operariam igualmente às unidades fonológicas das representações em PF. Por exemplo, todo ato de externalização da sílaba [ba], ou seja, de uma entidade mental interna à FL, produz uma entidade no mundo que independe da mente humana (i.e., um som). Porém, não há nenhum construto no mundo, fora da mente, que corresponda a essa entidade mental, ou seja, à sílaba. As "palavras", ou as instruções de LF, atuariam da mesma forma.

A posição de Chomsky vai contra a doutrina referencialista que admite, por exemplo, que um NP denota a entidade que o carrega, ou seja, que os símbolos internos à FL representam diretamente seus objetos no mundo. ${ }^{200}$ É preciso ter cautela ao assumir a doutrina referencialista para a linguagem humana, pois, como salienta Chomsky, não é sempre

\footnotetext{
${ }^{198}$ Trecho original: "an aspect of the environment to which these processes adapt the animal's behavior".

${ }^{199}$ GALLISTEL, C. R. Representations in animal cognition: an introduction. Cognition, v. 37, 1990, p. 1-22.

${ }^{200}$ Um exemplo clássico é fornecido em Chierchia e McConnell-Ginet (1990), em que um nome como Pavarotti refere-se ou denota o indivíduo que o possui (i.e., o cantor popular).
} 
evidente que o objeto denotado realmente existe. Por exemplo, retomando um exercício de Dennett (2012 apud CHOMSKY, 2013b, p. 40), ${ }^{201}$ é factual admitir que as cidades de Paris e Londres existem, mas o mesmo não se aplica aos quilômetros que separam essas duas cidades, ou seja, não é trivial admitir que os quilômetros também existam. Outro exemplo recuperado por Chomsky (2013b, p. 41-42) é o seguinte:

\begin{abstract}
"Considerem o famoso enigma do barco de Teseu, associado a Plutarco. Suponha que esse barco está no museu de Atenas. Uma de suas tábuas cai e ela é substituída por outra, etc., até que todas as suas tábuas tenham sido substituídas. Ele é ainda, claramente, o barco de Teseu. Suponha também que as tábuas tenham sido guardadas e utilizadas para reconstruir o barco de Teseu a partir de seus materiais originais. Esse também é o barco de Teseu. Mas, agora, há dois barcos, cada um o barco de Teseu, o que não é possível. Um paradoxo, se a doutrina referencialista estiver correta e o NP barco de Teseu selecionar uma entidade no mundo independente da mente; mas não é um paradoxo se a entidade interna barco de Teseu apresentar uma perspectiva que não fornece uma resposta clara para cada situação em que ela possa ser conjurada" (CHOMSKY, 2013b, p. 41-42, tradução nossa). ${ }^{202}$
\end{abstract}

Portanto, um símbolo interno à FL não está para um objeto específico no mundo; pelo contrário, qualquer unidade representacional interna à FL — no nosso caso, as instruções de LF - correlaciona-se casualmente com uma entidade no mundo. Conjecturamos que isso se deve ao fato de que a linguagem humana emprega um dispositivo intermediário -i.e., um $\mathrm{AC}$ - para se referir às coisas do mundo, e que sua natureza altamente subespecificada impede que esse dispositivo siga uma relação referencialista. ${ }^{203}$ Como vimos anteriormente na

${ }^{201}$ DENNETT, D. Sakes and dints, and other definitions that philosophers really need not seek. Times Literary Supplement, 2012, p. 12-14.

202 Trecho original: "Consider the famous puzzle of the ship of Theseus, tracing to Plutarch. Suppose that the ship is in the Athens museum, a board falls off and is replaced by another one, etc., until every board has been replaced. It is still plainly the ship of Theseus. Suppose further that the boards have been collected and used to reconstruct the ship of Theseus out of its original materials. That is also the ship of Theseus. But now there are two ships, each the ship of Theseus, which cannot be. A paradox, if the referentialist doctrine holds, and the NP ship of Theseus picks out an entity in the mind-independent world; but no paradox if the internal entity ship of Theseus provides perspectives that do not happen to provide a clear answer for every situation that can be conjured up."

${ }^{203}$ Noam Chomsky, em comunicação pessoal, destaca que "[...] isso nos sugere que o léxico humano seria apenas "mais", como Darwin e outros assumiram. Mas me parece que o léxico não é apenas mais, mas diferente desde o início. Mesmo as palavras mais simples usadas para se referir não têm análogos nos animais. Presumivelmente, a evolução, de algum modo misterioso, produziu os conceitos, alguns deles mais tarde disponíveis para a lexicalização como átomos computacionais [...] Pode ser que (assim como ocorre com os fonemas) há uma rede de propriedades que permite uma gama de possíveis conceitos, e que quando esses conceitos são apropriados pela faculdade da linguagem, outro sistema cognitivo pode também entrar com experiência variável para modular o que aparece nas línguas, dando às línguas variação (até mesmo idioletal)" 
Figura 5, recuperada novamente abaixo, uma raiz/AC corresponde a uma entidade cognitiva que se vale de uma correspondência de um-para-muitos, uma vez que um mesmo exemplar pode ser associado livremente a mais de uma entidade ou evento no mundo, diferentemente das representações primatas, cuja relação com um determinado conteúdo é coextensiva.

Figura 5. Propriedades referenciais das representações simbólicas de primatas não humanos e humanos.

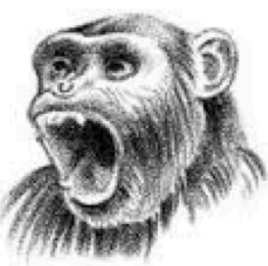

\begin{tabular}{ccccc}
\multicolumn{1}{r}{ Representação } & Externalização & & Referente \\
& $\mathrm{S}_{1}$ & LEOPARDO & $\longrightarrow$ & "Leopardo" \\
$\begin{array}{c}(1: 1) \\
\text { Categorias }\end{array}$ & $\mathrm{S}_{2}$ & ÁGUIA & $\longrightarrow$ & "Águia" \\
Referenciais & $\mathrm{S}_{3}$ & COBRA & $\longrightarrow$ & "Cobra"
\end{tabular}
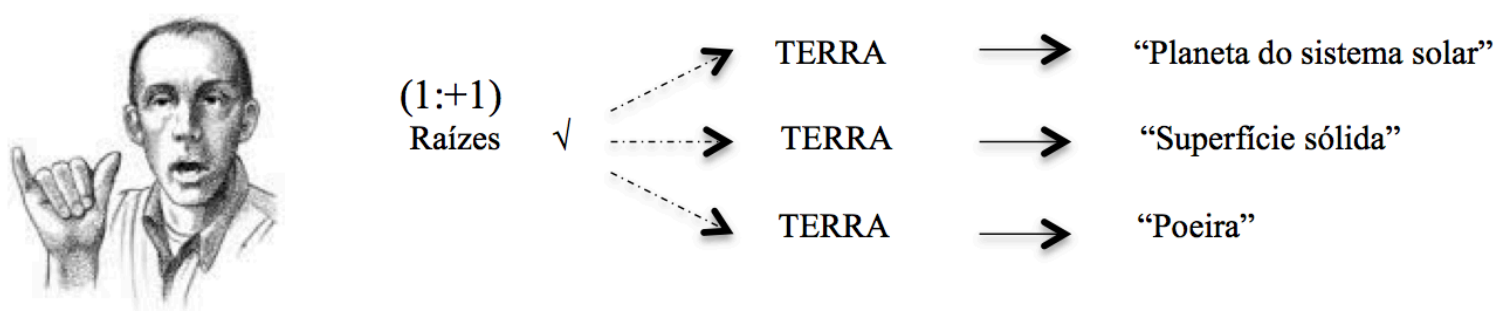

Sendo assim, a nosso ver, foi o estabelecimento de um AC que promoveu essa assimetria representacional, notada por Chomsky (2010a, 2015, 2016), entre primatas humanos e não humanos. Para finalizar este capítulo, discutimos, na próxima seção, o modo como a AI pode ser colocada em funcionamento em consonância com o que determinam os desiderata para uma sintaxe autônoma.

[Do original: "[...] it sounds as though the human lexicon is just "more," as Darwin and others have assumed. But it seems to me that it is not more, but different, from the very beginning. Even the simplest words used to refer have no animal analogues. Presumably, evolution in some mysterious way yielded the concepts, some of them later available for lexicalization as computational atoms [...] Could be that (rather like phonemes) there is a network of properties that permits a range of possible concepts, and that when these are appropriated by the language faculty, other cognitive system may also enter with varying experience to modulate what appears in the language, giving language (and even idiolectal) variation.]. Compartilhamos com Chomsky dessas assunções. Em nossa explicação, o descontinuísmo com animais não humanos decorre, fundamentalmente, do modo como operamos com os conceitos, notadamente, por intermédio de um AC, e da maneira como esses conceitos são lexicalizados na forma de instruções de LF. A ausência de um dispositivo intermediário em animais não humanos faz com a correlação com uma entidade externa à mente seja referencial, unidirecional. 


\subsection{A Abordagem Isomórfica e o ideal de uma sintaxe autônoma}

Com o intuito de obter uma hipótese sobre a gramática em que a sintaxe é derivacional $a b$ ovo, ou seja, isenta de interferência lexical desde o início da derivação, assumimos as seguintes estratégias teóricas para assegurar a satisfação dos desiderata elencados no Capítulo 2. Cada desideratum será discutido em separado no que segue.

\section{- Desideratum \#1:}

As entradas lexicais não devem ser as responsáveis por projetar a estrutura sintática.

Para satisfazer o desideratum 1, assumimos que toda relação entre os constituintes de uma estrutura sintática se estabelece de modo configuracional, em linha com os modelos neoconstrucionistas, tais como XS e a MD. De acordo com essa perspectiva, a sintaxe deriva estruturas que são dissociadas de um conteúdo enciclopédico e cuja semântica composicional é lida diretamente de seus próprios núcleos funcionais, não de uma entrada lexical complexa (Cf. MARANTZ, 1997, 2013; BORER, 2003, 2005b, 2013). A estrutura sintática, portanto, não é derivada em torno de uma entrada lexical. Muito pelo contrário, a sintaxe dá origem a uma série de estruturas templáticas que determinam uma interpretação. Assim, a estrutura argumental de um verbo é determinada pela configuração de seus núcleos funcionais. $\mathrm{O}$ verbo chutar, por exemplo, não representa uma entrada lexical predeterminada com a capacidade de atribuir o papel de agente a um DP. Na realidade, um DP, inserido em uma posição estrutural específica, [Spec, vP], da qual o AC atrelado ao conteúdo 'chutar' participa, será interpretado como um agente.

Como discutimos extensamente no Capítulo 2, a conjectura de que as entradas lexicais contêm instruções pré-sintáticas a serem saturadas nos demanda uma explicação para a origem de tais informações e para o modo como elas foram agrupadas. Relegá-las à GU não nos parece ser uma explicação adequada, tendo em vista as considerações feitas pelo Problema de Wallace-Darwin, bem como os critérios para se chegar a uma hipótese sobre a gramática que vá "além da adequação explicativa". Contra esse posicionamento lexicocentrista, propomos que as entradas lexicais — no nosso caso, os traços formais - são primitivos internamente simples, cuja disposição configuracional, associada a uma 
determinada disposição de valores, é o que promove a construção de um significado linguístico específico. ${ }^{204}$

No que concerne à estrutura argumental, propomos que o núcleo $v$ pode apresentar, pelo menos, dois valores $\Sigma$, cada qual associado à possibilidade de se relacionar ou não com um agente/causa. Para descrever esses valores, recorremos à hipótese do v (Cf. CHOMSKY, 2000, 2001), que distingue dois tipos de núcleos verbais, nomeadamente: (i) um núcleo forte, $v^{*}$, capaz de se vincular a um argumento externo (AExt), e (ii) um núcleo fraco, $v$, que carece dessa possibilidade. O primeiro núcleo está associado aos verbos transitivos e inergativos, os quais relacionam um conceito interpretado como "extensível no tempo" a um agente/causa. Esses dois tipos verbais estão caracterizados nos esquemas em (88a) e (88b). Já o segundo núcleo vincula-se aos inacusativos e à contraparte intransitiva de verbos de alternância, como é o caso do verbo quebrar (e.g., em sua versão transitiva/causativa: A bola quebrou o vidro; e em sua versão inacusativa/incoativa: $O$ vidro quebrou). Nesses dois últimos grupos de verbos, não há uma causa aparente, o que os associa apenas a um argumento interno (AInt). Em geral, esses verbos introduzem uma mudança de estado. Ilustramos verbos inacusativos/incoativos em (88c).

(88) Estruturas argumentais

$\begin{array}{lcc}\text { a. Transitivas } & \text { b. Inergativas } & \text { c. Inacusativas } \\ {\left[v^{* \mathrm{P}} \text { AExt }\left[v^{*}, \mathrm{AInt}\right]\right.} & {\left[v^{* \mathrm{P}} \operatorname{AExt}\left[v^{*}, \varnothing\right]\right.} & {\left[{ }^{\mathrm{P}} \varnothing\left[v^{\prime} \text { AInt }\right]\right.} \\ \text { e.g., comer } & \text { e.g., dançar } & \text { e.g., aterrissar } \\ \text { ler } & \text { cantar } & \text { secar } \\ \text { quebrar } & \text { trabalhar } & \text { quebrar }\end{array}$

$v^{*}$ e $v$ serão sintetizados em um único traço categorial $v$. Os valores desse traços são, no caso de $v^{*},<\mathrm{A} / \mathrm{C}>v_{[\mathrm{V}]}$, em que $\mathrm{A} / \mathrm{C}$ está para agente/causa, ${ }^{205} \mathrm{e}$, no caso de $v,<\mathrm{BEC}>v_{[\mathrm{V}]}$,

\footnotetext{
${ }^{204}$ E válido destacar que, embora tenhamos descrito um traço formal como um par ordenado, seu arranjo interno não implica uma estrutura complexa como as entradas lexicais assumidas pelo lexicalismo e os feixes de traços formais assumidos pelas propostas minimalistas atuais. Hipotetizamos que tal esqueleto templático estava presente na cognição antes da emergência da FL, tendo em vista o esquema parte-todo das células do sistema $\mathrm{F}$ (correspondente aos ATR-VAL), cujas origens não se circunscrevem à linguagem.

${ }^{205}$ Essa caracterização toma por base a distinção entre $v_{\mathrm{DO}}$, ou seja, núcleo formador de verbos agentivos, cujo AExt é fundamentalmente um agente (e.g., verbos inergativos e verbos transitivos que não alternam, tais como

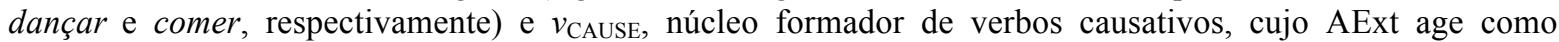
"causa" da ação (e.g., verbos transitivos que participam de alternância, quebrar) (Cf. HARLEY, 1999, 2005; FOLLI; HARLEY, 2005; MARANTZ, 1997). Decidimos não cindi-lo, por ora, pelo fato de não nos aprofundarmos nas filigranas dessa discussão e para simplificar a exposição da natureza configuracional da AI. Estamos cientes, entretanto, de que esses dois tipos de $v$ apresentam distinções distribucionais. Por exemplo,
} 
em que BEC — do inglês, become - indica a capacidade de introduzir a interpretação de uma mudança de estado (Cf. FOLLI; HARLEY, 2005; MARANTZ, 1997). ${ }^{206}$ Ambos os traços, $<\mathrm{A} / \mathrm{C}>v_{[\mathrm{V}]}$ e $<\mathrm{BEC}>v_{[\mathrm{V}]}$, atribuem a um AC em seu complemento uma perspectiva [V] e podem abrigar um DP na posição de complemento. Nas construções inergativas, porém, a ausência de um DP concatenado em seu complemento não compromete a aceitabilidade da estrutura (i.e., $\left.\left\{\mathrm{AExt},\left\{\left[<\mathrm{A} / \mathrm{C}>v_{[\mathrm{V}]}[\mathrm{AC}]_{\mathrm{V}}\right](\mathrm{AInt})\right]\right\}\right\}$ ). Somente $<\mathrm{A} / \mathrm{C}>v_{[\mathrm{V}]}$, no entanto, pode atribuir um agente/causa à interpretação “extensível no tempo". Em vista disso, a depender do valor de um traço formal $v$ e da disposição de DPs localmente concatenados, obteremos as diferentes organizações argumentais em (88).

Verbos transitivos agentivos e inergativos decorrem de uma configuração sintática em que um traço $<\mathrm{A} / \mathrm{C}>v_{[\mathrm{V}]}$ toma um $\mathrm{AC}$ como seu complemento. A presença desse traço permite que o DP concatenado em seu especificador seja interpretado como o agente da ação descrita pelo conteúdo de um AC. Esses tipos verbais serão diferenciados apenas pós-sintaticamente, a depender do número de DPs que se concatenar à combinação $\left[<\mathrm{A} / \mathrm{C}>v_{[\mathrm{V}]}[\mathrm{AC}]_{\mathrm{V}}\right]$ : se um único DP, então obtemos um verbo inergativo; se dois DPs, um verbo transitivo agentivo. Verbos inacusativos, por sua vez, derivam de uma configuração em que $<\mathrm{BEC}>v_{[\mathrm{V}]}$ tem um $\mathrm{AC}$ como seu complemento. A incapacidade de vincular um agente/causa ao evento inibe que as estruturas das quais $\left\langle\mathrm{BEC}>v_{[\mathrm{V}]}\right.$ participa interpretem um DP eventualmente concatenado em seu especificador. Por fim, um verbo causativo é gerado a partir de uma configuração em que $<\mathrm{A} / \mathrm{C}>v_{[\mathrm{V}]}$ e $<\mathrm{BEC}>v_{[\mathrm{V}]}$ estão concatenados a um mesmo $\mathrm{AC}$, tendo em vista que em uma sentença como A bola quebrou o vidro, a interpretação inclui uma causa, expressa pelo AExt, e uma mudança de estado "ficar quebrado".

Essas diferentes configurações dos traços categorias $v$ estão representadas em (89).

$v_{\text {CAUSE, }}$ contrariamente ao $v_{\text {DO }}$, não impõe nenhuma interpretação agentiva ao DP que serve como seu AExt, uma vez que um "causador" pode corresponder a uma entidade inanimada (e.g., A bola quebrou o vidro), entre outras propriedades.

${ }^{206}$ Essa distinção entre A/C e BEC deriva da Generalização de Burzio (Cf. BURZIO, 1986), em que sentenças com um AE e transitivas levam a uma interpretação de agentividade/causalidade, ao passo que sentenças sem um AE e intransitivas carregam uma interpretação incoativa, ou seja, sem uma causa aparente, em que há uma mudança de estado. 
(89) Configurações argumentais de acordo com a AI

a. Agentivos/Inergativos

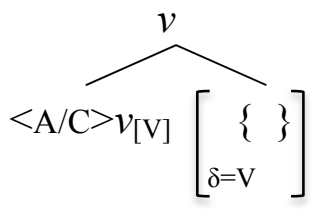

b. Inacusativos

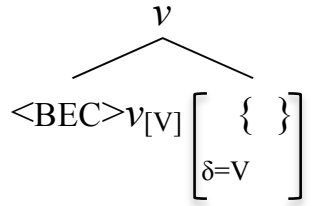

c. Causativos

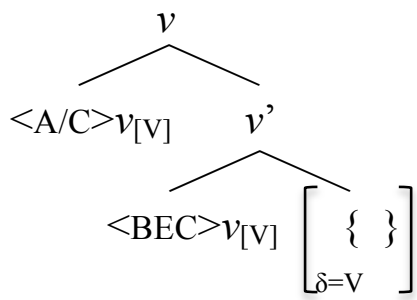

No que diz respeito aos DPs que irão servir como argumentos para esse conjunto de estruturas, sugerimos que eles são derivados paralelamente no espaço computacional. Com base em Nunes (2012), admitimos que a formação de um DP ocorre como um segundo nó raiz de estrutura sintática que, somente após formado, é concatenado aos núcleos verbais em (89). Merge delimita um AC e, subsequentemente, concatena a esse AC traços formais cujo domínio é $\delta=[\mathrm{N}]$. Uma vez exaurida a Numeração associada à formação desse nó raiz, o DP formado pode, então, ser concatenado a uma das configurações em (89), seja na forma de um complemento ou na forma de um especificador. Em (90), ilustramos como se dá a formação paralela de um DP e sua posterior concatenação à configuração verbal em (89a), dando origem a uma sentença inergativa como Os três alunos trabalharam. Cada um dos exemplos corresponde a um passo derivacional.

(90) a. $K=\{\varnothing\}$

b. $\mathrm{N}^{\prime}=\left[<\mathrm{SUBS}>n_{[\mathrm{N}] 1},<\mathrm{MASC}>\mathrm{Gen}_{[\mathrm{N}] 1},<\mathrm{PL}>\mathrm{Num}_{[\mathrm{N}] 1},<3>\mathrm{Q}_{[\mathrm{N}] 1},<\mathrm{DEF}>\mathrm{D}_{[\mathrm{N}] 1}\right]$ $\mathrm{K}=\{\varnothing\}$

c. $\mathrm{N}^{\prime \prime}=\left[<\mathrm{SUBS}>n_{[\mathrm{N}] 0},<\mathrm{MASC} \mathrm{Gen}_{[\mathrm{N}] 1},<\mathrm{PL}>\mathrm{Num}_{[\mathrm{N}] 1},<3>\mathrm{Q}_{[\mathrm{N}] 1},<\mathrm{DEF}>\mathrm{D}_{[\mathrm{N}] 1}\right]$

$\mathrm{K}=\{\varnothing\}$

$\mathrm{L}=<\mathrm{SUBS}>n_{[\mathrm{N}]}$

d. N" $=\left[<\mathrm{SUBS}>n_{[\mathrm{N}] 0},<\mathrm{MASC}>\mathrm{Gen}_{[\mathrm{N}] 1},<\mathrm{PL}>\mathrm{Num}_{[\mathrm{N}] 1},<3>\mathrm{Q}_{[\mathrm{N}] 1},<\mathrm{DEF}>\mathrm{D}_{[\mathrm{N}] 1}\right]$ $\mathrm{M}=\left\{<\mathrm{SUBS}>n_{[\mathrm{N}]},[\{\varnothing\}]_{\mathrm{N}}\right\}$ 
e. $\mathrm{N}^{\prime \prime}=\left[<\mathrm{SUBS}>n_{[\mathrm{N}] 0},<\mathrm{MASC}>\mathrm{Gen}_{[\mathrm{N}] 0},<\mathrm{PL}>\mathrm{Num}_{[\mathrm{N}] 1},<3>\mathrm{Q}_{[\mathrm{N}] 1},<\mathrm{DEF}>\mathrm{D}_{[\mathrm{N}] 1}\right]$

$\mathrm{M}=\left\{<\mathrm{SUBS}>n_{[\mathrm{N}]},[\{\varnothing\}]_{\mathrm{N}}\right\}$

$\mathrm{O}=<$ MASC $\operatorname{Gen}_{[\mathrm{N}]}$

f. $\mathrm{N}^{\prime \prime}{ }^{\prime}=\left[<\mathrm{SUBS}>n_{[\mathrm{N}] 0},<\mathrm{MASC}>\mathrm{Gen}_{[\mathrm{N}] 0},<\mathrm{PL}>\mathrm{Num}_{[\mathrm{N}] 1},<3>\mathrm{Q}_{[\mathrm{N}] 1},<\mathrm{DEF}>\mathrm{D}_{[\mathrm{N}] 1}\right]$ $\mathrm{P}=\left\{<\operatorname{MASC} \operatorname{Gen}_{[\mathrm{N}]},\left\{<\operatorname{SUBS}>n_{[\mathrm{N}]},[\{\varnothing\}]_{\mathrm{N}}\right\}\right\}$

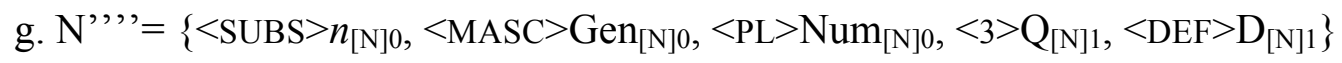

$\mathrm{P}=\left\{<\operatorname{MASC}>\mathrm{Gen}_{[\mathrm{N}]},\left\{<\mathrm{SUBS}>n_{[\mathrm{N}]},[\{\varnothing\}]_{\mathrm{N}}\right\}\right\}$

$\mathrm{Q}=<\mathrm{PL}>\operatorname{Num}_{[\mathrm{N}]}$

h. $\mathrm{N}^{\prime \prime}, \mathrm{\prime}^{\prime}=\left[<\mathrm{SUBS}>n_{[\mathrm{N}] 0},<\mathrm{MASC}>\mathrm{Gen}_{[\mathrm{N}] 0},<\mathrm{PL}>\mathrm{Num}_{[\mathrm{N}] 0},<3>\mathrm{Q}_{[\mathrm{N}] 1},<\mathrm{DEF}>\mathrm{D}_{[\mathrm{N}] 1}\right]$ $\mathrm{R}=\left\{<\mathrm{PL}>\operatorname{Num}_{[\mathrm{N}]},\left\{<\mathrm{MASC} \mathrm{Gen}_{[\mathrm{N}]},\left\{<\mathrm{SUBS}>n_{[\mathrm{N}]},[\{\varnothing\}]_{\mathrm{N}}\right\}\right\}\right\}$

i. $\mathrm{N}^{\prime},{ }^{\prime \prime}=\left[<\mathrm{SUBS}>n_{[\mathrm{N}] 0},<\mathrm{MASC}>\mathrm{Gen}_{[\mathrm{N}] 0},<\mathrm{PL}>\mathrm{Num}_{[\mathrm{N}] 0},<3>\mathrm{Q}_{[\mathrm{N}] 0},<\mathrm{DEF}>\mathrm{D}_{[\mathrm{N}] 1}\right]$ $\mathrm{R}=\left\{<\mathrm{PL}>\operatorname{Num}_{[\mathrm{N}]},\left\{<\mathrm{MASC} \operatorname{Gen}_{[\mathrm{N}]},\left\{<\mathrm{SUBS}>n_{[\mathrm{N}]},[\{\varnothing\}]_{\mathrm{N}}\right\}\right\}\right\}$ $\mathrm{S}=<3>\mathrm{Q}_{[\mathrm{N}]}$

j. ${ }^{\prime}{ }^{\prime \prime}{ }^{\prime}=\left[<\mathrm{SUBS}>n_{[\mathrm{N}] 0},<\mathrm{MASC} \mathrm{Gen}_{[\mathrm{N}] 0},<\mathrm{PL}>\mathrm{Num}_{[\mathrm{N}] 0},<3>\mathrm{Q}_{[\mathrm{N}] 0},<\mathrm{DEF}>\mathrm{D}_{[\mathrm{N}] 1}\right]$ $\mathrm{T}=\left\{<3>\mathrm{Q}_{[\mathrm{N}]},\left\{<\mathrm{PL}>\mathrm{Num}_{[\mathrm{N}]},\left\{<\mathrm{MASC} \mathrm{Gen}_{[\mathrm{N}]},\left\{<\mathrm{SUBS}>n_{[\mathrm{N}]},[\{\varnothing\}]_{\mathrm{N}}\right\}\right\}\right\}\right\}$

k. N ${ }^{\prime,},{ }^{\prime}=\left[<\mathrm{SUBS}>n_{[\mathrm{N}] 0},<\mathrm{MASC}>\mathrm{Gen}_{[\mathrm{N}] 0},<\mathrm{PL}>\mathrm{Num}_{[\mathrm{N}] 0},<3>\mathrm{Q}_{[\mathrm{N}] 0},<\mathrm{DEF}>\mathrm{D}_{[\mathrm{N}] 0}\right]$ $\mathrm{T}=\left\{<3>\mathrm{Q}_{[\mathrm{N}]},\left\{<\mathrm{PL}>\mathrm{Num}_{[\mathrm{N}]},\left\{<\mathrm{MASC} \mathrm{Gen}_{[\mathrm{N}]},\left\{<\mathrm{SUBS}>n_{[\mathrm{N}]},[\{\varnothing\}]_{\mathrm{N}}\right\}\right\}\right\}\right\}$ $\mathrm{U}=<\mathrm{DEF}>\mathrm{D}_{[\mathrm{N}]}$

1. $\mathrm{N}^{\prime},{ }^{\prime,},{ }^{\prime}=\left[\mathrm{SUBS}>n_{[\mathrm{N}] 0},<\mathrm{MASC}>\mathrm{Gen}_{[\mathrm{N}] 0},<\mathrm{PL}>\mathrm{Num}_{[\mathrm{N}] 0},<3>\mathrm{Q}_{[\mathrm{N}] 0},<\mathrm{DEF}>\mathrm{D}_{[\mathrm{N}] 0}\right]$ $\mathrm{V}=$

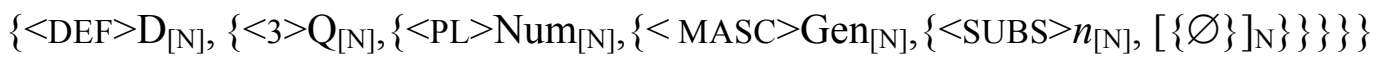

m. $\mathrm{A}=\left\{<\mathrm{A} / \mathrm{C}>v_{[\mathrm{v}]},[\{\varnothing\}]_{\mathrm{v}}\right\}$

$\mathrm{V}=$

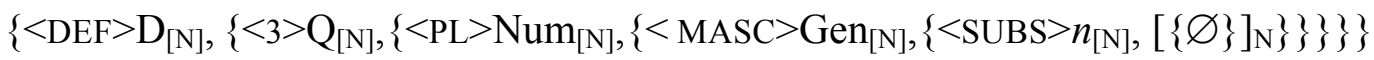


n. $X=$

$\left\{\left\{<\mathrm{DEF}>\mathrm{D}_{[\mathrm{N}]},\left\{<3>\mathrm{Q}_{[\mathrm{N}]},\left\{<\mathrm{PL}>\mathrm{Num}_{[\mathrm{N}]},\left\{<\mathrm{MASC} \mathrm{Gen}_{[\mathrm{N}]},\left\{<\mathrm{SUBS}>n_{[\mathrm{N}]},[\{\varnothing\}]_{\mathrm{N}}\right\}\right\}\right\}\right\}\right\}\right.$, $\left.\left\{<\mathrm{A} / \mathrm{C}>v_{[\mathrm{V}]},[\{\varnothing\}]_{\mathrm{v}}\right\}\right\}$

Notem que, em (90a), um conjunto vazio é formado a partir da operação Merge, que delimita uma porção do espaço computacional. Seguindo a discussão feita em Boeckx (2015, p. 77), assumimos que, em termos sintáticos, um conjunto vazio não tem nada de excepcional. Em outras palavras, um conjunto vazio é um conjunto como outro qualquer. Dado que Merge é fundamentalmente uma operação que forma conjuntos, devemos assumir que um conjunto vazio é algo que Merge também é capaz de formar. Assim sendo, qualquer teoria que assuma uma operação como Merge deve prever a existência de conjuntos vazios (i.e., sem conteúdo, sem valores). Boeckx destaca ainda que:

“[...] para que se possa vislumbrar a opção de se concatenar algo com um conjunto vazio, é necessário interpretar Merge como uma operação livre, sem desencadeadores, já que o conjunto vazio não pode satisfazer qualquer requisito veicular plausível [em alusão ao Vehicle Requirement on Merge, de Pesetsky e Torrego (2006)] que se imporia a Merge em um modelo de sintaxe à prova de falhas" (BOECKX, 2015, p. 77, tradução nossa). ${ }^{207}$

Essa perspectiva acerca de Merge é exatamente o que demanda o desideratum 4, que buscamos abarcar nesta tese. Em outras palavras, a assunção de um conjunto vazio como uma das possibilidades de aplicação de Merge reitera a assunção de que as aplicações de Merge ocorrem livremente na gramática. ${ }^{208}$

\footnotetext{
${ }^{207}$ Trecho original: "[...] that in order to entertain the option of merging with the empty set, it is necessary to view Merge as a free, untriggered operation, as the empty set cannot satisfy any plausible vehicle requirement that one would impose on Merge in a crash-proof syntax model".

${ }^{208}$ Um breve comentário sobre a formação dos compostos. Seguimos, com Nóbrega (2014, 2015b, 2016), a hipótese de que um composto resulta da concatenação entre dois constituintes complexos, normalmente dois sintagmas, concatenados em uma relação de complementação, adjunção ou coordenação. Esse OS é, em seguida, recategorizado por um traço categorial, seja ele $<\Sigma>\mathrm{n}_{[\mathrm{N}]},<\Sigma>v_{[\mathrm{V}]}$ ou $<\Sigma>a_{[\mathrm{A}]}$. Os membros de um composto são, da mesma forma que o DP complexo em (90), derivados paralelamente no espaço computacional. Logo após, eles são concatenados entre si formando um novo OS. Esse OS formado é, subsequentemente, concatenado a um terceiro traço categorial (que pode ser transposicional, tendo em vista casos de exocentricidade categorial, e.g., [[pisca $\left.]_{\mathrm{V}}[p i s c a]_{\mathrm{V}}\right]_{\mathrm{N}}$ Cf. NÓBREGA; PANAGIOTIDIS, 2018), o qual força os constituintes do composto a serem movidos em conjunto. Esse domínio categorial também intervém em relações de ligação, impedindo que apenas um dos membros do composto seja retomado por meio de anáforas. Detalhes do passo-a-passo derivacional de um composto, bem como das motivações para a assunção desse domínio categorial podem ser vistos nas referências acima.
} 


\section{- Desideratum \#2:}

Informações lexicais não devem ser pré-empacotadas arbitrária e gratuitamente.

Vimos que, de acordo com a AI, o Léxico-I compõe-se de uma lista de primitivos isolados e desprovidos de uma estrutura interna, que, após inseridos na sintaxe, servem como um núcleo independente. Essa conjectura segue o princípio "um traço, um núcleo”, de Kayne (2005), mencionado no Capítulo 2. Ela é reafirmada, de certo modo, pelo nosso pressuposto 3. Esse pressuposto determina que "Merge é o único mecanismo gerativo capaz de derivar objetos linguísticos”. Em vista disso, devemos esperar que qualquer forma de encaixamento estrutural somente será estabelecida por meio de Merge, e que na ausência da formação de um arranjo de traços na forma de um feixe via Merge, todo traço formal deve servir como um núcleo. Uma consequência do pressuposto 3, portanto, é que não deve haver encaixamento de entradas lexicais internamente ao Léxico-I — formando entradas lexicais complexas-, nem mesmo de hierarquias funcionais predeterminadas ou de feixes de traços. O pressuposto 3 , nesse sentido, consegue satisfazer o desiderata $2 .^{209}$

\section{- Desideratum \#3:}

Hierarquias funcionais devem ser emergentes, não predeterminadas.

Em decorrência da necessidade de se distribuir as categorias funcionais derivadas a partir de $\kappa$ a uma projeção funcional particular, seja ela verbal ou nominal, todo traço formal fixado pela interface $f_{0}$ é marcado com um domínio $\delta$. Conjecturamos que, através desse domínio, o sistema C-I pode, então, identificar quais traços formais arranjados por Merge participam de uma mesma hierarquia funcional. Desse modo, conseguimos assegurar que toda hierarquia funcional é, fundamentalmente, emergente e não predeterminada, como sugerem os trabalhos em cartografia. Hipotetizamos também que o ordenamento do grupo de traços que compõe uma determinada projeção é determinado com base em exigências feitas pelo sistema C-I em torno da disposição hierárquica das categorias universais $\kappa$. Estamos cientes de que mais trabalhos devem ser elaborados a fim de justificar por que o sistema C-I faz essas exigências distribucionais e não outras. Através dessas assunções, somos capazes de nos aproximar do desideratum 3.

\footnotetext{
${ }^{209}$ Pronomes, comumente analisados na forma de feixes de traços, podem corresponder a uma projeção funcional derivada internamente à FLN, via Merge, a qual carece de um AC em seu complemento. Essa projeção receberá no ramo de PF um único expoente fonológico (e.g., 1P.SG $=/_{\pi} e u /$; Cf. HACHEM, 2015). Nesse sentido, não haveria a necessidade de os pré-empacotar em um léxico.
} 


\section{- Desideratum \#4:}

A aplicação de Merge deve estar dissociada da valoração de traços.

Esse desideratum é um pré-requisito para um modelo neoconstrucionista, uma vez que o sistema computacional deve ter liberdade combinatorial para derivar qualquer tipo de arranjo estrutural, os quais são, presumivelmente, avaliados e filtrados pelo sistema C-I. Ao isentar a operação Merge de um mecanismo de valoração, permitimos que ela se aplique livremente, sem a interferência de instruções lexicais, como os traços desencadeadores (e.g., traços de borda; Cf. CHOMSKY, 2005). Como acabamos de mencionar, a própria assunção de um conjunto vazio como parte dos conjuntos formados por Merge internamente à FLN é um indicativo de que Merge opera sem prescrições feitas pelas entradas lexicais. Nesse sentido, nos adequamos integralmente ao que sugere o desideratum 4.

\section{- Desideratum \#5:}

A GU deve conter apenas um único sistema combinatorial, implementado pela operação Merge.

A assunção dos pressupostos 1, 2 e 3 contempla, em nosso entendimento, as expectativas colocadas pelo desideratum 5. É relevante destacar ainda que as propriedades entendidas como contra-argumentos à ideia de que Merge é o único caractere da FL exclusivo à espécie não são um problema para a AI. Mostramos que essas propriedades —a extensão, a aquisição ilimitada e o caráter dependente de aprendizado do léxico humano- decorrem de Merge. Ao formar um AC, Merge abriu a possibilidade de que os conceitos alocados em C-I pudessem ser associados às estruturas derivadas. A formação de um AC e sua indexação, após a associação de S-M à FLN, fez com que esses conceitos recebessem uma forma e passassem a compor o conhecimento de mundo do falante, criando paralelamente o Léxico-E e o LéxicoC. Essa integração entre os sistemas C-I e S-M, via Merge, foi o que proporcionou, em nosso entendimento, a emergência de um repertório lexical extenso, de aquisição ilimitada, na espécie. Tal repertório representa as instruções listadas em PF e LF, uma consequência direta do estabelecimento de um AC na sintaxe. Ainda, de acordo com a AI, parte do léxico da espécie humana, o Léxico-I, deriva de habilidades inatas à espécie, paralelamente ao que se observa nos sistemas de comunicação animal. 
Antes de finalizar este capítulo, discutimos brevemente a distribuição dos traços transposicionais e dos traços modificadores. Vimos, na subseção 4.4.2, que os chamados traços transposicionais instanciam afixos transposicionais, enquanto os traços modificadores realizam afixos não transposicionais. No português, bem como nas demais línguas indoeuropeias, esses traços limitam-se à chamada morfologia derivacional. Há inúmeros trabalhos que buscam sistematizar a distribuição desse tipo de morfologia - comumente manifestada através de afixos - e averiguar a existência de um ordenamento sugestivamente universal, como se observa, em certa medida, na distribuição das categorias flexionais. Em princípio, a única generalização que pode ser feita com relação à sua distribuição é a de que os afixos derivacionais são realizados mais próximos da raiz do que os afixos flexionais, atrelados às projeções estendidas vistas na seção 4.4 (Cf. GREENBERG, 1963).

O ordenamento dos afixos recebeu diferentes tratamentos na literatura, muitas vezes a partir de uma mesma propriedade, como apontam Manova e Aronoff (2010) e Saarinen e Hay (2014). Ora sua distribuição toma por base propriedades fonológicas e semânticas, como se verifica nos modelos que descrevem a relação entre a morfologia e a fonologia em termos de estratos/classes (Cf. SIEGEL, 1974; ALLEN, 1978; KIPARSKY, 1982; MOHANAN, 1986, entre outros), ora ela se concentra em estabelecer uma relação com a sintaxe, como é o caso da intuição que guia o "Princípio do Espelho", de Baker (1985), descrito anteriormente. Esse último concentrou-se em avaliar a disposição das categorias flexionais. É nos modelos que partem de estratos/classes lexicais que encontramos uma melhor caracterização da morfologia derivacional.

Esses últimos modelos tendem a classificar os afixos de uma língua com respeito à relação fonológica e semântica que eles apresentam com uma base. Por exemplo, afixos são agrupados entre (i) opacos fonológica e semanticamente, provocando a alteração do acento de sua base (e.g., captive, captivity) e (ii) transparentes fonológica e semanticamente, não sendo capazes de alterar o acento de sua base (e.g., insane, insaneness). Essa distribuição remonta a distinção feita em Chomsky e Halle (1968) acerca das fronteiras entre morfemas, fracos (+) e fortes (\#), cada qual relacionado aos dois grupos acima, respectivamente. É a partir dessa divisão que os estratos são criados e o ordenamento dos afixos é estabelecido, já que afixos de diferentes estratos/classes seriam concatenados em estágios separados da derivação. Um exemplo dessa distribuição dos afixos em classes lexicais está representado em (91), retirado de Spencer (1991, p. 79): 
(91) Classes lexicais do inglês (SPENCER, 1991, p. 79)

a. Classe 1 - Sufixos: +ion, $+i t y,+y,+a l,+a t e,+o u s,+i v e,+a b l e,+i z e$

Prefixos: $r e^{+}, \mathrm{con}^{+}, \mathrm{de}+, \mathrm{sub}+, \mathrm{pre}^{+}, \mathrm{in}+, \mathrm{en}^{+}, \mathrm{be} \mathrm{e}^{+}$

b. Classe 2 - Sufixos: \#ness, \#less, \#hood, \#ful, \#ly, \#y, \#like, \#ist, \#ize

Prefixos: re\#, sub\#, un\#, non\#, de\#, semi\#, anti\#

Reparem que essa divisão em classes desconsidera o papel funcional dos morfemas associados a uma base, por exemplo, o fato de que um morfema como + able altera a categoria de sua base diferentemente dos morfemas re+ e pre+, embora todos estejam alocados em uma mesma classe. Ainda, se a informação fonológica de um morfema é inserida tardiamente, como assumimos, então qualquer distribuição em classes é epifenomenal e deve corresponder ao modo como esses morfemas estão concatenados na estrutura, tal como sugere o "Princípio do Espelho". As abordagens não lexicalistas, como a MD e XS, buscam abarcar essa distinção entre morfemas fracos e fortes, ou morfemas de classe 1 e 2, a partir de sua proximidade estrutural a uma raiz. Por exemplo, um núcleo categorial concatenado localmente a uma raiz tem a capacidade de (i) influenciar seu significado (e.g., induzindo uma interpretação idiossincrática) e de (ii) influenciar sua realização fonológica (Cf. MARANTZ, 2001; MARVIN, 2002, 2013; ARAD, 2003, 2005; EMBICK, 2010, entre outros).

Por exemplo, o fato de -inh, mas não -zinh extrair um significado idiossincrático de uma raiz nos indica que sua concatenação pode ocorrer em diferentes posições da estrutura sintática, distantes ou locais à raiz (Cf. ARMELIN, 2015; e.g., caipirinha 'bebida alcoólica' ou 'uma garota pequena vestida de caipira', em contraste com caipirazinha 'uma garota pequena vestida de caipira'). Da mesma forma, o contraste entre captivity e insaneness nos indica que -ity e -ness, apesar de ambos serem transposicionais, formando nomes a partir de adjetivos, estão concatenados em posições estruturalmente distintas com relação a uma mesma raiz. Seguimos essa reinterpretação da distribuição dos morfemas derivacionais e partimos dela para guiar a disposição dos afixos modificadores pela estrutura, muito embora qualquer influência que esses morfemas possam apresentar no conteúdo de um AC estará listado, juntamente com seu contexto sintático, nas instruções de LF de um dado índice.

Embora não pareça existir uma hierarquia funcional universal da qual os morfemas derivacionais participam, como destacam as revisões de Manova e Aronoff (2010) e Saarinen e Hay (2014), a expectativa é que sua realização esteja circunscrita ao domínio sintático próximo da raiz, ou seja, o domínio $\kappa$ : classificação. Prevemos ainda que a distribuição de afixos transposicionais é muito mais restrita do que a dos afixos modificadores, uma distinção 
que não é feita nem pela MD e nem por XS, tendo em vista que ambos circunscrevem os morfemas derivacionais a um único tipo de primitivo formal, núcleos categorizadores e Cfuntores, respectivamente.

Por exemplo, enquanto a transposição de projeções liderada pelos transposicionais parece se limitar a cinco variações de categoria, ou seja, a pelo menos cinco combinações de afixos transposicionais em sequência, como exemplificado em (92), os modificadores podem se aplicar, em princípio, sem um limite máximo, como se verifica em (93), já que a adição de outros afixos modificadores a uma mesma base é capaz de derivar palavras ainda aceitáveis. Isso é, na realidade, o que deveríamos esperar, tendo em vista que os modificadores de modo geral, podem ser concatenados ilimitadamente a uma estrutura sintática, sendo sua limitação uma questão de processamento (IRUNTZUN; GALLEGO, 2007).

(92) a. computacionalizável

$$
\begin{aligned}
& \text { comput- } \varnothing(a) \text {-cio(n)-al-iz-ável } \\
& {\left[\left[\left[\left[\left[\left[\text { comput] (a) }<\Sigma>v_{[\mathrm{V}]}\right]<\mathrm{C} \tilde{\mathrm{AOO}} / \mathrm{CIO}>n_{[\mathrm{V}]}(\mathrm{n})\right]<\mathrm{AL}>a_{[\mathrm{N}]}\right]<\mathrm{IZ}>v_{[\mathrm{N}]}(\mathrm{a})\right]<\mathrm{VEL}>a_{[\mathrm{V}]}\right]\right.}
\end{aligned}
$$

b. americanizabilidade

americ-an-iz(a)-bil-(i)dade

$$
\left.\left[\left[\left[[\text { americ }]<\mathrm{AN}>n_{[\mathrm{N}]}\right]<\mathrm{IZ}>v_{[\mathrm{N}]}(a)\right]<\mathrm{BIL}>a_{[\mathrm{V}]}\right] ?<\mathrm{DADE}>n_{[\mathrm{A}]}\right]
$$

(93) a. míssil antiantiantimíssil

$$
\operatorname{missil}\left[<\mathrm{ANTI}_{[\mathrm{N}]}-\left[<\mathrm{ANTI}_{[\mathrm{N}]}-\left[<\mathrm{ANTI}_{[\mathrm{N}]}-\text { missil }\right]\right]\right] \ldots
$$

b. ex-antiantibissexual

$$
\ldots\left[<\mathrm{EX}_{[\mathrm{N}]}\left[<\mathrm{ANTI}_{[\mathrm{N}]}\left[<\mathrm{ANTI}_{[\mathrm{N}]}\left[<\mathrm{BI}_{[\mathrm{N}]}\left[[\mathrm{sex}]<\mathrm{AL}>a_{[\mathrm{N}]}\right]\right]\right]\right]\right.
$$

Com base nesse conjunto de apontamentos, acreditamos satisfazer, através da AI, os desiderata para se chegar a uma sintaxe autônoma e, com isso, explicar o desenvolvimento filogenético e ontogenético do conhecimento linguístico humano em uniformidade com o que as teorias naturalistas assumem acerca da evolução de qualquer organismo.

\subsection{Resumo}

Neste capítulo, propusemos uma nova hipótese para a gramática, a AI, com o intuito de chegar a uma explicação acerca da articulação entre as competências lexicais e sintáticas 
na espécie humana, coerente com os critérios de adequação evolutiva e biológica decorrentes do "Problema de Wallace-Darwin". Com a AI, buscamos colocar a gramática no caminho para se ir "além da descrição explicativa", reduzindo o papel de caracteres exclusivos ao genótipo humano no desenvolvimento da linguagem e, paralelamente, eliminando qualquer codificação de informações combinatoriais na forma de instruções lexicais predeterminadas pela GU.

Em síntese, a AI admite ainda que a operação Merge é o único mecanismo capaz de gerar representações estruturais internamente à FLN. Em vista disso, Merge está a cargo da formação da estrutura interna das palavras e das sentenças. Adicionalmente, sua aplicação está dissociada de qualquer influência lexical, fato que impede que os traços formais projetem a estrutura sintática. Os primitivos manipulados por Merge derivam das células fixadas por um sistema referencial externo à FLN, o sistema $\mathrm{F}$, compartilhado por homologia com primatas não humanos. Ao postular a existência do sistema F, a AI remove da FLN as bases biológicas do léxico humano, uma assunção que, consequentemente, reduz a complexidade da GU.

Ainda, assumindo que primatas não humanos apresentam habilidades perceptuais paralelas às da espécie humana (Cf. SEYFARTH; CHENEY, 2005), nos parece razoável conjecturar que o evento evolutivo responsável por dar origem à porção conceitual do léxico humano, a que chamamos de Léxico-C, foi o surgimento de um item destituído de conteúdo internamente à FLN —viz., um AC—, o qual passou a ser associado às representações conceituais derivadas da percepção, disponíveis no sistema C-I. Consequentemente, isso permitiu que essas representações fossem atreladas a uma estrutura sintática e externalizadas através do sistema S-M, provocando uma explosão vocabular na espécie.

Sugerimos que as células que compõem o sistema $\mathrm{F}$ humano apresentam como ATR -i.e., propriedades inatas de uma espécie responsáveis por regular a categorização de determinadas categorias do mundo - as categorias universais $\kappa$ vislumbradas pela "Hipótese da Coluna Universal” (HCU), de Wiltschko (2014, 2015). É através dessas categorias universais que categorias funcionais específicas de uma língua são formadas. Essas células em F representam um molde isomórfico a partir do qual os traços formais de uma língua são derivados. A variação no modo como esse molde é fixado e organizado internamente à FLN é o que dá origem à multiplicidade de traços formais de uma língua L. Vimos que, pelo menos, três classes de traços formais podem ser formadas: (i) traços formais "canônicos", (ii) traços transposicionais e (iii) traços modificadores. Sua variação, em princípio, é um dos fatores que promove parte da variação entre as línguas naturais. Hipotetizamos que o ordenamento das 
estruturas sintáticas em sequências lineares deve estar a cargo de um segundo fator que propicia a variação entre as línguas. Esse segundo fator para a variação seria um efeito da associação do sistema S-M à FLN.

No próximo capitulo, apresentamos os desdobramentos da AI, especialmente no que diz respeito à evolução humana. Apresentamos também as questões residuais dessa nossa hipótese e reunimos as conclusões finais sobre a tese. 


\section{Capítulo 5}

\section{Evolução, contrastes e conclusões}

Neste capítulo final, localizamos a emergência da FL, vinculando-a a uma espécie, a um local e a um ponto no tempo, através da investigação de registros arqueológicos e de reconstruções genéticas das populações sapiens. Conjecturamos que a FL, tal como caracterizada no último capítulo, é sugestivamente exclusiva ao $H$. sapiens, muito embora as bases cognitivas para o desenvolvimento de uma consciência simbólica já estivessem, por hipótese, minimamente organizadas desde o surgimento do $H$. heidelbergensis, o provável ancestral comum entre o H. neanderthalensis e o H. sapiens. Discutimos, logo em seguida, um conjunto de análises e de fenômenos que divergem dos pressupostos globais da AI e, então, nos encaminhamos para nossas considerações finais.

\subsection{Evolução humana e os primeiros registros de uma consciência simbólica}

Determinar, exatamente, quando a FL emergiu é uma tarefa praticamente inexequível. Tal impedimento está intimamente atrelado ao fato de que a linguagem não fossiliza, uma vez que a cognição não deixa marcas nos registros fósseis (DEACON, 1997; LEWONTIN, 1998; FITCH, 2010; BERWICK; CHOMSKY, 2016). Tampouco os comportamentos manifestados pela cognição são preservados (TATTERSALL, 2008, 2010, 2011, 2017). Para elucidar essa questão, temos, a nosso alcance, somente evidências indiretas, a saber, os registros materiais deixados pelas diferentes espécies hominínias. Em vista disso, os trabalhos que examinam o desenvolvimento da competência linguística buscam um respaldo empírico nas evidências que sinalizam a fixação de uma consciência simbólica. É tomando por base essa associação que geralmente se relaciona o estabelecimento da FL ao aparecimento de registros arqueológicos explicitamente simbólicos. A lógica que guia tal inferência segue a seguinte assunção: dado 
que raciocínio simbólico e linguagem estão interligados, a produção de artefatos simbólicos serve como um indicativo para a disponibilidade de uma competência linguística.

Ao avaliar os registros materiais disponíveis, fica evidente que as primeiras expressões de um comportamento mediado simbolicamente são extremamente recentes, tanto em termos geológicos quanto no que diz respeito à história evolutiva humana. Sabemos que os primeiros membros da subfamília Homininae, pertencente à família Hominidae, surgiram na África há aproximadamente 6-7 milhões de anos (TATTERSALL, 2008, 2011, 2016a, 2016b, 2017). ${ }^{210}$ Os primeiros registros arqueológicos associados a esses indivíduos começam a aparecer por volta de 3.3-3.4 milhões de anos atrás: as primeiras ferramentas líticas. Esses artefatos, cuja produção inicial é atribuída aos australopitecinos, correspondem a lâminas afiadas resultantes do choque entre um tipo de rocha e um percursor (SEMAW, 2000; MCPHERRON et al., 2010; HARMAND et al., 2015). Sua produção representa um enorme salto cognitivo, pois ela nos indica que esses primeiros hominínios estavam, pela primeira vez, produzindo —e não apenas empregando- ferramentas. ${ }^{211}$ Sua manufatura implica, além de uma apreciação da qualidade das rochas que poderiam servir como matéria-prima, planejamento e previsão (Cf. TATTERSALL, 2008, 2010; KLEIN, 2009).

Entretanto, esse salto cognitivo não proporcionou a emergência consecutiva de novas técnicas para a produção de ferramentas. O que se observa é que as técnicas de elaboração da primeira indústria lítica, também chamada de indústria Olduvaiense, à qual essas ferramentas pertencem, manteve-se inalterada por praticamente 1.6 milhão de anos, tendo sido replicadas pelas diferentes espécies hominínias que se sucederam. É somente após o aparecimento dos primeiros membros do gênero Homo — viz., hominínios com uma estrutura corporal similar a dos humanos modernos-, que uma segunda indústria lítica desponta. Mais precisamente, novas técnicas de produção de ferramentas, indicando um avanço cognitivo, apareceram há cerca de 1.5-1.8 milhão de anos após a instalação da indústria Olduvaiense (Cf. LEPRE et al., 2011). Essas novas ferramentas, chamadas de "machados de mão", dizem respeito a artefatos

\footnotetext{
${ }^{210}$ A família Hominidae está dividida em duas subfamílias: a Ponginae, que possui um único gênero vivo, do qual fazem parte os orangotangos, e a Homininae, que inclui os grandes e pequenos monos, notadamente, gorilas, chimpanzés e, paralelamente, os humanos (NORDHAUSEN; FILHO, 2015, p. 29-31). Nos interessa, nesta discussão, os primeiros membros da subfamília Homininae, especialmente aqueles que vão desde o ancestral comum entre monos e humanos e o ramo evolutivo que dá origem aos humanos modernos, incluindo as espécies atreladas ao gênero Australopithecus e ao gênero Homo.

${ }^{211} \mathrm{O}$ uso de ferramentas por animais não humanos, isto é, o emprego de um objeto com o objetivo de modificar o ambiente (LAWICK-GOODALL et al., 1973), tem sido extensamente descrito nas últimas três décadas. Essa habilidade é observada tanto em invertebrados, como aranhas e polvos, como também em vertebrados, aves e mamíferos (e.g., elefantes, cetáceos e primatas). Presumivelmente, essas tradições comportamentais são muito anteriores ao surgimento da família Hominidae e, portanto, já eram comuns há alguns milhões de anos. É por esse motivo que a produção de ferramentas configura-se como um grande salto cognitivo.
} 
deliberadamente produzidos, retocados dos dois lados, alongados, grandes o suficiente para caber na palma da mão, simétricos e com um formato de pera. Esse padrão nos sugere que, os lascadores estavam partindo, desde então, de um "molde mental" predeterminado para atingir esse formato particular (Cf. SCHICK; TOTH, 1993), diferentemente do que se nota no caráter fragmentário e irregular das ferramentas da primeira indústria lítica.

Esse contraste pode ser visto na comparação entre a Figura 10, que ilustra um típico exemplar de uma ferramenta Olduvaiense, e na Figura 11, em que há uma representação de um "machado de mão":.212

Figura 10. Típico exemplar de um núcleo para corte vinculado à indústria lítica Olduvaiense, encontrada no Valle del Duero (Espanha).

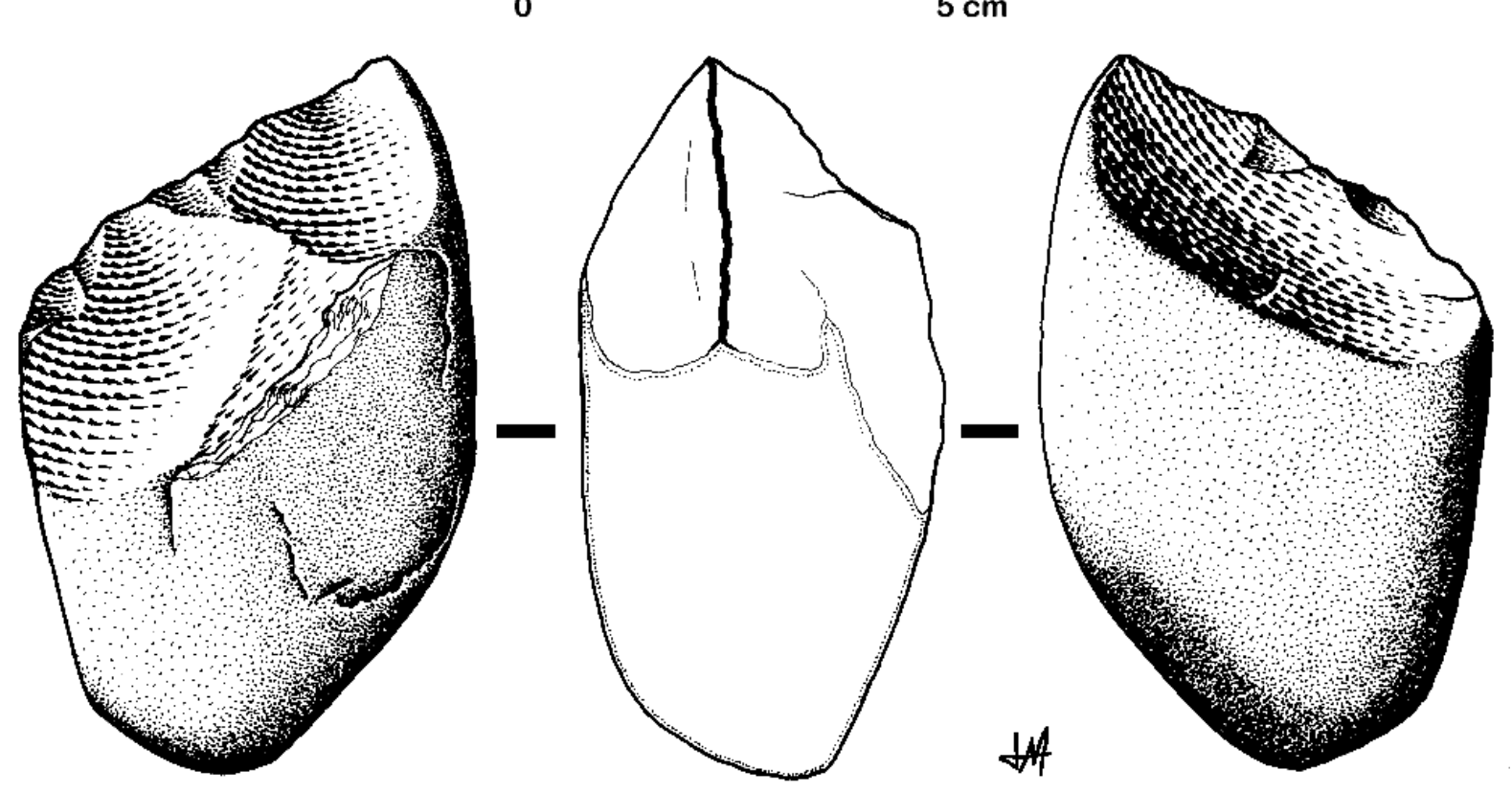

Fonte: José-Manuel Benito Álvarez

https://en.wikipedia.org/wiki/File:Chopping_tool.gif\#/media/File:Chopping_tool.gif

\footnotetext{
${ }^{212}$ É importante destacar que o surgimento de uma nova indústria lítica não implica o desaparecimento das tecnologias anteriores. Esses diferentes modos para a elaboração de ferramentas continuaram sendo produzidos pelas espécies hominínias posteriores. O que é de interesse, neste capítulo, é o seu aparecimento nos registros arqueológicos, pois ele nos serve como um indício de um avanço cognitivo.
} 
Figura 11. Típico exemplar de um "machado de mão" vinculado à indústria lítica Acheulense, encontrado no Valle del Duero (Espanha).

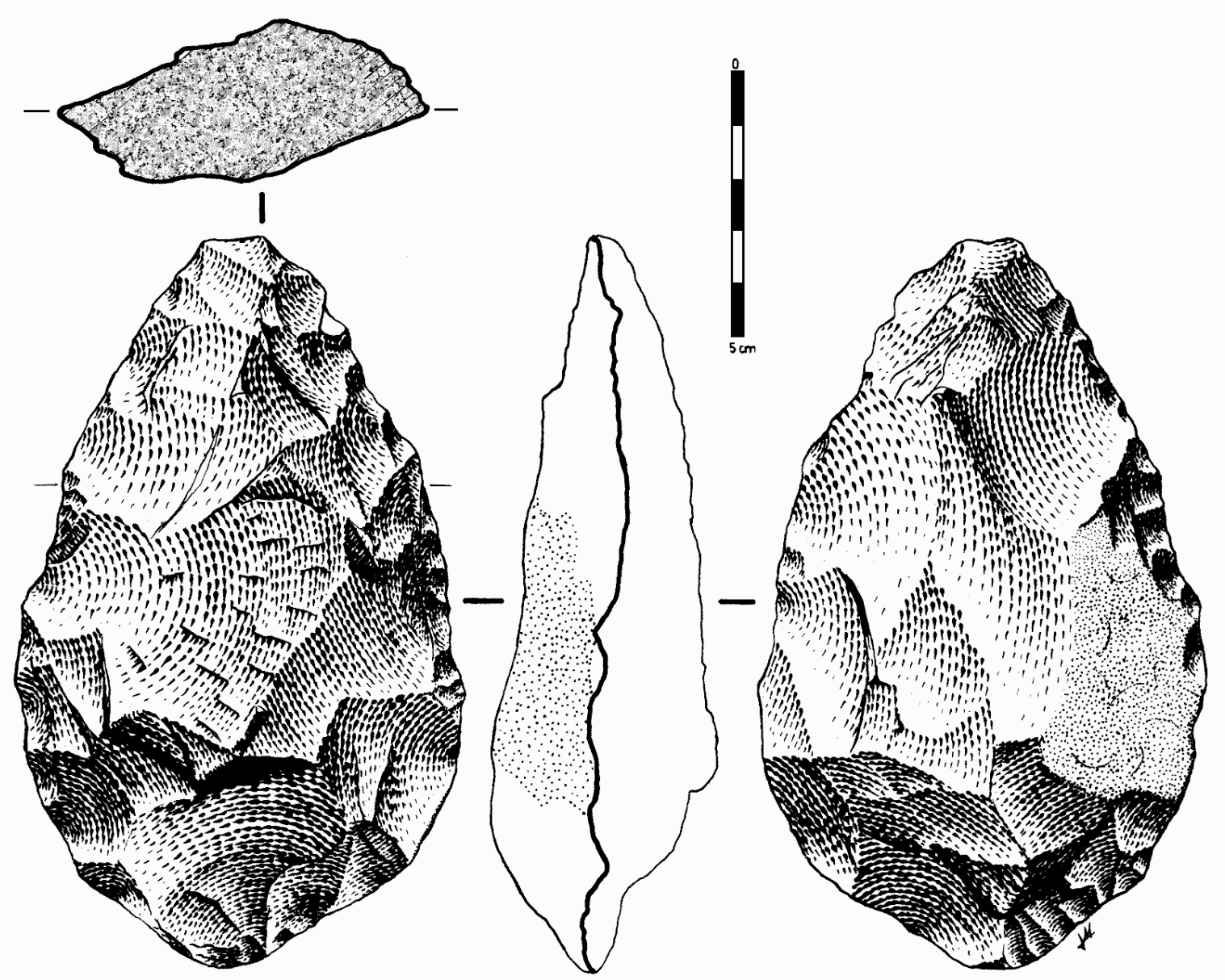

Fonte: José-Manuel Benito Álvarez

https://en.wikipedia.org/wiki/Stone_tool\#/media/File:Hand_axe_spanish.gif

Embora as ferramentas elaboradas nessa segunda indústria lítica, chamada de indústria Acheulense, fossem mais refinadas, indicando um elevado grau de sofisticação cognitiva, suas técnicas também não estimularam a produção subsequente de outras formas de ferramentas sutilmente mais aprimoradas. Muito pelo contrário, o que verificamos é novamente a ausência de inovação tecnológica nos registros arqueológicos, tendo em vista que essas novas técnicas permaneceram invariáveis por outro milhão de ano, enquanto espécies hominínias surgiam e se extinguiam. Ao explorar esses longos períodos de estase no surgimento de novos artefatos, Tattersall $(2008,2010,2011,2012,2016 a, 2017)$ aponta que há uma assimetria sintomática entre inovação anatômica e inovação tecnológica. Apesar de notarmos uma sistematicidade no crescimento do cérebro, associada ao aparecimento de novas espécies hominínias, não há, em 
contrapartida, evidências para um desenvolvimento cumulativo da cognição, o que se percebe, por exemplo, no caráter episódico e absolutamente dessincronizado do aparecimento de novas tecnologias líticas. Essa assimetria legitima o problema notado, primeiramente, por Wallace $(1869,1871)$, descrito na subseção 2.3.2.

O aumento do cérebro tornou os primeiros hominínios mais competitivos. No entanto, como frisa Tattersall, esse aumento não está associado à emergência de raciocínio simbólico ou de graus intermediários de raciocínio simbólico. O surgimento de novas ferramentas líticas representa, fundamentalmente, um desenvolvimento significativo da inteligência. Não há, durante o período que compreende os 3.4 milhões-120 mil anos atrás, registros arqueológicos que possam ser considerados simbólicos. Como sugere Tattersall (2008, 2010, 2012, 2016a, 2016b, 2017), raciocínio simbólico apenas pode ser inferido a partir de artefatos que sejam explicitamente simbólicos e que estejam inseridos em um contexto, isto é, eles não dever ser expressões isoladas. Além disso, espera-se que a emergência de habilidades associadas a um raciocínio simbólico promova o aparecimento de atividades mais dinâmicas e em uma menor escala de tempo, o que também não é observado nesse intervalo.

É somente há 80.000-100.000 anos atrás, há quase 100.000 anos após o H. sapiens se fixar como uma entidade anatomicamente distinta, que constatamos os primeiros registros materiais explicitamente simbólicos sendo produzidos sistematicamente. Por exemplo, há 100.000 anos, em sítios arqueológicos do Mediterrâneo e do sul da África, foram encontradas conchas de gastrópodes coloridas com ocre vermelho e perfuradas para serem utilizadas, presumivelmente, na forma de miçangas em ornamentos corporais (HENSHILWOOD et al., 2004; VANHAEREN et al., 2006; BOUZZOUGAR et al., 2007; D'ERRICO; VANHAEREN, 2009). Essas conchas são muito pequenas para terem servido de alimento e sua seleção parece ter sido deliberada, pois são todas conchas adultas. Sua produção é creditada ao H. sapiens. Tal indicativo de ornamentação corporal nos serve como uma forte evidência para a presença de raciocínio simbólico, já que o uso de ornamentos corporais está associado, em diversas sociedades humanas, a status social e a um grau de ocupação na hierarquia de um grupo (VANHAEREN, 2005; VANHAEREN; D’ERRICO, 2006; KUHN; STINER, 2007).

Um segundo exemplo indicativo de um comportamento mediado simbolicamente são as inscrições geométricas gravadas em placas de ocre vermelho, encontradas na caverna de Blombos, na África do Sul, as quais datam de 60-80 mil anos atrás (HENSHILWOOD et al., 2002). Exames das intersecções das linhas cruzadas indicam que elas não foram produzidas como resultado de cruzamentos aleatórios, mas que as linhas foram feitas, primeiramente, em uma direção e, em seguida, em outra, tal como ilustrado na Figura 12, abaixo. A elaboração 
desses padrões geométricos, consideravelmente incomuns até aquele momento, nos apontam para a expressão de uma consciência simbólica. Além disso, o fato de existirem mais de uma placa de ocre com inscrições geométricas sinaliza um padrão que se repetia regularmente.

Figura 12. Placa de ocre com inscrições geométricas encontrada na caverna de Blombos, África do Sul.

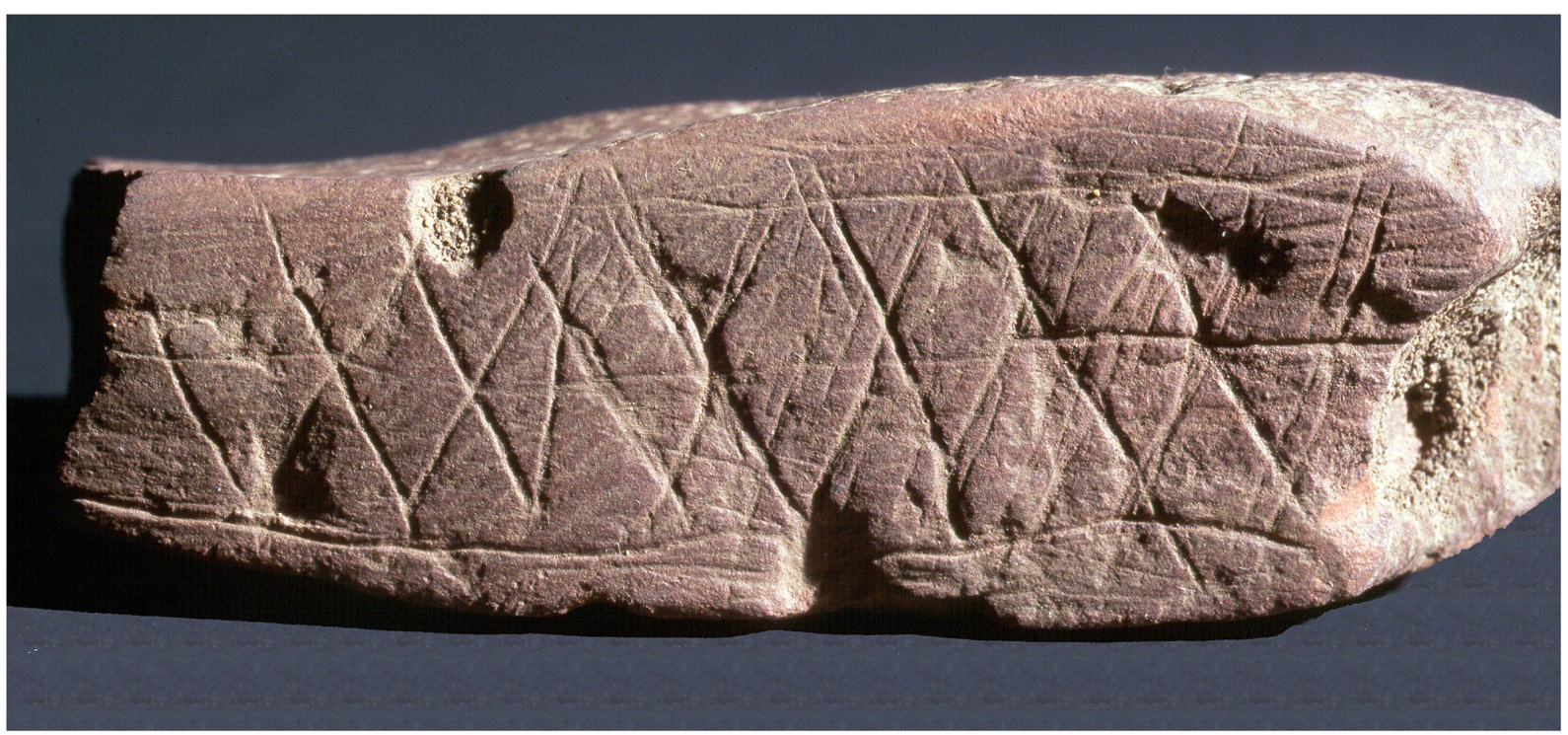

Fonte: Evolutionary Studies Institute University of the Witwatersrand.

Esses registros da cultura material dos primeiros humanos modernos nos indicam que raciocínio simbólico e, possivelmente, as bases para uma competência linguística, teriam sido fixados há aproximadamente 80.000-100.000 anos atrás. Os dois exemplos destacados estão presentes em um mesmo contexto e em uma localização geográfica muito próxima, na África do Sul (Cf. TATTERSALL, 2008, 2010, 2016a, 2016b). Soma-se a eles, a divisão simbólica dos espaços habitados por esses hominínios, verificada em uma região próxima ao rio Klasies, também na África do Sul (Cf. DEACON; DEACON, 1999). É relevante assinalar que outros registros materiais sugestivamente simbólicos, e mais antigos do que esses exemplos, foram também encontrados. Porém, eles não estão inseridos em um contexto evidente. Exemplos são: uma concha com gravações geométricas, recuperada em Trinil, na Indonésia (Cf. JOORDENS et al., 2015), a qual dada cerca de 500 mil anos atrás, creditada ao Homo erectus, e um caroço de pedra que se assemelha, vagamente, a uma figura antropomórfica, conhecido como a "Vênus de Berekhat Ram", encontrada em Israel, datando cerca de 130 mil anos atrás (Cf. GOREN-INBAR, 1986; D’ERRICO; NOWELL, 2000).

No entanto, dois estudos genômicos sobre a primeira cisão populacional da linhagem sapiens nos leva a reconsiderar a assunção de que a emergência da FL seja simultânea ao 
aparecimento dos primeiros registros simbólicos, há 80.000-100.000 anos. Behar et al. (2008) e Gronau et al. (2011) revelam que, por volta de 125.000 anos atrás —ou 121.000-128.000 anos no tempo de calibração-, a linhagem sapiens se dividiu em dois grupos populacionais, os quais se dispersaram para regiões distintas, nomeadamente, os grupos Khoe-San e NigerCordofanos. Essa dispersão populacional promoveu um isolamento genético das populações descendentes (Cf. AMBOSE, 1998). Huijbregts (2017, p. 281), ao contrastar esses estudos genômicos com as datas dos registros arqueológicos elencados acima, observa um paradoxo:

\begin{abstract}
"Uma vez que a primeira divergência populacional de humanos anatomicamente modernos deu origem a populações capazes de falar, a dotação da linguagem deve preceder a divergência genética. Por outro lado, humanos comportamentalmente modernos com uma capacidade para falar (admitindo-se que um comportamento simbólico sirva como um indicativo para uma linguagem comunicativa) só apareceram muito mais tarde. Ou seja, a linguagem é tanto anterior quanto posterior à primeira cisão da linhagem humana" (HUIJBREGTS, 2017, p. 281, tradução nossa). ${ }^{213}$
\end{abstract}

Sendo assim, uma vez que os registros arqueológicos indicativos de uma consciência simbólica são posteriores à divergência das linhagens sapiens, e considerando-se que os dois grupos descendentes desenvolveram habilidades linguísticas idênticas, devemos presumir que a emergência da competência linguística, da FL, é anterior à divergência populacional, ou seja, anterior a 125.000 anos e, certamente, deve ser anterior à dispersão humana para fora do continente africano, que se iniciou há cerca de 60.000 mil anos (HENN et al., 2012).

Para solucionar esse paradoxo, Huijbregts (2017) sugere que a competência linguística humana deve ter emergido na reorganização genética que deu origem à entidade física $H$. sapiens, por volta de 175.000-200.000 anos atrás (WHITE et al., 2003; MCDOUGALL et al., 2005). Essa capacidade se espalhou pela população, mas não foi externalizada de imediato, o que se justifica pela ausência de registros materiais simbólicos nos primeiros 100.000 anos da presença dos H. sapiens. Dessa forma, para Huijbregts (2017), a competência linguística humana emerge silenciosamente, tendo sido fixada tardiamente, próximo ao momento em que começamos a encontrar os primeiros registros evidentemente simbólicos, há 80.000-100.000 anos atrás. Essas correlações servem como uma evidência adicional para se admitir que a

\footnotetext{
${ }^{213}$ Trecho original: "Since the first diverging ancestral populations of anatomically modern humans gave rise to current populations capable of speech, possession of language must have preceded genetic divergence. On the other hand, behaviorally modern humans with a capacity for speech (accepting symbolic behavior as a proxy for communicative language) did not appear until much later. I.e. language both preceded and followed the first human lineage split”
} 
linguagem humana emergiu como um sistema do pensamento, tal como propuseram Chomsky (2011, 2015, 2016) e Berwick e Chomsky $(2011,2016)$. Em vista disso, devemos assumir que a externalização da competência linguística é secundária em dois sentidos: (i) em sua função, considerando-se a assimetria entre os sistemas S-M e C-I; e também (ii) no tempo evolutivo, uma vez que ela é posterior à emergência da competência linguística e da cisão dos grupos populacionais sapiens.

A conjectura de Huijbregts (2017) foi desafiada recentemente pela descoberta de que um conjunto de pinturas rupestres da Espanha — viz., das cavernas La Pasiega, Maltravieso e Ardales - foi produzido pelos neandertais (HOFFMANN; STANDMAN et al., 2018). Até então, a assunção mais bem aceita era a de que as pinturas rupestres da Europa tivessem sido elaboradas após a chegada dos $H$. sapiens migrando para fora do continente africano, sendo que a mais antiga datava cerca de 40.000 anos atrás (PIKE et al., 2012). Uma nova datação dessas pinturas, através da avaliação cronológica das crostas de calcita que se acumularam sobre elas, nos indica que sua produção ocorreu por volta de 64.800 anos atrás, antes do $H$. sapiens ter atingido aquela região. Portanto, a assunção de que os neandertais correspondem a uma espécie destituída de habilidades para expressão simbólica cai por terra. Além disso, essa descoberta não é uma expressão isolada: um estudo publicado simultaneamente revela que os neandertais faziam uso decorativo de conchas perfuradas e tingidas com ocre (HOFFMANN; ANGELUCCI et al., 2018). Essas conchas perfuradas foram encontradas em uma caverna no sul da Espanha, Cueva de los Aviones, e datam cerca de 115.000 anos atrás. Soma-se ainda a esses indícios uma inscrição geométrica no formato de "jogo da velha" gravada na parede da caverna Gorhan, em Gibraltar (RODRIGUEZ-VIDAL et al., 2014).

Esses registros descartam a hipótese de que somente o H. sapiens fosse uma espécie hominínia dotada de raciocínio simbólico. Entretanto, é importante destacar que as pinturas atribuídas ao $H$. neanderthalensis não apresentam claramente um conteúdo figurativo, já que as representações mais evidentes reduzem-se a estênceis de mãos. De qualquer maneira, sua descoberta torna imperativo determinar por que expressões de uma consciência simbólica cuja complexidade ainda é difícil de ser avaliada - são encontradas tanto em sítios habitados pelos $H$. neanderthalensis, uma espécie hominínia essencialmente europeia, quanto em sítios habitados pelos H. sapiens, uma espécie hominínia africana. Além disso, devemos esclarecer em que medida as capacidades simbólicas dessas duas espécies se igualavam e divergiam, uma questão praticamente irresolúvel no momento.

Considerando esse conjunto de informações, e tendo em vista que o H. sapiens não descende diretamente do $H$. neanderthalensis, hipotetizamos que as bases cognitivas para 
uma consciência ou raciocínio simbólico começaram a ser moldadas após o surgimento da entidade física $H$. heidelbergensis, há 600.000 anos atrás, o suposto ancestral comum entre os neandertais e os humanos anatomicamente modernos, tendo, por hipótese, sido herdadas por essas duas espécies descendentes. O H. heidelbergensis, embora não tenha deixado registros materiais que nos indiquem qualquer expressão de uma consciência simbólica, corresponde a uma espécie hominínia cognitivamente mais sofisticada, se comparada às espécies anteriores. Eles foram os primeiros a construir abrigos artificiais, a fazer o uso doméstico do fogo de modo regular, a produzir lanças, entre outras habilidades inovadoras, todas elas com uma datação próxima há 400.000 anos atrás (Cf. TATTERSALL, 2009).

Tattersall (2011) comenta que o H. heidelbergensis "tinha uma inteligência intuitiva muito sofisticada e formas complexas de comunicação envolvendo vocalizações, gestos e uma linguagem corporal, mas não há base para se acreditar que essa linguagem era comunicada ou processada mentalmente da maneira como fazemos — mesmo sob forma rudimentar". 214 Esses apontamentos nos sugerem que há possíveis reflexos de uma cognição que já opera de modo mais elaborado, muito especulativamente em virtude de uma consciência rudimentarmente simbólica. É com base nessas considerações, e com o objetivo de justificar as descobertas acerca do comportamento sugestivamente simbólico dos neandertais, que especulamos que as bases cognitivas para uma consciência simbólica já estavam presentes há 600.000 anos, muito embora elas não tenham sido, em princípio, externalizadas. Esse último apontamento não é, de modo algum, incomum, tendo em vista que os ancestrais dos pássaros apresentaram penas por milhares de anos antes de passar a usá-las para o voo.

Essa nossa conjectura nos parece, dadas as evidências disponíveis no momento, a mais razoável, tendo em conta que os neandertais e os humanos modernos são duas espécies que emergiram separadamente, em locais distantes, e que produziram — com graus variados de elaboração - registros materiais simbólicos e contextualizados. Apresentamos, na Figura 13, uma árvore evolucionária provisória da família Hominidae, para ilustrar as relações evolutivas entre essas três espécies hominínias: o $H$. heidelbergensis, o $H$. neanderthalensis e o $H$. sapiens.

\footnotetext{
${ }^{214}$ Trecho original: "[...] had a very sophisticated intuitive intelligence, and complex ways of communicating involving vocalization, gesture, and body language; but we have no grounds for believing it communicated or mentally processed information in the ways that we do - even in rudimentary form".
} 
Figura 13. Árvore evolucionária da família Hominidae.

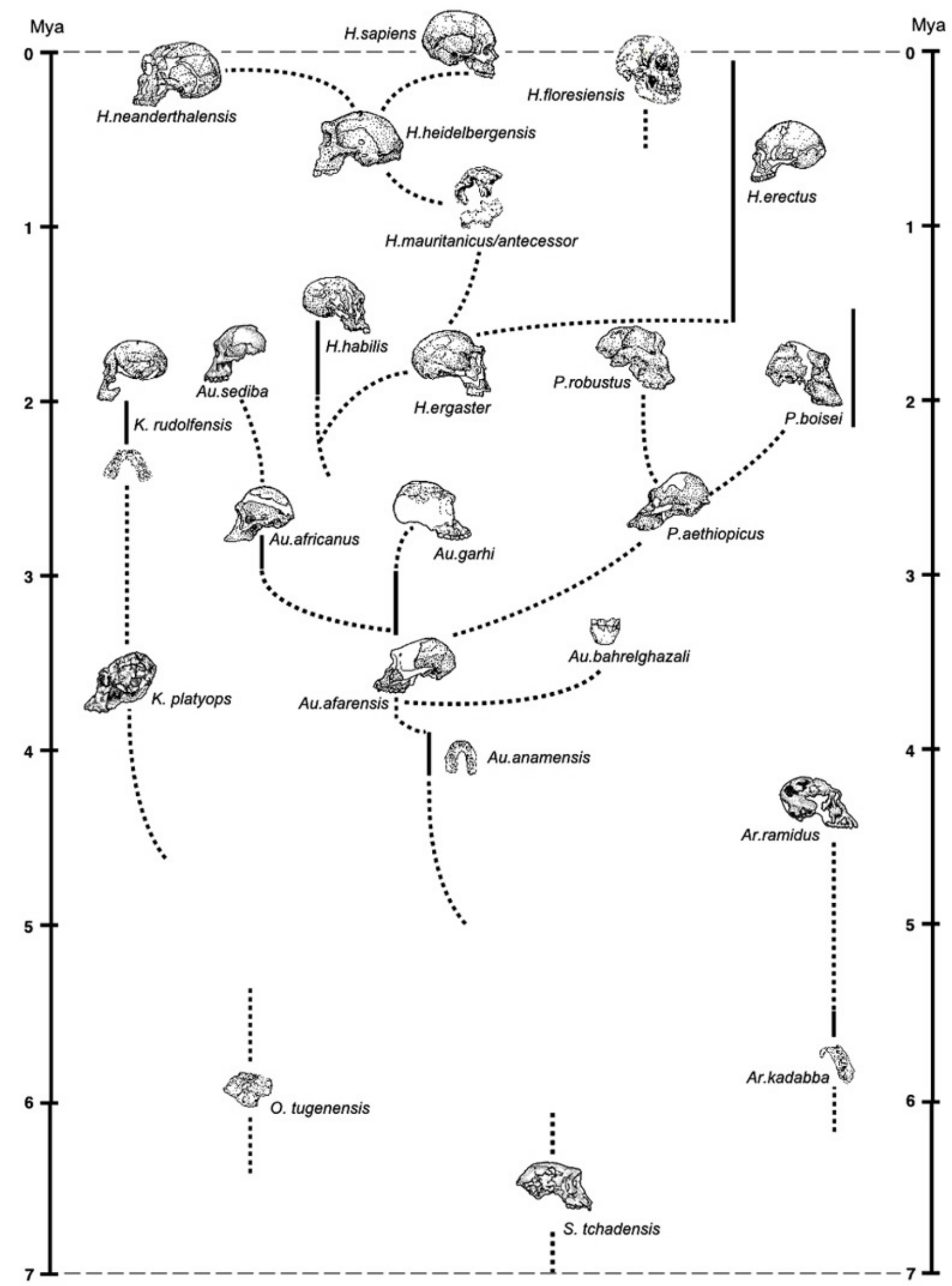

Fonte: Tattersall (2011), http://journalofcosmology.com/Consciousness 151.html. 
É evidente que a literatura ainda carece de um maior entendimento sobre o modo como se estrutura um raciocínio simbólico e, em que medida, raciocínio simbólico difere de uma competência linguística, ou seja, de uma expressão da FL. Se é realmente verdade que o único componente da FL, exclusivo à espécie humana, reduz-se a um sistema combinatorial recursivo, binário e cujos itens combinados se encontram em uma relação assimétrica, então podemos conjecturar que as eventuais diferenças entre um raciocínio simbólico e a fixação de uma FL residem no estabelecimento de um sistema combinatorial com essas propriedades. Dessa maneira, indivíduos dotados de raciocínio simbólico apresentariam, sugestivamente, um sistema combinatorial limitado (recursivo, porém linear, ou um sistema de estado finito) e símbolos disponíveis para serem manipulados. A FL representaria a transição desse sistema combinatorial limitado para um sistema combinatorial recursivo, em que os primitivos são combinados dois-a-dois, gerando estruturas hierarquicamente arranjadas.

Apontamos, na seção 4.2, que habilidades combinatoriais estão presentes em sistemas de comunicação animal, por exemplo, no arranjo de notas em um canto, no caso dos pássaros. Entretanto, as propriedades combinatoriais desses sistemas diferem consideravelmente das habilidades observadas na linguagem humana (BERWICK et al., 2011). Uma mesma espécie de pássaro canoro pode produzir algo em torno de 100-200 cantos, como é o caso do rouxinol (Luscinia megarhynchos) (TODT, 1970). Porém, todos esses diferentes cantos irão veicular um mesmo conteúdo: ora demarcação territorial, ora disponibilidade para acasalamento (MARLER, 1970). Assim sendo, podemos conjecturar que uma forma rudimentar de raciocínio simbólico corresponde a um intermediário entre o sistema combinatorial verificado nos sistemas de comunicação animal e a linguagem humana. Raciocínio simbólico deve envolver, minimamente, a habilidade para se criar um sistema composicional, em que símbolos discretos, com conteúdos distintos, são concatenados através de um sistema combinatorial limitado, essencialmente linear, diferentemente do canto dos pássaros, que não apresenta qualquer composicionalidade (BERWICK et al., 2011). O poder expressivo de um raciocínio simbólico rudimentar é limitado, uma vez que sequências lineares impedem a transmissão de informações elaboradas (GOUCHA; ZACCARELLA; FRIEDERICI, 2017). ${ }^{215}$

\footnotetext{
${ }^{215}$ Podemos especular que o caractere herdado dos H. heidelbergensis seja um sistema combinatorial capaz de gerar estruturas planas e que, eventualmente, permitiu que as células do sistema F pudessem ser combinadas, algo semelhante à operação "Combinar" proposta por Boeckx (2006, 2009) e por Hornstein (2009). Essa associação entre um sistema combinatorial capaz de gerar estruturas planas e o sistema $\mathrm{F}$ pode corresponder às bases de um raciocínio simbólico. O estabelecimento de um mecanismo combinatorial binário e endocêntrico, capaz de promover encaixamento, é o que caracterizaria o surgimento da FL, conectando o sistema F, C-I, e, mais tardiamente, S-M. Um evento evolutivo que teria ocorrido, em princípio, somente no H. sapiens, há 175.000-200.000 anos.
} 
Se a caracterização acima for adequada para se distinguir raciocínio simbólico de linguagem, então podemos conjecturar que uma eventual divergência entre os neandertais e os humanos modernos tenha sido a reorganização do funcionamento desse sistema combinatorial herdado do $H$. heidelbergensis . Presumivelmente, essa reorganização teria ocorrido em uma pequena população de caçadores-coletores subsaarianos da linhagem $H$. sapiens, por volta de 175.000-200.000 anos atrás, dando origem à operação Merge e, simultaneamente à FL, como descrita na Figura 7. De novo, salientamos que ainda é necessário um maior entendimento de qual é a diferença entre raciocínio simbólico e uma FL, para, então, começarmos a estabelecer possíveis divergências e semelhanças entre as habilidades simbólicas dos neandertais e dos humanos modernos. Acreditamos que a sugestão elaborada nesta seção pode nos servir como um primeiro caminho para se chegar a um maior entendimento sobre esses descompassos.

Resumimos, no Quadro 5, abaixo, a sequência de eventos evolutivos destacados nesta seção. Esse conjunto de eventos representa nossas conjecturas principais acerca das etapas para o surgimento de uma FL nos humanos modernos. A maioria das informações reunidas foram retiradas de Tattersall (2012, p. 35-38). 
Quadro 5. Principais eventos evolutivos envolvidos na emergência da FL.

\begin{tabular}{ll}
\hline Eventos & Datas em anos atrás \\
\hline Primeiros hominínios bípedes na África & $6-7.000 .000$ \\
Primeiras ferramentas líticas & $3.3-3.4 .000 .000$ \\
Primeiros fósseis atribuídos ao gênero Homo & $2-2.5 .000 .000$ \\
Início da segunda indústria lítica & $1.5-1.8 .000 .000$ \\
Aparecimento do H. heidelbergensis e possível & 600.000 \\
emergência das bases para raciocínio simbólico & \\
Primeiras evidências da linhagem neandertal na Europa & $\sim 530.000$ \\
Primeiras evidências do H. sapiens na África e & $175-200.000$ \\
possível emergência da FL & \\
Primeira cisão populacional da linhagem sapiens & $121-128.000$ \\
Conchas perfuradas para ornamentação corporal & $\sim 115.000$ \\
em populações neandertais e sapiens & \\
Inscrições em placas de ocre no sul da África & $80-100.000$ \\
Primeiras pinturas rupestres na Europa & $\sim 64.800$ \\
Início do êxodo do H. sapiens para fora da África & 60.000 \\
Primeiros humanos modernos na Europa & $40.000-30.000$ \\
Extinção dos neandertais & $\sim 30.000$ \\
\hline
\end{tabular}

Após essa caracterização da localização espacial e temporal da FL, bem como dos impasses evolutivos envolvendo seu surgimento na espécie humana, discutimos, na próxima seção, contrastes entre a AI e outras duas abordagens.

\subsection{Contrastes}

Um primeiro contraste que gostaríamos de explorar brevemente são as propriedades combinatoriais observadas no sistema de vocalizações de alarme dos macacos de Campbell (Cercopithecus campbelli). Ouattara, Lemasson e Zuberbühler (2009a, 2009b) e Ouattara et al. (2009), ao investigar o sistema de vocalizações desses macacos, notaram padrões que se assemelham a um caso de "morfologia derivacional". Verifica-se, basicamente, três vocalizações independentes nesse sistema: (i) boom, produzida em um contexto não predatório, (ii) hok, uma vocalização para águias e (iii) krak, uma vocalização para leopardos. 
Adicionalmente a essas três vocalizações, os macacos de Campbell apresentam um segmento "sufixal" -oo que se "concatena" às vocalizações hok e krak. De acordo com os autores, a presença desse segmento amplia o significado denotado pela vocalização que serve como base, transformando, por exemplo, a vocalização para águia, hok, em um alerta aéreo, hok-oo, como em (94d), e a vocalização para leopardos, krak, em um alerta geral, como em (94e).

(94) Vocalização de alarme dos macacos de Campbell na floresta Tai (SCHLENKER et al., 2016, p. 22)
a. boom boom: 'situação não predatória'
b. hok: 'águia'
c. krak: 'leopardo'
d. hok-oo: 'alerta aéreo'
e. krak-oo: 'alerta geral'

O exemplo em (94e), krak-oo, serve como uma vocalização menos marcada, ou seja, um "elsewhere". Isso se deve ao fato de que ele pode ser produzido em contextos em que há uma águia, um leopardo, um encontro entre grupos e para indicar uma árvore caindo. Ainda, Schlenker et al. (2014), ao analisarem as propriedades das vocalizações desses macacos em duas regiões distintas, na floresta Tai, Costa do Marfim, descrita em (94), e na ilha Tiwai, em Serra Leoa, verificaram um caso de variação dialetal. Em Tai, por exemplo, os macacos de Campbell têm como predadores leopardos e águias. Em Tiwai, por outro lado, leopardos não são encontrados há muitas décadas. Nesse segundo contexto, a vocalização krak, associada a leopardos, passou a caracterizar um alerta geral, como se nota em (95).

(95) Vocalizações de alarme dos macacos Campbell em Tiwai (SCHLENKER et al., 2016:22)
a. boom boom: 'situação não predatória'
b. hok: 'águia'
c. krak: 'alerta geral'
d. hok-oo: 'alerta aéreo'
e. krak-oo: 'alerta geral'

Percebemos, nessas duas situações — da concatenação de segmentos e da genericidade de uma vocalização - que temos um descompasso entre forma e conteúdo. Superficialmente, 
esse descompasso parece contradizer a assunção colocada pela AI, vista no Capítulo 3, de que as categorias referenciais de primatas não humanos apresentam uma relação coextensiva com uma entidade ou evento no mundo e, dessa forma, não deveriam recuperar outros referentes. O que nós argumentamos, com relação a esses casos, é que nos contextos em que a relação entre forma e conteúdo não segue um ideal um-para-um (i.e., 1 vocalização $=1$ conteúdo), o que temos é uma subespecificação da forma (i.e., da vocalização) para se adequar a mais de uma categoria referencial rígida do sistema F. Não seria o caso de que as representações em F estariam sendo subespecificadas em conteúdo. Um argumento em favor dessa proposta reside no fato de que primatas não humanos não são dotados com um mecanismo de aprendizagem vocal, como discutimos na subseção 3.4.1. Essa restrição poderia fazer com que as instruções acústicas inatas e restritas de suas vocalizações fossem subespecificadas a fim de servir como expoentes de mais de uma das células de seu sistema F.

Dessa maneira, todo desvio com relação ao ideal um-para-um (i.e., 1 vocalização $=1$ conteúdo) deve estar associado a uma subespecificação da forma (i.e., da vocalização) para se adequar a mais de um contexto de uso. Comparativamente, esses descompassos entre forma e conteúdo são fenômenos de superfície semelhantes àqueles verificados na linguagem humana, como alomorfia contextual e sincretismo. Ainda, dado que as células do sistema F apresentam um conteúdo rígido, qualquer eventual combinação entre células deveria resultar em uma vocalização cujo conteúdo fosse a soma das partes concatenadas. Entretanto, o que nós vemos nos contextos em que há a adição do segmento -oo é a formação de uma vocalização cujo conteúdo é sugestivamente idiossincrático. Por esse motivo, nós sugerimos que os aparentes aspectos combinatoriais atestados no sistema de vocalização dos macacos de Campbell são, a princípio, efeitos de homofonia, em que o suposto segmento -oo corresponde à parte de uma vocalização independente, homófona parcialmente às vocalizações hok e krak.

Seguindo o raciocínio descrito no Capítulo 3, argumentamos que as células do sistema F dos macacos de Campbell, passíveis de serem externalizadas através das vocalizações em (94) e (95), são:

(96) Conjunto de células do sistema F de macacos de Campbell

a. $<$ ALERTA $_{\text {Campbell, }}, x>=$ associadas às vocalizações que sinalizam um alerta geral

b. $\left\langle\operatorname{VOAR}_{\text {Campbell }}, x>=\right.$ associadas às vocalizações para um ataque predatório aéreo

c. $<$ CAMINHAR $_{\text {Campbell }}, x>=$ associadas às vocalizações para um ataque terrestre 
No caso das vocalizações dos macacos de Campbell da Floresta Tai, temos um caso de alomorfia contextual. Uma mesma célula em F pode estar associada a mais de uma forma, ou seja, de uma vocalização, a depender da situação predatória $(s)$. Por exemplo, as vocalizações boom e krakoo correspondem a um alerta geral e, portanto, estariam associadas à célula $<$ ALERTA $_{\text {Campbell }}, x>$. Entretanto, a realização da célula $<$ ALERTA $_{\text {Campbell }}, x>$ como boom ou krakoo é determinada pela situação: se predatória ou não. O mesmo se verifica no caso da produção das vocalizações hok e hokoo, já que a produção de hok exige em seu contexto um valor determinado (viz., $x$ valorado como "águia"). Fatos paralelos a esses são encontrados nos casos de alomorfia contextual da linguagem humana, em que mais de uma forma realiza um mesmo conteúdo, tal como a morfologia de passado irregular do inglês, cujos expoentes para o traço $<$ PASS $>$ podem ser $/_{\pi} \mathrm{t} /, /_{\pi} \varnothing / \mathrm{e} / /_{\pi}$ ed/, como vimos no exemplo (87), do Capítulo 4.

Em (97), apresentamos um conjunto de instruções hipotéticas associadas à distribuição das vocalizações de alerta dos macacos de Campbell em Tai. Ao lado esquerdo da regra, estão os expoentes que materializam as vocalizações, enquanto ao lado direito, estão seus contextos de inserção. Essas instruções foram inspiradas nas instruções de PF da linguagem humana, apenas com o objetivo de formalizar nossa explicação.

(97) Instruções fonológicas de um macaco de Campbell adulto em Tai
a. $/$ boom $+/ \quad \leftarrow<$ ALERTA $_{\text {Campbell, }} x>/ x$ não é um predador em $s$.
b. /hok/ $\quad \leftarrow<\operatorname{VOAR}_{\text {Campbell, }} x>/ x$ é uma águia em $s$.
c. /hokoo/ $\leftarrow \rightarrow<\operatorname{VOAR}_{\text {Campbell, }} x>$
d. $/ \mathrm{krak} / \quad \leftarrow<$ CAMINHAR $_{\text {Campbell }}, x>/ x$ é um leopardo em $s$.
e. $/$ krakoo/ $\leftarrow \rightarrow<$ ALERTA $_{\text {Campbell, }} x>$

Para os casos de variação dialetal associados à vocalização krak em Tiwai, admitimos que essa vocalização servia, anteriormente, como expoente para a célula $<$ CAMINHAR $_{\text {Campbell, }}$, $x>\mathrm{e}$, após a extinção dos leopardos na região, essa vocalização passou a se vincular à célula $<$ ALERTA $_{\text {Campbell, }} x>$. Percebam que o que está em jogo é a redistribuição da forma, que deixou de se associar a um conteúdo por razões sócio-ecológicas. Não haveria, como sugerem Schelenker et al. (2016), através de uma formalização distinta, uma alteração no conteúdo da célula $<$ CAMINHAR $_{\text {Campbell, }} x>$ em F, que, porventura, pudesse sugerir uma subespecificação ou empobrecimento a ponto de chegar à se tornar a célula $<$ ALERTA $_{\text {Campbell }}, x>$. Dessa forma, nós sugerimos que as instruções fonológicas de um macaco de Campbell adulto em Tiwai são aquelas em (98). A distribuição de krak e krakoo é, a princípio, um caso de variação livre. 
(98) Instruções fonológicas de um macaco Campbell adulto em Tiwai
a. /boom $+/ \quad \leftarrow<$ ALERTA $_{\text {Campbell, }} x>/ x$ não é um predador em $s$
b. /hok/ $\quad \leftarrow<\operatorname{VOAR}_{\text {Campbell, }} x>/ x$ é uma águia em $s$.
c. /hokoo/ $\quad \leftrightarrow<$ VOAR $_{\text {Campbell, }} x>$
d. $/ \mathrm{krak} / \quad \leftarrow<$ ALERTA $_{\text {Campbell }}, x>$
e. $/ \mathrm{krakoo} / \quad \leftarrow<$ ALERTA $_{\text {Campbell, }}, x>$

Um segundo contraste que gostaríamos de estabelecer é com relação à assunção de que traços formais heterogêneos não existem, tal como sugere Boeckx (2015). Para minimizar a influência do léxico no funcionamento sintático, o autor propõe que a FL contém um léxico homogêneo, composto apenas por traços de borda. A justificativa é a seguinte: uma vez que as unidades manipuladas pela sintaxe devem ser combináveis, elas deveriam conter somente uma única propriedade, a capacidade de se concatenar. É por essa razão que o traço de borda seria, hipoteticamente, a única propriedade dos itens lexicais relevante para a sintaxe. Assim, todo item lexical é, de acordo com Boeckx, idêntico um ao outro, e suas diferenças são determinadas através de um sistema de fases e do modo como os traços de borda são enviados para as interfaces com os sistemas externos.

Boeckx (2015) assume que Merge produz apenas conjuntos simétricos. As assimetrias estruturais, geralmente atreladas à rotulação nos modelos gerativos canônicos, são derivadas, em seu modelo, através de um sistema de fases que opera com o intuito de eliminar simetrias na sintaxe. A transferência cíclica de uma estrutura sintática gera pontos de assimetria, os quais permitem, em princípio, que os sistemas externos possam atribuir a esses itens lexicais homogêneos um conteúdo e uma forma. O raciocínio pode ser descrito do seguinte modo: ao se combinarem dois traços de borda em uma derivação, $\alpha$ e $\beta$, uma fronteira de fases deve ser estabelecida, a fim de possibilitar que esses dois elementos obtenham uma identidade, já que ambos são idênticos. Nesse momento, há transferência parcial do OS que eles formam para as interfaces — por exemplo, de $\beta$ - e, epifenomenalmente, $\beta$, o elemento enviado, passa a ser interpretado como o complemento e $\alpha$ passa a ser interpretado como o núcleo do OS ainda sendo derivado.

Admitindo que os sistemas externos exigem, pelo menos, uma especificação categorial mínima, um rótulo é atribuído ao item lexical que foi transferido. Seguindo a distinção entre nomes e não nomes, proposta por Kayne (2011), o autor argumenta que as fases contendo um complemento intransitivo, tal como é o caso do Spell-Out de $\beta$, da combinação $\{\alpha, \beta\}$, serão 
interpretadas como uma raiz nominal (i.e., $\sqrt{ } \mathrm{N}$ ). Paralelamente, $\alpha$ será interpretado como um categorizador nominal, assim que for enviado para as interfaces. Desse modo, todo singleton -i.e., todo conjunto constituído por um único elemento- é lido pelas interfaces como um nome. Como resultado, ao inserir uma fronteira de fase entre os traços de borda $\alpha$ e $\beta$, em $\{\alpha$, $\beta\}$, ambos adquirem uma identidade: $\beta$ permite a atribuição de uma identidade a $\alpha$, e $\alpha$, por ter permanecido na sintaxe, atribui uma identidade a $\beta$. $\beta$ será interpretado, como dissemos, como uma raiz nominal $\sqrt{ } \mathrm{N}$.

Em seguida, um terceiro item lexical, diga-se $\gamma$, é concatenado a $\alpha$. Uma vez que $\alpha$ já tem identidade (i.e., um rótulo), em virtude de ter sido rotulado por $\beta$ após seu Spell-Out, $\alpha$ pode figurar como distinto (derivacionalmente) de $\gamma$, mesmo na ausência de uma fronteira de fases entre eles. A derivação, então, prossegue e um terceiro item lexical é concatenado, $\delta$, produzindo $\{\delta, \gamma, \alpha\}$. Nesse ponto da derivação, uma fronteira de fase deve ser inserida entre $\delta$ e $\gamma$, já que há dois elementos idênticos em uma posição contígua, gerando um ponto de simetria. Assim, o estabelecimento de uma fronteira de fase entre $\delta$ e $\gamma$ assegura que a derivação continue. Tomando $\delta$ como um núcleo de fase, o resto da unidade (i.e., $\{\gamma, \alpha\}$ ) será interpretado como seu complemento. Já que $\alpha$ já tem identidade, $\gamma$ será rotulado por $\delta$ e $\delta$ recebe sua identidade como sendo o rótulo do conjunto $\{\gamma, \alpha\}$. Nesse contexto, em que há uma fase transitiva, $\delta$ é responsável por rotular um conjunto com dois membros, $\{\gamma, \alpha\}$, e por meio dessa rotulação acaba recebendo uma identidade. Complementos de fase transitivos, como é o caso de $\{\gamma, \alpha\}$, são lidos pelas interfaces como não verbos, tais como os verbos e as preposições (e.g., $\gamma$ seria materializado, pós-sintaticamente, como uma raiz verbal $\sqrt{ } \mathrm{V}$, e $\delta$ como um categorizador verbal $v$ ).

Embora esse sistema funcione para estruturas sintáticas com nomes e verbos simples, ele deixa de explicar a morfologia derivacional. Se nomes somente são formados por meio de um complemento de fase intransitivo, então, não seria possível explicar a formação de nomes complexos que contêm diferentes morfemas derivacionais não transposicionais, como míssil antiantiantimíssil, em que vemos uma longa sequência de cadeias nominais. Essas formações não são previstas pela proposta de Boeckx (2015). Ainda, de que modo os sistemas externos assegurariam as diferenças de conteúdo verificadas nos morfemas derivacionais, em especial, nos morfemas não transposicionais, que, como apontamos, somente agregam um conteúdo específico à estrutura, sem interferir em questões de rotulação. Em nossa perspectiva, apesar de Boeckx elaborar um modelo altamente simples para se esclarecer a relação entre o léxico e a sintaxe, a eliminação de traços formais heterogêneos impede que certos processos de formação de palavras sejam abarcados. Ainda, a ausência de um conteúdo predeterminado nos 
itens concatenados pela sintaxe, torna a derivação de uma sentença altamente dependente das interfaces. $\mathrm{O}$ autor também não nos fornece um modo de limitar o papel das interfaces e de determinar como os diferentes valores de um mesmo traço formal serão definidos através dessas duas formas de Spell-Out.

Por essa razão, acreditamos que a manutenção de traços formais heterogêneos seja explicativamente mais adequada do que uma hipótese em que a sintaxe manipula apenas itens homogêneos. Com a AI, nós somos capazes de garantir não apenas uma explicação para as diferentes formas que a morfologia derivacional pode tomar — dados que são normalmente negligenciados por sintaticistas-, como também asseguramos, de igual modo, a satisfação do critério de adequação evolutiva, já que não sobrecarregamos de forma alguma a GU em nossa explicação para o surgimento do léxico, apesar de admitir traços formais heterogêneos. Além disso, pela AI, nós somos capazes de estabelecer objetivamente as diferenças envolvendo os diferentes precursores filogenéticos do léxico humano, em particular, do léxico funcional e do léxico conceitual, os quais acabam sendo uniformizados pela abordagem de Boeckx. Uniformizá-los não é uma estratégia interessantes, tendo em vista as evidentes diferenças formais que eles apresentam, tal como destacamos no Capítulo 3.

Após essas dois contrastes, passamos, finalmente, para a apresentação das conclusões e considerações finais desta tese.

\subsection{Conclusões}

Nesta tese, buscamos fornecer uma explicação para o surgimento do léxico humano capaz de ser, ao mesmo tempo, adequada para a explicação dos fenômenos linguísticos e condizente com o desenvolvimento recente da FL. Avaliamos a interação entre o léxico e a sintaxe, com o objetivo de filtrar as propriedades elementares de cada um desses módulos, para, então, determinar quais seriam suas bases biológicas e de que maneira eles poderiam ter sido integrados durante a evolução humana. Partimos da premissa de que traços formais são dispositivos fundamentais para a explicação dos fatos linguísticos, mas que sua postulação deve ser bem fundamentada de um ponto de vista biológico. Argumentamos, ainda, que há uma ligação estreita entre as propriedades do léxico funcional humano com a natureza das representações subjacentes aos sistemas de vocalização de alerta de animais não humanos, em particular, de primatas não humanos. Dessa correlação, inferimos os precursores filogenéticos dos traços formais. 
Essa assunção nos é essencial, pois, em nossa perspectiva, as especificidades do léxico funcional, bem como a universalidade de seus domínios, são sugestivamente um produto do modo como a espécie humana é capaz de perceber e de categorizar certos aspectos do mundo. Embora seja possível observar categorias funcionais distintas translinguisticamente, elas estão restritas a categorias mais amplas, presumivelmente universais, que não devem corresponder a uma predeterminação exclusiva ao genótipo humano, mas a um produto da seleção natural. Esse seu caráter inato deve ser um reflexo de pressões adaptativas que vieram se aplicando nas espécies hominínias ancestrais, chegando ao conjunto que encontramos nos humanos anatomicamente modernos hoje em dia. Admitimos que esse conjunto representa as categorias universais propostas pela HCU, de Wiltschko (2014, 2015). As categorias universais da HCU, ao mesmo tempo que nos auxiliam na explicação da genericidade das categorias universais, nos permitem limitar a postulação de novos traços formais.

Evidentemente, não abordamos certas discussões envolvendo o papel computacional dos traços formais na teoria sintática, as quais são caras para qualquer linguista interessado na explicação da linguagem humana. Entre essas discussões está a natureza dos movimentos de constituintes internamente à gramática. Há alternativas sendo propostas atualmente que visam atribuir às interfaces, especialmente com o sistema S-M, as motivações para movimentos sintáticos (Cf. RICHARDS, 2016; SUNDARESAN, 2016). Por necessidade de circunscrever os limites da tese, não tivemos a oportunidade de nos aprofundar e explorar uma explicação nos termos da AI. Esse mesmo apontamento deve ser estendido para as questões envolvendo a parametrização linguística. Esses são dois assuntos que temos o interesse de desenvolver nos próximos anos, a fim de atestar a validade da AI.

Um comentário deve ser feito com relação ao estabelecimento de um componente morfológico no caminho para a interface com o sistema S-M, que estaria a cargo da variação superficial entre as línguas. Em nosso entendimento, um componente morfológico, tal como vislumbrado pela MD, repleto de operações específicas, não seria biologicamente plausível, a não ser que essas operações fossem motivadas biologicamente. Certamente, seguindo os considerações elaboradas ao longo desta tese, as operações desse componente morfológico não devem corresponder a uma determinação da GU. Embora não tenhamos explorado questões de superficialização e de parametrização, como já apontamos, acreditamos que um componente morfológico menos oneroso, como o que vem sendo sugerido pela nanossintaxe (Cf. BYE; SVENONIUS, 2012; SVENONIUS, 2016), esteja mais alinhado aos critérios de adequação evolutiva. 
No que diz respeito a fases, seguimos Harley (2014), em sua proposta de que fases estão fundamentalmente associadas a um critério computacional. Desse modo, nos afastamos da assunção de que um mecanismo de Spell-Out cíclico esteja vinculado à determinação de domínios de interpretação, semântica e fonológica, como extensamente assumido pela MD (Cf. MARVIN, 2002, 2013; ARAD, 2003, 2005; EMBICK, 2010, 2015, entre outros). As instruções em LF e em PF, que compõem nossos Léxicos E e C, contam com contextos de inserção bem explícitos, os quais eliminam a necessidade de delimitá-los estruturalmente através de domínios cíclicos.

A despeito dessas ponderações, que, possivelmente, devem ter acompanhado alguns leitores, acreditamos que as propostas sugeridas nesta tese nos fornecem uma nova maneira de se interpretar a interface entre o léxico e a sintaxe, bem como o próprio funcionamento dos sistemas de comunicação animal, uma vez que rompe com um longa tradição da primatologia e da linguística teórica, notadamente: a de atrelar as vocalizações de alerta ao conteúdo conceitual das palavras. Esta tese também nos fornece ferramentas para identificar pontos de variação nos traços formais, que, em nosso entendimento, representam novas maneiras de se estabelecer as distinções entre morfemas funcionais flexionais e morfemas funcionais derivacionais, sejam eles transposicionais ou não.

Em conclusão, através de uma única equação, Merge + Interfaces, asseguramos a emergência paralela do repertório lexical e da sintaxe, bem como de sua articulação internamente à gramática. Reduzimos as incertezas com relação ao desenvolvimento do léxico e tornamos sua fixação coerente com o desenvolvimento da FL. Apontamos que, por meio de um evento evolutivo pontual — viz., a integração de sistemas pré-adaptados via Merge-, a espécie humana deu um grande salto evolutivo, ampliando enormemente seu poder expressivo através do surgimento da linguagem. 


\section{Referências bibliográficas}

ABELS, K. Successive cyclicity, Anti-locality, and Adposition stranding. 2003. Tese (Doutorado em Linguística) - Universidade de Connecticut, Storrs, 2003.

ABNEY, S. P. The English noun phrase in its sentential aspect. 1987. Tese (Doutorado em Linguística) - Massachusetts Institute of Technology, Cambridge, MA, 1987.

ACEDO-MATELLÁN, V.; REAL-PUIGDOLLERS, C. Inserting roots into (functional) nodes: Categories and cross-linguistic variation. Linguistic Analysis, v. 39, 2014, p. 125-168.

ACQUAVIVA, P. Roots and lexicality in Distributed Morphology. In: GALANI, A.; REDINGER, D.; YEO, N. (orgs.) York-Essex Morphology Meeting, v. 5, 2009a, p. 1-21.

The Roots of Nominality, the Nominality of Roots. Manuscrito. University College Dublin, 2009b. Disponível em: http:// ling.auf.net/lingbuzz/000824.

ACQUAVIVA, P.; PANAGIOTIDIS, P. Lexical decomposition meets conceptual atomism. Lingue e Linguaggio, v. 11, n. 2, 2012, p. 165-180.

ACKEMA, P.; NEELEMAN, A. Beyond morphology: Interface conditions on word formation. Oxford: Oxford University Press, 2004.

ADAMS, V. Complex words in English. Essex: Pearson Education, 2001.

ADGER, D. Core syntax: A Minimalist Approach. Oxford: Oxford University Press, 2003.

A minimalist theory of feature structure. In: KIBORT, A.; CORBETT, G. (org.) Features: Perspectives on a key notion in linguistics. Oxford: Oxford University Press, 2010, p. $185-218$.

The syntax of substance. Cambridge, MA: MIT Press, 2013.

ADGER, D.; SVENONIUS, P. Features in minimalist syntax. In: BOECKX, C. (org.) The Oxford handbook of linguistic minimalism. Oxford: Oxford University Press, 2011, p. $27-$ 51.

AIKHENVALD, A. Y. Classifiers: A typology of noun categorization devices. Oxford: Oxford University Press, 2000.

ALEXIADOU, A. Functional structure in nominals: Nominalization and ergativity. Amsterdam: John Benjamins, 2001. 
ALLEN, M. Morphological investigations. 1978. Tese (Doutorado em Linguística) Universidade de Connecticut, Storrs, 1978.

AL-MUTAIRI, F. R. The Minimalist Program: The nature and plausibility of Chomsky's biolinguistics. Cambridge: Cambridge University Press, 2014.

AMBROSE, S. H. Late Pleistocene human population bottlenecks, volcanic winter, and differentiation of modern humans. Journal of Human Evolution, v. 34, 1998, p 623-651.

ARAD, M. Locality constraints on the interpretation of roots: The case of Hebrew denominal verbs. Natural Language and Linguistic Theory, v. 21, 2003, p. 737-778

Roots and Patterns: Hebrew Morpho-syntax. Studies in Natural Language and Linguistic Theory. Amsterdam: Sprinter, 2005.

ARBIB, M. A. How the brain got language: The mirror system hypothesis. Oxford: Oxford University Press, 2012.

ARMELIN, P. R. G. A. A relação entre gênero e morfologia avaliativa nos nominais do português brasileiro: Uma abordagem sintática da formação de palavras. 2015. Tese (Doutorado em Linguística) - Universidade de São Paulo, São Paulo, 2015.

ARNOLD, K.; ZUBERBÜHLER, K. The alarm calling system of adult male putty-nosed monkey Cercopithecus nictitans martini. Animal Behavior, v. 72, 2006a, p. 643-653.

. Semantic combinations in primate calls. Nature, v. 441, 2006b, p. 303.

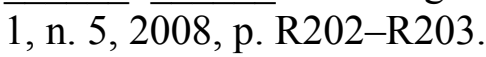

Meaningful call combinations in a non-human primate. Current Biology, v.

. Call combinations in monkeys: Compositional or idiomatic expressions?

Brain and Language, v. 120, n. 3, 2012, p. 303-309.

Female putty-nosed monkeys use experimentally altered contextual

information to disambiguate the cause of male alarm calls. PLoS One, v. 8, n. 6, 2013.

ARONOFF, M. Word-formation in Generative Grammar. Cambridge, MA: MIT Press, 1976.

BACH, E. Nouns and noun phrases. In: BACH, E.; HARMS, R. T. (orgs.) Universals in linguistic theory. Nova York: Holt, Rinehart and Winston, 1968, p. 90-122.

BAKER, M. The mirror principle and morphosyntactic explanation. Linguistic Inquiry, v. 16, n. 3, 1985, p. 373-415.

The macroparameter in a microparametric world. In: BIBERAUER, T. (org.) The limits of syntactic variation. Amsterdam: John Benjamins. 2008, p. 351-373. 
BASÍLIO, M. Formação e classes de palavras no Português do Brasil. São Paulo: Contexto, 2004.

BEARD, R. Lexeme-Morpheme Base Morphology: A general the inflection and word formation. Alban: SUNY Press, 1995.

BEHAR, D. M.; VILLEMS, R.; SOODYALL, H.; BLUE-SMITH, J.; PEREIRA, L.; METSPALU, E. et al. The dawn of human matrilineal diversity. American Journal of Human Genetics, v. 82, n. 5, 2008, p. 1130-1140.

BELLETTI, A. (org) Structures and beyond. The cartography of syntactic structures, Vol. 3. Oxford: Oxford University Press, 2004.

BENTON, M. J. Phylogeny of the major tetrapod groups - morphological data and divergence dates. Journal of Molecular Evolution, v. 30, 1990, p. 409-424.

BERWICK, R. Syntax facit saltum redux: Biolinguistics and the leap to syntax. In: DI SCIULLO, A-M.; BOECKX, C. (orgs.) The biolinguistic enterprise: New perspectives on the evolution and nature of human language faculty. Oxford: Oxford University Press, 2011a, p. 65-99.

All you need is Merge: Biology, computation and language from the bottom-up. In: DI SCIULLO, A-M.; BOECKX, C. (orgs.) The biolinguistic enterprise: New perspectives on the evolution and nature of human language faculty. Oxford: Oxford University Press, 2011b, p. 461-491.

A feeling for the phenotype. In: MCGILVRAY, J. (org.) The Cambridge companion to Chomsky. Cambridge: Cambridge University Press, 2017, p. 87-109.

BERWICK, R. C.; BECKERS, G. J. L.; OKANOYA, K.; BOLHUIS, J. J. A bird's eye view of human language evolution. Frontiers in Evolutionary Neuroscience, v. 4, n. 5, 2012.

BERWICK, R. C.; CHOMSKY, N. The biolinguistic program: the current state of its development. In: DI SCIULLO, A-M.; BOECKX, C. (orgs.) The biolinguistic enterprise: New perspectives on the evolution and nature of human language faculty. Oxford: Oxford University Press, 2011, p. 19-41.

Why only us: Language and evolution. Cambridge, MA: MIT Press, 2016.

BERWICK, R. C.; OKANOYA, K.; BECKERS, G. J. L.; BOLHUIS, J. J. Songs to syntax: the linguistics of birdsongs. Trends in Cognitive Science. v. 15, 2011, p. 113-121.

BIBERAUER, T. Emergent features: A minimalist perspective. Annual Meeting of the Societas Linguistica Europaea, SLE 49. Manuscrito. 2016.

BIBERAUER, T.; ROBERTS, I. Rethinking formal hierarchies: A proposed unification. Cambridge Occasional Papers in Linguistics, v. 7, 2015, p. 1-31.

BICKERTON, D. Species and language. Chicago: The Chicago University Press, 1990. 
. Language and human behavior. Londres: University College London Press, 1995.

. Language evolution: A brief guide for linguists. Lingua, v. 117, 2007, p. 510-526.

. Catastrophic evolution: the case for a single step from protolanguage to full human language. In: HURFORD, J. R.; KENNEDY, M. S.; KNIGHT, C. (orgs.) Approaches to the evolution of language: Social and cognitive bases. Cambridge: Cambridge University Press, 1998, p. 341-358.

How protolanguage became language. In: KNIGHT, C.; STUDDERT-KENNEDY, M.; HURFORD, J. R. (orgs.) The evolutionary emergence of language: Social function and the origins of linguistic form. Cambridge: Cambridge University Press, 2000, p. 264-284.

. Adam's tongue: How humans made language, how language made humans. Nova York: Hill and Wang, 2009.

. More than nature needs: Language, mind and evolution. Cambridge, MA: Harvard University Press, 2014.

BLOOM, P. How children learn the meanings of words. Cambridge, MA: MIT Press, 2000.

BOBALJIK, J. D. Where's Phi? Agreement as a post-syntactic operation. In: HARBOUR, D.; ADGER, D.; BÉJAR, S. (orgs.) Phi Theory. Oxford: Oxford University Press, 2008, p. 295328.

BOECKX, C. Linguistic Minimalism: Origins, Concepts, Methods, and Aims. Oxford University Press, 2006.

Bare syntax. Oxford: Oxford University Press, 2008.

. The nature of Merge: Consequences for language, mind, and biology. In: PIATTELLI-PALMARINI, M.; URIAGEREKA, J.; SALABURU, P. (orgs.) On minds and language: A dialogue with Noam Chomsky in the Basque Country. Oxford: Oxford University Press, 2009, p. 44-57.

Defeating lexicocentrism. Ms., ICREA/Universitat Autònoma de Barcelona, 2010. Disponível em: http://ling.auf.net/lingbuzz/001130.

Press, 2011a.

(org.) The Oxford handbook of linguistic minimalism. Oxford: Oxford University

The emergence of the language faculty from a biolinguistic point of view. In: TALLERMAN, M.; GIBSON, K. (orgs.) The Oxford handbook of language evolution. Oxford: Oxford University Press, 2011b, p. 492-501.

Some reflections on Darwin's problem in the context of Cartesian biolinguistics. In: DI SCIULlO, A-M.; BOECKX, C. (orgs.) The biolinguistic enterprise: New perspectives on the evolution and nature of human language faculty. Oxford: Oxford University Press, 2011c, p. 42-64. 
. The I-language mosaic. In: BOECKX, C.; HORNO-CHÉLIZ, M. C.; MEDÍVILGIRÓ, J. L. (orgs.), Language, from a biological perspective. Cambridge: Cambridge Scholars Publishing, 2012, p. 23-51.

. Biolinguistics: Forays into human cognitive biology. Journal of Anthropological Sciences, v. 91, 2013a, p. 63-89. 484.

Merge: Biolinguistic considerations. English linguistics, v. 30, n. 2, 2013b, p. 463-

Elementary syntactic structures: Prospects of a feature-free syntax. Cambridge: Cambridge University Press, 2015.

BOECKX, C.; URIAGEREKA, J. Minimalism. In: RAMCHAND, G.; REISS, C. (orgs.) The Oxford handbook of linguistic interfaces. Oxford: Oxford University Press, 2007, p. 541573.

BOLHUIS, J. J.; OKANOYA, K.; SCHARFF, C. Twitter evolution: Converging mechanisms in birdsong and human speech. Nature Reviews Neuroscience, v. 11, n. 11, 2010, p. 747759.

BOLHUIS, J. J.; TATTERSALL, I.; CHOMSKY, N.; BERWICK, R. How could language have evolved? PLOS Biology, v. 12, n. 8, 2014, e1001934.

BORER, H. Parametric syntax. Dordrecht: Foris, 1984.

Anaphoric AGR. In: JAEGGLI, O.; SAFIR, K. (orgs.) The Null Subject Parameter. Dordrecht: Kluver, 1989, p. 69-109.

. Deconstructing the Construct. In: JOHNSON, K.; ROBERTS, I. (orgs.) Beyond Principles and Parameters. Dordrecht: Kluwer, 1991, p. 43-90.

Exo-skeletal vs. Endo-skeletal explanations: syntactic projections and the lexicon. In: MOORE, J.; POLINSKY, M. (orgs.) The nature of explanation in linguistic theory. Chicago: University of Chicago Press (CSLI), 2003, p. 31-67.

. In name only: Structuring sense, Vol. I. Oxford: Oxford University Press, 2005a.

Press, 2005b.

The normal course of events: Structuring sense, Vol. II. Oxford: Oxford University

. Taking form. Structuring sense. Volume III. Oxford: Oxford University Press, 2013.

. Wherefore roots? Theoretical Linguistics, v. 40, n. 3/4, 2014a, p. 343-359.

The category of roots. In: ALEXIADOU, A.; BORER, H.; SCHÄFER, F. (orgs.) The syntax of roots and the roots of syntax. Oxford: Oxford University Press, 2014b, p. 112-148. 
BOUZZOUGAR, A.; BARTON, N.; VANHAEREN, M.; D'ERRICO, F.; COLLCUTT, S.; HIGHAM, T. et al. 82,000-year-old shell beads from North Africa and implications for the origins of modern human behavior. Procedings of the National Academy of Sciences of the United States of America (PNAS), v. 104, 2007, pp. 9964-9969.

BRAME, M. The general theory of binding and fusion. Linguistic Analysis, v. 7, 1981, p. 277-325.

BRESNAN, J.; ASUDEH, A.; TOIVONEN, I.; WECHSLER, S. Lexical-Functional Syntax. Malden: Wiley Blackwell, 2016.

BURGE, T. Origins of objectivity. Oxford: Oxford University Press, 2010.

BURZIO, L. Italian syntax. Dordrecht: Reidel, 1986.

BUSS, D. M.; HASELTON, M. G.; SHACKELFORD, T. K.; BLESKE, A. L.; WAKEFIELD, J. C. Adaptations, exaptations, and spandrels. American Psychologist, v. 53, n. 5,1998, p. 533-548.

BYE, P.; SVENONIUS, P. Non-concatenative morphology as epiphenomenon. In: TROMMER, J. (org.) The morphology and phonology of exponence. Oxford: Oxford University Press, 2012, pp. 427-495.

CAHA, P. The nanosyntax of case. 2009. Tese (Doutorado em Linguística) - Universitetet i Tromsø, Tromsø, 2009.

CAREY, S. Do constraints on word meanings reflect prelinguistic cognitive architecture? The Japanese Journal of Cognitive Science, v. 4, 1997, p. 35-58.

. The origin of concepts. Oxford: Oxford University Press, 2009.

CARRUTHERS, P. The architecture of the mind. Oxford: Oxford University Press, 2006.

CÄSAR, C.; ZUBERBÜHLER, K. Referential alarm calling behaviour in New World primates. Current Zoology, v. 58, 2012, p. 680-697.

CHENEY, D. L; SEYFARTH, R. M. Selective forces affecting the predator alarm calls of vervet monkeys. Behaviour, v. 76, n. 1/2, 1981, p. 25-61.

Social and non-social knowledge in vervet monkeys. Philosophical Transactions of the Royal Society of London B, v. 308, 1985a, p. 187-201.

Vervet monkey alarm calls: manipulation through shared information? Behaviour, v. 94, 1985b, p. 150-66.

. Assessment of meaning and the detection of unreliable signals by vervet monkeys. Animal Behaviour, v. 36, 1988, p. 477-486.

How monkeys see the world: Inside the mind of another species. Chicago: The University of Chicago Press, 1990a. 
Attending to behaviour versus attending to knowledge: Examining monkey's attribution of mental states. Animal Behaviour, v. 40, 1990b, p. 747-753.

. Why animals don't have language. The Tanner Lectures of Human Values, v. 19, 1997, p. 173-210.

Constraints and pre-adaptations in the earliest stages of language evolution. The Linguistic Review, v. 22, 2005, p. 135-159.

- Baboon metaphysics: The evolution of a social mind. Chicago: The University of Chicago Press, 2007.

CHIERCHIA, G.; MCCONNELL-GINET, S. Meaning and grammar: An introduction to semantics. Cambridge, MA: MIT Press, 1990.

CHOMSKY, N. Aspects of the theory of syntax. Cambridge, MA: MIT Press, 1965.

Cartesian linguistics: A chapter in the history of rationalist thought. Nova York: Harper \& Row, 1966.

. Language and mind. Nova York: Harcourt Brace and World, Inc., 1968.

. Remarks on nominalization. In: JACOBS, R.; ROSENBAUM, P. (orgs.) Readings in English Tranformational Grammar. Waltham, MA: Ginn and Company, 1970, p. 184221.

. The Case Against B. F. Skinner. The New York Review of Books, 1971.

. Reflections on language. Nova York: Pantheon, 1975.

. Rules and representations. Nova York: Columbia University Press, 1980a.

. On cognitive structures and their development: a reply to Piaget. In: PIATTELLIPALMARINI, M. (org.) Language and learning: The debate between Jean Piaget and Noam Chomsky. Nova York: Routledge, 1980b, p. 35-52.

. Lectures on Government and Binding. Dordrecht: Foris, 1981.

. Knowledge of language. Nova York: Praeger, 1986.

MIT Press, 1988.

A minimalist program for linguistic theory. In: HALE, K.; KEYSER, S. J. (orgs.) The view from Building 20: Essays in linguistics in honor of Sylvain Bromberger. Cambridge, MA: MIT Press, 1993, p. 1-52. 
- Bare phrase structure. In: MIT Occasional Papers in Linguistics 5, 1994 [Reimpresso em WEBELHUTH, G. (ed.) Government and Binding Theory and the Minimalist Program. Oxford: Blackwell, 1995, p. 383-439].

The Minimalist Program. Cambridge, MA: MIT Press, 1995.

Minimalist Inquiries: The framework. In: MARTIN, R.; MICHAELS, D.; URIAGEREKA, J. (orgs.) Step by step: Essays on minimalist syntax in honor of Howard Lasnik. Cambridge, MA: MIT Press, 2000, 89-155.

. Derivation by phase. In: KENSTOWICZ, M. (org.) Ken Hale: A life in language. Cambridge, MA: MIT Press, 2001, p. 1-52.

. On Nature and Language. Cambridge: Cambridge University Press, 2002.

. Beyond explanatory adequacy. In: BELLETTI, A. (org.) Structures and beyond: The cartography of syntactic structures. Oxford: Oxford University Press, 2004, p. 104-131.

. Three factors in language design. Linguistic Inquiry, v. 36, n. 1, 2005, p. 1-22.

. Approaching UG from below. In: SAUERLAND, U.; GÄRTNER, H-M. (orgs.) Interfaces + Recursion $=$ Language ? Berlin e Nova York: Mouton de Gruyter, 2007, p. 129.

. On phases. In: OTERO, C.; FREIDIN, R.; ZUBIZARRETA, M-L. (orgs.)

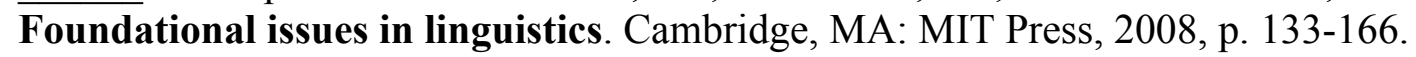

Some simple evo-devo theses: how true might they be for language? In: LARSON, Richard; DÉPREZ, V.; YAMAKIDO, H. (orgs.) The evolution of human language: Biolinguistic perspectives. Cambridge: Cambridge University Press, 2010a, p. 45-62.

Poverty of stimulus: unfinished business. Transcrição da conferência proferida na Johannes-Gutenberg University Mainz, 2010b. Disponível em: http://www.unimainz.de/presse/35914.php.

Language and other cognitive systems. What is special about language? Language Learning and Development, v. 7, n. 4, 2011, p. 263-278.

Problems of projection. Lingua, v. 130, 2013a, p. 33-49.

. Notes on denotation and denoting. In: CAPONIGRO, I.; CECCHETTO, Carlo. (orgs.) From grammar to meaning: The spontaneous logicality of language. Cambridge: Cambridge University Press, 2013b, p. 38-45.

. Problems of projection: Extensions. In: DI DOMENICO, E.; HAMANN, C.; MATTEINI, S. (orgs.) Structures, strategies and beyond: Studies in honor of Adriana Belletti. Amsterdam: John Benjamins, 2015, p. 1-16.

What kind of creatures are we? Nova York: Columbia University Press, 2016. 
. Language architecture and its import for evolution. Neuroscience and Behavioral Reviews, v. 81, 2017, p. 295-300.

CHOMSKY, N.; HALLE, M. The sound pattern of English. Nova York: Harper and How, 1968.

CINQUE, G. Adverbs and functional heads. Oxford: Oxford University Press, 1999.

. (org.) Functional structure in DP and IP. The cartography of syntactic structures, Vol. 1. Oxford: Oxford University Press, 2002.

Restructuring and functional heads. The cartography of syntactic structures, Vol. 4. Oxford: Oxford University Press, 2006. 2013, p. 50-65.

Cognition, universal grammar, and typological generalizations. Lingua, v. 130, A source of parametric variation in the lexicon. Linguistica, v. 56, n. 1, 2016, p. 8392.

CINQUE, G.; RIZZI, L. The cartography of syntactic structures. In CISCL Working Papers on Language and Cognition 2, 2008, p. 43-59.

. The cartography of syntactic structures. In: HEINE, B.; NARROG, H. (orgs.) The Oxford handbook of linguistic analysis. Oxford: Oxford University Press, 2010, p 5165 .

CLARK, B. Syntactic theory and the evolution of syntax. Biolinguistics, v. 7, 2013, p. 169197.

CLARK, E.; CLARK, H. When nouns surfaces as verbs. Language, v. 55, 1979, p. 767-811.

COLLINS, C. Local economy. Cambridge, MA: The MIT Press, 1997.

. Eliminating labels. In: EPSTEIN, S.; SEELY, D. T. (orgs.) Derivation and explanation in the Minimalist Program. Malden, MA: Blackwell, 2002, p. 42-64

. Merge $(X, Y)=\{X, Y\}$. In: BAUKE, L.; BLÜMEL, A. (orgs.) Labels and Roots. Berlim: De Mouton Gruyter, 2017, p. 47-68.

COMINS, J. A.; GENTNER, T. Q. Pattern-induced covert category learning in songbirds. Current Biology, v. 25, 2015, p. 1873-1877.

CRISMA, P.; MARTEN, L.; SYBESMA, R. The point of Bantu, Chinese, and Romance nominal classification. Rivista di Linguistica, v. 23, n. 2, 2011, p. 251-299.

CROCKFORD, C.; HERBINGER, I.; VIGILAND, L.; BOESCH, C. Wild chimpanzees have group-specific calls: A case for vocal learning? Ethology, v. 110, 2004, p. 221-243. 
CROCKFORD, C.; WITTIG, R. M.; MUNDRY, R.; ZUBERBÜHLER, K. Wild chimpanzees inform ignorant group members of danger. Current Biology, v. 22, 2012, p. 142-146.

CROFT, W. Radical Construction Grammar: Syntactic theory in typological perspective. Oxford: Oxford University Press, 2001.

DAMASIO, H.; TRANEL, D.; GRABOWSKI, T. J.; ADOLPHS, R.; DAMASIO, A. R. Neural systems behind word and concept retrieval. Cognition, v. 92, 2004, p. 179-229.

DARWIN, C. On the origins of species. Londres: John Murray, 1859.

The descent of man, and selection in relation to sex. Londres: John Murray, 1871.

The expression of the emotions in man and animals. Londres: John Murray, 1872.

DEACON, T. The symbolic species: The coevolution of language and the brain. Nova York, NY: W. W. Norton \& Co, 1997.

DEACON, H.; DEACON, J. Human beginnings in South Africa: Uncovering secrets of the Stone Age. Cape Town: David Philip, 1999.

DE BELDER, M. Roots and affixes: Eliminating lexical concepts from the syntax. 2011. Tese (Doutorado em Linguística) - Universidade de Utrecht, Utrecht, 2011.

DE BELDER, M.; VAN CRAENENBROECK, J. How to merge a root. Linguistic Inquiry, v. 46, n. 4, 2015, p. 625-655.

D'ERRICO, F.; HENSHILWOOD, C.; VANHAEREN, M.; van NIEKERK, K. Nassarius kraussianus Shell Beads from Blombos Cave: Evidence for Symbolic Behaviour in the Middle Stone Age. Journal of Human Evolution, v. 48, 2005, p. 3-24.

D'ERRICO, F; NOWELL, A. A new look at the Berekhat Ram figurine: implications for the origin of symbolism. Cambridge Anchaeological Journal, v. 10, n. 1, 2000, p. 23-167.

D'ERRICO, F.; VANHAEREN, M. Earliest personal ornaments and their significance for the origin of language debate. In: BOTHA, R.; KNIGHT, C. The cradle of language. Oxford: Oxford University Press, 2009, p. 16-40.

DI BITETTI, M. S. Food-associated calls of tufted capuchin monkeys (Cebus apella nigritus) are functionally referential signals. Behaviour, v. 140, 2003, p. 565-592.

DI SCIULLO, A-M. Asymmetry in morphology. Cambridge, MA: MIT Press, 2005.

DI SCIULLO, A-M.; WILLIAMS, E. On the definition of word. Cambridge, MA: MIT Press, 1987.

DIXON, R. M. W. Noun classifiers and noun classes. In: Where have the adjectives gone? And other essays on semantics and syntax. The Hague: Mouton, 1986, p. 211-233. 
. Noun classes and noun classification in typological perspective. In: CRAIG, C. G. (org.) Noun classification and categorization. Amsterdam: John Benjamins, 1986, p. 105112.

DEN DIKKEN, M. Introduction. In:

(org.) The Cambridge handbook of Generative syntax. Cambridge: Cambridge University Press, 2013, p. 3-25.

DOUGLAS, P. H.; MOSCOVICE, L. R. Pointing and pantomime in wild apes? Female bonobos use referential and iconic gestures to request genito-genital rubbing. Scientific Reports, v. 5, 2010, 13999.

DOUPE, A. J.; KUHL, P. K. Birdsong and human speech: common themes and mechanisms. Annual Review of Neuroscience, v. 22, 1999, p. 567-631.

DRYER, M. S. Are grammatical relations universal? In: BYBEE, J.; HAIMAN, J.; THOMPSON, S. (orgs.) Essays on language function and language type: Dedicated to $\mathrm{T}$. Givon. Amsterdam: John Benjamins, 1997, p. 115-143

ELOWSON, M.; SNOWDON, C. T. Pygmy marmosets, Cebuella pygmaea, modify vocal structure in response to changed social environment. Animal Behaviour, v. 47, 1994, p. $1267-1277$.

EMBICK, D. Features, syntax, and categories in the Latin perfect. Linguistic Inquiry, v. 31, n. 2, 2000, p. 185-230. $\overline{\text { Press, } 2010 .}$

Localism versus Globalism in morphology and phonology. Cambridge, MA: MIT The morpheme: A theoretical introduction. Berlim: De Gruyter Mouton, 2015.

EMBICK, D.; NOYER, R. Distributed Morphology and the syntax-morphology interface. In: RAMCHAND, G.; REISS, C. (orgs.) The Oxford handbook of linguistic interfaces. Oxford: Oxford University Press, 2007, p. 289-324.

EMONDS, J. A unified theory of syntactic categories. Dordrecht: Foris Publications, 1985.

From primate to human in two easy steps. In SAUL, N.; JAMES, S. (orgs.) The evolution of literature: Legacies of Darwin in European cultures. Rodopi: Amsterdam, 2011, p. 43-69.

ENGESSER, S.; CRANE, J. M. S.; SAVAGE, J. L.; RUSSELL, A. F.; TOWNSEND, S. W. Experimental evidence for phonemic contrasts in a nonhuman vocal system. PLOS Biology, v. 13, n. 6, 2015, e1002171.

EPSTEIN, S. D. Why nurture is natural too. Biolinguistics, v. 10, 2016, p. 197-201.

EPSTEIN, S. D; KITAHARA, K.; SEELY, T. D. Is the Faculty of Language a "perfect solution" to the interface systems? In: MCGILVRAY, J. (org.) The Cambridge companion to Chomsky. Cambridge: Cambridge University Press, 2017, p. 50-68. 
ERNST, T. The syntax of adjuncts. Cambridge: Cambridge University Press, 2002.

EVANS, C. S. Referential signals. In: OWINGS, D. H.; BEECHER, M. D.; THOMPSON, N. (orgs.) Communication: Perspectives in ecology. Nova York: Plenum Press, 1997, p. 99-143.

EVANS, C., MARLER, P. Language and animal communication: Parallels and contrasts. In: ROITBLAT, J. A. M. H. (org.), Comparative approaches to cognitive science. Cambridge, MA: MIT Press, 1995, p. 341-382.

EVERAERT, M. B. H.; HUYBREGTS, M. A. C.; CHOMSKY, N.; BERWICK, R.; BOLHUIS, J. J. Structures, not strings: Linguistics as part of the cognitive sciences. Trends in Cognitive Sciences, v. 19, n. 12, 2015, p. 729-743.

FEDUREK, P.; SLOCOMBE, K. E. Primate vocal communication: A useful tool for understanding human speech and language evolution? Human Biology, v. 82, n. 2, 2011, p. 153-173.

FISCHER, J. Primate vocal production and the riddle of language evolution. Psychonomic Bulletin and Review, v. 24, 2017, p. 72-78.

FISCHER, J.; PRICE, T. Meaning, intention, and inference in primate vocal communication. Neuroscience and Biobehavioral Reviews, v. 82, 2016, p. 22-31.

FITCH, W. T. The evolution of language. In: GAZZANIGA, M. (org.) The Cognitive Neurosciences III. Cambridge, MA: MIT Press, 2004, p. 837-846.

The evolution of language. Cambridge: Cambridge University Press, 2010.

Empirical approaches to the study of language evolution. Neuroscience and Behavioral Reviews, v. 24, 2017, p. 3-33.

FITCH, W. T.; HAUSER, M. D. Vocal production in nonhuman primates: Acoustics, physiology, and functional constraints on "honest" advertisement. American Journal of Primatology, v. 37, 1995, p. 191-220.

FITCH, W. T.; HAUSER, M. D.; CHOMSKY, N. The evolution of language faculty: Clarifications and implications. Cognition, v. 97, 2005, p. 179-210.

FITCH, W. T.; ZUBERBÜHLER, K. Primate precursors to human language: Beyond discontinuity. In: ALTENMÜLLER, E.; SCHMIDT, S.; ZIMMERMANN, E. (orgs.) Evolution of emotional communication: From sounds in nonhuman mammals to speech and music in man. Oxford: Oxford University Press, 2013, p. 26-48.

FICHTEL, C.; VAN SCHAIK, C. Semantic differences in sifaka (Propithecus verrauxi) alarm calls: A reflection of genetic or cultural variants? Ethology, 112, 2006, p. 839-849.

FISCHER J.; CHENEY, D. L.; SEYFARTH, R. M. Development of infant baboon responses to female graded variants of barks. Proceedings of the Royal Society, London, Series B, v. 267,2000 , p. 2317-2321. 
FISCHER, J.; HAMMERSCHMIDT, K.; CHENEY, D. L.; SEYFARTH, R. M. Acoustic features of male baboon loud calls: Influence of context, age, and individuality. Journal of the Acoustical Society of America, v. 111, 2002, p. 1465-1474.

FODOR, J. In critical condition: Polemical essays on cognitive science and the philosophy of mind. Cambridge, MA: MIT Press, 1998.

FOLLI, R.; HARLEY, H. Flavours of v: consuming results in Italian and English. In: KEMPCHINSKY, P.; SLABAKOVA, R. (orgs.) Aspectual inquiries. Dordrecht: Springer, 2005 , p. $1-25$

FOLTRAN, M. J. D.; NÓBREGA, V. A. Entre nomes, adjetivos e advérvios: A natureza da modificação. Ms. Universidade Federal do Paraná/Universidade de São Paulo, 2017.

FORTUNY, J. The emergence of order in syntax. John Benjamins, Amsterdam, 2008.

FREITAS, M. L de A. Two nominalizing suffixes in Brazilian Portuguese: Locality constraints in morphophonological realization. Cadernos de Estudos Linguísticos, v. 56, n. 1, 2014, p. 87-113.

. Estudo experimental sobre os nominalizadores -ção e -mento: Localidade, ciclicidade e produtividade. 2015. Tese (Doutorado em Linguística) - Universidade Estadual de Campinas, Campinas, 2015.

FUJITA, K. Review of Biolinguistics: Exploring the biology of language by Lyle Jenkins. Gengo Kenkyu, v. 121, 2002, p. 165-178.

A prospect for evolutionary adequacy: Merge and the evolution and development of human language. Biolinguistics, v. 3, n. 2-3, 2009, p. 128-153.

On the parallel evolution of syntax and lexicon: A Merge-only view. Journal of Neurolinguistics, v. 43, 2017, p. 178-192.

GALLISTEL, C. R. Learning organs. In: BRICMONT, J.; FRANCK, J. (orgs.) Chomsky Notebook. Nova York: Columbia University Press, 2010, p. 193-202.

GARGETT, V. Some observations on black eagles in the Matopos, Rhodesia. Ostrich (Supplement), v. 9, 1971, p. 91-124.

GIVÓN, T. Syntax: A Functional-Typological Introduction. Amsterdam: John Benjamins Publishing Company, 1984.

GOREN-INBAR, N. A figurine from the Acheulean site of Berekhat Ram. Mitekufat Haeven, v. 19, 1986, p. 7-12.

GOODALL, J. The chimpanzees of Gombe: Patterns of behavior. Cambridge, MA: Belknap Press, 1986. 
GOUCHA, T.; ZACCARELLA, E.; FRIEDERICI, A. D. A revival of Homo loquens as a builder of labeled structures: Neurocognitive considerations. Neuroscience Biobehavioral Review, v. 81, 2017, p. 213-224.

GOULD, S. J. The structure of evolutionary theory. Cambridge, MA: Harvard University Press, 2002.

GOULD, J. L.; MARLER, P. Learning by instinct. Scientific American, v. 256, n. 1, 1986, p. 74-85.

GOULD, S. J.; VRBA, E. S. Exaptation: A missing term in the science of form. Paleobiology, v. 8, 1982, p. 4-15.

GOUZOULES, H.; GOUZOULES, S. Design features and developmental modification of pigtail macaque (Macaca nemestrina) agonistic screams. Animal Behaviour, v. 37, 1989, p. $383-401$.

GREENBERG, J. H. Some universals of grammar with particular reference to the order of meaningful elements. In:

MIT Press, 1963, p. 73-113. . (org.) Universals of grammar. 2a edição. Cambridge, MA:

GRIMSHAW, J. Complement selection and the lexicon. Linguistic Inquiry, v. 10, 1979, p. 279-326.

Extended projection. Ms., Brandeis University, 1991.

GRINEVALD, C. Making sense of nominal classification systems: Noun classifiers and the grammaticalization variable. In: WISCHER, I.; DIEWALD, G. (orgs.) New reflections on grammaticalization. Amsterdam: John Benjamins, 2002, p. 259-275.

GRONAU, I.; HUBISZ, M. J.; GULKO, B.; DANKO, C. G., SIEPEL, A. Bayesian inference of ancient human demography from individual genome sequences. Nature Genetics, v. 43, 2011, p. 1031-1034.

GUÉRON, J.; HOEKSTRA, T. T-chains and the constituent structure of auxiliaries. In: CARDINALETTI, A.; CINQUE, G.; GIUSTI, G. (orgs.) Constituent structures. Veneza: Annali di Ca' Foscari, 1988, p. 35-99.

GYGER, M.; KARAKASHIAN, S. J.; MARLER, P. Avian alarm-calling: Is there an audience effect? Animal Behavior, v. 34, 1985, p. 1570-1572.

HACHEM, M. Multifunctionality: The internal and external syntax of D- and W-items in German and Dutch. 2015. Tese (Doutorado em Linguística) - Universidade de Utrecht, Utrecht, 2015.

HAEGEMAN, L. Introduction to Government and Binding Theory. Malden, MA: Blackwell, 1994.

HALLE, M. Prolegomena to a theory of word-formation. Linguistic Inquiry, v. 4, n. 1, 1973, p. 3-16. 
. Distributed Morphology: Impoverishment and fission. MIT Working Papers in Linguistics 30: PF - Papers at the interface. Cambridge, MA: MIT Press, 1997, p. 425-449.

HALLE, M.; MARANTZ, A. Distributed Morphology and the pieces of inflection. In: HALE, K.; KEYSER, S. J. (orgs.) The view from Building 20: Essays in honor of Sylvain Bromberger. Cambridge, MA: MIT Press, 1993, p. 111-176.

Some key features on Distributed Morphology. In: CARNIE, A.; HARLEY, H.; BURES, T. (orgs.) Papers on phonology and morphology, v. 21. Cambridge, MA: MIT Papers in Linguistics MITWPL, 1994, p. 275-288.

HAMMERSCHMIDT, K.; FISCHER, J. Constraints in primate vocal production. In: GRIEBEL, U.; OLLER, K. (orgs.) The evolution of communicative creativity: From fixed signals to contextual flexibility. Cambridge, MA: MIT Press, 2008, p. 93-119.

HARBOUR, D. "Not plus" isn't "not there": Bivalence in person, number, and gender. In: MATUSHANSKY, O.; MARANTZ, A. (orgs.) Distributed Morphology today: Morphemes for Morris Halle. Cambridge, MA: MIT Press, p. 135-150.

HARLEY, H. Denominal verbs and aktionsartin. In: PYLKKÄNEN, L.; VAN HOUT, A. (orgs.) Proceedings of the 2nd Penn/MIT Roundtable on Event Structure. Cambridge, MA: MITWPL, 1999, p. 73-85.

How do verbs get their names? Denominal verbs, manner incorporation and the ontology of verb roots in English. In: ERTESCHIK-SHIR, N.; RAPOPORT, T. (orgs.) The syntax of aspect: Deriving thematic and aspectual interpretation. Oxford: Oxford University Press, 2005, p. 42-64.

. On the identity of roots. Theoretical Linguistics, v. 40, n.3/4, 2014, p. 225-276.

HARLEY, H.; NOYER, R. Distributed Morphology. GLOT International, v. 4, n. 4, 1999, p. 3-9.

. Formal versus encyclopedic properties of vocabulary: Evidence from nominalisations. In: PEETERS, B. (org.) The lexicon-encyclopedia interface. Oxford: Elsevier, 2000, p. 349-374.

HARLOW, H. F.; DODSWORTH, R. O.; HARLOW, M. K. Total social isolation in monkeys. Proceedings of the National Academy of Sciences of the United States of America (PNAS), v. 54, 1965, p. 90-97.

HARMAND, S., LEWIS, J.E., FEIBEL, C.S., LEPRE, C., et al. 3.3-million-year-old stone tools from lomekwi 3, West Turkana, Kenya. Nature, v. 521, 2015, p. 310-316.

HASPELMATH, M. Pre-established categories don't exist: Consequences for language description and typology. Linguistic Typology, v. 11, n. 1, 2007, p. 119-132.

HASPELMATH, M; SIMS, A. Understanding morphology. Londres: Hoder Education An Hachette UK Company, 2010. 
HAUSER, M. D. How infant vervet monkeys learn to recognize starling alarm calls: The role of experience. Behaviour, v. 105, 1988, p. 187-201.

- Ontogenetic changes in the comprehension and production of vervet monkey (Cercopithecus aethiops) vocalizations. Journal of Comparative Psychology, v. 103, 1989, p. 149-158.

Articulatory and social factors influence the acoustic structure of rhesus monkey vocalizations: A learned mode of production? Journal of the Acoustic Society of America, v. 91, 1992, p 2175-2179.

The evolution of communication. Cambridge, MA: MIT Press, 1996.

Wild minds: What animals really think. Nova York: Owl Books, 2001.

HAUSER, M. D.; CAREY, S. Building a cognitive creature from a set of primitives: evolutionary and developmental insights. In: ALLEN, C.; CUMMINGS, D. (orgs.) The evolution of mind. Oxford: Oxford University Press, 1998, p. 51-106.

Spontaneous representations of small numbers of objects by rhesus macaques: Examinations of content and format. Cognitive Psychology, v. 47, n. 4, 2003, p. $367-401$.

HAUSER, M. D.; CAREY, S.; HAUSER, L. Spontaneous number representation in semifree-ranging rhesus monkeys. Proceedings of the Royal Society - London, v. 267, 2000, p. 829-833.

HAUSER, M. D; CHOMSKY, N.; FITCH, W. T. The Faculty of Language: What is it, Who has it, and how did it evolve? Science, v. 298, 2002, p. 1569-1579.

HAUSER, M. D.; MACNEILAGE, P.; WARE, M. Numerical representations in primates. Proceedings of the National Academy of Sciences (PNAS), v. 93, 1996, p. 1514-1517.

HEINZ, J.; IDSARDI, W. What complexity differences reveal about domains in language. Topics in Cognitive Sciences, v. 5, n. 1, 2013, p. 111-131.

HENN, B. M.; BOTIGUÉ, L. R.; GRAVEL, S.; WANG, W.; BRISBIN, A.; BYRNES, J. K. et al. Genomic ancestry of North Africans supports back-to-Africa migrations. PLOS Genetics, 2012. 8:e1002397.

HENSHILWOOD, C.; D'ERRICO, F.; VANHAEREN, M.; VAN NIEKERK, K.; JACOBS, Z. Middle Stone Age shell beads from South Africa. Science, v. 304, 2004, p. 404.

HENSHILWOOD, C.; D’ERRICO, F.; YATES, R.; JACOBS, Z.; TRIBOLO, C.; DULLER, G. A. T.; MERCIER, N. et al. Emergence of modern human behavior: Middle Stone Age engravings from South Africa. Science, v. 295, 2002, p. 1278-1280.

HEYES, C. M.; HUBER, F. The evolution of cognition. Cambridge, MA: MIT Press, 2000. 
HINZEN, W. An essay on naming and truth. Oxford: Oxford University Press, 2007.

The Successor Function + Lex = Human Language? In GROHMANN, K. (org.), InterPhase: Phase-theoretic investigations of linguistic interfaces. Oxford: Oxford University Press, 2009, p. 25-47.

. Language and thought. In: BOECKX, C. (org.) The Oxford handbook of linguistic minimalism. Oxford: Oxford University Press, 2011, p. 499-522.

HOCKETT, C. F. Logical considerations in the study of animal communication In: LANYON, W. E.; TAVOLGA, W. N. (orgs.) Animal sounds and communication. Washington, DC: American Institute of Biological Sciences, 1960a, p. 392-430.

The origin of speech. Scientific American, v. 203, 1960b, p. 88-111.

HOFFMANN, D. L.; STANDISH, C. D. et al. (2018). U-Th dating of carbonate crusts reveals Neanderthal origin of Iberian cave art. Science, v. 359, n. 6378, p. 912-915.

HOFFMANN, D. L.; ANGELUCCI, D. E., et al. (2018). Symbolic use of marine shells and mineral pigments by Iberian Neanderthals 115,000 years ago. Science, v. 4, n. 2, eaar5255.

HORNSTEIN, N. A theory of syntax. Cambridge: Cambridge University Press, 2009.

. On Merge. In In MCGILVRAY, J. (org.) The Cambridge companion to Chomsky. Cambridge: Cambridge University Press, 2017, p. 69-86.

HORNSTEIN, N.; NUNES, J. Adjunction, labeling and Bare Phrase Structure. Biolinguistics, v. 2, n. 1, 2008, p. 57-86.

HORNSTEIN, N.; NUNES, J.; GROHMANN, K. Understanding Minimalism. Cambridge: Cambridge University Press, 2005.

HUMPHREYS, G. W.; FORDE, E. M. E. Hierarchies, similarity, and interactivity in object recognition: "category-specific" neuropsychological deficits. Behavioral and Brain Sciences, v. 24, 2001, p. 453-509.

HURFORD, J. R. The origins of meaning: Language in the light of evolution. Oxford: Oxford University Press, 2007.

The origins of grammar: Language in the light of evolution II. Oxford: Oxford University Press, 2012.

IRURTZUN, A.; GALlEGO, A. J. Consequences of pair-Merge (at the interfaces). ASJU, XLI-2, 2007, p. 179-200.

JACKENDOFF, R. X-Bar Syntax: A study of phrase structure. Cambridge, MA: MIT Press, 1977.

Patterns in the mind. Nova York: Basic Books, 1994. 
Possible stages in the evolution of the language capacity. Trends in Cognitive Sciences, v. 3, 1999, p. 272-279.

Foundations of language: Brain, meaning and evolution. Oxford: Oxford University Press, 2002.

Language, consciousness, culture: Essays on mental structure. Cambridge, MA: The MIT Press, 2007. 624.

. What is the human language faculty? Two views. Language, v. 87, 2011, p. 586-

JACKENDOFF, R.; PINKER, S. The nature of the language faculty and its implications for evolution of language (Reply to Fitch, Hauser, and Chomsky). Cognition, v. 97, 2005, p. 211-225.

JOORDENS, J. C. A.; D'ERRICO, F.; WESSELINGH, F. P.; MUNRO, S.; DE VOS, J., et al., 2015. Homo erectus at Trinil on Java used shells for tool production and engraving. Nature, v. 518, 2015, p. 228-231.

JOOS, M. Readings in linguistics: The development of descriptive linguistics in America since 1925. Washington, DC: American Council of Learned Societies, 1957.

KABUYA, N. The noun classes and concord of Congo Copperbelt Swahili. Studies in African Linguistics, v. 28, n. 1, 1999, p. 93-108.

KAMINSKI, J.; CALL, J.; FISCHER, J. Word learning in a domestic dog: Evidence for 'fast mapping'. Science, v. 304, 2004, p. 1682-1683.

KAPLAN, R. M.; BRESNAN, J. Lexical-Functional Grammar: A formal system for grammatical representation. In: DALRYMPLE, M.; KAPLAN, R. M.; MAXWELL, J. T. III; ZAENEN, A. (orgs.) Formal issues in Lexical-Functional Grammar. Stanford: CSLI Publications, 1995, p. 29-130.

KARAKASHIAN, S. J.; GYGER, M., MARLER, P. Audience effects on alarm calling in chickens. Journal of Comparative Psychology, v. 102, 1988, p. 129-135.

KATZ, J.; PESETSKY, D. The Identity Thesis for Language and Music. Manuscrito. MIT, 2009. Disponível em: http://ling.auf.net/lingbuzz/000959.

KAYNE, R. S. Movement and silence. Oxford: Oxford University Press, 2005.

Antisymmetry and the lexicon. In: DI SCIULLO, A-M.; BOECKX, C. (orgs.) The biolinguistic enterprise: New perspectives on the evolution and nature of the human language faculty. Oxford: Oxford University Press, 2011, p. 329-353.

KIBORT, A.; CORBETT, G. Introduction. In: . (org.) Features: Perspectives on a key notion in linguistics. Oxford: Oxford University Press, 2010, p. 1-13. 
KIPARSKY, P. Lexical morphology and phonology. In The Linguistic Society of Korea (org.) Linguistics in the morning calm. Seoul: Hanshin Publishing Co, 1982, p. 1-91.

KIRCHHOF, J.; HAMMERSCHMIDT, K. Functionally referential alarm calls in tamarins (Saguinus fuscicollis and Saguinus mystax): Evidence from playback experiments. Ethology, v. 112, 2006, p. 346-354.

KLEIN, R. G. The human career: Human biological and cultural origins. 3a ed. Chicago: University of Chicago Press, 2009.

KLOCHMANN, H. The design of semi-lexicality: Evidence from case and agreement in the nominal domain. 2017. Tese (Doutorado em Linguística) - Universidade de Utrecht, Utrecht, 2017.

KNOTT, A. Sensorimotor cognition and natural language syntax. Cambridge, MA: MIT Press, 2012.

KUHN, S. L.; STINER, M. C. Paleolithic ornaments: implications for cognition, demography and identity. Diogenes, v. 214, 2007, p. 40-48.

KUMAR, S.; HEDGES, S. B. A molecular timescale for vertebrate evolution. Nature, v. 392, 1998, p. 917-920.

LABELLE, M. The acquisition of grammatical categories: A state of the art. In: COHEN, H.; LEFEBVRE, C. (orgs.) Handbook of categorization in Cognitive Science. Amsterdam: Elsevier, 2005, p. 433-457

LAKOFF, G. Irregularity in syntax. Nova York: Holt, Rinehart and Winston, 1970.

LALAND, K. N. Darwin's unfinished symphony: How culture made the human mind. Princeton: Princeton University Press, 2017.

LANGACKER, R. W. Foundations of Cognitive Grammar. Stanford: Stanford University Press, 1987.

LANGENDOEN, T. D. Merge. In: CARNIE, A.; WILLIE, M.; HARLEY, H. (orgs.) Formal approaches to functional phenomena: In honor of Eloise Jelinek. Amsterdam: John Benjamins, 2003, p. 307-318.

LASNIK, H.; LIDZ, J. L. The argument from the Poverty of the Stimulus. In ROBERTS, I. (org.) The Oxford handbook of Universal Grammar. Oxford: Oxford University Press, 2016, p. 221-231.

LAURENCE, S.; MARGOLIS, E. The poverty of the stimulus argument. British Journal for the Philosophy of Science, v. 52, 2001, p. 217-276.

LAWICK-GOODALL, J. van; LAWICK, H. van; PACKER, C. Tool-use in free-living baboons in the Gombe National Park, Tanzania. Nature, v. 241, 1973, p. 212-213. 
LENNEBERG, E. H. A biological perspective of language. In: in the study of language. Cambridge, MA: MIT Press, 1964, p. 65-88. (org.) New directions

LEPRE, C. J.; ROCHE, H.; KENT, D. V.; HARMAND, S.; QUINN, R. L.; BRUGAL, J.-P. et al. An earlier origin for the Acheulian. Nature, v. 477, 2011, p. 82-85.

LEVIN, B.; RAPPAPORT HOVAV, M. Argument realization. Cambridge: Cambridge University Press, 2005.

LEVINE, R. D.; MEURERS, W. D. Head-Driven Phrase Structure Grammar: Linguistic approach, formal foundations, and computational realization. In: BROWN, K. (org.), The encyclopedia of language and linguistics. Oxford: Elsevier Science Publisher B.V. (NorthHolland), 2006, p. 237-252.

LEWONTIN, R. The evolution of cognition: Questions we will never answer. In: SCARBOROUGH, D.; STERNBERG, S. (orgs.) An invitation to cognitive science: Methods, models, and conceptual issues. Vol. 4. Cambridge, MA: MIT Press, 1998, p. 107132.

. The triple helix: Gene, organism and environment. Cambridge, MA: Harvard University Press, 2008.

LIEBER, R. Deconstructing Morphology. Chicago: The University of Chicago Press, 1992.

Semantic of derivational morphology. In: MAIENBORN, C.; VON HEUSINGER, K.; PORTNER, P. (orgs.) Semantics: An international handbook of natural language meaning. Berlim: De Gruyter Mouton, 2012, p. 2098-2119.

LIU, W. C.; GARDNER, T. J; NOTTEBOHN, F. Juvenile zebra finches can use multiple strategies to learn the song. Proceedings of the National Academy of Sciences of the United States of America (PNAS), v. 101, n. 52, 2004.

LOHNDAL, T. Without specifiers: Phrase structure and events. 2012. Tese (Doutorado em Linguística) - Universidade de Maryland, College Park, 2012.

Phrase structure and argument structure: A case study of the syntax-semantics interface. Oxford: Oxford University Press, 2014.

Formal grammar: Theory and Variation across English and Norwegian. Londres e Nova York: Routledge, 2017.

LONGOBARDI, G. Methods in parametric linguistics and cognitive history. In PICA, P.; ROORYCK, J. (org.) Linguistic Variation Yearbook 3, Amsterdam: John Benjamins, 2003, p. 101-138.

LUST, B. Child language: Acquisition and growth. Cambridge: Cambridge University Press, 2006. 
MACEDONIA, J. M. What is communicated in the antipredator calls of lemurs: evidence from playback experiments with ring-tailed and ruffed lemurs. Ethology, v. 86, 1990, p. 177190.

MACEDONIA, J. M.; EVANS, C. S. Variation among mammalian alarm call systems and the problem of meaning in animal signals. Ethology, v. 93, 1993, p. 177-197.

MANOVA, S.; ARONOFF, M. Modeling affix order. Morphology, v. 20, 2010, p. 109-131.

MARANTZ, A. On the nature of grammatical relations. Cambridge, MA: MIT Press, 1984.

Morphology. Ms. MIT, 1995.

. No escape from syntax: Don't try morphological analysis in the privacy of your own Lexicon. In: DIMITRIADIS, A.; SIEGEL, L.; SUREK-CLARK, C.; WILLIAMS, A. (orgs.)

Proceedings of the 21st Penn Linguistics Colloquium. Philadelphia: UPenn Working Papers in Linguistics, 1997, p. 201-225.

Case and licensing. In: REULAND, E. (org.) Arguments and Case: Explaining Burzio's Generalization. Filadélfia: John Benjamins, 2000, p. 11-30.

Words and things. Manuscrito, MIT/NYU, 2001.

Phases and words. In CHOE, S-H (org.) Phases in the theory of grammar. Seoul: Dong In, 2008, p. 191-222.

- Locality domains for contextual allomorphy across the interfaces. In: MATUSHANSKY, O.; MARANTZ, A. (orgs.) Distributed Morphology Today: Morphemes for Morris Halle. Cambridge, MA: MIT Press, 2013, p. 95-115.

MARLER, P. The logical analysis of animal communication. Journal of Theoretical Biology, v. 1, 1961, p. 295-317.

Birdsong and speech development: could there be parallels? American Scientist, v. 58, 1970, p. 669-673.

Primate vocalization: Affective or symbolic? In SEBEOK, T. A.; UMIKERSEBEOK, J. (orgs.) Speaking of apes: A critical anthology of two-way communication with man. Nova York e Londres: Plenum Press, 1980, p. 221-230.

Origins of music and speech: insights from animals. In WALLIN, B.; MERKER, B.; BROWN, S. (orgs.) The origins of music. Cambridge, MA: MIT Press, 2000, p. 31-48.

MARLER, P.; EVANS, C. S.; HAUSER, M. D. Animal signals: Motivational, referential, or both? In PAPOUSEK, U.; JÜRGENS, U.; PAPOUSEK, M. (orgs.) Nonverbal vocal communication: Comparative and developmental approaches. Cambridge, U.K.: Cambridge University Press, 1992, p. 66-86. 
MARLER, P.; TENAZA, R. Signaling behavior of apes with special reference to vocalization. In: SEBEOK, T. A. How animals communicate. Bloomington: Indiana University Press, 1977, p. 965-1032.

MARTIN, R.; URIAGEREKA, J. Some possible foundations of the Minimalist Program. In: MARTIN, R.; MICHAELS, D.; URIAGEREKA, J. (orgs.), Step by step: Essays in minimalist syntax in honor of Howard Lasnik. Cambridge, MA: MIT Press, 2000, p. 1-30.

MARVIN, T. Topics in the stress and syntax of words. 2002. Tese (Doutorado em Linguística) - MIT, Cambridge, 2002.

Is word structure relevant for stress assignment? In: MATUSHANSKY, O.; MARANTZ, A. (orgs.) Distributed Morphology today: Morphemes for Morris Halle. Cambridge, MA: MIT Press, 2013, p. 79-94.

MCDOUGALL, I.; BROWN, F. H.; FLEAGLE, J. G. Stratigraphic placement and age of modern humans from Kibish, Ethiopia. Nature, v. 433, 2005, p. 733-736.

MCFADDEN, T. The position of morphological case in the derivation: A study on the syntax-morphology interface. 2004. Tese (Doutorado em Linguística) - Universidade da Pennsylvania, Filadélfia, 2004.

Structural Case, locality and cyclicity. In: GROHMANN, K. (org.) Explorations of Phase Theory: Features and Arguments. Berlim: Mouton de Gruyter, 2009, p. 107-130.

MCPHERRON, S.; ALEMSEGED, Z.; MAREAN, C.W.; WYNNE, J.G.; REED, D.; GERAADS, D. et al. Evidence for stone-tool-assisted consumption of animal tissues before 3.39 million years ago at Dikika, Ethiopia. Nature, v. 466, 2010, p. 857-860.

MITANI, J.; BRANDT, K. L. Social factors influence the acoustic variability in the longdistance calls of male chimpanzees. Ethology, v. 96, 1994, p. 233-252.

MITHEN, S. J. The prehistory of the mind: A search for the origins of art, religion and science. Londres: Thames \& Hudson, 1996.

The singing Neanderthals: The origins of music, language, mind and body. Londres: Weidenfeld and Nicholson, 2005.

Holistic communication and the co-evolution of language and music: Resurrecting an old idea. In: BOTHA, R.; KNIGHT, C. (orgs.) The pre-history of language. Oxford: Oxford University Press, 2009, p. 58-76.

MIYAGAWA, S. Integration hypothesis: A parallel model of language development in evolution. In: WATANABE, S.; HOFMAN, M. A.; SHIMIZU, T. (orgs.) Evolution of the brain, cognition, and emotion in vertebrates. Amsterdam: Springer, 2017, p. 225-247.

MIYAGAWA, S.; BERWICK, R. C.; OKANOYA, K. The emergence of hierarchical structure in human language. Frontiers in Psychology, v. 4, n. 71, 2013. 
MIYAGAWA, S.; OJIMA, S.; BERWICK, R. C.; OKANOYA, K. The integration hypothesis of human language evolution and the nature of contemporary languages. Frontiers in Psychology, v. 5, n. 564, 2014.

MIYAGAWA, S.; LESURE, C.; NÓBREGA, V. A. Cross-Modality Information Transfer: A hypothesis about the relationship among prehistoric cave paintings, symbolic thinking, and the emergence of language. Frontiers in Psychology, v. 9, n. 115, 2018.

MIYAGAWA, S.; WU, D.; KOIZUMI, M. Deriving Case Theory. Manuscrito, MIT, 2018.

MOCZEK, A. P. On the origins of novelty in development and evolution. BioEssays, v. 30, n. 5, 2008, p. 432-447.

MOHANAN, K.P. The theory of lexical phonology. Dordrecht: Reidel, 1986.

MORENO, M.; PANAGIOTIDIS, P. The categorial anatomy of adjectives. Manuscrito. Universidade do Chipre, 2018.

MUNARO, N. On the edge-feature of particles, interjections and short answers. In: DI SCIULLO, A-M.; HILL, V. (orgs.) Edges, heads and projections: Interface properties, 2010, p. 67-86.

MURPHY, E. Labels, cognomes, and cyclic computation: An ethological perspective. Frontiers in Psychology, v. 6, n. 715, 2015a.

. Reference, phases and individuation: Topics at the labeling interpretive interface. Opticon1826, v. 17, 2015b, p. 1-13.

. Phasal eliminativism, anti-lexicalism, and the status of the unarticulated. Biolinguistics, v. 10, 2016, p. 21-50.

MUYSKEN, P.; VAN RIEMSDIJK, H. Projecting features and feature projections. In: . (orgs.) Features and projections. Berlin: Mouton de Gruyter, 1986, p. 1-30.

NEWMEYER, F. J. Functional explanation in linguistics and the origins of language. Language \& Communication, v. 11, 1991, p. 3-28.

. On the supposed 'counterfunctionality' of Universal Grammar: Some evolutionary implications. In: HURFORD, J. R.; STUDDERT-KENNEDY, M.; KNIGHT, C. (orgs.) Approaches to the evolution of language. Cambridge: Cambridge University Press, 1998, p. 305-319.

NÓBREGA, V. A. Tópicos em composição: Estrutura, formação e acento. 2014. Dissertação (Mestrado em Linguística) - Universidade de São Paulo, São Paulo, 2014.

50.

. Raízes: Primitivos sintáticos defectivos. Caderno de Squibs, v. 1, n. 1, 2015a, p. 43- 
Domínios de localidade e a interpretação dos compostos nas interfaces. In: PILATI, E. N. S. (org.) Temas em Teoria Gerativa: Homenagem a Lucia Lobato. Curitiba: Blanche, 2016, p. 245-259.

NÓBREGA, V. A.; MIYAGAWA, S. The precedence of syntax in the rapid emergence of human language in evolution as defined by the integration hypothesis. Frontiers in Psychology, v. 6, n. 271, 2015.

NÓBREGA, V. A.; PANAGIOTIDIS, P. Headedness in compounding: A new approach to exocentricity. Manuscrito, Universidade de São Paulo/Universidade do Chipre, 2018.

NORDHAUSEN, M. Y.; FILHO, P. C. O. Nós, primatas. In: NEVES, W. A.; RANGEL JR., M. J.; MURRIETA, R. S. S. (orgs.) Assim caminhou a humanidade. São Paulo: Palas Athena, 2015, p. 14-47.

NOTTEBOHM, F. Continental patterns of song variability in Zonotrichia capensis: some possible ecological correlates. The American Naturalist, v. 109, 1975, p. 605-624.

NUNES, J. M. Linearization of chains and Sideward Movement. Cambridge, MA: MIT Press, 2004.

. Sideward Movement: Triggers, timing, and outputs. In: URIBE-ETXEBARRIA, M.; VALMALA, V. (orgs.) Ways of structure building. Oxford: Oxford University Press, 2012, p. 114-142.

ODA, R. Lemur vocal communication and the origin of human language. In: MATSUZAWA, T. (org.) Primate origins of human cognition and behavior. Hong Kong: Springer, 2008, p. 115-134.

O'GRADY, W. How children learn language. Cambridge: Cambridge University Press, 2005.

OKANOYA, K. Sexual display as a syntactic vehicle: the evolution of syntax in birdsong and human language evolution through sexual selection. In: WRAY, A. (org.) The transition to language. Oxford: Oxford University Press, 2002, p. 46-63.

Language evolution and an emergent property. Current Opinion in Neurobiology, v. 17, 2007, 271e276.

OKANOYA, K.; MERKER, B. Neural substrates for string-context mutual segmentation: a path to human language. In: LYON, C.; NEHANIV, C. L.; CANGELOSI, A. (orgs.), Emergence of communication and language. Londres: Springer-Verlag, 2007, p. 421-434.

OLIVEIRA, S. M. Os sufixos nominalizadores -ção e -mento. Estudos Linguísticos, v. 36, n. 1, 2007, p. 87-96.

OTT, D. The evolution of I-language: Lexicalization as the key evolutionary novelty. Biolinguistics, v. 3, n. 2, 2009, p. 255-269. 
OUATTARA, K.; LEMASSON, A.; ZUBERBÜHLER, K. Campbell's monkeys use affixation to alter call meaning. PLoS ONE, v. 4, n. 11, 2009a, e7808.

OUATTARA, K.; LEMASSON, A.; ZUBERBÜHLER, K. Campbell's monkeys concatenate vocalizations into context-specific call sequences. Proceedings of the National Academy of Sciences of the United States of America (PNAS), v. 106, n. 51, 2009b, p. 22026-22031.

OUATTARA, K.; ZUBERBÜHLER, K.; N'GORAN, E. K.; GOMBERT, J.-E.; LEMASSON, A. The alarm call system of female Campbell's monkeys. Animal Behaviour, v. 78, 2009, p. 35-44.

OWREN, M. J.; DIETER, J. A.; SEYFARTH, R. M.; CHENEY, D. L. Vocalizations of rhesus and Japanese macaques cross-fostered between species show evidence of only limited modification. Developmental Psychobiology, v. 26, 1993, p. 389-406.

OWREN, M. J.; RENDALL, D. An affect-conditioning model of nonhuman primate vocal signaling. In: OWINGS, D. H.; BEECHER, M. D.; THOMPSON, N. S. (orgs) Communication: Perspectives in ethology. Boston: Springer, 1997, p. 299-346

Sound on the rebound: Bringing form and function back to the forefront in understanding nonhuman primate vocal signaling. Evolutionary Anthropology, v. 10, 2001, p. 58-71.

PÄÄBO, S. The human condition: A molecular approach. Cell, v. 157, n. 1, 2014a, p. 216226.

Neanderthal man: In search of lost genomes. Nova York: Basic Books, 2014b.

PAGE, R. D. M.; HOLMES, E. C. Molecular evolution: A phylogenetic approach. Oxford: Blackwell, 1998.

PANAGIOTIDIS, P. A minimalist approach to roots. In: KOSTA, P.; SCHURCKS, L.; RADEV-BORK, T. Minimalism and Beyond: Radicalizing the interfaces. Amsterdam: John Benjamins, 2014, p. 287-303.

Categorial Features: A generative theory of word class categories. Cambridge: Cambridge University Press, 2015.

PFAU, R. Grammar as processor: A Distributed Morphology account of spontaneous speech errors. Amsterdam: John Benjamins, 2009.

PFENNING, A. R.; HARA, E.; WHITNEY, O.; RIVAS, M. V.; WANG, R.; ROULHAC, P. L.; et al. Convergent transcriptional specializations in the brains of humans and song- learning birds. Science, v. 346, 2014.

PESETSKY, D. Paths and categories. 1982. Tese (Doutorado em Linguística) - MIT, Cambridge, MA, 1982. 
PESETSKY, D.; TORREGO, E. Probes, goals and syntactic categories. In Proceedings of the North Eastern Linguistic Society Annual Meeting. Japão - Universidade de Keio, 2006.

PIATELLI-PALMARINI, M.; URIAGEREKA, J.; SALABURU, P. (orgs.) On minds \& language: A dialogue with Noam Chomsky in the Basque Country. Oxford: Oxford University Press, 2009.

PIETROSKI, P. Events and semantic architecture. Oxford: Oxford University Press, 2005. 317-341.

Minimalist meaning, internalist interpretation. Biolinguistics, v. 2, n. 4, 2008, p.

Concepts, meanings and truth: First nature, second nature and hard work. Mind \& Language, v. 25, n. 3, 2010, p. 247-278.

Minimal semantic instructions. In: BOECKX, C. (org.) The Oxford handbook of linguistic minimalism. Oxford: Oxford University Press, 2011, p. 472-498.

Language and conceptual reanalysis. In: DI SCIULLO, A-M. (org.) Towards a biolinguistic understanding of grammar: Essays on interfaces. Amsterdam: John Benjamins, 2012, p. 57-86.

PIKE, A. W. G.; HOFFMANN, D. L.; GARCÍA-DIEZ, M.; PETTITT, P. B.; ALCOLEA, J.; DE BALBÍN, R. et al. U-series dating of Paleolithic art in 11 caves in Spain. Science, v. 336, 2012, p. 1409-1413.

PINKER, S.; BLOOM, P. Natural selection and natural language. Behavioral and Brain Sciences, v. 13, 1990, p. 707-784.

PINKER, S.; JACKENDOFF, R. The Faculty of Language: What's special about it? Cognition, v. 95, 2005, p. 201-36.

POLLARD, C.; SAG I. Head-Driven Phrase Structure Grammar. Chicago: University of Chicago Press, 1994.

POVINELLI, D. J. Behind the ape's appearance: Escaping anthropocentrism in the study of other minds. Daedalus, v. 133, n. 1, 2004, p. 29-41.

PREMACK, D. Gavagai!: or the future history of the animal language controversy. Cambridge, MA: MIT Press, 1986.

PREMACK, D.; WOODRUFF, G. Does the chimpanzee have a "theory of mind"? Behavioral and Brain Sciences, v. 4, 1978, p. 515-526.

PRICE, T.; WADEWITZ, P.; CHENEY, D. L.; SEYFARTH, R. M.; HAMMERSCHMIDT, K; FISCHER, J. Vervets revisited: A quantitative analysis of alarm call structure and context specificity. Scientific Reports, v. 5, p. 1-11, 2015. 
PRUD'HOMME, B.; MINERVINO, C.; HOCINE, M.; CANDE, J. D.; AOUANE, A.; DUFOUR, H. D.; KASSNER V. A.; GOMPEL, N. Body plan innovation in treehoppers through the evolution of an extra wing-like appendage. Nature, v. 473, 2011, p. 83-86.

PULVERMÜLLER, F. Brain embodiment of syntax and grammar: discrete combinatorial mechanisms spelt out in neuronal circuits. Brain and Language, v. 112, 2010, p. 167-179.

QUEIROZ, J.; EL-HANI, C. N. Towards a multi-level approach to the emergence of meaning processes in living systems. Acta Biotheoretica, v. 54, 2006, p. 179-206.

RAMCHAND, G. Verb meaning and the lexicon: A first-phase syntax. Cambridge: Cambridge University Press, 2008.

RAMCHAND, G.; SVENONIUS, P. Deriving the functional hierarchies. Language Sciences, v. 46, 2014, p. 152-174.

RAPPAPORT-HOVAV, M.; LEVIN, B. Interface Strategies. Utrecht: UiL OTS Working papers, 1995.

. Building verb meanings. In: BUTT, M.; GEUDER, W. (orgs.) The projection of arguments. Stanford: CSLI Publications, 1998, p. 97-134.

REICH, D. Who we are and how we got here: Ancient DNA and the new science of the human past. Nova York: Pantheon Books, 2018.

RICHARDS, M. Two kinds of variation in a minimalist system. Linguistische Arbeits Berichte, v. 87, 2008, p. 133-162.

RICHARD, N. Contiguity theory. Cambridge, MA: MIT Press, 2016.

RITTER, E.; WILTSCHKO, M. Anchoring events to utterances without tense. Proceedings of the 24th West Coast Conference on Formal Linguistics, 2005, p. 343-351.

Varieties of INFL: TENSE, LOCATION, and PERSON. In: VAN CRAENENBROECK, J. (org.) Alternatives to cartography. Berlim: Mouton de Gruyter, 2009, p. 153-201.

. The composition of INFL: An exploration of "tense, tenseless" languages, and tenseless constructions. Natural Language and Linguistic Theory, v. 32, n. 4, 2014, p. 1331-1386.

RIZZI, L. Relativized minimality. Cambridge, MA: MIT Press, 1990.

The fine structure of the left periphery. In: HAEGEMAN, L. (org.) Elements of grammar. Dordrecht: Kluwer, 1997, p. 281-337.

On the cartography of syntactic structures. In: . (org.) The structure of $\mathbf{C P}$ and IP. The Cartography of Syntactic Structures. Oxford: Oxford University Press, 2004, p. 3-15. 
. Some elements of syntactic computation. In: BICKERTON, D.; SZATHMÁRY, E. (orgs.) Biological foundations and origin of syntax. Cambridge, MA: MIT Press, 2009, p. 63-88.

On the elements of syntactic variation. In: PICALLO, C. (org.). Linguistic variation in the Minimalist framework. Oxford: Oxford University Press, 2014, p. 13-35.

RIZZI, L.; CINQUE, G. Functional categories and syntactic theory. Annual Review of Linguistics, v. 2, 2016, p. 139-163.

ROBERTS, T. F.; HISEY, E.; TANAKA, M.; KEARNEY, M. G.; CHATTREE, G.; YANG, C. F., et al. Identification of a motor-to-auditory pathway important for vocal learning. Nature Neuroscience, v. 20, n. 7, 2017, p. 978-986.

ROCHA, L. C. de A. A nominalização no português do Brasil. Revista de Estudos da Linguagem, v. 8, n. 1, 1999, p. 5-52.

RODRÍGUEZ-VIDAL, J.; D’ERRICO, F.; PACHECO, F. G.; BLASCO, R.; ROSELL, J.; JENNINGS, R. P. et al. A rock engraving made by Neanderthals in Gibraltar. Proceedings of the National Academy of Sciences of the United States of America (PNAS), v. 111, n. 37, 2014, p. 13301-13306.

ROSS, J. R. On declarative sentences. In: JACOBS, R.; ROSENBAUM, P. (orgs.) Readings in English Transformational Grammar. Waltham, MA: Blaisdell, 1970, p. 222-272.

ROY, I. Deadjectival nominalizations and the structure of the adjective. In ALEXIADOU, A.; RATHER, M. (orgs.) The syntax of nominalizations across languages and frameworks. Berlim: de Gruyter Mouton, 2010, p. 129-158.

SAARINEN, P.; HAY, J. Affix ordering in derivation. In LIEBER, R. (org.) The Oxford handbook on derivation morphology. Oxford: Oxford University Press, 2014, p. 371-383.

SAG, I.; WASOW, T. Syntactic Theory: A formal introduction. Stanford: CSLI Publications, 1999.

SAG, I.; WASOW, T.; BENDER, E. M. Syntactic Theory: A formal introduction. 2a Ed. Chicago: The University of Chicago Press, 2003.

SAMUELS, B. The Third Factor in phonology. Biolinguistics, v. 3, n. 2-3, 2009, p. 355-382. Press, 2011.

Phonological architecture: A biolinguistic perspective. Oxford: Oxford University . The emergence of phonological forms. In: DI SCIULLO, A-M. (org.) Towards a biolinguistic understanding of grammar. Amsterdam: John Benjamins, 2012, p. 193-213. $\overline{161-171 .}$.

Biolinguistics in phonology: a prospectus. Phonological Studies, v. 18, 2015, p.

SCALISE, S. Generative morphology. Dordrecht: Foris, 1984. 
SCHEL, A. M.; TOWNSEND, S. W.; MACHANDA, Z.; ZUBERBÜHLER, K.; SLOCOMBE, K. E. Chimpanzee alarm call production meets key criteria for intentionality. PLOS One 8:e76674, 2013.

SCHICK, K. D.; TOTH, N. Making silente stones speak: Human evolution and the dawn of technology. Nova York: Simon and Schuster, 1993.

SCHLENKER, P., CHEMLA, E., ARNOLD, K., LEMASSON, A., OUATTARA, K., KEENAN, S. et al. Monkey semantics: two 'dialects' of Campbell's monkey alarm calls. Linguist and Philos, v. 37, 2014, p. 439-501.

SCHLENKER, P.; CHEMLA, E.; SCHEL, A. M.; FULLER, J.; GAUTIER, J. P.; KUHN, J. Formal monkey linguistics. Theoretical linguistics, v. 42, n. 1-2, 2016, p. 1-90.

SEARLE, J. R. What is language? Some preliminary remarks. Ethics and politics, 2009, p. 173-202.

SEELY, D. T. Merge, derivational c-command, and subcategorization in a label-free syntax. In BOECKX, C. (org.) Minimalist Essays. Amsterdam: John Benjamins, 2006, p. 182-217.

SEMAW, S. The world's earliest stone artifacts from Gona, Ethiopia: The implications for understanding stone technology and patterns of human evolution between 2.6-1.5 million years ago. Journal of Archaeological Sciences, v. 27, 2000, p. 1197-1214.

SEYFARTH, R. M.; CHENEY, D. L. Vocal development in vervet monkeys. Animal Behaviour, v. 34, 1986, p. 1640-1658.

. Meaning, reference, and intentionality in the natural vocalizations of monkeys. In: ROIBLAT, H. L.; HERMAN, L. M.; NACHTIGALL, P. E. Language and communication: Comparative perspectives. Londres: Lawrence Erlbaum, 1993, p. 195-219.

. Some general features of vocal development in nonhuman primates. In:

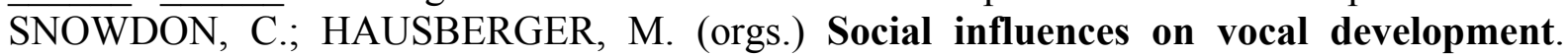
Cambridge: Cambridge University Press, 1997, p. 249-273.

. Signalers and receivers in animal communication. Annual Review of

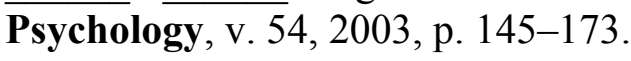

. Production, usage, and comprehension in animal vocalizations. Brain and Language, v. 115, 2010, p. 92-100.

SEYFARTH, R. M.; CHENEY, D. L; MARLER, P. Monkey responses to three different alarm calls: evidence of predator classification and semantic communication. Science, v. 210, 1980a, p. 801-803.

. Vervet monkey alarm calls: Semantic communication in a free-

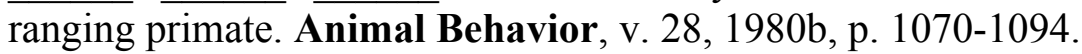

SIEGEL, D. Topics in English morphology. Cambridge, MA: MIT, 1974. 
SIGURĐSSON, H. Á. The nominative puzzle and the low nominative hypothesis. Linguistic Inquiry, v. 37, 2006, p. 289-308.

. The No Case Generalization. In: ALEXIADOU, A.; HANKAMER, J.; MCFADDEN, T.; NUGER, J.; SCHÄFER, F. (orgs.) Advances in comparative Germanic syntax. Amsterdam: John Benjamins, 2009, p. 249-279.

On UG and materialization. Linguistic Analysis, v. 37, 2012, p. 367-368.

SILONI, T. Noun phrases and nominalizations: The syntax of DPs. Dordrecht: Kluwer, 1997.

ŠIMÍK, R. The elimination of formal wh-features and a theory of free wh-movement. Ms., Universität Potsdam, 2012. Disponível em: https://amor.cms.huberlin.de/ $\sim \operatorname{simikrad/pdf/simik-wh-features.pdf.~}$

SHETTLEWORTH, S. Cognition, evolution and behavior. Oxford: Oxford University Press, 1998.

SHERMAN, P. W. Nepotism and the evolution of alarm calls. Science, v. 197, 1977, p. 12461253.

. The limits of ground squirrel nepotism. In: BARLOW, G. W.; SILVERBERG, J. (orgs.) Sociobiology: Beyond nature/nurture. Boulder, CO: Westview, 1980, p. 505-544.

Alarm calls of Belding's ground squirrels to aerial predators: nepotism or selfpreservation? Behavioral Ecology and Sociobiology, v. 17, 1985, p. 313-323.

SHLONSKY, U. The hierarchical representation of subject verb agreement. Haifa University: 1989. Disponível em: https://archive-ouverte.unige.ch/unige:83251.

SLOCOMBE, K. E.; KALLER, T.; CALL, J.; ZUBERBÜHLER, K. Chimpanzees extract social information from agonistic screams. PLOS ONE 5:e11473, 2010.

SMITH, C. The parameter of aspect. Dordrecht: Kluwer, 1991.

SNOWDON, C. T. Language capacities of nonhuman primates. Yearbook of Physical Anthropology, v. 33, 1990, p. 215-243.

SNOWDON, C.; ELOWSON, M.; ROUSH, R. Social influences on vocal development in New World primates. In: SNOWDON, C.; HAUSBERGER, M. (orgs.) Social influences on vocal development. Cambridge: Cambridge University Press, 1997, p. 234, 248.

SPELKE, E. Core knowledge. American Psychologist, v. 55, 2000, p. 1233-1243.

What makes us smart? Core knowledge and natural language In: GENTNER, D.; GOLDIN-MEADOW, S. (orgs.) Language in mind: Advances in the study of language and thought. Cambridge, MA: MIT Press, 2003, p. 277-312. 
SPERBER, D; WILSON, D. Relevance: Communication and cognition. Oxford: Blackwell, 1986.

SPIERINGS, M. J.; TEN CATE, C. Budgerigars and zebra finches differ in how they generalize in an artificial grammar learning experiment. Proceedings of the National Academy of Sciences of the United States of America (PNAS), v. 113, v. 27, 2016.

STARKE, M. Move dissolves into merge. 2001. Tese (Doutorado em Linguística) Universidade de Genebra, Genebra, 2001.

STOUT, D. Possible relations between language and technology in human evolution. In NOWELL, A.; DAVIDSON, I. (orgs.) Stone tools and the evolution of human cognition. Colorado: University Press of Colorado, 2010, p. 159-184.

STRUHSAKER, T. T. Auditory communication among vervet monekys (Cercopithecus aethiops). In: ALTMANN, S. A. (org.) Social communication among primates. Chicago: Chicago University Press, 1967, p. 281-324.

. Nanosyntax: A short primer to a new approach to language. In: SVENONIUS, P.; RAMCHAND, G.; STARKE, M.; TARALDSEN, K. T. (orgs.) Nordlyd, v. 36, 2009, p. 1-6.

SUDARESAN, S. Towards resolving the counter-cyclicity of the EPP. Manuscrito. Universidade de Leipzig/ZAS Berlim, 2016.

SVENONIUS, P. Spans and words. In: SIDDIQI, D.; HARLEY, H. (orgs.) Morphological metatheory. Amsterdam: John Benjamins, 2016, p. 201-222.

SZABOLCSI, A. The noun phrase. In: KIEFER, F.; KISS, K. É. (orgs.) The syntactic structure of hungarian. San Diego: Academic Press, 1994, p. 179-274.

TALLERMAN, M. The origins of the lexicon: How a word store evolved. In: BOTHA, Rudolf; KNIGHT, Chris. (orgs.) The prehistory of language. Oxford: Oxford University Press, 2009, p. 181-200.

Protolanguage. In: TALlERMAN, M.; GIBSON, K. R. (orgs.) The Oxford handbook of language evolution. Oxford: Oxford University Press, 2012, p. 479-491.

Can the integration hypothesis account for language evolution? Journal of Neurolinguistics, v. 43, 2017, p. 254-262.

TALLERMAN, M.; GIBSON, K. R. Introduction: the evolution of language. In (orgs.) The Oxford handbook of language evolution. Oxford: Oxford University Press, 2012, p. 1-35.

TALMY, L. Lexicalization patterns: semantic structure in lexical forms. In SHOPEN, T. (org.) Language typology and syntactic description. V. 3. Cambridge: Cambridge University Press, 1985, p. 57-149.

TANNER, J. E.; BYRNE, R. Representation of action through iconic gesture in a captive lowland gorilla. Current Anthropology, v. 37, 1996, p. 162-173. 
TATTERSALL, I. Becoming human. Nova York: Harcourt Brace \& Company, 1998.

An evolutionary framework for the acquisition of symbolic cognition by Homo sapiens. Comparative Cognition and Behavior Reviews, v. 3, 2008, p. 99-114.

The fossil trail: How we know what we think we know about human evolution, $2^{\mathrm{a}}$ ed. Oxford: Oxford University Press, 2009.

. Human evolution and cognition. Theory in Biosciences, v. 129, 2010, p. 193-201.

. Evolution of modern human consciousness. Journal of Cosmology, v. 14, 2011.

. Masters of the planet: The Search for our Human Origins. Nova York: Palgrave Macmillan, 2012.

A tentative framework for the acquisition of language and modern human cognition.

Journal of Anthropological Sciences, v. 94, 2016a, p. 157-166.

. Language origins: An evolutionary framework. Topoi, v. 35, n. 1, $2016 b$.

The material record and the antiquity of language. Neuroscience and Behavioral Reviews, v. 81, 2017, p. 247-254.

THOMPSON, R. K. R. Natural and relational concepts in animals. In: ROIBLAT, H.; MEYER, J. A. (orgs.) Comparative approaches to cognitive science. Cambridge, MA: MIT Press, 1995, p. 175-224

THORPE, W. H. The learning of song patterns by birds, with special reference to the song of the Chaffinch, Fringilla coelebs. Ibis, v. 100, 1958, p. 535-570.

TODT, D. Ordering os sequences in the nightingale's song. Verhandlungen der Deutschen Zoologischen Gesellschaf, v. 64, 1970, p. 249-252.

TOMASELlO, M.; CARPENTER, M.; CALL, J.; BEHNE, T.; MOLL, H. Understanding and sharing intentions: The origins of cultural cognition. Behavioral \& Brain Sciences, $n$. 28,2005 , p. 675-735.

TOWNSEND, S. W.; MANSER, M. B. Functionally referential communication in mammals: The past, present and the future. Ethology, v. 119, n. 1, 2013, p. 1-11.

TUTUSAUS, J. The language by-product conjecture and the formal definition of Merge: Some logical consequences. 2012. Dissertação (Mestrado em Linguística). Universidade de Barcelona, Barcelona, 2012.

URIAGEREKA, J. Warps: Some thoughts on categorization. Theoretical Linguistics, v. 25, 1999, p. 31-73. Press, 2008.

Syntactic anchors: On semantic structuring. Cambridge: Cambridge University 
VANHAEREN, M. The evolutionary significance of beadmaking and use. In: D'ERRICO, F.; BACKWELL, L. (orgs.) From tools to symbols. Johannesburg: Wits University Press, 2005, p. 525-535.

VANHAEREN, M.; D'ERRICO, F. Aurignacian ethnolinguistic-geography of Europe revealed by personal ornaments. Journal of Archaeological Sciences, v. 33, 2006, p. 11051128 .

VANHAEREN, M.; D'ERRICO, F.; STRINGER, C.; JAMES, S. L.; TODD, J. A.; MIENIS, H. K. Middle paleolithic shell beads in Israel and Algeria. Science, v. 312, 2006, p. 17851788.

VAN HOUT, A. Event semantics of verb frame alternations. Tilburg: Tilburg University, 1996.

VAN RIEMSDIJK, R. Categorial feature magnetism: The endocentricity and distribution of projections. Journal of Comparative Germanic Linguistics, v. 2, 1998, p. 1-48.

VIGLIOCCO, G.; HARTSUIKER, R. The interplay of meaning, sound, and syntax in sentence production. Psychological Bulletin, v. 128, 2006, p. 442-472.

WAGNER, G. P.; MÜLLER, G. B. Evolutionary innovations overcome ancestral constraints: A re-examination of character evolution in male sepsid flies. Evolution and Development, v. 4, 2002, p. 1-6.

WALLACE, A. R. Sir Charles Lyell on geological climates and the origin of species. Quarterly Review, v. 126, 1869, p. 359-394.

Contributions to the theory of natural selection. 2a ed. Londres: Macmillan, 1871.

WALSH, M. The Murinypata language of North-west Australia. 1976. Tese (Doutorado em Linguística) - Australian National University, 1976.

WATANABE, A. Case absorption and wh-agreement. Dordrecht: Kluwer, 1996.

The pied-piper feature. In: CHENG, L.; CORVER, N. (orgs.) Wh-movement:

Moving on. Cambridge, MA: MIT Press, 2006, p. 47-70.

WEST-EBERHARD, M. J. Developmental plasticity and the origin of species diferences. Proceedings of the National Academy of Sciences of the United States of America (PNAS), v. 102, 2005, p. 6543-6549.

WRAY, A. Protolanguage as a holistic system for social interaction. Language and Communication, v. 18, 1998, p. 47-67.

Holistic utterances in protolanguage: The link from primates to humans. In: KNIGHT, C.; STUDDERT-KENNEDY, M.; HURFORD, J. R. (orgs.) The evolutionary emergence of language: Social function and the origins of linguistic form. Cambridge: Cambridge University Press, 2000, p. 285-302. 
. Dual processing in protolanguage: Performance without competence. In: WRAY, A. (org.) The transition to language. Oxford: Oxford University Press, 2002, pp. 113-137.

WHEELER, B. C.; FISCHER, J. Functionally referential signals: A promising paradigm whose time has passed. Evolutionary Anthropology, v. 21, 2012, p. 195-205.

WHITE, T. D. et al. Pleistocene Homo sapiens from Middle Awash, Ethiopia. Nature, v. 423, 2003, p. 742-747.

WILBRECHT, L; NOTTEBOHM, F. Vocal learning in birds and humans. Mental retardation and developmental disabilities research reviews, v. 9, 2003, p. 135-148.

WILLIAMS, E. Dumping lexicalism. In RAMCHAND, G.; REISS, C. (orgs.) The Oxford handbook of linguistic interfaces. Oxford: Oxford University Press, 2007, p. 353-381.

Generative Semantics, Generative Morphosyntax. Syntax, 2012, p. 1-32.

WILTSCHKO, M. The universal structure of categories: Towards a formal typology. Cambridge: Cambridge University Press, 2014.

The functional structure of the clause: Main issues. In: FÁBREGAS, A.; MATEU, J.; PUTNAM, M. (orgs.). Contemporary linguistic parameters. Londres: Bloomsbury, 2015, p. 147-176.

WINTER, P.; HANDLEY, P.; PLOOG, D.; SCHOTT, D. Ontogeny of squirrel monkey calls under normal conditions and under acoustic isolation. Behaviour, v. 47, 1973, p. 230-239.

WURMBRAND, S. The Merge Condition: A syntactic approach to selection. In: KOSTA, P.; SCHURCKS, L.; RADEV-BORK, T. Minimalism and beyond: Radicalizing the interfaces. Amsterdam: John Benjamins, 2014, p. 130-166.

ZEIJLSTRA, H. On the syntactic flexibility of formal features. In: BIBERAUER, T. (org.). The limits of syntactic variation. Amsterdam: John Benjamins, 2008, p. 143-174.

There is only one way to agree. The Linguistic Review, v. 29, 2012, p. 491-453.

ZHU, Z.; DENNELL, R.; HUANG, W.; WU, Y.; QIU, S.; YANG, S. et al. Hominin occupation of the Chinese Loess Plateau since about 2.1 million years ago. Nature, 2018.

ZUBERBÜHLER, K. Predator-specific alarm calls in Campbell's guenons. Behavioral Ecology and Sociobiology, v. 50, 2001, p. 414-422.

. A syntactic rule in forest monkey communication. Animal Behaviour, v. 63, n. 2, 2002, p. 293-299.

Referential signaling in non-human primates: Cognitive precursors and limitations for the evolution of language. Advances in the Study of Behavior, v. 33, 2003, p. 265-307. 
Survival signals: The biology and psychology of animal alarm calling. Advances in the Study of Behavior, v. 40, 2009, p. 277-322.

The cognitive capacities of non-human primates. In: BOECKX, C.; GROHMANN, K. K. The Cambridge handbook of biolinguistics. Cambridge: Cambridge University Press, 2013, p. 415-430

ZUBERBÜHLER, K.; CHENEY, D. L.; SEYFARTH, R. M. Conceptual semantics in a nonhuman primate. Journal of Comparative Psychology, v. 113, 1999, p. 33-42.

ZUBERBÜHLER, K.; NÖE, R.; SEYFARTH, R. M. Diana monkey long-distance calls: Messages for conspecifics and predators. Animal Behavior, v. 53, 1997, p. 589-604.

ZWART, J-W. Structure and order: Asymmetric merge. In: BOECKX, C. (org). The Oxford handbook of linguistic minimalism. Oxford: Oxford University Press, 2010, p. 96-118.

YIP, M. The search for phonology in other species. Trends in Cognitive Sciences, v, 10, 2006, p. 442-445. 